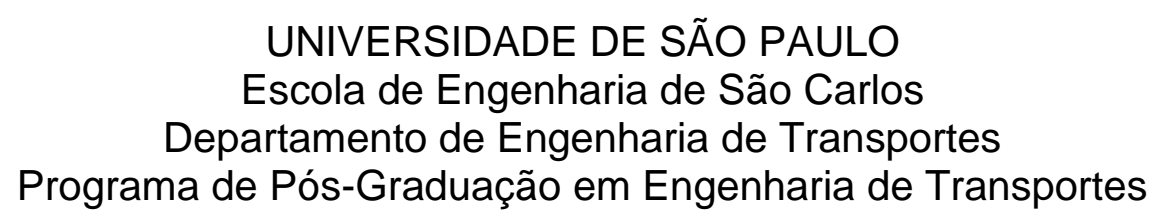

Frank Alves Ferreira

\title{
A mobilidade urbana sustentável no discurso de pesquisadores e decisores
}



Frank Alves Ferreira

\section{A mobilidade urbana sustentável no discurso de pesquisadores e decisores}

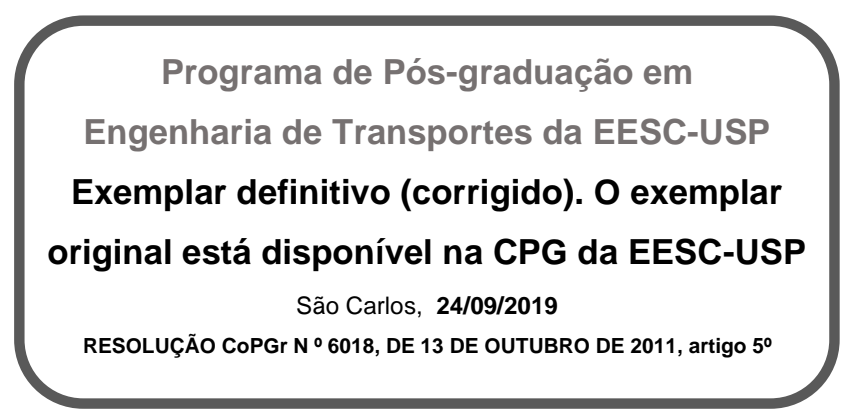

Dissertação apresentada à Escola de Engenharia de São Carlos, da Universidade de São Paulo, como parte dos requisitos para obtenção do título de Mestre em Ciências, Programa de Pós-Graduação em Engenharia de Transportes. Área de Concentração: Planejamento e Operação de Sistemas de Transportes.

Orientador:

Prof. Titular Antônio Nélson Rodrigues da Silva 
AUTORIZO A REPRODUÇÃO TOTAL OU PARCIAL DESTE TRABALHO, POR QUALQUER MEIO CONVENCIONAL OU ELETRÔNICO, PARA FINS DE ESTUDO E PESQUISA, DESDE QUE CITADA A FONTE.

Ficha catalográfica elaborada pela Biblioteca Prof. Dr. Sérgio Rodrigues Fontes da EESC/USP com os dados inseridos pelo(a) autor(a).

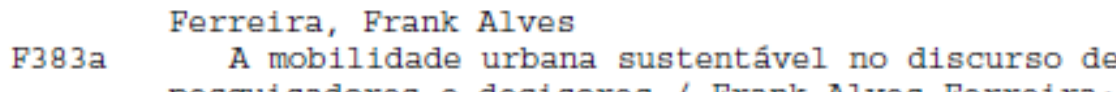
pesquisadores e decisores / Frank Alves Ferreira; orientador Antônio Nélson Rodrigues da Silva. Så Carlos, 2019.

Dissertaçăo (Mestrado) - Programa de pós-Graduaçåo em Bngenharia de Transportes e Ârea de Concentração em planejamento e Operaçăo de Sistemas de Transporte -- Escola de Bngenharia de Săo Carlos da Universidade de Såo Paulo, 2019.

1. mobilidade urbana sustentável. 2. modos nåo motorizados. 3. avaliaçåo com especialistas. I. Título.

Eduardo Graziosi Silva - CRB - 8/8907 


\section{FOLHA DE JULGAMENTO}

Candidato: Engenheiro FRANK ALVES FERREIRA.

Título da dissertação: "A mobilidade urbana sustentável no discurso de pesquisadores e decisores".

Data da defesa: 26/07/2019.

Comissão Julgadora:

Prof. Titular Antonio Nelson Rodrigues da Silva (Orientador)

(Escola de Engenharia de São Carlos/EESC)

Prof. Dr. Licínio da Silva Portugal

(Universidade Federal do Rio de Janeiro/UFRJ)

Prof. Dr. Enilson Medeiros dos Santos

(Universidade Federal do Rio Grande do Norte/UFRN)

\section{Resultado:}

APRONADO

ARROVADO

Coordenadora do Programa de Pós-Graduação em Engenharia de Transportes:

Profa. Associada Ana Paula Camargo Larocca

Presidente da Comissão de Pós-Graduação:

Prof. Titular Murilo Araujo Romero 

Aos meus pais, Egidio e Elizabete 



\section{Agradecimentos}

Ao Prof. Antônio Nélson, pela excelente orientação, disponibilidade e incentivo para conclusão deste trabalho. Muito obrigado por todos os ensinamentos.

A todos os profissionais que responderam os questionários e contribuíram enormemente para a realização deste trabalho. Ao grupo DePICT, em especial ao Gustavo Manzato, Janice Providelo e Murilo Fabricio que, juntamente com Prof. Antônio Nélson, conduziram os grupos focais.

Aos demais professores do departamento de Engenharia de Transportes da EESC/USP pelos conhecimentos compartilhados.

Aos colegas de pós-graduação, em especial à Andreza Dornelas, Angélica Oliveira, Gabriel Oliveira, Lucas Assirati e Mariana Thebit, que estiveram comigo ao longo desta jornada, compartilhando momentos de estudo, trabalho e, principalmente, amizade.

À CAPES pelo apoio financeiro.

Aos colegas da Empresa de Trens Urbanos de Porto Alegre - TRENSURB pelo apoio e incentivo. À Barbato Engenharia, em especial à Christiana, pelas oportunidades.

Aos meus pais, Egidio e Elizabete, que sempre me incentivaram aos estudos e apoiam minhas decisões. À minha irmã, Edelaide, e aos meus sobrinhos, Maria Eduarda e Marthin, por todo carinho e compreensão.

À todas as pessoas que, de forma direta ou indireta, contribuíram para a realização deste trabalho. 



\section{Resumo}

Ferreira, F. A. A MOBILIDADE URBANA SUSTENTÁVEL NO DISCURSO DE PESQUISADORES E DECISORES. 146 p. Dissertação de Mestrado - Escola de Engenharia de São Carlos, Universidade de São Paulo, 2019.

Este estudo tem por objetivo analisar a visão de pesquisadores e decisores brasileiros, sobre diferentes temas relacionados à mobilidade urbana sustentável. Os dados analisados, parcialmente definidos em grupos focais e coletados por questionários online, são referentes a uma amostra de 2863 profissionais de diversas áreas. Foram identificados respondentes em 676 cidades, de todos os estados e do Distrito Federal. Os tópicos abordados indicam que pedestres e ciclistas estão interessados tanto em ações voltadas para melhoria da infraestrutura dos modos não motorizados, quanto em medidas políticas para reduzir o espaço dos modos motorizados. Em uma análise geral, ficou evidente a diferença de posicionamento para os temas centrais avaliados (economia, engenharia, modos não motorizados, planejamento urbano e sustentabilidade). Os respondentes concordaram mais com os julgamentos que favoreciam medidas para melhores condições de mobilidade urbana. A sentença que representou 0 discurso sobre planejamento urbano recebeu 0 maior grau de concordância. A partir destas considerações, fica evidente que os respondentes estão conscientes para uma mudança de paradigma no planejamento de transportes. Para a avaliação em relação à aplicação de investimentos a diferentes tipos de infraestrutura, foi observada uma tendência em favorecer pedestres, ciclistas e o transporte público. Nas análises das questões divididas em grupos, foram observadas divergências de opinião principalmente para os respondentes que indicaram conhecer detalhadamente o texto da Lei da Mobilidade, reforçando a importância dessas diretrizes para a promoção dos modos de transporte sustentáveis.

Palavras-chave: mobilidade urbana sustentável. modos não motorizados. avaliação com especialistas. 



\title{
Abstract
}

\author{
Ferreira, F. A. SUSTAINABLE URBAN MOBILITY IN THE DISCOURSE OF \\ RESEARCHERS AND DECISION MAKERS. 146 p. Master Thesis - São Carlos \\ School of Engineering, University of São Paulo, 2019.
}

This study aimed at analyzing the vision of Brazilian researchers and decision makers on different themes related to sustainable urban mobility. The data analyzed, partially defined in focus groups and collected by online questionnaires, refer to a sample of 2863 professionals from different areas. Respondents were identified in 676 cities, from all states and the Federal District. The topics covered indicate that pedestrians and cyclists are interested both in actions aimed at improving the infrastructure of nonmotorized modes and in policies to reduce the space of motorized modes. In a general analysis, the difference in position was evident for the central themes evaluated (economy, engineering, non-motorized modes, urban planning and sustainability). The respondents agreed more with the judgments that favored measures for better conditions of urban mobility. The sentence that represented the discourse on urban planning received the highest degree of agreement. From these considerations, it is evident that respondents are aware of a paradigm change in transportation planning. For the evaluation regarding the implementation of investments to different types of infrastructure, there was a tendency to favor pedestrians, cyclists and public transport. In the analysis of the questions divided into groups, differences of opinion were observed mainly for the respondents who indicated to know in detail the text of the Law of Mobility, reinforcing the importance of these guidelines for the promotion of sustainable transport modes.

Keywords: sustainable urban mobility. non-motorized modes. evaluation by experts. 



\section{Lista de Figuras}

Figura 2-1 - Distribuição percentual das viagens por modo de transportes 31

Figura 3-1 - Indicação das ordenadas e proporção de frequências para determinada categoria, adaptado de Guilford (1954). .45

Figura 3-2 - Etapas de aplicação do método. 48

Figura 4-1 - Distribuição dos respondentes por região, por estado e as cidades com maior número de respostas .50

Figura 4-2 - Percentual de concordância do Grupo 1 para cada uma das sentenças 54

Figura 4-3 - Percentual de concordância do Grupo 2 para cada uma das sentenças 55

Figura 4-4 - Grau de concordância para as sentenças segundo a atuação profissional 59

Figura 4-5 - Grau de concordância para as sentenças segundo o tempo de experiência

Figura 4-6 - Grau de concordância para as sentenças, segundo o conhecimento da Política Nacional de Mobilidade Urbana. 62

Figura 4-7 - Grau de concordância para as sentenças, segundo o tamanho da cidade

Figura 4-8 - Grau de concordância para as sentenças, segundo a região do Brasil .64 Figura 4-9 - Análise das respostas da Questão 7 .65

Figura 4-10 - Avaliação das respostas da sentença Q7 entre diferentes grupos..... 66

Figura 4-11 - Análise da Questão 8 e avaliação das respostas entre diferentes grupos 
Figura 4-12 - Análise da Questão 9 e avaliação das respostas entre diferentes grupos 68

Figura 4-13 - Análise da Questão 10 e avaliação das respostas entre diferentes grupos 69

Figura 4-14 - Análise das respostas da Questão 11 …...................................... 70

Figura 4-15 - Avaliação das respostas da sentença Q11 entre diferentes grupos.... 71 Figura 4-16 - Análise da Questão 12 e avaliação das respostas entre diferentes grupos 72

Figura 4-17 - Análise da Questão 13 e avaliação das respostas entre diferentes grupos 73

Figura 4-18 - Análise da Questão 14 e avaliação das respostas entre diferentes grupos 74

Figura 4-19 - Análise da Questão 15 e avaliação das respostas entre diferentes grupos 75

Figura 4-20 - Síntese da comparação entre grupos para as sentenças avaliadas (Q1 a Q15) pelos profissionais da área de transportes (Grupo 1), com destaque para os grupos que apresentam diferenças em cada questão. 76 Figura 4-21 - Síntese da comparação entre grupos para as sentenças avaliadas (Q1 a Q15) pelos profissionais de outras áreas (Grupo 2), com destaque para os grupos que apresentam diferenças em cada questão 77 Figura 4-22 - Média das respostas para a pergunta acerca do investimentos em infraestrutura de transporte para a promoção da mobilidade sustentável 78 Figura 4-23 - Distribuição dos investimentos em infraestrutura para pedestres entre as categorias de conhecimento da PNMU do Grupo 1 80 Figura 4-24 - Relação entre a média de investimento em infraestrutura para transportes e grau de concordância com a sentença "Em um sistema urbano deve haver equilíbrio de investimento entre as infraestruturas necessárias para os diferentes modos de transporte (individual motorizado, transporte público, bicicleta e a pé)" do Grupo 1 (profissionais da área de transportes) 83 Figura 4-25 - Relação entre a média de investimento em infraestrutura para transportes e grau de concordância com a sentença "Em um sistema urbano deve haver equilíbrio de investimento entre as infraestruturas necessárias para os diferentes modos de transporte (individual motorizado, transporte público, bicicleta e a pé)" do Grupo 2 (profissionais de outras áreas) 
Figura 4-26 - Relação entre a média de investimento em infraestrutura para transportes e grau de concordância com a sentença "O oferecimento de infraestrutura adequada influencia no uso dos modos não motorizados (a pé e bicicleta)" do Grupo 1

Figura 4-27 - Relação entre a média de investimento em infraestrutura para transportes e grau de concordância com a sentença "O oferecimento de infraestrutura adequada influencia no uso dos modos não motorizados (a pé e bicicleta)" do Grupo 2

Figura A-1 - Diagrama do primeiro bloco de questões ....................................100

Figura A-2 - Distribuição dos respondentes por gênero .....................................101

Figura A-3 - Distribuição dos respondentes por faixa etária.................................102

Figura A-4 - Distribuição dos respondentes por escolaridade .............................. 105

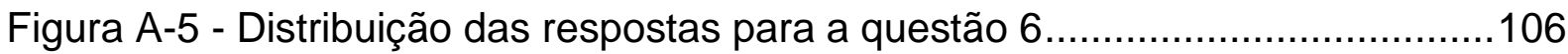

Figura A-6 - Ano de conclusão do ensino técnico ........................................... 108

Figura A-7 - Distribuição das respostas para a questão 10 .................................109

Figura A-8 - Ano de conclusão do curso de graduação .....................................111

Figura A-9 - Participação dos respondentes em cursos de pós-graduação .............112

Figura A-10 - Distribuição das respostas para a questão 15: "Você já participou de alguma capacitação em temas relacionados ao planejamento de transportes?" ....113 Figura A-11 - Diagrama do segundo bloco de questões ....................................114

Figura A-12 - Experiência na área de transportes ............................................115

Figura A-13 - Setor de atuação dos respondentes ...........................................116

Figura A-14 - Funções exercidas (cargos) dos respondentes ..............................117

Figura A-15 - Tempo de experiência dos respondentes......................................118

Figura A-16 - Nível de influência para tomada de decisão dos respondentes ........119

Figura A-17 - Nível de conhecimento da Política Nacional de Mobilidade Urbana..120 Figura A-18 - Frequência de utilização dos modos de transporte nos deslocamentos diários

Figura A-19 - Distribuição das respostas para Q1 .........................................122

Figura A-20 - Distribuição das respostas para Q2 .........................................123

Figura A-21 - Distribuição das respostas para Q3 ........................................124

Figura A-22 - Distribuição das respostas para Q4 ....................................... 125

Figura A-23 - Distribuição das respostas para Q5 .........................................126

Figura A-24 - Distribuição das respostas para Q6 .............................................127 
Figura A-25 - Distribuição das respostas para Q7 .......................................... 128

Figura A-26 - Distribuição das respostas para Q8 ………................................ 129

Figura A-27 - Distribuição das respostas para Q9 …….................................... 130

Figura A-28 - Distribuição das respostas para Q10 ………………................... 131

Figura A-29 - Distribuição das respostas para Q11 .......................................... 132

Figura A-30 - Distribuição das respostas para Q12 ........................................... 133

Figura A-31 - Distribuição das respostas para Q13 ......................................... 134

Figura A-32 - Distribuição das respostas para Q14 ......................................... 135

Figura A-33 - Distribuição das respostas para Q15 ......................................... 136

Figura A-34 - Média de investimento em infraestrutura para a promoção da mobilidade

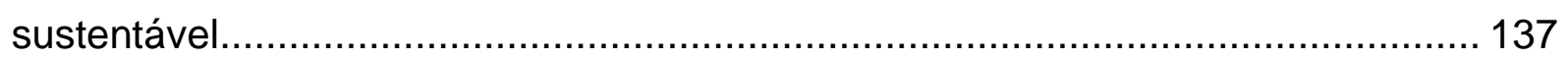

Figura B-1 - Distribuição das categorias da sentença Q1 na curva normal ............ 140

Figura B-2 - Distribuição das categorias da sentença Q2 na curva normal ............ 141

Figura B-3 - Distribuição das categorias da sentença Q3 na curva normal ............ 142

Figura B-4 - Distribuição das categorias da sentença Q4 na curva normal ............ 143

Figura B-5 - Distribuição das categorias da sentença Q5 na curva normal ............ 144

Figura B-6 - Distribuição das categorias da sentença Q6 na curva normal ............ 145 


\section{Lista de Tabelas}

Tabela 2-1 - Histórico das Políticas de Mobilidade nos últimos 20 anos no Brasil ....32

Tabela 3-1 - Discursos e as sentenças analisadas de Q1 a Q6. 41

Tabela 3-2 - Discursos e as sentenças analisadas de Q7 a Q15 .42

Tabela 4-1 - Distribuição dos respondentes por gênero, idade, formação, atuação profissional, tempo de experiência, principal modo de transporte e conhecimento da PNMU. .51

Tabela 4-2 - Distribuição das respostas informadas para cada sentença pelo Grupo 1 $(\mathrm{n}=1138)$ .53

Tabela 4-3 - Distribuição das respostas informadas para cada sentença pelo Grupo 2 $(\mathrm{n}=1725)$ .54

Tabela 4-4 - Cálculo da escala intervalar de referência para o Grupo 1 .56

Tabela 4-5 - Média, desvio padrão e coeficiente de variação para cada sentença do Grupo 1 .56

Tabela 4-6 - Escala intervalar de referência para o Grupo 2 .57

Tabela 4-7 - Média, desvio padrão e coeficiente de variação para cada sentença do Grupo 2 .58

Tabela 4-8 - Teste qui-quadrado de independência entre as variáveis investimento em infraestrutura para pedestres e conhecimento da PNMU do Grupo 1 .79 Tabela 4-9 - Síntese do teste qui-quadrado de independência ( $p$-valor) entre as variáveis investimento em infraestrutura e os respondentes do Grupo 1 .81

Tabela 4-10 - Síntese do teste qui-quadrado de independência ( $p$-valor) entre as variáveis investimento em infraestrutura e os respondentes do Grupo 2.

Tabela A-1 - Distribuição dos respondentes por gênero 101

Tabela A-2 - Distribuição dos respondentes por faixa etária 102 
Tabela A-3 - Lista das 25 cidades com maior número de respondentes 103

Tabela A-4 - Frequência de participação por estado

Tabela A-5 - Distribuição dos respondentes por escolaridade. 105 Tabela A-6 - Distribuição das respostas para a questão 6: "Você já participou de alguma capacitação em temas relacionados ao planejamento de transportes?" .... 106 Tabela A-7 - Lista dos cursos dos respondentes com ensino técnico 107

Tabela A-8 - Ano de conclusão do ensino técnico. 108 Tabela A-9 - Distribuição das respostas para a questão 10: "Você já participou de alguma capacitação em temas relacionados ao planejamento de transportes?".... 109 Tabela A-10 - Lista dos principais cursos de graduação dos respondentes ........... 110 Tabela A-11 - Ano de conclusão do curso de graduação ...................................... 111 Tabela A-12 - Participação dos respondentes em cursos de pós-graduação.......... 112 Tabela A-13 - Distribuição das respostas para a questão 15: "Você já participou de alguma capacitação em temas relacionados ao planejamento de transportes?".... 113 Tabela A-14 - Distribuição das respostas para a Questão 17: "Você possui experiência

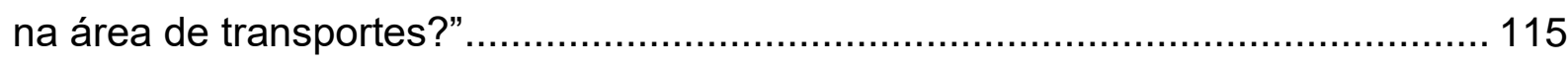

Tabela A-15 - Setor de atuação dos respondentes ………................................. 116

Tabela A-16 - Funções exercidas (cargos) dos respondentes................................ 117

Tabela A-17 - Tempo de experiência dos respondentes ....................................... 118

Tabela A-18 - Nível de influência para tomada de decisão dos respondentes ....... 119 Tabela A-19 - Nível de conhecimento da Política Nacional de Mobilidade Urbana (PNMU) 120

Tabela A-20 - Frequência de utilização dos modos de transporte nos deslocamentos diários 121

Tabela A-21 - Distribuição das respostas para Q1 122

Tabela A-22 - Distribuição das respostas para Q2 123

Tabela A-23 - Distribuição das respostas para Q3 124

Tabela A-24 - Distribuição das respostas para Q4 125

Tabela A-25 - Distribuição das respostas para Q5 126

Tabela A-26 - Distribuição das respostas para Q6 127

Tabela A-27 - Distribuição das respostas para Q7 128

Tabela A-28 - Distribuição das respostas para Q8 129

Tabela A-29 - Distribuição das respostas para Q9 130

Tabela A-30 - Distribuição das respostas para Q10 
Tabela A-31 - Distribuição das respostas para Q11 ……...................................132

Tabela A-32 - Distribuição das respostas para Q12 ……...................................133

Tabela A-33 - Distribuição das respostas para Q13 ……....................................134

Tabela A-34 - Distribuição das respostas para Q14 ……………….....................135

Tabela A-35 - Distribuição das respostas para Q15 …….................................136

Tabela A-36 - Média de investimento em infraestrutura para a promoção da mobilidade

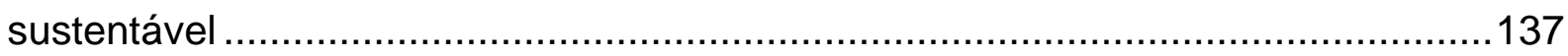

Tabela B-1 - Método dos Intervalos Sucessivos para a sentença Q1 ....................140

Tabela B-2 - Método dos Intervalos Sucessivos para a sentença Q2 .....................141

Tabela B-3 - Método dos Intervalos Sucessivos para a sentença Q3 .....................142

Tabela B-4 - Método dos Intervalos Sucessivos para a sentença Q4 ....................143

Tabela B-5 - Método dos Intervalos Sucessivos para a sentença Q5 .....................144

Tabela B-6 - Método dos Intervalos Sucessivos para a sentença Q6 .....................145

Tabela B-7 - Cálculo da escala intervalar de referência para o Grupo 1 .................146 



\section{Sumário}

1 Introdução

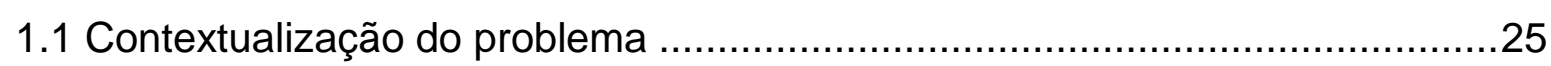

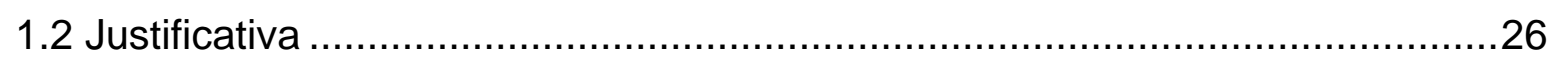

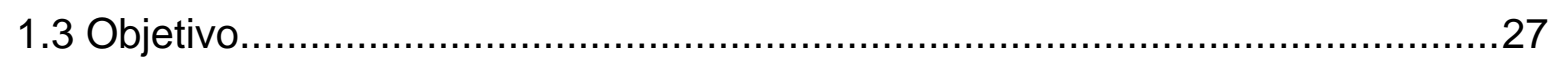

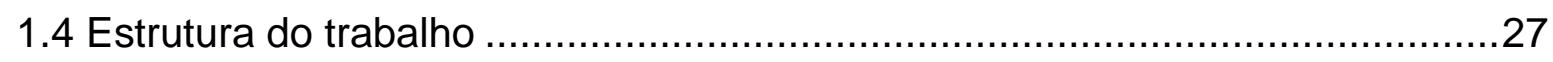

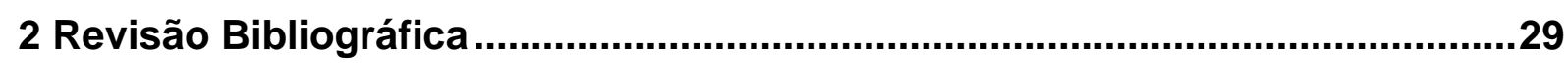

2.1 O paradigma da mobilidade urbana sustentável..........................................29

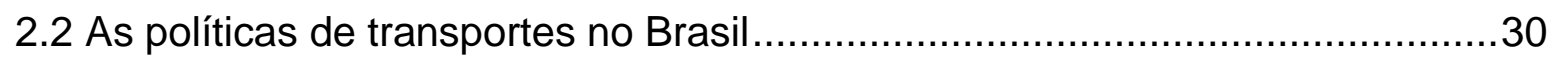

2.3 Estudos sobre a percepção de especialistas da área de transportes ...............34

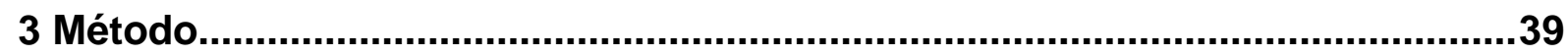

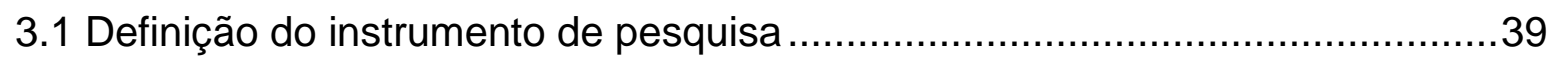

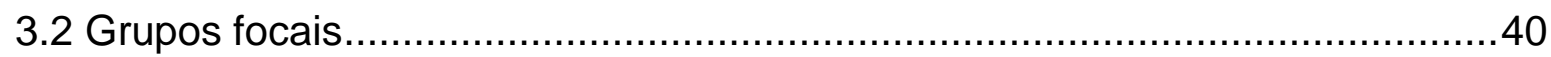

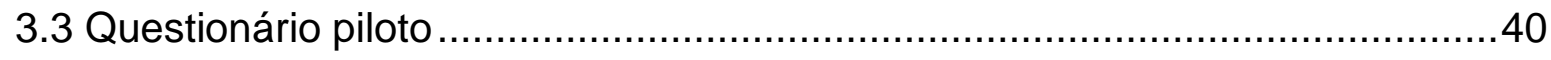

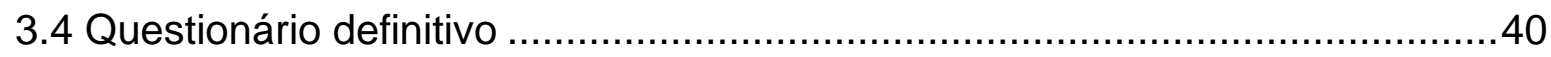

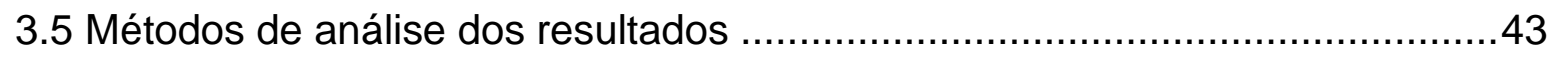

3.5.1 Método dos Intervalos Sucessivos (MIS) .............................................. 44

3.5.2 Avaliação das diferenças entre grupos: ANOVA, Teste de Tukey e Teste de

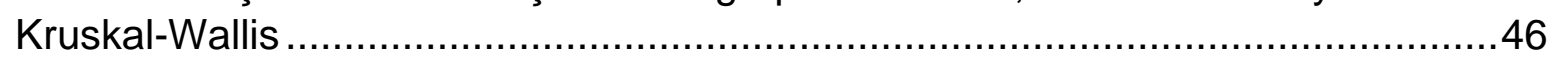

3.5.3 Avaliação do nível de investimento para diferentes tipos de infraestruturas de

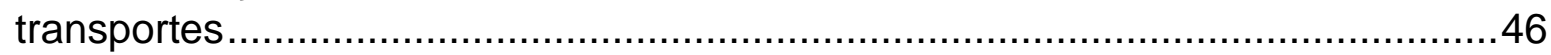

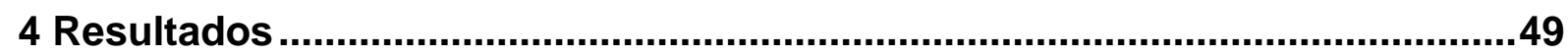

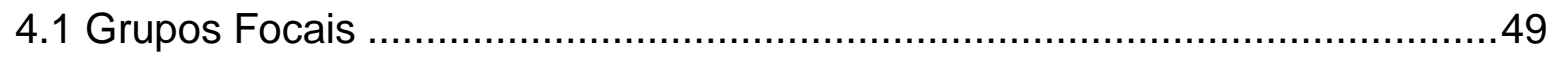

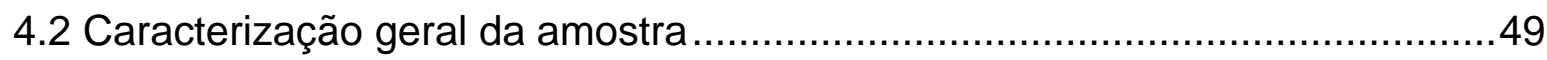

4.3 Avaliação das sentenças sobre Economia, Engenharia, Planejamento Urbano e

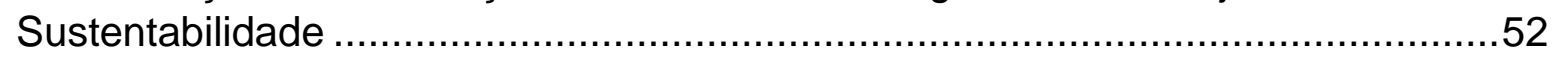


4.4 Avaliação das sentenças sobre Modos Não Motorizados

4.5 Avaliação do nível de investimento para diferentes tipos de infraestruturas de transportes

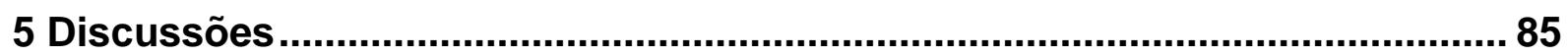

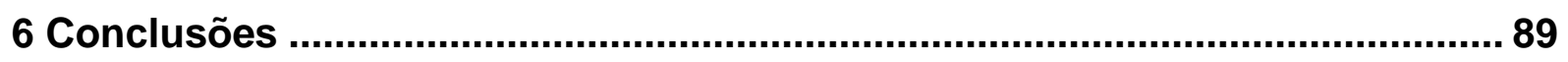

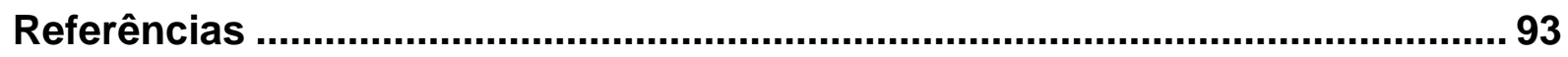

Apêndice A Respostas do Questionário Online ............................................. 99

Apêndice B Aplicação do Método dos Intervalos Sucessivos ...................... 139 
Capítulo

\section{Introdução}

Neste Capítulo é realizada uma contextualização do problema estudado e apresentada a justificativa, o objetivo e a estrutura do presente documento.

\subsection{Contextualização do problema}

Iniciativas governamentais incentivando a promoção da mobilidade urbana nas cidades brasileiras resultam de uma política urbana recente, praticamente iniciada pelo Estatuto da Cidade (Lei no 10.257/2001; BRASIL, 2001) e, especificamente, pela lei que instituiu a Política Nacional de Mobilidade Urbana (Lei no 12.587/2012; BRASIL, 2012). A Lei no 12.587/2012, também conhecida como Lei da Mobilidade, aborda o papel da União, Estados e Municípios na implantação da Política, esclarece os direitos dos usuários dos sistemas de mobilidade, dá diretrizes para a regulação dos serviços de transporte público coletivo e para o planejamento e gestão dos sistemas de mobilidade urbana (MINISTÉRIO DAS CIDADES, 2015).

Entre os principais pontos da Política Nacional de Mobilidade Urbana (PNMU) está a exigência legal para as cidades acima de 20 mil habitantes e todas as demais obrigadas, na forma da lei, à elaboração do plano diretor, de elaborar um Plano de Mobilidade Urbana (PMU), integrado e compatível com os respectivos planos diretores ou neles inserido (BRASIL, 2012). No que se refere à elaboração do PMU, desde que a PNMU entrou em vigor, ocorreram sucessivas prorrogações de prazo para que os municípios concluíssem esse processo (CALDEIRA; BASTOS, 2018).

Em levantamento realizado pelo Ministério das Cidades (2016) junto a 3.341 municípios sobre a elaboração de seus Planos de Mobilidade Urbana, identificou-se 
que apenas 197 municípios possuíam o documento elaborado (correspondendo a $27 \%$ da população brasileira). Outro dado relevante é que, destes municípios que declararam possuir PMU, 163 deles estão nas regiões Sul e Sudeste. Esses dados indicam que o planejamento na área de mobilidade urbana ainda é deficiente em todo o país.

Esta falta de planejamento tem reflexos na forma como a estruturação das cidades brasileiras vem sendo tratada, priorizando o espaço construído para a circulação dos veículos em detrimento das pessoas, o que tem contribuído para diversos impactos negativos, tais como: altos custos sociais dos congestionamentos, aumento do consumo de energia, aumento da poluição e aumento dos acidentes de trânsito (VASCONCELLOS, 2014). Como apontado por Banister (2008), essas questões exigem uma mudança de paradigma no processo de planejamento. O momento é propício para os formuladores de políticas adotarem abordagens para promover os modos não motorizados como uma forma de impulsionar a mobilidade urbana sustentável e melhorar a qualidade de vida das pessoas (GABRIELLI et al., 2014).

\subsection{Justificativa}

No contexto brasileiro, uma das possíveis barreiras para a implantação dos planos de mobilidade pode estar na dificuldade de técnicos e gestores em não compreenderem integralmente o conceito de mobilidade urbana sustentável (MIRANDA et al., 2009; COSTA, 2016; SANTOS, 2017; MACHADO; SALOMÃO PICCININI, 2018). Os estudos realizados para caracterizar a percepção de pesquisadores, técnicos e gestores em relação aos conceitos do planejamento da mobilidade sustentável foram destinados a avaliar o posicionamento dos entrevistados, principalmente, em cidades médias (MAGAGNIN; RODRIGUES DA SILVA, 2008; MIRANDA et al., 2009; MAGAGNIN; RIBEIRO; PIRES, 2016; SANTOS, 2017) e a partir de uma amostra limitada de respondentes (AMORIM; OLIVEIRA; RODRIGUES DA SILVA, 2014).

Em virtude disso, é interessante a realização de uma pesquisa que englobe um número maior de entrevistados, de maneira que seja possível investigar a visão de pesquisadores e decisores inseridos em diferentes realidades da mobilidade urbana brasileira. Assim, o presente estudo pretende ampliar significativamente a 
abrangência geográfica das pesquisas anteriores para o contexto brasileiro, incorporando ainda a visão dos modos não motorizados na consulta aos respondentes.

\subsection{Objetivo}

O principal objetivo deste trabalho é analisar a visão de pesquisadores e decisores sobre diferentes temas relacionados à mobilidade urbana sustentável.

Com o intuito de orientar o desenvolvimento do trabalho, as seguintes questões foram consideradas:

- Quais são os aspectos considerados importantes por pedestres e ciclistas para um ambiente propício ao uso dos modos não motorizados?

- Como especialistas se posicionam em relação aos temas de economia, engenharia, modos não motorizados, planejamento urbano e sustentabilidade?

- Existe concordância entre a visão de especialistas da área de transportes e especialistas de outras áreas?

- Quando considerada a perspectiva de diferentes grupos de avaliação (por tipo de atuação, tempo de experiência, conhecimento da Política Nacional de Mobilidade Urbana, tamanho da cidade e região), existe diferença nesse posicionamento?

\subsection{Estrutura do trabalho}

O presente trabalho está estruturado em sete capítulos. O primeiro consiste na presente Introdução, que descreve o problema a ser abordado, apresenta o objetivo e a justificativa do trabalho. $O$ capítulo 2 apresenta a contextualização do tema a partir de uma síntese da revisão da literatura. O capítulo seguinte descreve os procedimentos metodológicos utilizados. Os resultados são apresentados no Capítulo 4. As discussões geradas por esses resultados são abordadas no capítulo 5. As principais conclusões são descritas no Capítulo 6, anterior às referências bibliográficas citadas no texto. 
Capítulo

\section{Revisão Bibliográfica}

Neste capítulo, que contém uma breve revisão de conceitos relativos à pesquisa realizada, três aspectos são abordados. O primeiro busca compreender a construção do paradigma da mobilidade urbana sustentável. O segundo trata de aspectos relacionados às políticas para promoção da mobilidade urbana sustentável no Brasil. Em seguida, são abordadas pesquisas e metodologias empregadas para avaliar a percepção de especialistas em relação a temas voltados ao planejamento de transportes.

\subsection{O paradigma da mobilidade urbana sustentável}

A mobilidade urbana tem sido objeto de estudo por diversos autores (GÖSSLING et al., 2018). Essas discussões têm levado a uma ruptura na forma tradicional de realizar o planejamento de transportes (WEGENER, 2013; JONES, 2014). Segundo Banister (2008), a mobilidade sustentável aparece como um novo paradigma, tornando-se um ponto chave de investigação e intervenção para governantes e outros atores interessados em promover metas de sustentabilidade (GABRIELLI et al., 2014).

A abordagem conhecida como predict and provide, por meio da qual as soluções geralmente fornecem a infraestrutura adicional necessária para acomodar o aumento previsto da demanda por viagens motorizadas, gerou uma série de problemas locais e globais (KRAWCZYK; RATCLIFFE, 2005; TENNØY, 2010). As externalidades causadas pelo uso irrestrito dos veículos motorizados impactam fortemente a qualidade de vida da população (DOUGHTY; MURRAY, 2016; SULTANA; SALON; KUBY, 2017). 
Litman (2003) indica que um transporte mais eficiente, equitativo e ambientalmente sensível requer mudanças na forma de pensamento e na identificação e avaliação das soluções para os problemas de transporte.

Nesse sentido, muitos governos tem investido nos sistemas voltados para os modos não motorizados (CAULFIELD; LEAHY, 2011; CAULFIELD, 2014; LANZENDORF; BUSCH-GEERTSEMA, 2014; KUKELY; ABA; FLEISCHER, 2017). Conforme abordado por Geraghty et al. (2009), o desenvolvimento de um sistema de transporte que favorece a caminhada e ciclismo é fundamental para melhorar a qualidade do ar e os problemas de transporte de uma região, bem como para proporcionar melhores condições de vida a seus cidadãos.

Entre os principais fatores associados ao planejamento e às políticas de mobilidade para influenciar na decisão de se locomover de bicicleta e a pé estão a disponibilidade de infraestrutura e de transporte público (DE SOUSA; SANCHES; FERREIRA, 2014; BRAUN et al., 2016). Além disso, características como densidade populacional, conectividade da rede e uso misto do solo também estão relacionadas ao uso dos modos não motorizados (SAELENS; SALLIS; FRANK, 2003).

A mobilidade sustentável tem um papel central a desempenhar no futuro das cidades, mas é somente através do entendimento e aceitação pela população que as medidas terão sucesso (HICKMAN; HALL; BANISTER, 2013).

\subsection{As políticas de transportes no Brasil}

No Brasil, o tema da mobilidade urbana ganhou notoriedade em 2013, quando milhares de manifestantes percorreram as ruas de capitais e dezenas de cidades no interior do país para reivindicar melhorias no transporte público, redução das tarifas de ônibus, mais investimento em educação e saúde, além de outras reclamações para diversas áreas (ANTP, 2017; BBC, 2018). No ano passado, uma nova manifestação mostrou a fragilidade do nosso sistema de transportes. Mais especificamente nos últimos dias do mês de maio de 2018, ocorreu uma crise de abastecimento de combustíveis no Brasil em virtude de uma greve de caminhoneiros nas estradas de 
todo o país, afetando vários subsistemas que compõem o sistema de transporte das cidades (ARBEX; CUNHA, 2018).

Conforme apontado por Carvalho (2016) são grandes os desafios para os dirigentes e gestores públicos do transporte no sentido de planejar políticas mitigadoras das externalidades negativas produzidas pelo transporte individual motorizado e planejar sistemas dentro dos conceitos do desenvolvimento sustentável.

No último relatório do Sistema de Mobilidade Urbana (ANTP, 2016), no qual são divulgadas informações sobre a mobilidade das cidades com mais de 60 mil habitantes, fica evidente a importância do planejamento aos modos não motorizados no Brasil. Conforme apresentado na Figura 2-1, para as 533 cidades avaliadas, a maior parte das viagens é realizada a pé e por bicicleta (43\%), seguidos dos meios de transporte individual motorizado (29\%) e de transporte público $(28 \%)$.

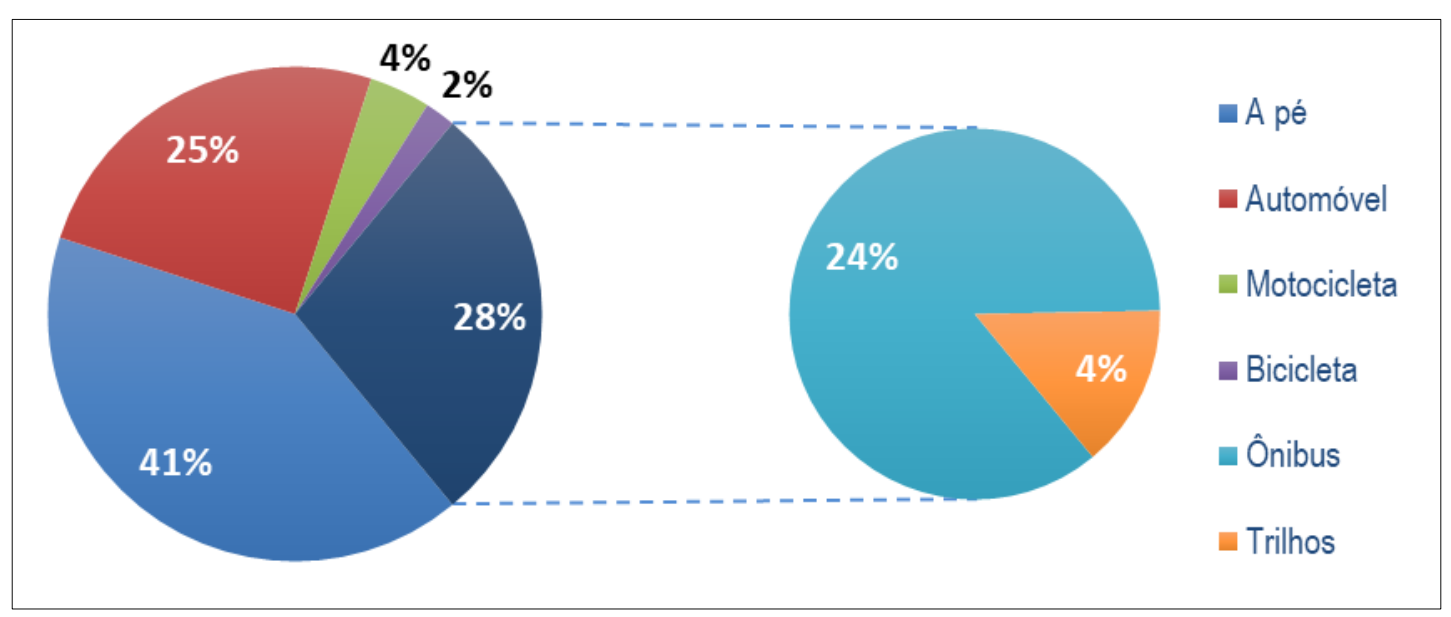

Figura 2-1 - Distribuição percentual das viagens por modo de transportes Fonte: (ANTP, 2016)

Em se tratando de lei e diretrizes, desde a Constituição Federal de 1988 busca-se regulamentar e consolidar uma política de planejamento urbano no Brasil (LIMA NETO; GALINDO, 2015). Nos últimos anos observa-se uma quantidade significativa de leis promulgadas que tiveram grande impacto nas condições reais da mobilidade (XAVIER, 2015). Conforme resumo do livro Cidades Humanas para um Brasil Urbano (ANTP, 2017), as principais leis estão descritas na Tabela 2-1. 
Tabela 2-1 - Histórico das Políticas de Mobilidade nos últimos 20 anos no Brasil

\begin{tabular}{|c|c|c|}
\hline ANO & LEI & DESCRIÇÃO \\
\hline 1997 & $\begin{array}{l}\text { Código de Trânsito } \\
\text { Brasileiro - CTB }\end{array}$ & $\begin{array}{l}\text { Alterou profundamente a estrutura da organização institucional da } \\
\text { área, principalmente por meio da "municipalização" do trânsito, } \\
\text { colocando as autoridades locais no centro do planejamento e da } \\
\text { gestão do trânsito. Adicionalmente, o CTB alterou toda a estrutura de } \\
\text { fiscalização, de formação de condutores de veículo, da educação para } \\
\text { o trânsito e da imposição de penalidades, aproximando-se de códigos } \\
\text { similares em sociedades mais desenvolvidas. }\end{array}$ \\
\hline 2001 & $\begin{array}{l}\text { Estatuto das } \\
\text { Cidades (Lei no } \\
\text { 10.257/2001) }\end{array}$ & $\begin{array}{l}\text { Torna obrigatório a todos os municípios com mais de } 20 \text { mil habitantes } \\
\text { a realização de um Plano Diretor para a cidade. Define a } \\
\text { obrigatoriedade de ordenação e controle do uso do solo e de garantir } \\
\text { o acesso ao transporte e sua oferta de acordo com os interesses e as } \\
\text { necessidades da população. }\end{array}$ \\
\hline 2004 & $\begin{array}{l}\text { Decreto de } \\
\text { acessibilidade } \\
\text { universal (Decreto } \\
\text { Federal no } \\
5.296 / 2004)\end{array}$ & $\begin{array}{l}\text { Regulamentou as leis } \mathrm{n}^{0} 10.048 \text { e } \mathrm{n}^{0} 10.098 \text { de } 2000 \text { e definiu os } \\
\text { direitos da pessoa com deficiência ou com mobilidade reduzida, } \\
\text { determinando o planejamento e a adaptação das construções e dos } \\
\text { equipamentos públicos de forma a eliminar dificuldades e barreiras a } \\
\text { estas pessoas. }\end{array}$ \\
\hline 2012 & $\begin{array}{l}\text { Lei de Mobilidade } \\
\text { Urbana (lei ํo- } \\
12.587 / 2012)\end{array}$ & $\begin{array}{l}\text { Definiu as diretrizes da Política Nacional de Mobilidade Urbana, atribui } \\
\text { prioridade aos meios de transporte não motorizados e ao serviço } \\
\text { público coletivo e incluiu a possibilidade legal de aplicar restrições ao } \\
\text { uso de automóveis. Foi a primeira lei abrangente sobre o tema dentro } \\
\text { da perspectiva da equidade e da sustentabilidade. }\end{array}$ \\
\hline 2015 & $\begin{array}{l}\text { Estatuto da } \\
\text { Metrópole (lei no } \\
13.089 / 2015)\end{array}$ & $\begin{array}{l}\text { Define no artigo } 1^{\circ} \text { que a lei "estabelece diretrizes gerais para o } \\
\text { planejamento, a gestão e a execução das funções públicas de } \\
\text { interesse comum em regiões metropolitanas e em aglomerações } \\
\text { urbanas instituídas pelos estados, normas gerais sobre o plano de } \\
\text { desenvolvimento urbano integrado e outros instrumentos de } \\
\text { governança interfederativa, e critérios para o apoio da União a ações } \\
\text { que envolvam governança interfederativa no campo do } \\
\text { desenvolvimento urbano". O Estatuto define também, no artigo } 10 \text {, } \\
\text { que "As regiões metropolitanas e as aglomerações urbanas deverão } \\
\text { contar com plano de desenvolvimento urbano integrado, aprovado } \\
\text { mediante lei estadual", mas enfatiza que isto não desobriga os } \\
\text { municípios de ter o seu próprio Plano Diretor, conforme determina a } \\
\text { Constituição Federal. }\end{array}$ \\
\hline 2015 & $\begin{array}{l}\text { Lei brasileira de } \\
\text { inclusão da pessoa } \\
\text { com deficiência (Lei } \\
\text { no 13.146/2015) }\end{array}$ & $\begin{array}{l}\text { Define no capítulo } X \text {, artigo } 46 \text {, que "O direito ao transporte e à } \\
\text { mobilidade da pessoa com deficiência ou com mobilidade reduzida } \\
\text { será assegurado em igualdade de oportunidades com as demais } \\
\text { pessoas, por meio de identificação e de eliminação de todos os } \\
\text { obstáculos e barreiras ao seu acesso". Em artigos seguintes, a lei } \\
\text { define a obrigatoriedade de facilidade de acesso nos estacionamentos } \\
\text { para veículos que transportem pessoas com deficiência e de que } \\
\text { todos os veículos públicos e terminais de transporte permitam o } \\
\text { acesso fácil a estas pessoas. }\end{array}$ \\
\hline 2015 & $\begin{array}{l}\text { Transporte público } \\
\text { como direito social } \\
\text { (PEC no } 90 / 11 \text {, de } \\
\text { 2015) }\end{array}$ & $\begin{array}{l}\text { Aprovado pela Emenda Constitucional - PEC no 90/11, agregando ao } \\
\text { artigo } 6^{\circ} \text { da Constituição, que trata dos direitos sociais, o transporte, } \\
\text { na forma que se segue: Art. } 6 \text { o: São direitos sociais a educação, a } \\
\text { saúde, a alimentação, o trabalho, a moradia, o transporte, o lazer, a } \\
\text { segurança, a previdência social, a proteção à maternidade e a } \\
\text { infância, a assistência aos desamparados, na forma desta } \\
\text { Constituição. }\end{array}$ \\
\hline
\end{tabular}


Na Tabela 2-1, é possível perceber um esforço federal em estruturar e definir um escopo para políticas urbanas (CALDEIRA; BASTOS, 2018) e, que tais políticas, evoluíram de uma abordagem mais restrita a uma perspectiva mais geral da mobilidade urbana (LIMA NETO; GALINDO, 2015). No entanto, apesar da aprovação de diversas leis e marcos regulatórios, não se observa um desenvolvimento urbano organizado nas cidades brasileiras (RODRIGUES DA SILVA et al., 2015).

Em 2015, o transporte passou a ser considerado como direito social previsto pela Constituição Brasileira. No entanto, apesar de toda a significância que a mobilidade tem na sociedade, no Brasil não se observa a democratização do transporte e das infraestruturas urbanas (GUIMARÃES; LUCAS, 2017; SILVA; FIGUEIREDO, 2018). O movimento para promover a mudança enfrenta enormes obstáculos, relacionados a interesses econômicos, da indústria automotiva, da classe média e de políticos conservadores (VASCONCELLOS, 2018).

O uso de aplicativos de celulares para compartilhar viagens é uma das novidades que podem alterar a mobilidade urbana das cidades, como é o caso do compartilhamento de bicicletas, carros e, mais recentemente, patinetes elétricos (CASSEL; LADEIRA; CYBIS, 2018; GÖSSLING et al., 2018). A demanda reprimida de viagens urbanas tem atraído usuários, geralmente mais jovens e com maior nível de escolaridade, que algumas vezes, buscam evitar inconvenientes como procurar vaga de estacionamento e não poder ingerir bebida alcoólica antes de dirigir (SILVA; BALASSIANO, 2018). No entanto, no Brasil e no mundo, a regulamentação destes serviços oferecidos por aplicativos tem provocado uma ampla discussão na população, envolvendo especialistas, a mídia e o poder público (PEREIRA; FREITAS, 2017; G1, 2018).

Essas competências também levam a um grande desafio, que é a gestão da mobilidade urbana para os diferentes contextos brasileiros, principalmente nas regiões metropolitanas (RODRIGUES DA SILVA; COSTA; MACEDO, 2008). Nota-se que o sucesso de políticas e provimento de recursos federais aos municípios depende essencialmente da motivação e competência dos gestores municipais em estruturar propostas coerentes e passíveis de seleção (ALVES; HUMBERTO; SIQUEIRA, 2018). 
No Brasil, existem alguns desafios a serem vencidos para o desenvolvimento urbano e planejamento da mobilidade. Entre eles podem ser citados o investimento em infraestrutura, crescimento do transporte individual e queda do transporte público, custeio da operação de transporte público e o envelhecimento da população (CARVALHO, 2016).

\subsection{Estudos sobre a percepção de especialistas da área de transportes}

Alguns estudos têm buscado avaliar a percepção de especialistas sobre questões relacionadas diretamente com o planejamento de transportes (COLE et al., 2010; IMRAN; PEARCE, 2015; LEGACY, 2016; ALDRED et al., 2017; TE BRÖMMELSTROET et al., 2017). A maneira como os planejadores percebem o problema influencia na definição dos objetivos, no planejamento, possíveis alternativas, métodos de avaliação e, consequentemente, nos resultados (TENNØY, 2010).

Em 2010, Cole et al. avaliaram a percepção de representantes de instituições públicas, privadas e do setor comunitário da Austrália para as barreiras de um transporte ativo. Neste estudo, potenciais participantes foram identificados por meio de agências comunitárias relevantes, departamentos governamentais e funcionários individuais. Assim, foi identificado que os 33 líderes entrevistados possuíam diferentes visões sobre o seu papel para a promoção do transporte sustentável. Entre elas, estavam que o transporte sustentável não está sendo incluído na formação da estratégia de governo e nas atividades de planejamento, diretrizes e programas inconsistentes entre os interessados e uma falta de comprometimento de recursos.

Em outro estudo de caso (TENNØY, 2010), por meio de entrevistas e pesquisas à 82 planejadores noruegueses, verificou-se que enquanto alguns dos respondentes pensam que a redução dos volumes de tráfego rodoviário urbano é um objetivo importante e realista, outros acham irreal e menos importante. Isso indica que, para uma mudança nos problemas relacionados ao transporte, os profissionais de planejamento precisam mudar suas maneiras de pensar e agir. 
Ainda nesse sentido, Curtis e Low (2012) analisaram como as barreiras institucionais influenciam na transição do planejamento tradicional para o sustentável e como seria possível superá-las, ao estudar três cidades na Austrália (Melbourne, Sydney e Perth). Neste estudo, foram apresentadas algumas sentenças para 45 políticos e gestores envolvidos com a área de transportes, com diferentes níveis de influência, e procurouse verificar o seu grau de concordância com tais afirmações. Cada sentença se enquadrava segundo quatro visões: economia, engenharia, planejamento urbano e sustentabilidade. Os autores demonstram o efeito do discurso de técnicos, políticos e acadêmicos como papel fundamental na mudança de paradigma.

Uma primeira adaptação da pesquisa de Curtis e Low (2012) foi realizada no Brasil por Amorim et al. (2014). Um questionário online, contendo a tradução das 72 sentenças da pesquisa original, foi aplicado a 20 entrevistados, que representavam dois grupos (pesquisadores e técnicos/gestores). Apesar de certa variabilidade observada nas respostas, não foram identificadas fortes disparidades entre as respostas das duas categorias de entrevistados analisadas. Tanto os pesquisadores como os técnicos/gestores demonstraram estar alinhados com os principais conceitos que envolvem a questão da mobilidade urbana, nos quatro discursos que foram analisados.

Em estudo realizado há quase uma década, Magagnin e Rodrigues da Silva (2008) procuraram verificar se os conceitos de mobilidade urbana estavam claros para técnicos ligados às áreas de planejamento urbano e de transportes em uma cidade brasileira. Os resultados, obtidos por meio de um questionário aplicado antes e depois do uso de uma ferramenta computacional, mostraram que a mobilidade ainda era entendida essencialmente como sinônimo de planejamento de infraestrutura (sistema viário), indicando uma visão parcial do tema por parte dos entrevistados.

Miranda et al. (2009) também buscaram avaliar a reação de técnicos e gestores de transportes, identificando possíveis barreiras para a implantação de um plano de mobilidade contendo os conceitos de sustentabilidade. A partir da proposta de um plano de mobilidade municipal, técnicos e gestores da prefeitura de uma cidade média avaliaram um conjunto de ações sugeridas para a melhoria da mobilidade urbana. Os resultados obtidos levaram a algumas conclusões, entre elas a de que os técnicos e 
gestores pareciam não dominar integralmente o conceito de mobilidade urbana sustentável, a existência de problemas no arranjo legal vinculado ao Plano Diretor e a outros dispositivos legais já consolidados e a prioridade de ação voltada para o modo motorizado individual.

O estudo realizado por Jones e Azevedo (2013), abordou o processo de transformação econômica, social e cultural e a promoção dos modos não motorizados em uma cidade média no Brasil. A abordagem utilizada foram grupos focais, observações em campo da infraestrutura disponível com funcionários e planejadores no âmbito municipal e entrevistas com ciclistas. Neste estudo se verificou que os estímulos aos modos motorizados individuais estão alimentando um rápido crescimento da frota brasileira. Neste contexto, o transporte não motorizado tem recebido pouco investimento, principalmente porque é realizado por grupos de baixa renda e ainda existe um estigma cultural associado à sua prática.

Em outro estudo, Magagnin et al. (2016) avaliaram se a população e técnicos em transportes possuíam domínio sobre problemas associados à mobilidade de uma cidade brasileira de porte médio. A metodologia utilizada consistiu em entrevista estruturada e registros fotográficos. Os resultados apontaram que à falta de planejamento integrado e os modos não motorizados foram igualmente relevantes para os dois segmentos. Também foi constatado que a população possui um domínio sobre os problemas associados à mobilidade que afetam seu dia a dia e os técnicos possuem uma visão ampla e global destes problemas na cidade.

Santos (2017) avaliou as barreiras na barreiras na implementação do plano de mobilidade urbana nas cidades de pequeno e médio porte a partir da aplicação de um questionário online à gestores públicos e especialistas. Entre as principias conclusões estão as limitações orçamentárias, falta de participação pública na elaboração dos planos, ausência de uma base de dados integrada e falta de mão de obra qualificada nas prefeituras.

Estudos reportados na literatura mostram diferentes abordagens para caracterizar a percepção de pesquisadores, técnicos e gestores em relação aos conceitos do planejamento da mobilidade sustentável, sendo o principal método de coleta de dados 
os questionários online. No entanto, tais pesquisas se mostram limitadas tanto em número de respondentes quanto na diversidade de municípios avaliados, indicando uma importante lacuna a ser preenchida para esta área do conhecimento. 
Capítulo

\section{Método}

O método de pesquisa utilizado neste estudo possui as seguintes etapas: i) definição do instrumento de pesquisa; ii) identificação dos principais aspectos do ambiente construído para usuários na escolha dos modos não motorizados por meio de grupos focais; iii) elaboração e aplicação de um questionário piloto, destinado a identificar possíveis falhas e propor melhorias para o questionário definitivo; iv) elaboração e aplicação do questionário online definitivo; $v$ ) análise estatística dos dados coletados no questionário, utilizando o Método dos Intervalos Sucessivos, ANOVA, Teste de Tukey e Teste Kruskal-Wallis; vi) avaliação do nível de investimento aplicado pelos entrevistados a diferentes tipos de infraestruturas de transportes; e vii) avaliação e discussão dos resultados.

\subsection{Definição do instrumento de pesquisa}

O instrumento de pesquisa elaborado para este estudo foi baseado em questionário originalmente desenvolvido por Curtis e Low (2012) para aplicação na Austrália. No Brasil, este questionário teve uma primeira tradução e adaptação feita por Amorim et al. (2014), com um total de setenta e duas sentenças. Nos dois casos, quatro temas (ou discursos, como proposto no estudo original) principais eram abordados: Economia, Engenharia, Planejamento Urbano e Sustentabilidade. Como o estudo de Amorim et al. (2014) envolveu uma amostra reduzida, tanto em termos de número como de abrangência geográfica, a presente pesquisa buscou ampliar esta amostra e, portanto, sua representatividade. 


\subsection{Grupos focais}

Uma série de grupos focais, realizados em uma cidade brasileira de médio porte, teve por objetivo identificar os principais aspectos do ambiente construído para usuários na escolha dos modos não motorizados. As reuniões dos grupos focais foram organizadas e conduzidas pelo projeto DePICT (Desenho e Implantação de Políticas para Incentivo a viagens não motorizadas). Os resultados dos grupos focais permitiram criar nove sentenças que incorporam aspectos importantes no planejamento do transporte não motorizado. Essas sentenças formaram um novo tema para ser abordado no questionário.

\subsection{Questionário piloto}

Um estudo piloto, realizado entre os meses de novembro e dezembro de 2016, pela internet, foi aplicado a 60 profissionais da área de transportes. Este estudo tinha o objetivo de identificar possíveis falhas e propor melhorias para o questionário definitivo. No questionário proposto, adicionalmente às nove questões elaboradas a partir dos grupos focais, foram incluídas setenta e duas sentenças baseadas no estudo desenvolvido por Curtis e Low (2012) e adaptado para o Brasil por Amorim et al. (2014).

Após o estudo piloto, optou-se por restringir o número de questões propostas visando reduzir o tempo de resposta dos questionários. Como Curtis e Low (2012) já haviam selecionado seis sentenças que abrangem a ideia central dos discursos com o viés pró-mobilidade, o questionário definitivo abordou tanto estas sentenças como uma questão que avalia o grau de investimento a diferentes tipos de infraestrutura de transportes. Além destas, também foram incluídas as nove sentenças elaboradas a partir dos grupos focais. Assim, o questionário definitivo avaliou no total dezesseis questões.

\subsection{Questionário definitivo}

As questões selecionadas foram implementadas em uma plataforma para pesquisas online e os potenciais respondentes contatados por e-mail. O software utilizado para criação e hospedagem do questionário permitiu associar o e-mail de cada destinatário 
ao servidor da plataforma, tornando possível verificar a qualquer instante se os convidados haviam começado e terminado de responder o questionário.

O questionário foi dividido em três blocos: (1) Perfil do entrevistado; (2) Avaliação das sentenças; e (3) Atribuição de grau de investimento a diferentes tipos de infraestrutura de transportes. O primeiro bloco contém perguntas relacionadas a informações próprias do entrevistado, tais como gênero, idade, cidade, estado, formação, atuação profissional e principal modo de transporte utilizado em seus deslocamentos. $O$ segundo bloco está constituído das sentenças afirmativas sobre planejamento de transportes. Cada sentença se encaixa em um dos discursos estudados, mas os respondentes não são informados disso, de forma a não influenciar suas respostas.

As seis primeiras sentenças avaliadas, adaptadas do estudo de Curtis e Low (2012), estão descritas na Tabela 3-1.

Tabela 3-1 - Discursos e as sentenças analisadas de Q1 a Q6

\begin{tabular}{|c|c|c|}
\hline DISCURSO & $\mathbf{Q}$ & SENTENÇA \\
\hline $\begin{array}{l}\text { Planejamento } \\
\text { Urbano }\end{array}$ & Q1 & $\begin{array}{l}\text { No planejamento de uma cidade, a infraestrutura de transporte deveria } \\
\text { proporcionar um sistema integrado de uso do solo e transportes. }\end{array}$ \\
\hline Engenharia & Q2 & $\begin{array}{l}\text { Em um sistema urbano deve haver equilíbrio de investimento entre as } \\
\text { infraestruturas necessárias para os diferentes modos de transporte } \\
\text { (individual motorizado, transporte público, bicicleta e a pé). }\end{array}$ \\
\hline Economia & Q3 & $\begin{array}{l}\text { Investimentos em todos os principais tipos de infraestrutura de } \\
\text { transportes (estradas, ferrovias, aeroportos, ciclovias e passeios) } \\
\text { contribuem para o crescimento das oportunidades de emprego. }\end{array}$ \\
\hline \multirow{3}{*}{ Sustentabilidade } & Q4 & $\begin{array}{l}\text { A gestão da demanda de viagens por carro - buscando a redução dessa } \\
\text { demanda - deve constar em qualquer estratégia de transporte urbano. }\end{array}$ \\
\hline & Q5 & $\begin{array}{l}\text { A redução do transporte desnecessário de cargas, obtida através de um } \\
\text { adequado planejamento logístico, pode se converter em benefícios } \\
\text { econômicos para as empresas. }\end{array}$ \\
\hline & Q6 & $\begin{array}{l}\text { Os custos totais de viagens (incluindo mortes e lesões derivadas de } \\
\text { acidentes de trânsito e doenças decorrentes de poluição, bem como o } \\
\text { isolamento daqueles que não tem acesso ao automóvel em uma cidade } \\
\text { dependente do carro) devem sempre ser considerados em qualquer } \\
\text { análise de custo-benefício. }\end{array}$ \\
\hline
\end{tabular}

As outras nove questões, que representam a visão sobre os modos não motorizados, elaboradas a partir dos grupos focais, estão descritas na Tabela 3-2. 
Tabela 3-2 - Discursos e as sentenças analisadas de Q7 a Q15

\begin{tabular}{|c|c|c|}
\hline DISCURSO & $\mathbf{Q}$ & SENTENÇA \\
\hline \multirow{9}{*}{$\begin{array}{l}\text { Modos não } \\
\text { motorizados }\end{array}$} & Q7 & $\begin{array}{l}\text { Você acredita que a redução do limite de velocidade para os veículos } \\
\text { motorizados (automóveis, motocicletas, caminhões e ônibus) em } \\
\text { algumas vias possa estimular a locomoção de pedestres e ciclistas? }\end{array}$ \\
\hline & Q8 & $\begin{array}{l}\text { Na sua opinião, qual a importância de investimentos em sinalização, } \\
\text { manutenção e continuidade da rede viária para o compartilhamento das } \\
\text { vias entre os diferentes modos de transporte (individual motorizado, } \\
\text { transporte público, a pé e bicicleta)? }\end{array}$ \\
\hline & Q9 & $\begin{array}{l}\text { O oferecimento de infraestrutura adequada influencia no uso dos modos } \\
\text { não motorizados (a pé e bicicleta)? }\end{array}$ \\
\hline & Q10 & $\begin{array}{l}\text { Características do ambiente, como topografia irregular e clima quente, } \\
\text { inviabilizam o uso dos modos não motorizados, independentemente da } \\
\text { infraestrutura viária disponível? }\end{array}$ \\
\hline & Q11 & $\begin{array}{l}\text { Como você avalia o custo das infraestruturas adequadas para os modos } \\
\text { não motorizados (a pé e bicicleta), quando comparadas às infraestruturas } \\
\text { para outros modos de transporte urbano. }\end{array}$ \\
\hline & Q12 & $\begin{array}{l}\text { Manifeste a sua opinião com relação à seguinte frase: Modos não } \\
\text { motorizados (a pé e bicicleta) são considerados de baixo custo e, por este } \\
\text { motivo, poderiam ser utilizados pela maioria da população. }\end{array}$ \\
\hline & Q13 & $\begin{array}{l}\text { O aumento do uso dos modos não motorizados (a pé e bicicleta) pode } \\
\text { estimular o desenvolvimento de atividades em novas áreas de expansão } \\
\text { urbana? }\end{array}$ \\
\hline & Q14 & $\begin{array}{l}\text { Qual a sua sensação de segurança, em relação a roubos e violência, em } \\
\text { áreas com tráfego de pedestres e ciclistas em todos os horários do dia? }\end{array}$ \\
\hline & Q15 & $\begin{array}{l}\text { Buscando promover uma mudança cultural da população em relação ao } \\
\text { transporte sustentável, como você avalia as medidas que destinam o } \\
\text { espaço normalmente utilizado pelos veículos motorizados para pedestres } \\
\text { e ciclistas nos finais de semana. }\end{array}$ \\
\hline
\end{tabular}

Para avaliação das sentenças, o respondente se baseava em alternativas em escala de Likert, através da qual indica seu grau de concordância com cada questão. As seis sentenças adaptadas do questionário de Curtis e Low (2012) possuíam sete categorias e as outras nove sentenças elaboradas a partir dos grupos focais possuíam cinco categorias de avaliação.

O último bloco contém uma questão que avalia o grau de investimento sugerido pelos respondentes a diferentes tipos de infraestrutura de transportes, buscando a promoção da mobilidade sustentável. As infraestruturas de transportes avaliadas foram para pedestres, ciclistas, transporte público coletivo, rodoviária, sobre trilhos (pesada e leve) e terminais de integração. Nesta questão o respondente deve atribuir valores de 0 (zero) para nenhuma contribuição e 100 (cem) para a máxima contribuição que o investimento público poderia fazer. 


\subsection{Métodos de análise dos resultados}

Inicialmente, para identificar obstáculos à mobilidade urbana sustentável a partir da opinião de especialistas, os respondentes foram divididos em dois grupos: i) profissionais que atuam ou atuaram na área de transportes; e ii) profissionais que não atuam ou atuaram na área de transportes. Em seguida, para cada um dos dois grupos, foi realizada a avaliação das quinze sentenças afirmativas e da questão sobre o grau de investimento aplicado a diferentes tipos de infraestrutura.

As quinze sentenças afirmativas foram organizadas contendo o número da questão e a frequência de cada categoria. Foi realizado o cálculo da porcentagem das respostas para cada alternativa. Para as seis primeiras sentenças, os resultados foram analisados utilizando o Método dos Intervalos Sucessivos (MIS), desenvolvido por Guilford (1954). Estas questões apresentavam os mesmos valores de categoria e, conforme descrito por Providelo e Sanches (2011), a aplicação do MIS é o método mais adequado para avaliar este tipo de questão, pois permite verificar que as distâncias entre as categorias das respostas na escala de Likert não são iguais. Após definida uma nova escala em relação ao grupo de sentenças, foram calculadas as médias para cada sentença e os valores foram plotados em gráficos.

A partir dos gráficos foi possível analisar o grau de concordância com os conceitos de mobilidade urbana sustentável presentes nas questões. Quanto maior o valor da média, maior é o grau de concordância com a sentença. Além disso, através dos gráficos, qualquer divergência entre os grupos para uma mesma sentença fica evidente, sendo possível identificá-la e analisar o provável motivo dessa disparidade. O mesmo vale para quando não houver divergência entre as categorias, indicando que concordam ou discordam de uma determinada afirmação.

As outras nove questões, que possuíam alternativas diferentes em relação ao texto da questão, foram analisadas utilizando o método mais comum para avaliação de pesquisas que utilizam escala de Likert. Foram associados valores de escala ordinal de 1 a 5 para as alternativas. A partir dessa consideração, a análise seguiu o mesmo procedimento das seis primeiras questões, foi calculada a média aritmética simples das respostas para cada questão e os valores plotados em gráficos. 
$\mathrm{Na}$ análise dos resultados, a amostra também foi dividida de forma a avaliar se há diferença no grau de concordância atribuído às sentenças por distintos grupos. Com base nas perguntas de caracterização inicial, os respondentes foram divididos em grupos conforme sua atuação profissional, tempo de experiência na área, conhecimento da Política Nacional de Mobilidade Urbana (PNMU), tamanho da cidade e região do País.

Quanto à atuação profissional, os respondentes foram divididos em quatro grupos diferentes: o primeiro grupo é constituído de profissionais que atuam como gestores (diretores, secretários, prefeitos etc.); o segundo por técnicos (engenheiros, arquitetos, técnicos); o terceiro grupo é formado somente por pesquisadores, principalmente professores e estudantes de pós-graduação; o último grupo é formado por profissionais que atuam ou já atuaram tanto como pesquisadores quanto como técnicos e/ou gestores.

Em relação ao tempo de experiência, os grupos foram divididos em respondentes que possuíam "até 5 anos", "de 6 a 10 anos", "de 11 a 15 anos" e "mais de 15 anos" de experiência. Sobre o conhecimento da Política Nacional de Mobilidade Urbana os respondentes indicavam o nível de conhecimento sobre o texto: "Sim, conhece detalhadamente"; "Sim, conhece superficialmente"; "Já ouviu falar, mais ainda não leu" e "Não conhece". Quanto ao tamanho da cidade, a divisão considerou respondentes de cidades com até 100 mil habitantes como "Cidades Pequenas", de 100 a 500 mil habitantes como "Cidades Médias" e mais de 500 mil habitantes como "Cidades Grandes". A divisão para as regiões foi em relação às 5 regiões brasileiras: Sul, Sudeste, Centro-oeste, Nordeste e Norte.

\subsubsection{Método dos Intervalos Sucessivos (MIS)}

O MIS baseia-se em escalas psicométricas e considera que a variável subjacente à escolha dos indivíduos segue uma distribuição de probabilidade normal. A curva normal padrão é dividida segundo o número de categorias, sendo a área sob cada segmento de curva correspondente à proporção de frequências (pj) observadas na categoria. 
Os valores dos limites superior e inferior de cada categoria ( $z_{1 j}$ e $\left.z_{2 j}\right)$ são obtidos por meio de uma tabela de distribuição normal padrão. Assim, determinando os valores centrais para os diferentes segmentos sob a curva $\left(\mathrm{Z}_{\mathrm{cj}}\right)$, podem ser estimados os valores de cada categoria, mensurados em unidades de desvio padrão. Os valores encontrados representam a escala intervalar da sentença avaliada. A Figura 3-1 ilustra, na curva normal, as ordenadas e a proporção de frequências para uma determinada categoria.

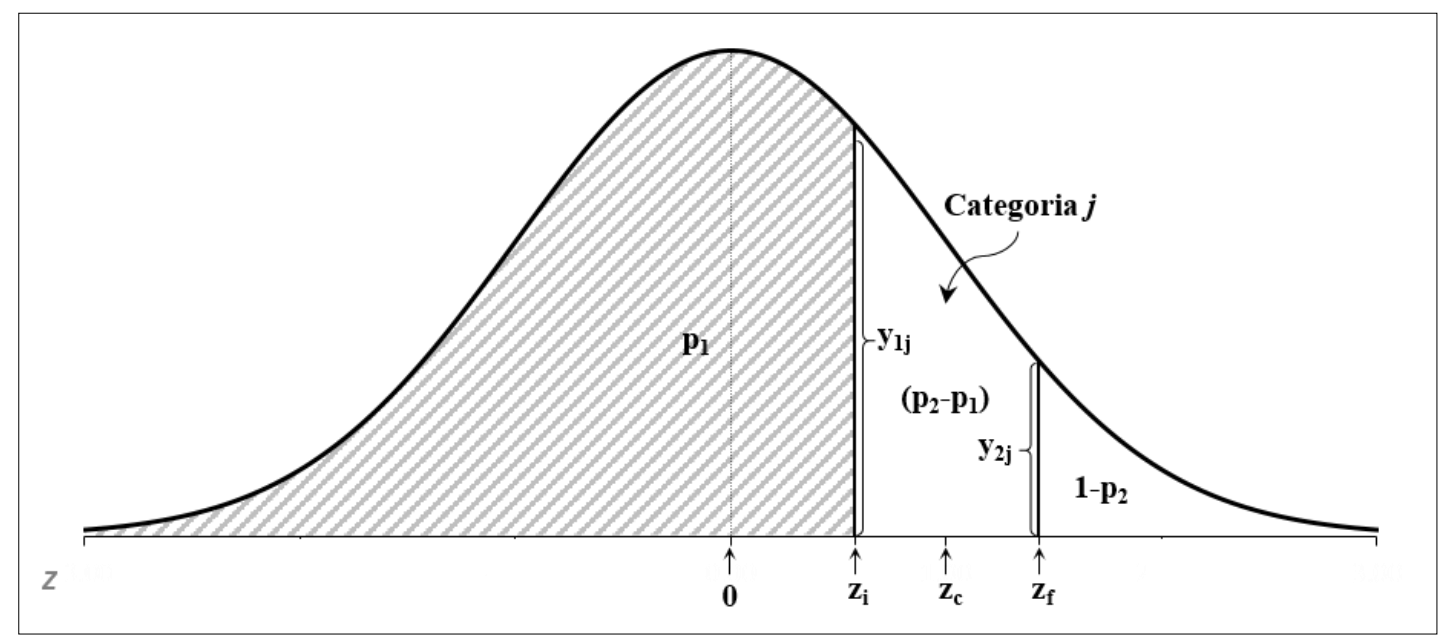

Figura 3-1 - Indicação das ordenadas e proporção de frequências para determinada categoria, adaptado de Guilford (1954)

Segundo Guilford (1954), quando diferentes sentenças são avaliadas, deve ser considerada como referência uma escala intervalar única. Para isso, a partir da diferença média entre categorias adjacentes (DM), é calculada a diferença média acumulada (DMA). Guilford (1954) sugere que o ponto de magnitude zero esteja localizado na categoria central. Assim, deduzindo o valor DMA da categoria central em todas as categorias, é estimada a escala intervalar de referência.

A partir dos valores da escala intervalar de referência, foram calculadas as médias das respostas de cada questão. Os resultados foram organizados de modo a realizar uma análise comparativa entre os graus de concordância e verificar a sintonia dos entrevistados com os conceitos de mobilidade sustentável. 


\subsubsection{Avaliação das diferenças entre grupos: ANOVA, Teste de Tukey e Teste de Kruskal-Wallis}

A partir dos valores de média encontrados para cada grupo, utilizando o software IBM SPSS, foram realizados testes estatísticos para verificar se existem diferenças entre os grupos.

Para cada grupo, foram realizados Testes de Hipótese em que as médias foram comparadas considerando um nível de significância de $5 \%$. Em todas as análises, foram consideradas as seguintes hipóteses:

- Hipótese nula $\left(\mathrm{H}_{0}\right)$ : os dados não fornecem evidências de que as médias (graus de concordância) das sentenças entre os grupos em estudo são diferentes, com $95 \%$ de confiança.

- Hipótese alternativa $\left(\mathrm{H}_{1}\right)$ : os dados não fornecem evidências de que as médias (graus de concordância) das sentenças entre os grupos em estudo são diferentes.

Assim, para valores de significância ( $p$-valor) menores que 0,05 a hipótese $\mathrm{H}_{0}$ é rejeitada em favor de $\mathrm{H}_{1}$, ou seja, há indicação de que os grupos indicam opiniões diferentes em relação à sentença avaliada.

Para as primeiras seis questões, incialmente foi realizado o teste estatístico ANOVA e, posteriormente, para identificar entre quais grupos existiam divergências foi realizado o Teste de Tukey. As outras nove questões foram avaliadas utilizando o teste não paramétrico de Kruskal-Wallis. A identificação das diferenças entre grupos foi realizada a partir da aplicação do teste entre pares de grupos.

\subsubsection{Avaliação do nível de investimento para diferentes tipos de infraestruturas de transportes}

A última questão foi analisada de acordo com o grau de investimento aplicado para cada um dos tipos de infraestrutura de transportes. A partir das médias, foi possível fazer um ranking de prioridade para os investimentos em infraestrutura de transportes, segundo a ótica de cada um dos grupos. Dessa forma, foi possível comparar a 
prioridade de investimento dada por diferentes grupos aos princípios indicados pela Política Nacional de Mobilidade Urbana (PNMU).

Em seguida, foram conduzidos testes qui-quadrado de independência entre o investimento aplicado aos tipos de infraestrutura e em relação aos diferentes grupos de respondentes analisados.

O teste qui-quadrado de independência foi empregado como teste de hipótese em tabelas de contingências construídas a partir de valores das variáveis quantitativas dos diferentes bancos de dados estudados. Dessa forma, o teste qui-quadrado é empregado para aceitar ou rejeitar a hipótese de independência entre as variáveis. Para um nível de significância de $5 \%$, quando $\mathrm{H}_{0}$ é rejeitada, não se pode descartar uma possível associação entre as variáveis analisadas.

Como o teste admite até $20 \%$ das contagens esperadas inferiores a 5,0 na tabela de contingência, o grau de investimento para cada infraestrutura foi classificado em três classes: de 0 a 33, de 34 a 66 e de 67 a 100. Assim, utilizando o software IBM SPSS, foram realizados os testes para verificar se existe associação entre as variáveis de investimento em infraestruturas de transporte e os diferentes grupos de respondentes.

Também foi analisado o coeficiente de contingência $V$ de Cramer, para avaliar o grau de associação das variáveis, onde o seu valor é representado entre zero e 1. Os valores próximos de zero correspondem a uma associação fraca e valores mais próximos de 1 correspondem a uma associação mais forte. Outro processo que foi utilizado na tentativa de identificar as categorias responsáveis por um valor significante da estatística qui-quadrado, foi a análise dos resíduos padronizados ajustados. Essa técnica indica que residuos ajustados padronizados estatisticamente significativos são os valores menores que $-1,96$ e maiores que 1,96 .

Uma última avaliação foi realizada para a questão dos investimentos, buscando relacionar as respostas atribuídas para duas sentenças (Q2 e Q9) que tratam sobre oferecimento de infraestrutura e o grau de investimento atribuído para quatro tipos (pedestres, ciclistas, transporte público e rodoviária). Para isso, foi calculado a média de investimento aplicado pelos respondentes de acordo com a categoria indicada para 
a sentença e avaliado se o discurso praticado pelos profissionais é efetivamente empregado na tomada de decisão para a promoção da mobilidade urbana com investimento em modos sustentáveis.

O esquema da Figura 3-2 apresenta as etapas de aplicação do método, indicando os principais itens descritos neste Capítulo.

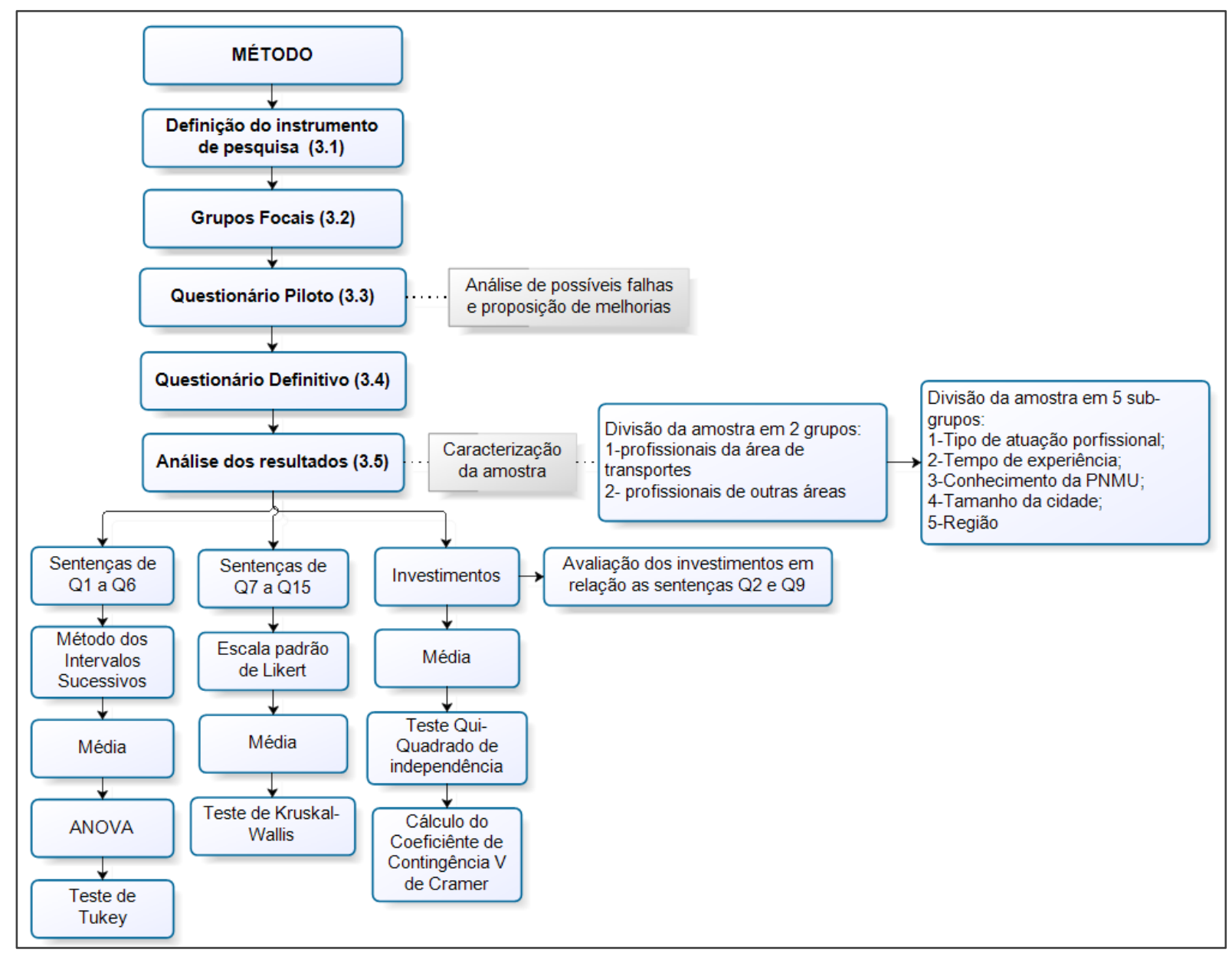

Figura 3-2 - Etapas de aplicação do método 
Capítulo

\section{Resultados}

Nesta seção serão apresentados os resultados da análise do questionário enviado, entre os meses de fevereiro e março de 2017, a 9813 profissionais de diversas áreas, com taxa de resposta de 29,2\% (2863 respostas válidas). Os respondentes foram divididos em dois grupos: 1) 1138 profissionais que atuam ou atuaram na área de transportes (39,7\% da amostra total); e 2) 1725 profissionais que não atuam na área de transportes $(60,3 \%$ da amostra total). No início do Capítulo será realizada uma breve descrição dos grupos focais e a caracterização geral da amostra. Em seguida, os resultados serão apresentados, para cada um dos dois grupos, conforme os seguintes subitens: i) avaliação das sentenças sobre engenharia, economia, planejamento urbano e sustentabilidade; ii) avaliação das sentenças sobre modos não motorizados; e iii) avaliação do grau de investimento em diferentes infraestruturas de transportes.

\subsection{Grupos Focais}

As três reuniões dos grupos focais foram realizadas na cidade de São Carlos - SP, ao longo de 2016, com uma média de sete participantes cada, todos com experiência em deslocamentos utilizando os modos a pé e bicicleta. As discussões foram estruturadas por sessões de brainstorming e análise de cenários. A partir das respostas dos participantes, foram elaboradas as nove questões que representam a visão sobre os modos não motorizados, descritas na Tabela 3-2.

\subsection{Caracterização geral da amostra}

A amostra representada por profissionais de diversas áreas é composta por 2863 respostas. Foram identificados respondentes em 676 cidades, de todos os estados e 
do Distrito Federal. A Figura 4-1 apresenta a distribuição por estado e as cidades com maior número de respostas.

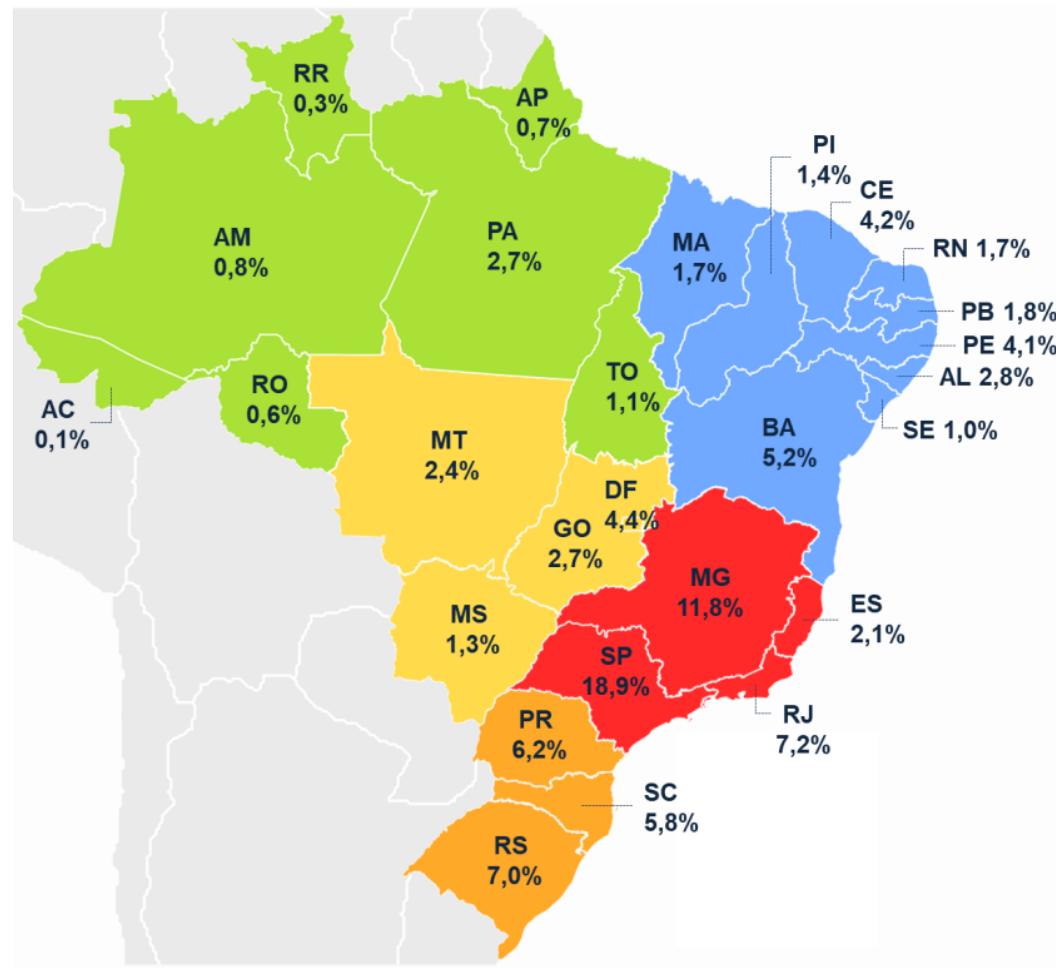

\begin{tabular}{lrll}
\hline \multicolumn{1}{|c}{ N $^{0}$ DE RESPOSTAS POR CIDADE } \\
\hline São Paulo (SP) & 159 & $(5,6 \%)$ \\
Brasília (DF) & 120 & $(4,2 \%)$ \\
Belo Horizonte (MG) & 115 & $(4,0 \%)$ \\
Rio de Janeiro (RJ) & 107 & $(3,7 \%)$ \\
Porto Alegre (RS) & 82 & $(2,9 \%)$ \\
Fortaleza (CE) & 82 & $(2,9 \%)$ \\
Recife (PE) & 79 & $(2,8 \%)$ \\
Salvador (BA) & 74 & $(2,6 \%)$ \\
Curitiba (PR) & 59 & $(2,1 \%)$ \\
Maceió (AL) & 57 & $(2,0 \%)$ \\
Florianópolis (SC) & 48 & $(1,7 \%)$ \\
Outras cidades & 1881 & $(65,7 \%)$ \\
\hline TOTAL & 2863 & $(100,0 \%)$ \\
\hline \multicolumn{1}{|c|}{ DISTRIBUIÇÃO POR REGIÃO } \\
\hline Região Sul & 543 & $(19,0 \%)$ \\
\hline Região Sudeste & 1140 & $(39,8 \%)$ \\
\hline Região Centro-oeste & 309 & $(10,8 \%)$ \\
\hline Região Nordeste & 686 & $(24,0 \%)$ \\
\hline Região Norte & 185 & $(6,5 \%)$ \\
\hline TOTAL & 2863 & $(100,0 \%)$ \\
\hline
\end{tabular}

Figura 4-1 - Distribuição dos respondentes por região, por estado e as cidades com maior número de respostas

Para fins de caracterização dos respondentes, além do gênero e da idade, a pesquisa identificou sua formação, atuação profissional, tempo de experiência, conhecimento da Política Nacional de Mobilidade Urbana - PNMU (Lei Federal oㅜ 12.578/2012) e principal modo de transporte, conforme resumido na Tabela 4-1. O perfil completo dos respondentes pode ser visualizado no Apêndice $A$, que apresenta um relatório dos dados obtidos com o questionário. 
Tabela 4-1 - Distribuição dos respondentes por gênero, idade, formação, atuação profissional, tempo de experiência, principal modo de transporte e conhecimento da PNMU

\begin{tabular}{|c|c|c|c|}
\hline CARACTERÍSTICAS & & TOTAL & $\%$ \\
\hline \multirow{2}{*}{ Gênero } & Feminino & 1440 & $50,3 \%$ \\
\hline & Masculino & 1423 & $49,7 \%$ \\
\hline \multirow{6}{*}{ Idade } & até 24 anos & 407 & $14,2 \%$ \\
\hline & de 25 a 30 anos & 685 & $23,9 \%$ \\
\hline & de 31 a 39 anos & 734 & $25,6 \%$ \\
\hline & de 40 a 49 anos & 523 & $18,3 \%$ \\
\hline & de 50 a 59 anos & 372 & $13,0 \%$ \\
\hline & maior que 60 anos & 142 & $5,0 \%$ \\
\hline \multirow{11}{*}{$\begin{array}{l}\text { Formação } \\
\text { (ensino médio, } \\
\text { técnico e superior) }\end{array}$} & Arquitetura e Urbanismo & 932 & $32,6 \%$ \\
\hline & Engenharia Civil & 569 & $19,9 \%$ \\
\hline & Geografia & 175 & $6,1 \%$ \\
\hline & Administração & 102 & $3,6 \%$ \\
\hline & Serviço Social & 102 & $3,6 \%$ \\
\hline & Direito & 94 & $3,2 \%$ \\
\hline & Engenharia Ambiental & 81 & $2,8 \%$ \\
\hline & Outras Engenharias & 66 & $2,3 \%$ \\
\hline & Gestão Ambiental & 46 & $1,6 \%$ \\
\hline & Outros cursos (graduação) & 630 & $22,0 \%$ \\
\hline & Ensino médio/técnico & 66 & $2,3 \%$ \\
\hline \multirow{3}{*}{ Pós-graduação } & Especialização & 1146 & $40,0 \%$ \\
\hline & Mestrado & 930 & $32,5 \%$ \\
\hline & Doutorado & 355 & $12,4 \%$ \\
\hline \multirow{4}{*}{ Atuação profissional } & Gestor (diretor, secretário, prefeito) & 223 & $7,8 \%$ \\
\hline & Técnico (arquiteto, engenheiro, entre outros) & 1350 & $47,2 \%$ \\
\hline & Pesquisador (professor, estudante) & 977 & $34,1 \%$ \\
\hline & Diversas Funções & 313 & $10,9 \%$ \\
\hline \multirow{4}{*}{ Tempo de experiência } & até 5 anos & 1554 & $54,3 \%$ \\
\hline & de 6 a 10 anos & 543 & $19,0 \%$ \\
\hline & de 11 a 15 anos & 240 & $8,4 \%$ \\
\hline & maior que 15 anos & 526 & $18,4 \%$ \\
\hline \multirow{4}{*}{$\begin{array}{l}\text { Conhecimento da } \\
\text { Política Nacional de } \\
\text { Mobilidade Urbana }\end{array}$} & Sim, conhece detalhadamente o texto & 559 & $19,5 \%$ \\
\hline & Sim, conhece superficialmente o texto & 1429 & $49,9 \%$ \\
\hline & Já ouviu falar, mas ainda não leu o texto & 668 & $23,3 \%$ \\
\hline & Não conhece & 207 & $7,2 \%$ \\
\hline \multirow{4}{*}{$\begin{array}{l}\text { Principal modo de } \\
\text { transporte }\end{array}$} & Modos não motorizados & 455 & $15,9 \%$ \\
\hline & Transporte público coletivo & 265 & $9,3 \%$ \\
\hline & Modos motorizados individuais & 1383 & $48,3 \%$ \\
\hline & Diversos modos & 760 & $26,5 \%$ \\
\hline
\end{tabular}

Nota: Valores destacados em negrito são os maiores de cada categoria

A amostra indicou que a maioria dos respondentes era do gênero feminino (50,3\%) e possuía idade entre 31 e 39 anos (25,6\%). Quanto à formação, predominou a participação de profissionais com graduação em Arquitetura e Urbanismo $(32,6 \%)$ e 
Engenharia Civil (19,9\%). Alguns dos outros cursos identificados com maiores proporções foram: Geografia (6,1\%), Administração (3,6\%), Serviço Social (3,6\%) e Direito $(3,2 \%)$. Além disso, em relação à pós-graduação, a maioria indicou possuir especialização $(40,0 \%)$. Também se observa uma elevada taxa de participação de profissionais com mestrado $(32,5 \%)$.

Entre os entrevistados, o grupo constituído de profissionais da área de transportes que atuam como técnicos (engenheiros, arquitetos, técnicos) formam cerca de 47,2\% da amostra. Os pesquisadores, caracterizados principalmente por professores e estudantes de pós-graduação, representaram $34,1 \%$. Entre os que trabalham como gestores (diretores, secretários, prefeitos etc.) a amostra é de cerca de 7,8\% dos respondentes. Um último grupo é formado por profissionais que atuam ou já atuaram tanto como pesquisadores quanto como técnicos/gestores (10,9\%). Quanto ao tempo de experiência dos respondentes, a maioria possui experiência de até cinco anos $(54,3 \%)$.

Os resultados sobre o conhecimento específico da Política Nacional de Mobilidade Urbana (PNMU) indicam que a maioria dos respondentes conhece o texto da Lei $\mathrm{n}^{\circ}$ $12.587(85,8 \%)$, sendo que $49,9 \%$ indicou que conhece superficialmente o texto. Outros $7,2 \%$ indicaram que não tiveram contato com o texto da PNMU. A maioria dos respondentes utiliza como principal modo de transporte modos motorizados individuais (48,3\%). Os usuários de modos não motorizados representam $15,9 \%$ da amostra.

\subsection{Avaliação das sentenças sobre Economia, Engenharia, Planejamento Urbano e Sustentabilidade}

A partir das respostas dos respondentes, que indicaram sua opinião para cada sentença, foi possível avaliar as diferentes visões para os temas propostos e verificar sua sintonia com conceitos de mobilidade sustentável.

A Tabela 4-2 apresenta a distribuição das respostas atribuídas em cada das seis sentenças para o Grupo 1, representado pela amostra dos 1138 especialistas da área de transportes (39,7\% da amostra total). 
Tabela 4-2 - Distribuição das respostas informadas para cada sentença pelo Grupo $1(n=1138)$

\begin{tabular}{cccccccc}
\hline \multicolumn{7}{c}{ GRUPO 1 - Especialistas da área de transportes } \\
\hline Q & $\begin{array}{c}\text { Discordo } \\
\text { totalmente }\end{array}$ & Discordo & $\begin{array}{c}\text { Discordo } \\
\text { parcial- } \\
\text { mente }\end{array}$ & Neutro & $\begin{array}{c}\text { Concordo } \\
\text { parcial- } \\
\text { mente }\end{array}$ & Concordo & $\begin{array}{c}\text { Concordo } \\
\text { totalmente }\end{array}$ \\
\hline $\begin{array}{c}\text { Q1 } \\
\text { (Planejamento } \\
\text { Urbano) }\end{array}$ & 1 & 0 & 1 & 2 & 36 & 209 & 889 \\
\hline Q2 & $(0,09 \%)$ & $(0,00 \%)$ & $(0,09 \%)$ & $(0,18 \%)$ & $(3,16 \%)$ & $(18,37 \%)$ & $(78,12 \%)$ \\
(Engenharia) & $(1,76 \%)$ & $(5,36 \%)$ & $(8,44 \%)$ & $(0,88 \%)$ & $(21,97 \%)$ & $(21,27 \%)$ & $(40,33 \%)$ \\
\hline $\begin{array}{c}\text { Q3 } \\
\text { (Economia) }\end{array}$ & 2 & 6 & 18 & 17 & 156 & 350 & 589 \\
\hline Q4 & $(0,18 \%)$ & $(0,53 \%)$ & $(1,58 \%)$ & $(1,49 \%)$ & $(13,71 \%)$ & $(30,76 \%)$ & $(51,76 \%)$ \\
$\begin{array}{c}\text { (Sustentabi- } \\
\text { lidade) }\end{array}$ & $(0,35 \%)$ & $(0,88 \%)$ & $(1,67 \%)$ & $(2,81 \%)$ & $(11,25 \%)$ & $(30,58 \%)$ & $(52,46 \%)$ \\
\hline Q5 & 1 & 4 & 5 & 43 & 66 & 396 & 623 \\
$\begin{array}{c}\text { Sustentabi- } \\
\text { lidade) }\end{array}$ & $(0,09 \%)$ & $(0,35 \%)$ & $(0,44 \%)$ & $(3,78 \%)$ & $(5,80 \%)$ & $(34,80 \%)$ & $(54,75 \%)$ \\
\hline Q6 & 1 & 5 & 15 & 44 & 111 & 380 & 582 \\
$\begin{array}{c}\text { (Sustentabi- } \\
\text { lidade) }\end{array}$ & $(0,09 \%)$ & $(0,44 \%)$ & $(1,32 \%)$ & $(3,87 \%)$ & $(9,75 \%)$ & $(33,39 \%)$ & $(51,14 \%)$ \\
\hline
\end{tabular}

Q1 - No planejamento de uma cidade, a infraestrutura de transporte deveria proporcionar um sistema integrado de uso do solo e transportes.

Q2 - Em um sistema urbano deve haver equilíbrio de investimento entre as infraestruturas necessárias para os diferentes modos de transporte (individual motorizado, transporte público, bicicleta e a pé).

Q3 - Investimentos em todos os principais tipos de infraestrutura de transportes (estradas, ferrovias, aeroportos, ciclovias e passeios) contribuem para o crescimento das oportunidades de emprego.

Q4 - A gestão da demanda de viagens por carro - buscando a redução dessa demanda - deve constar em qualquer estratégia de transporte urbano.

Q5 - A redução do transporte desnecessário de cargas, obtida através de um adequado planejamento logístico, pode se converter em benefícios econômicos para as empresas.

Q6 - Os custos totais de viagens (incluindo mortes e lesões derivadas de acidentes de trânsito e doenças decorrentes de poluição, bem como o isolamento daqueles que não tem acesso ao automóvel em uma cidade dependente do carro) devem sempre ser considerados em qualquer análise de custo-benefício.

O percentual de concordância para a maioria das sentenças foi elevado, conforme pode ser visualizado na Figura 4-2. Para a sentença Q1, 99,7\% dos respondentes expressaram concordância com a afirmativa sobre o planejamento integrado ao uso do solo. A sentença Q2, que trata sobre o investimento equilibrado em infraestrutura de transporte entre todos os modos, apresentou uma distribuição de respostas diferente das demais. O percentual de discordância para a sentença Q2 foi de 16,0\%, o que pode indicar uma divergência na opinião dos especialistas em relação a este tema. 


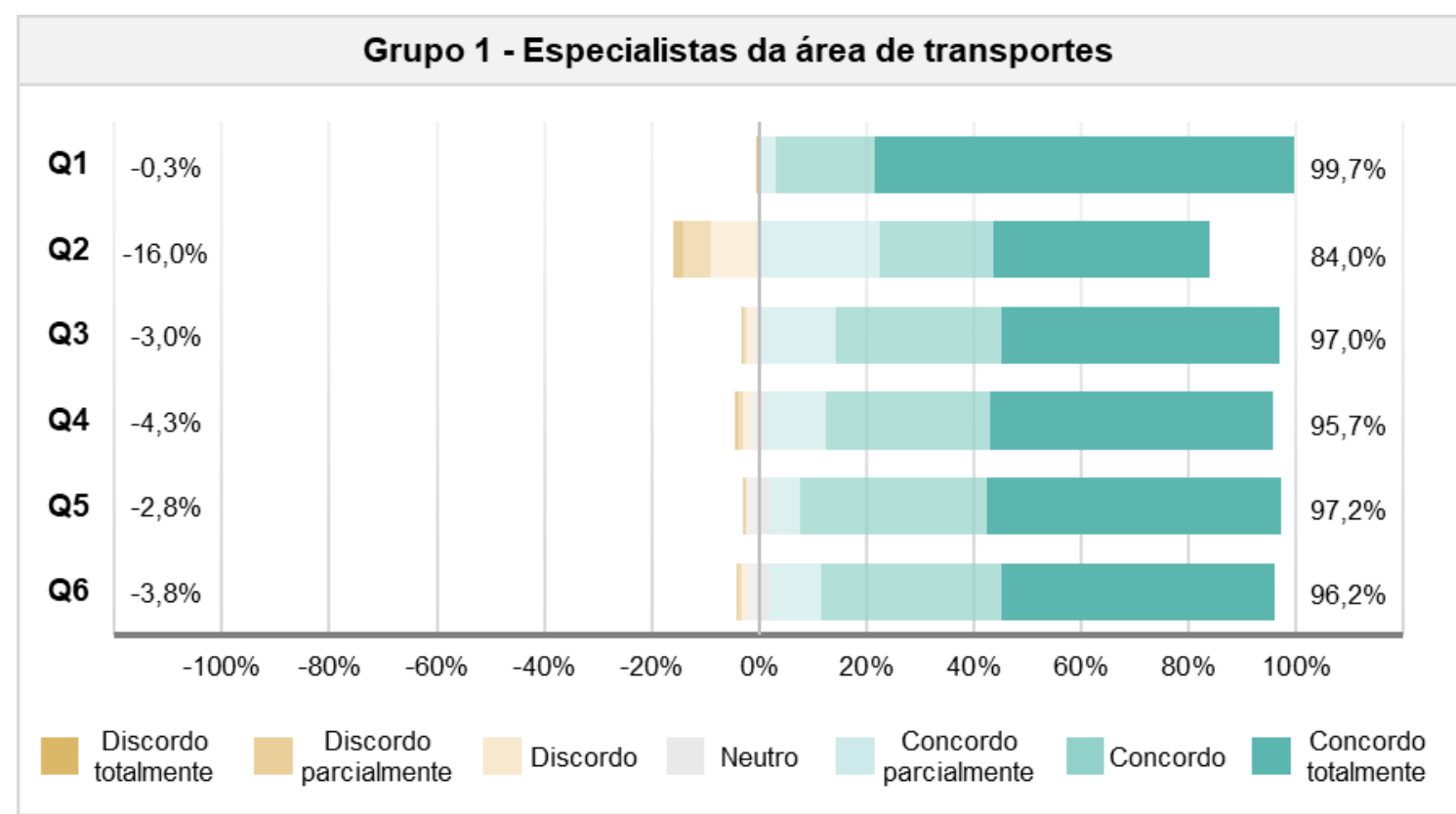

Figura 4-2 - Percentual de concordância do Grupo 1 para cada uma das sentenças

A distribuição das respostas do Grupo 2, formado por profissionais que não atuam na área de transportes, está apresentado na Tabela 4-3. Este grupo é composto por uma amostra de 1725 profissionais $(60,3 \%$ da amostra total).

Tabela 4-3 - Distribuição das respostas informadas para cada sentença pelo Grupo $2(n=1725)$

\begin{tabular}{|c|c|c|c|c|c|c|c|}
\hline \multicolumn{8}{|c|}{ Grupo 2 - Profissionais de outras áreas } \\
\hline \multirow[b]{2}{*}{$\mathbf{Q}$} & \multicolumn{7}{|c|}{ CATEGORIAS } \\
\hline & $\begin{array}{l}\text { Discordo } \\
\text { totalmente }\end{array}$ & Discordo & $\begin{array}{c}\text { Discordo } \\
\text { parcial- } \\
\text { mente }\end{array}$ & Neutro & $\begin{array}{c}\text { Concordo } \\
\text { parcial- } \\
\text { mente }\end{array}$ & Concordo & $\begin{array}{l}\text { Concordo } \\
\text { totalmente }\end{array}$ \\
\hline \multirow{2}{*}{$\begin{array}{c}\mathbf{Q 1} \\
\text { (Planejamento } \\
\text { Urbano) }\end{array}$} & 1 & 0 & 3 & 14 & 47 & 467 & 1193 \\
\hline & $(0,06 \%)$ & $(0 \%)$ & $(0,17 \%)$ & $(0,81 \%)$ & $(2,72 \%)$ & $(27,07 \%)$ & $(69,16 \%)$ \\
\hline \multirow{2}{*}{$\begin{array}{c}\text { Q2 } \\
\text { (Engenharia) }\end{array}$} & 23 & 79 & 94 & 17 & 275 & 413 & 824 \\
\hline & $(1,33 \%)$ & $(4,58 \%)$ & $(5,45 \%)$ & $(0,99 \%)$ & $(15,94 \%)$ & $(23,94 \%)$ & $(47,77 \%)$ \\
\hline \multirow{2}{*}{$\begin{array}{c}\text { Q3 } \\
\text { (Economia) }\end{array}$} & 0 & 8 & 16 & 41 & 165 & 572 & 923 \\
\hline & $(0 \%)$ & $(0,46 \%)$ & $(0,93 \%)$ & $(2,38 \%)$ & $(9,57 \%)$ & $(33,16 \%)$ & $(53,51 \%)$ \\
\hline \multirow{2}{*}{$\begin{array}{c}\text { Q4 } \\
\text { (Sustentabi- } \\
\text { lidade) }\end{array}$} & 7 & 22 & 29 & 62 & 203 & 613 & 789 \\
\hline & $(0,41 \%)$ & $(1,28 \%)$ & $(1,68 \%)$ & $(3,59 \%)$ & $(11,77 \%)$ & $(35,54 \%)$ & $(45,74 \%)$ \\
\hline \multirow{2}{*}{$\begin{array}{c}\text { Q5 } \\
\begin{array}{c}\text { (Sustentabi- } \\
\text { lidade) }\end{array}\end{array}$} & 1 & 5 & 9 & 96 & 94 & 640 & 880 \\
\hline & $(0,06 \%)$ & $(0,29 \%)$ & $(0,52 \%)$ & $(5,57 \%)$ & $(5,45 \%)$ & $(37,1 \%)$ & $(51,01 \%)$ \\
\hline \multirow{2}{*}{$\begin{array}{c}\text { Q6 } \\
\begin{array}{c}\text { (Sustentabi- } \\
\text { lidade) }\end{array}\end{array}$} & 2 & 11 & 18 & 90 & 167 & 673 & 764 \\
\hline & $(0,12 \%)$ & $(0,64 \%)$ & $(1,04 \%)$ & $(5,22 \%)$ & $(9,68 \%)$ & $(39,01 \%)$ & $(44,29 \%)$ \\
\hline
\end{tabular}


A distribuição das respostas para o Grupo 2 foi semelhante as respostas do Grupo 1, indicando alinhamento na opinião dos profissionais que participaram do questionário. No entanto, para todas as sentenças do Grupo 2, as categorias "concordo" e "concordo totalmente" obtiveram maiores percentuais de respostas em relação ao Grupo 1. As sentenças $Q 1$ e Q2 também foram as que receberam, respectivamente, o maior e o menor percentual de concordância, como apresentado na Figura 4-3.

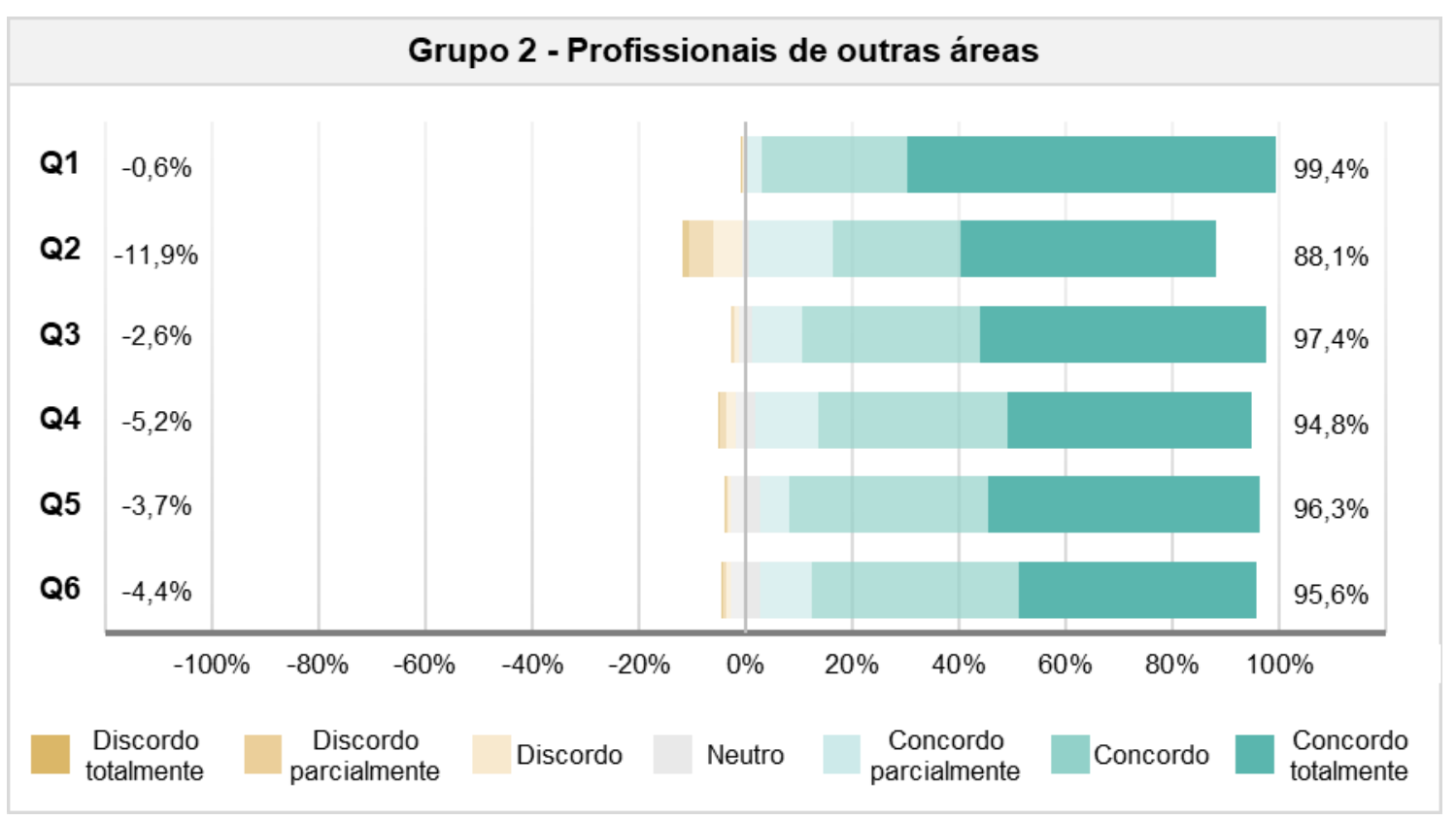

Figura 4-3 - Percentual de concordância do Grupo 2 para cada uma das sentenças

Conforme descrito no Capítulo 3, para a avaliação das respostas foi aplicado o Método dos Intervalos Sucessivos (MIS). A partir dos dados de frequência, para cada sentença, foram encontrados os valores centrais $\left(z_{c}\right)$ das categorias. Em seguida, a diferença média ( $\mathrm{D}_{\mathrm{Med}}$ ) entre as categorias adjacentes e a diferença média acumulada (DMA) foram calculadas. Por fim, considerando a categoria central com magnitude zero, se obteve a escala intervalar de referência, mensurada em unidades de desvio padrão.

A Tabela 4-4 demonstra a aplicação do método para o Grupo 1 (Especialistas da área de transportes), indicando a escala intervalar de referência utilizada na análise das seis sentenças (Q1 a Q6). A demonstração da aplicação do Método dos Intervalos Sucessivos está descrita no Apêndice B. 
Tabela 4-4 - Cálculo da escala intervalar de referência para o Grupo 1

\begin{tabular}{|c|c|c|c|c|c|c|c|}
\hline \multirow[b]{4}{*}{ DISCURSO } & \multicolumn{7}{|c|}{ Grupo 1 - Especialistas da área de transportes } \\
\hline & \multicolumn{7}{|c|}{ CATEGORIAS } \\
\hline & 1 & 2 & 3 & 4 & 5 & 6 & 7 \\
\hline & $\begin{array}{c}\text { Discordo } \\
\text { totalmen- } \\
\text { te }\end{array}$ & Discordo & $\begin{array}{l}\text { Discordo } \\
\text { parcial- } \\
\text { mente }\end{array}$ & Neutro & $\begin{array}{c}\text { Concordo } \\
\text { parcial- } \\
\text { mente }\end{array}$ & Concordo & $\begin{array}{c}\text { Concordo } \\
\text { totalmen- } \\
\text { te }\end{array}$ \\
\hline $\begin{array}{l}\text { Q1 Planejamento } \\
\text { Urbano }\end{array}$ & $-3,403$ & - & $-3,013$ & $-2,795$ & $-2,118$ & $-1,185$ & 0,378 \\
\hline Q2 Engenharia & $-2,468$ & $-1,728$ & $-1,219$ & $-0,995$ & $-0,612$ & $-0,025$ & 0,960 \\
\hline Q3 Economia & $-3,208$ & $-2,641$ & $-2,189$ & $-1,880$ & $-1,279$ & $-0,458$ & 0,770 \\
\hline Q4 Sustentabilidade & $-3,002$ & $-2,431$ & $-2,051$ & $-1,723$ & $-1,227$ & $-0,476$ & 0,759 \\
\hline Q5 Sustentabilidade & $-3,403$ & $-2,815$ & $-2,485$ & $-1,949$ & $-1,446$ & $-0,617$ & 0,724 \\
\hline Q6 Sustentabilidade & $-3,403$ & $-2,770$ & $-2,280$ & $-1,795$ & $-1,264$ & $-0,482$ & 0,780 \\
\hline$\sum$ Diferenças & - & 3,098 & 2,161 & 2,099 & 3,190 & 4,704 & 7,613 \\
\hline Diferença Média (DM) & 0,000 & 0,620 & 0,432 & 0,350 & 0,532 & 0,784 & 1,269 \\
\hline DM Acumulada (DMA) & 0,000 & 0,620 & 1,052 & 1,402 & 1,933 & 2,717 & 3,986 \\
\hline $\begin{array}{c}\text { Escala Intervalar de } \\
\text { Referência }\end{array}$ & $-1,402$ & $-0,782$ & $-0,350$ & 0,000 & 0,532 & 1,316 & 2,585 \\
\hline
\end{tabular}

Com base nos valores de referência para as categorias, foi estimada a importância atribuída pelos respondentes calculando a média das respostas para cada uma das sentenças. Valores mais altos para as médias indicam maior grau de concordância com a afirmativa. A seguir, a Tabela 4-5 apresenta a média, o desvio padrão e o coeficiente de variação (c.v.) de cada questão do Grupo 1.

Tabela 4-5 - Média, desvio padrão e coeficiente de variação para cada sentença do Grupo 1

\begin{tabular}{cllccc}
\hline $\mathbf{Q}$ & DISCURSO & IDEIA CENTRAL DA SENTENÇA & MÉDIA & $\begin{array}{c}\text { DESVIO } \\
\text { PADRÃO }\end{array}$ & C. V. \\
\hline Q1 & $\begin{array}{l}\text { Planejamento } \\
\text { Urbano }\end{array}$ & Integração do uso do solo em transporte & 2,276 & 0,606 & $26,6 \%$ \\
\hline $\mathbf{Q 2}$ & Engenharia & $\begin{array}{l}\text { Investimento equilibrado em infraestrutura } \\
\text { de transporte entre todos os modos }\end{array}$ & 1,343 & 1,183 & $88,1 \%$ \\
\hline $\mathbf{Q 3}$ & Economia & $\begin{array}{l}\text { Investimento em infraestrutura resulta em } \\
\text { aumento do número de empregos }\end{array}$ & 1,803 & 0,886 & $49,2 \%$ \\
\hline $\mathbf{Q 4}$ & Sustentabilidade & $\begin{array}{l}\text { A gestão da demanda reduz a demanda } \\
\text { por automóveis }\end{array}$ & 1,800 & 0,916 & $50,9 \%$ \\
\hline $\mathbf{Q 5}$ & Sustentabilidade & $\begin{array}{l}\text { O planejamento logístico traz benefícios } \\
\text { econômicos para as empresas }\end{array}$ & 1,898 & 0,823 & $43,4 \%$ \\
\hline Q6 & Sustentabilidade & $\begin{array}{l}\text { Análise de custo-benefício deve ser } \\
\text { considerada no custo total de viagens }\end{array}$ & 1,804 & 0,880 & $48,8 \%$ \\
\hline
\end{tabular}


Considerando que o maior valor da escala intervalar para a categoria "concordo totalmente" é 2,585 (Tabela 4-5), pode-se perceber que os valores de média encontrados para as afirmativas foram altos. A sentença Q1, que aborda a integração do uso do solo em transporte (discurso "Planejamento Urbano"), apresentou a maior média $(2,276)$ e menor coeficiente de variação $(26,6 \%)$. Na sequência, com o segundo maior grau de concordância $(1,898)$, aparece uma das questões do discurso "Sustentabilidade" (Q5), que trata sobre a importância do planejamento logístico para as empresas. As sentenças do discurso "Economia" Q3 (Investimento em infraestrutura resulta em aumento do número de empregos) e duas do discurso "Sustentabilidade", Q4 (A gestão da demanda reduzindo a demanda por automóveis) e Q6 (Análise de custo-benefício deve ser considerada no custo total de viagens), apresentaram valores de média e de coeficiente de variação muito próximos, não sendo possível afirmar que uma sentença apresentou maior grau de concordância que outra. O discurso "Engenharia", representado pela sentença sobre o investimento equilibrado em infraestrutura de transporte entre todos os modos, foi a que obteve a menor média $(1,343)$ e o maior desvio padrão $(1,183)$ entre os respondentes.

Seguindo o mesmo método (MIS), foram avaliadas as respostas do Grupo 2, formado por profissionais de outras áreas, como forma de realizar uma comparação com os resultados dos profissionais da área de transportes. Assim, a Tabela 4-6 indica a escala intervalar utilizada na análise do Grupo 2 e a Tabela 4-7 apresenta a média, o desvio padrão e o coeficiente de variação (c.v.) para cada sentença.

Tabela 4-6 - Escala intervalar de referência para o Grupo 2

\begin{tabular}{cccccccc}
\hline \multicolumn{7}{c}{ Grupo 2 - Profissionais de outras áreas } \\
\hline Categorias & $\begin{array}{c}1 \\
\text { Discordo } \\
\text { totalmen- } \\
\text { te }\end{array}$ & 2 & 3 & 4 & 5 & 6 & 7 \\
$\begin{array}{c}\text { Escala Intervalar } \\
\text { de Referência }\end{array}$ & $-1,529$ & $-0,867$ & $-0,433$ & 0,000 & 0,491 & 1,299 & 2,581 \\
\hline
\end{tabular}


Tabela 4-7 - Média, desvio padrão e coeficiente de variação para cada sentença do Grupo 2

\begin{tabular}{clllll}
\hline $\mathbf{Q}$ & DISCURSO & IDEIA CENTRAL DA SENTENÇA & MÉDIA & $\begin{array}{c}\text { DESVIO } \\
\text { PADRÃO }\end{array}$ & C. V. \\
\hline Q1 & $\begin{array}{l}\text { Planejamento } \\
\text { Urbano }\end{array}$ & Integração do uso do solo em transporte & 2,149 & 0,676 & $31,4 \%$ \\
\hline Q2 & Engenharia & $\begin{array}{l}\text { Investimento equilibrado em infraestrutura } \\
\text { de transporte entre todos os modos }\end{array}$ & 1,539 & 1,155 & $75,0 \%$ \\
\hline Q3 & Economia & $\begin{array}{l}\text { Investimento em infraestrutura resulta em } \\
\text { aumento do número de empregos }\end{array}$ & 1,851 & 0,853 & $46,1 \%$ \\
\hline Q4 & Sustentabilidade & $\begin{array}{l}\text { A gestão da demanda reduz a demanda } \\
\text { por automóveis }\end{array}$ & 1,676 & 0,944 & $56,3 \%$ \\
\hline Q5 & Sustentabilidade & $\begin{array}{l}\text { O planejamento logístico traz benefícios } \\
\text { econômicos para as empresas }\end{array}$ & 1,820 & 0,855 & $47,0 \%$ \\
\hline Q6 & Sustentabilidade & $\begin{array}{l}\text { Análise de custo-benefício deve ser } \\
\text { considerada no custo total de viagens }\end{array}$ & 1,686 & 0,895 & $53,1 \%$ \\
\hline
\end{tabular}

Assim como ocorreu no Grupo 1, o Grupo 2 indicou maior grau de concordância para a sentença referente a "Planejamento Urbano" (média de 2,149). A afirmativa com a segunda maior concordância indica que "os investimentos em infraestruturas de transportes resultam em aumento do número de empregos". O tema "Sustentabilidade" apresentou diferença na avaliação entre os Grupos 1 e 2. Enquanto para o Grupo 1, as três sentenças possuem médias altas e próximas (Q4-1,800; Q51,898 e Q6-1,804), para o Grupo 2 as sentenças Q4 e Q6 receberam grau de concordância menor do que a sentença Q5. Para os dois grupos, a sentença Q2, tema “Engenharia”, possui a menor média e o maior coeficiente de variação.

Também foram realizados testes estatísticos (ANOVA e Teste de Tukey) para verificar se há diferença no grau de concordância atribuído às sentenças por diferentes agrupamentos. Desta forma, os respondentes foram divididos em grupos conforme sua atuação profissional, tempo de experiência na área, conhecimento da Política Nacional de Mobilidade Urbana, porte da cidade e região do Brasil em que reside. Cabe salientar que a amostra continuou sendo avaliada diferenciando profissionais que atuam na área de transportes (Grupo 1) e profissionais de outras áreas (Grupo 2). Para cada grupo, foram realizados Testes de Hipótese em que as médias foram comparadas considerando um nível de significância de 5\%.

A primeira análise foi realizada comparando diferentes atuações profissionais. Os respondentes foram divididos em quatro grupos diferentes: o primeiro grupo é 
constituído de profissionais que atuam como gestores (diretores, secretários, prefeitos etc.); o segundo por técnicos (engenheiros, arquitetos, técnicos); o terceiro grupo é formado somente por pesquisadores, principalmente professores e estudantes de pós-graduação; o último grupo é formado por profissionais que atuam ou já atuaram tanto como pesquisadores quanto como técnicos e/ou gestores. Realizadas as transformações de escala para cada grupo, as médias e o valor de significância da ANOVA foram calculados. Em complemento à análise, foi realizado o Teste de Tukey para verificar entre quais grupos há diferenças, conforme apresentado na Figura 4-4.

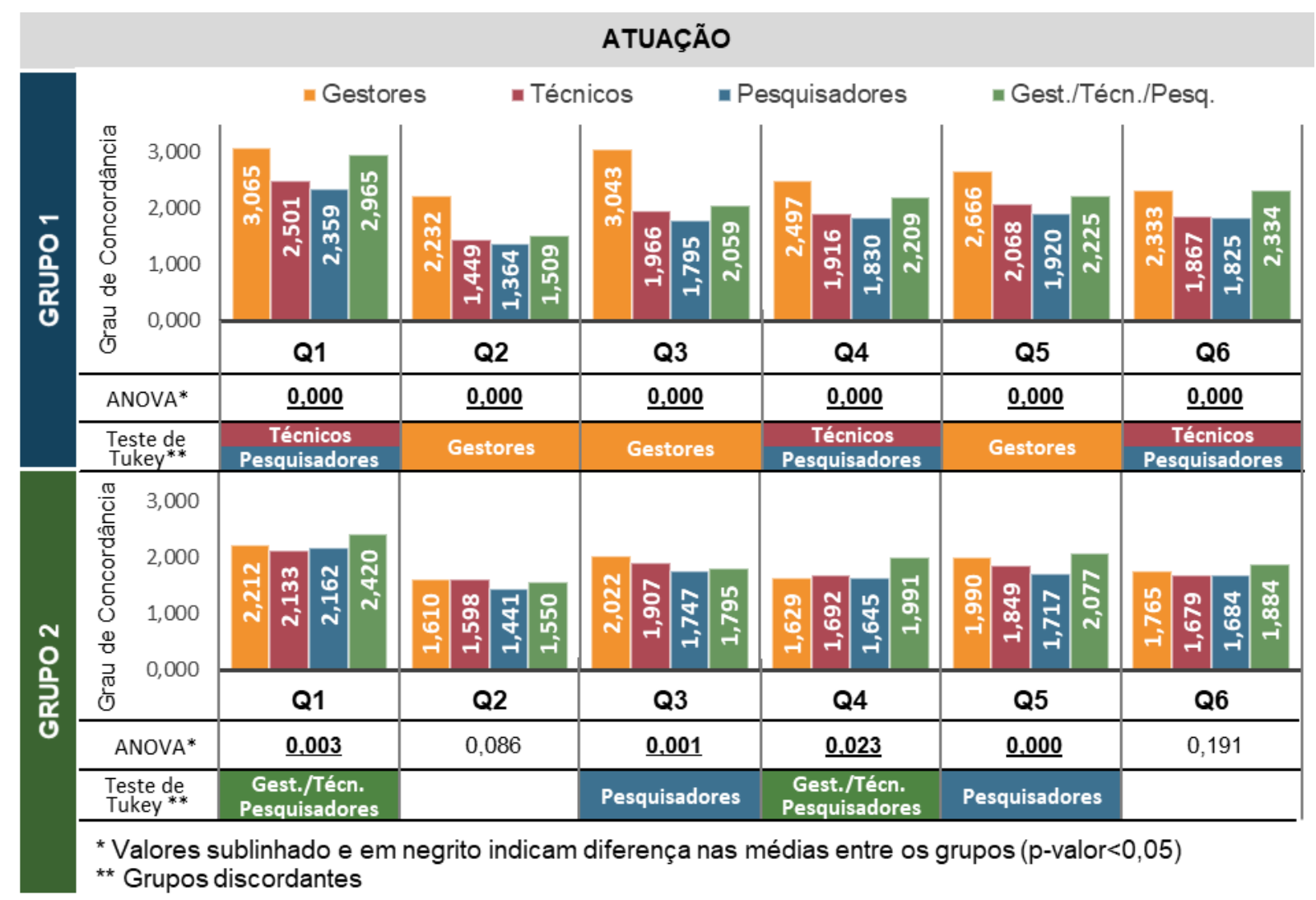

Figura 4-4 - Grau de concordância para as sentenças segundo a atuação profissional

Segundo os resultados do Grupo 1 (Figura 4-4), observa-se que, de maneira geral, "Gestores" indicaram maiores médias para as sentenças, com exceção das questões Q6 (discurso Sustentabilidade) em que o grupo formado por "Técnicos/Gestores/Pesquisadores" indicou maior grau de concordância. A partir da análise de variância, destaca-se que todas as sentenças indicam diferença na média dos respondentes ( $p$-valor $<0,05$ ). Os resultados do Teste de Tukey indicam que, para as sentenças Q1, Q4 e Q6 as diferenças se concentram entre os grupos Técnicos e 
Pesquisadores ( $p$-valor $<0,05$ ), que tiveram menores graus de concordância em relação aos outros dois grupos. Para as sentenças Q2, Q3 e Q5, a diferença entre as médias se deve ao grupo "Gestores", principalmente pelo fato de seu grau de concordância ser significativamente superior ao dos demais grupos.

Em relação ao Grupo 2, os profissionais que já atuaram como "gestores/técnicos/pesquisadores" foram os que representaram as maiores médias entre as questões. Destaca-se as sentenças Q1 (Planejamento Urbano) e Q4 (Sustentabilidade) como as que indicaram diferença estatística na opinião deste grupo em relação aos demais. Os grupos formados por "pesquisadores" e "técnicos" apresentaram concordância mais conservadora em relação às questões, como pode ser observado pelos menores valores de médias das sentenças. A partir da ANOVA e Teste de Tukey, percebe-se diferença na avaliação dos "pesquisadores" para as sentenças Q3 e Q5.

Seguindo o mesmo processo de avaliação (cálculo da média das respostas, teste ANOVA e de Tukey), a Figura 4-5 apresenta as análises realizadas em função do tempo de experiência na área para o Grupo 1 e Grupo 2. Nesta avaliação os profissionais foram divididos conforme as seguintes classes: até 5 anos, de 6 a 10 anos, de 11 a 15 anos e maior que 15 anos de experiência. 


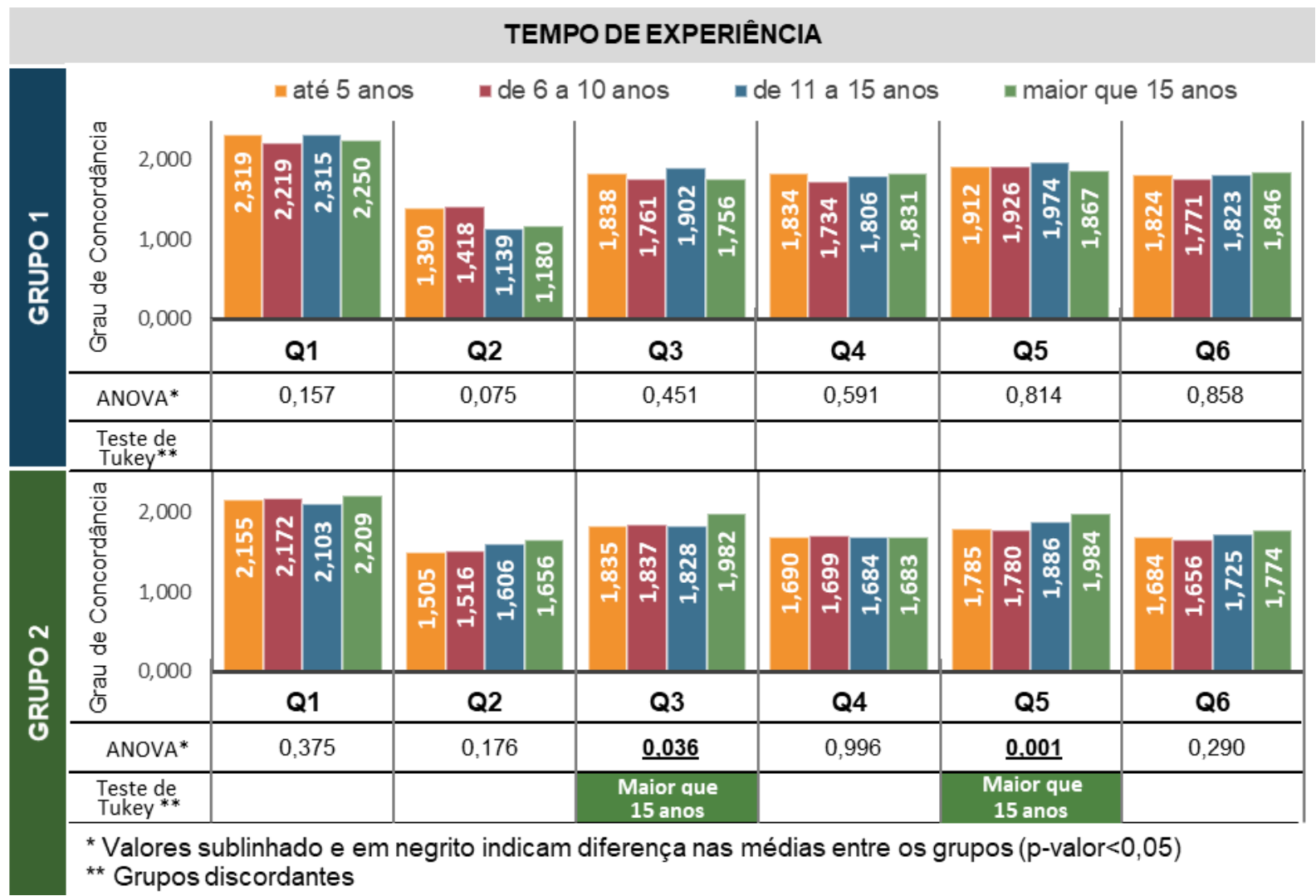

Figura 4-5 - Grau de concordância para as sentenças segundo o tempo de experiência

$\mathrm{Na}$ análise do Grupo 1 em relação ao tempo de experiência (Figura 4-5), as maiores médias para as sentenças não se concentraram em um único grupo. O resultado da ANOVA mostra que não houve variação significativa entre as médias em nenhuma das sentenças avaliadas ( $p$-valor $>0,05$ ) para o Grupo 1, o que sugere que a opinião do respondente independe do tempo de experiência na área de transportes. No entanto, para o Grupo 2, é possível perceber diferença nas avaliações dos profissionais que possuem experiência "maior que 15 anos" nas sentenças Q3 e Q5.

As avaliações em relação ao nível de conhecimento indicado para a Política Nacional de Mobilidade Urbana estão indicadas na Figura 4-6. As classes consideradas nessa divisão foram: "Sim, conhece detalhadamente o texto", "Sim, conhece, superficialmente o texto", "Já ouviu falar, mas ainda não leu o texto" e "Não conhece". 


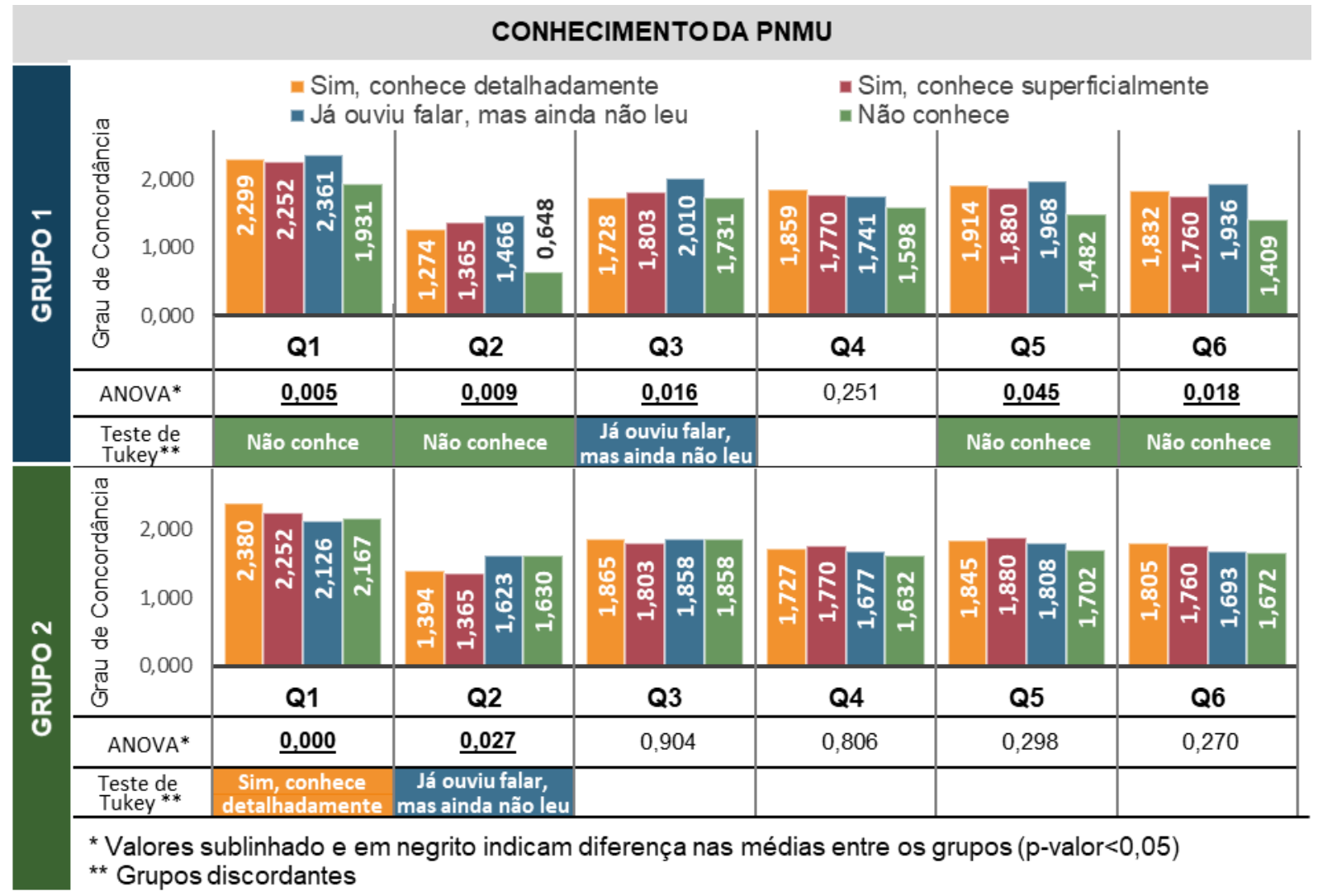

Figura 4-6 - Grau de concordância para as sentenças, segundo o conhecimento da Política Nacional de Mobilidade Urbana

Para análise realizada em função do nível de conhecimento indicado para a Política Nacional de Mobilidade Urbana no Grupo 1, os especialistas da área de transportes que "Já ouviram falar, mas ainda não leram o texto" apresentaram os maiores valores de média para a maioria das questões. Somente para a sentença Q4 (discurso "Sustentabilidade"), o grupo "Sim, conhece detalhadamente o texto" indicou maior grau de concordância. Segundo a análise de variância e Teste de Tukey, as sentenças Q1, Q2, Q5 e Q6 indicam diferença na opinião dos respondentes do grupo "Não conhece" e Q3 para o grupo “Já ouviu falar, mas ainda não leu o texto". Cabe destacar que, para a sentença Q2, os profissionais que "Não conhecem" o texto da PNMU indicaram grau de concordância significativamente menor que os outros grupos. $O$ Grupo 2 apresentou médias uniformes para a maioria das sentenças, destacando-se os valores dos grupos "Sim, conhece detalhadamente" o texto da PNMU para a sentença Q1 e “Já ouviu falar, mas ainda não leu o texto” para a sentença Q2.

A Figura 4-7 apresenta os resultados para a divisão em função do tamanho da cidade. 


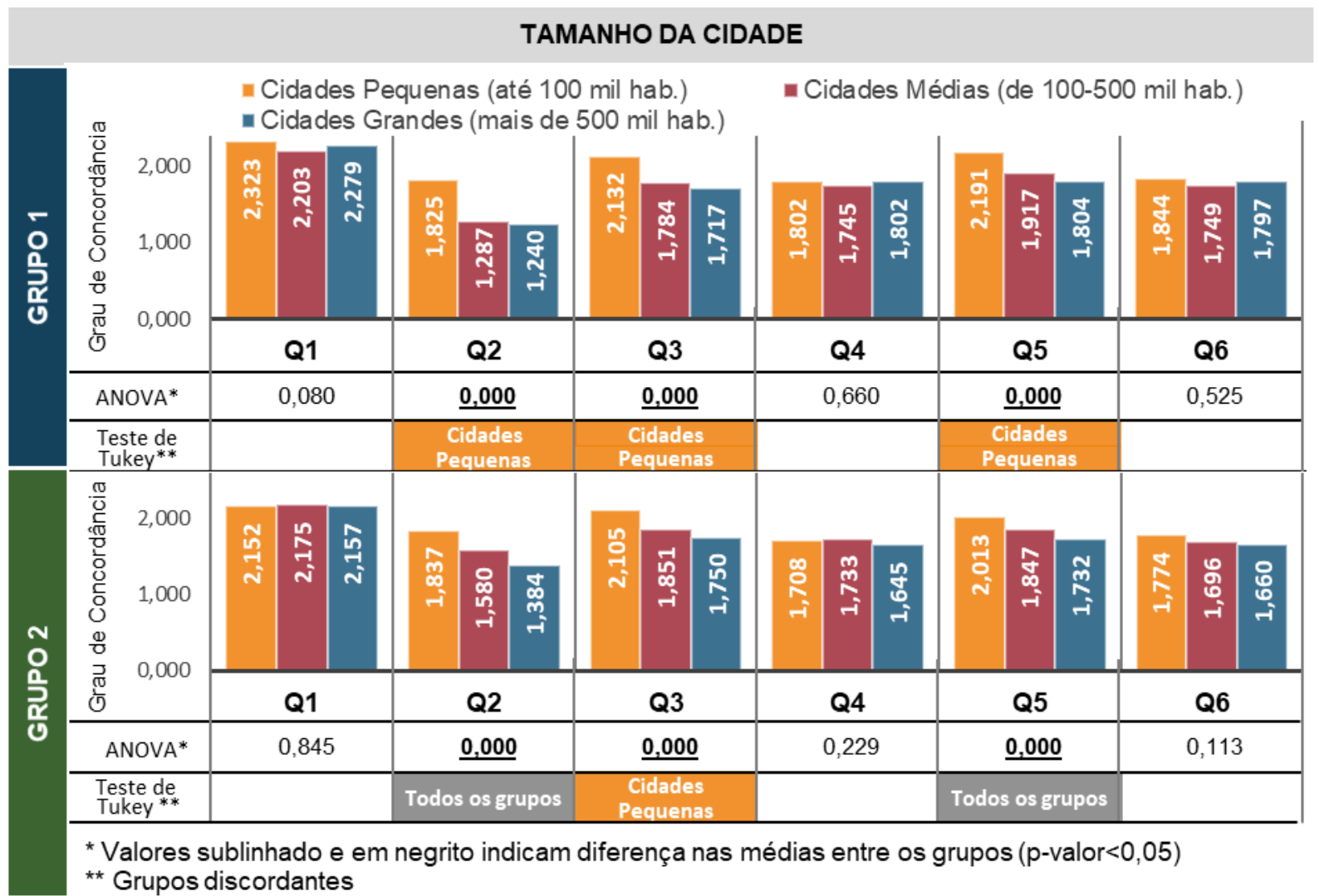

Figura 4-7 - Grau de concordância para as sentenças, segundo o tamanho da cidade

Em geral, para a divisão em relação ao tamanho da cidade (Figura 4-7), os Grupos 1 e 2 apresentaram avaliação semelhante para as sentenças. Para o Grupo 1 observase que o grupo de profissionais de "Cidades Pequenas" apresenta médias maiores para as sentenças, em comparação aos outros grupos. Segundo a análise de variância, as sentenças Q2, Q3 e Q5 sugerem diferença na opinião dos respondentes ( $p$-valor $<0,05)$. No Grupo 2, as mesmas sentenças apresentaram diferença na opinião dos respondentes, com destaque para as sentenças Q2 e Q5, que tiveram diferença entre todos os grupos avaliados.

A última análise foi realizada em relação à região do Brasil a que pertencia o respondente (Figura 4-8). 


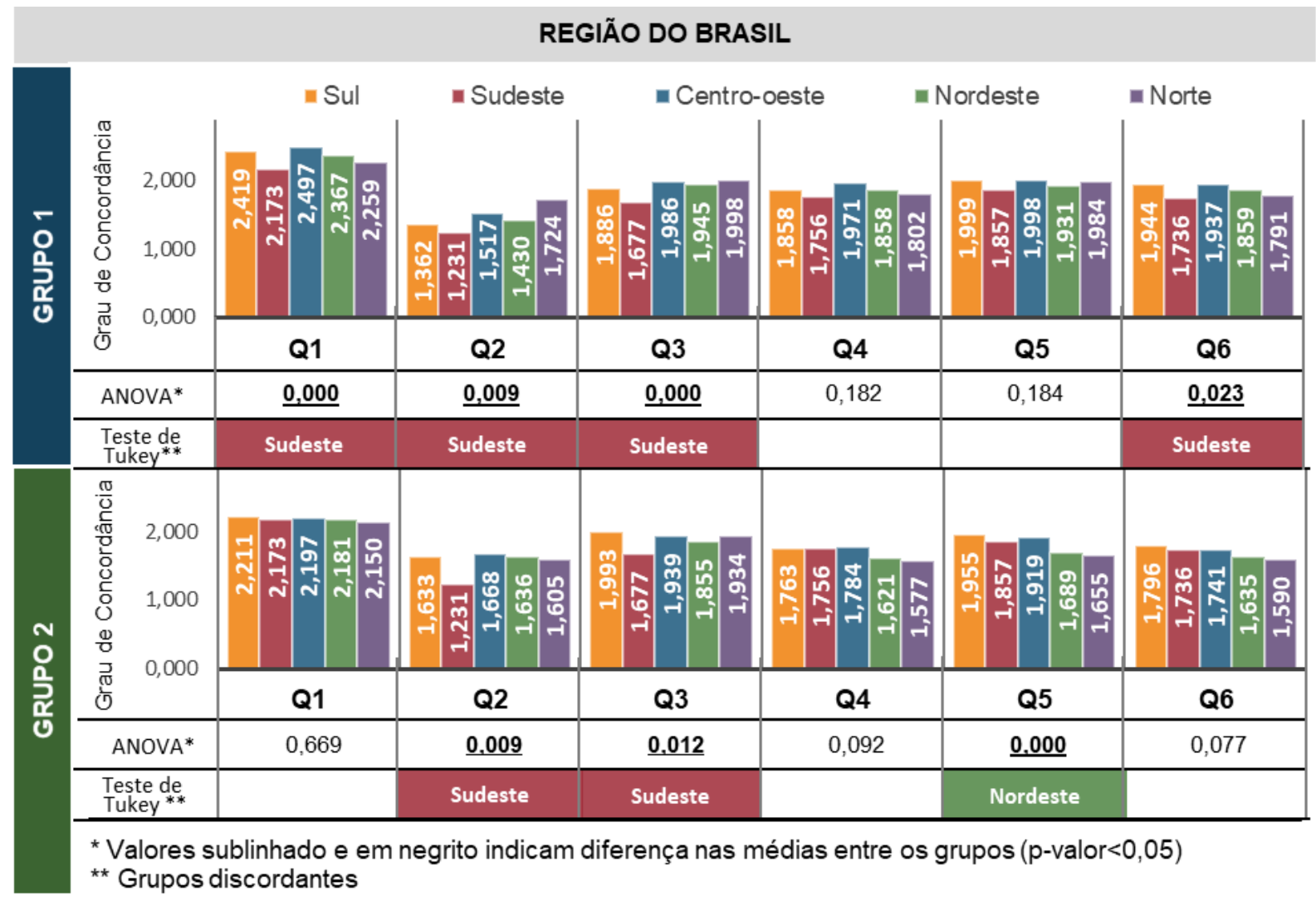

Figura 4-8 - Grau de concordância para as sentenças, segundo a região do Brasil

As médias para a divisão em relação à região se mostraram uniformes para todas as sentenças, não tendo a predominância de maiores valores para um determinado grupo. Segundo a análise de variância e o Teste de Tukey, os especialistas de transportes (Grupo 1) da região Sudeste apresentaram diferença nas médias para a maior parte das sentenças (Q1, Q2, Q3 e Q6) com os profissionais de outras regiões. Para os profissionais de outras áreas (Grupo 2 ) as diferenças foram para as regiões "sudeste" (sentenças Q2 e Q3) e "nordeste" (sentença Q5).

\subsection{Avaliação das sentenças sobre Modos Não Motorizados}

As sentenças sobre os modos não motorizados, foram elaboradas a partir das informações coletadas em grupos focais. Na sequência serão apresentadas as avaliações dos respondentes para as nove questões estudadas.

Na Figura 4-9 é apresentada a distribuição das respostas para a questões Q7, a partir da visão dos profissionais da área de transportes (Grupo 1) e profissionais de outras áreas (Grupo 2). 
Q7. Você acredita que a redução do limite de velocidade para os veículos motorizados (automóveis, motocicletas, caminhões e ônibus) em algumas vias possa estimular a locomoção de pedestres e ciclistas?

\begin{tabular}{|c|c|c|c|c|c|c|c|}
\hline & & & $\begin{array}{l}\text { initivamente } \\
\text { o estimula }\end{array}$ & $\begin{array}{l}\text { Quase não } \\
\text { estimula }\end{array}$ & $\begin{array}{l}\text { Pode ou não } \\
\text { estimular }\end{array}$ & $\begin{array}{c}\text { Estimula } \\
\text { parcialmente }\end{array}$ & $\begin{array}{l}\text { Estimula } \\
\text { totalmente }\end{array}$ \\
\hline \multirow{2}{*}{ 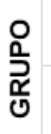 } & 1 & $5,7 \%$ & $10,0 \%$ & $26,4 \%$ & \multicolumn{2}{|c|}{$35,1 \%$} & $22,8 \%$ \\
\hline & 2 & $8,0 \%$ & $11,7 \%$ & $26,7 \%$ & \multicolumn{2}{|c|}{$33,0 \%$} & $20,7 \%$ \\
\hline
\end{tabular}

Figura 4-9 - Análise das respostas da Questão 7

A sentença Q7 trata sobre a redução do limite de velocidade em algumas vias como maneira de incentivar os modos não motorizados (a pé e bicicleta). A maioria dos profissionais da área de transportes (Grupo 1) percebe que esta ação "estimula parcialmente" $(35,1 \%)$ e "estimula totalmente" (22,8\%). Entre os profissionais de outras áreas (Grupo 2) também foi percebido como uma ação positiva a redução do limite de velocidade, tendo em vista que 53,7\% indicou que a medida em algum nível estimula a locomoção de pedestres e ciclistas. Para os dois grupos é possível perceber uma parcela resistente a um maior controle dos modos motorizados nas respostas das porcentagens das alternativas "definitivamente não estimula" e "quase não estimula".

Uma segunda etapa da análise dos dados foi verificar se há diferença nas respostas atribuídas às sentenças por diferentes grupos. Desta forma, seguindo a divisão que foi realizada no item 4.2, os respondentes foram divididos em grupos conforme sua atuação profissional, tempo de experiência na área, conhecimento da Política Nacional de Mobilidade Urbana, porte da cidade e região do Brasil em que reside. Para cada grupo, foi calculado o grau de concordância em relação às sentenças. Assim, seguindo a análise padrão para escala de Likert, para cada alternativa foi atribuído um valor (de 1 a 5) e calculada a média das respostas para cada sentença. Em complemento à análise, foi realizado o teste não paramétrico de Kruskal-Wallis para verificar se existem diferenças entre os grupos em estudo. Ao considerar um nível de significância de 5\%, a hipótese de os grupos possuírem a mesma opinião é rejeitada para os resultados de $p$-valor menores que 0,05. De posse deste resultado, para verificar entre quais grupos há diferenças, foram realizados testes entre pares de grupos. 
Assim, para as alternativas da sentença Q7, foram atribuídos os seguintes valores:

- (1) Definitivamente não estimula;

- (2) Quase não estimula;

- (3) Pode ou não estimular;

- (4) Estimula parcialmente;

- (5) Estimula totalmente.

Na Figura 4-10 são apresentadas as médias das respostas para cada grupo e a análise do teste de Kruskal-Wallis, onde foi indicada a diferença de opinião entre grupos.

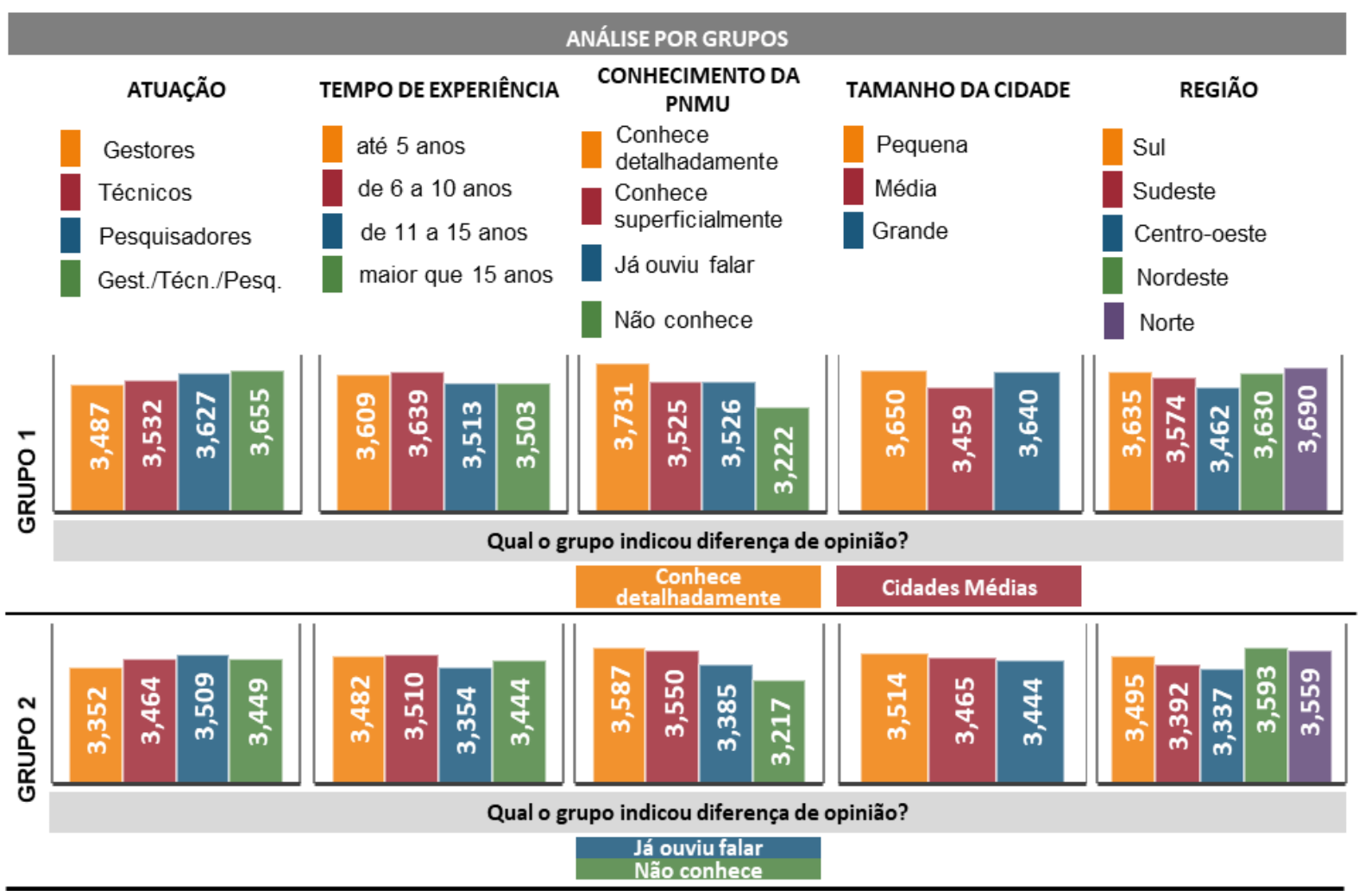

Figura 4-10 - Avaliação das respostas da sentença Q7 entre diferentes grupos

A partir da avaliação das respostas da sentença Q7 entre diferentes grupos é possível perceber que as médias dos profissionais da área de transportes e profissionais de outras áreas, de maneira geral, foram similares. A divisão em relação ao conhecimento da PNMU foi a que apresentou maiores diferenças entre as médias. Para os dois grupos, a maior média esteve representada pelo grupo formado pelos que conhecem detalhadamente o texto, o que indica um maior alinhamento com os 
conceitos de mobilidade urbana. Por outro lado, os profissionais que não conhecem a PNMU indicaram o menor grau de concordância para a questão. Entre os profissionais do Grupo 1, a divisão em relação ao tamanho da cidade também indicou divergência na opinião dos respondentes de "cidades médias".

A Questão 8 avalia a opinião dos profissionais em relação à importância de investimentos em sinalização, manutenção e continuidade da rede viária para o compartilhamento das vias entre diferentes modos de transporte. Os resultados da avaliação para esta questão e a análise entre diferentes grupos são apresentados na Figura 4-11.

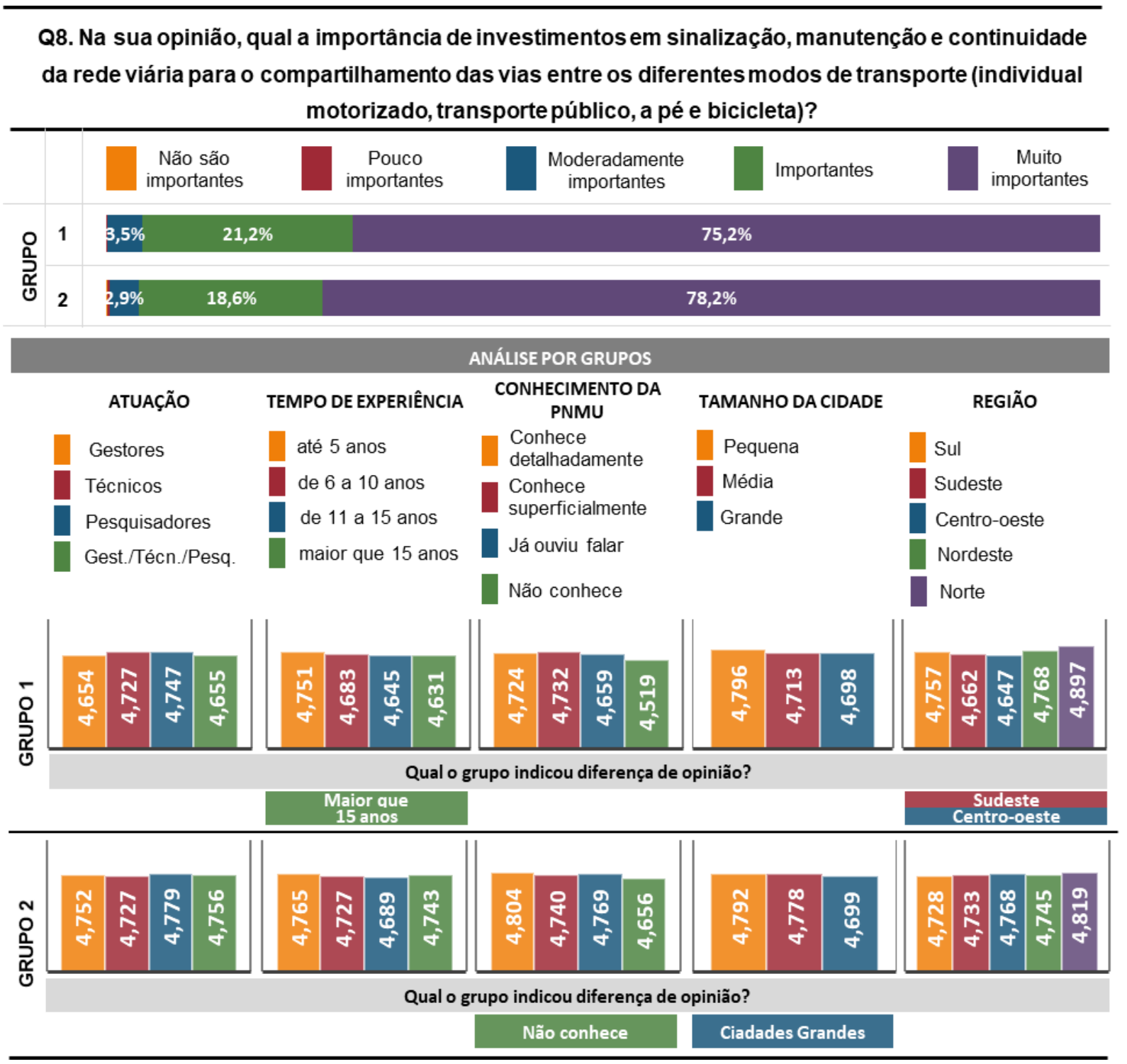

Figura 4-11 - Análise da Questão 8 e avaliação das respostas entre diferentes grupos 
A declaração com o maior nível de concordância (Q8) indicou que, para os respondentes, o compartilhamento de vias entre os modos de transporte motorizados e não motorizados é viável, desde que haja investimentos em sinalização, manutenção e continuidade da rede viária. É interessante avaliar que, para o Grupo 1, os profissionais com mais de 15 anos de experiência indicam diferença de opinião com as outras categorias. Esta avaliação pode indicar que, para estes profissionais, 0 novo conceito de mobilidade, por meio do qual se tem uma diminuição da segregação da rua por cada modo de transporte e o desenvolvimento de espaços urbanos voltados aos cidadãos, não é totalmente aceito. Da mesma forma que, para o grupo 2, os profissionais de cidades grandes e que não conhecem a PNMU apresentam diferença na avaliação em relação aos demais grupos.

Na Figura 4-12 é apresentada a análise das respostas para a Questão 9.

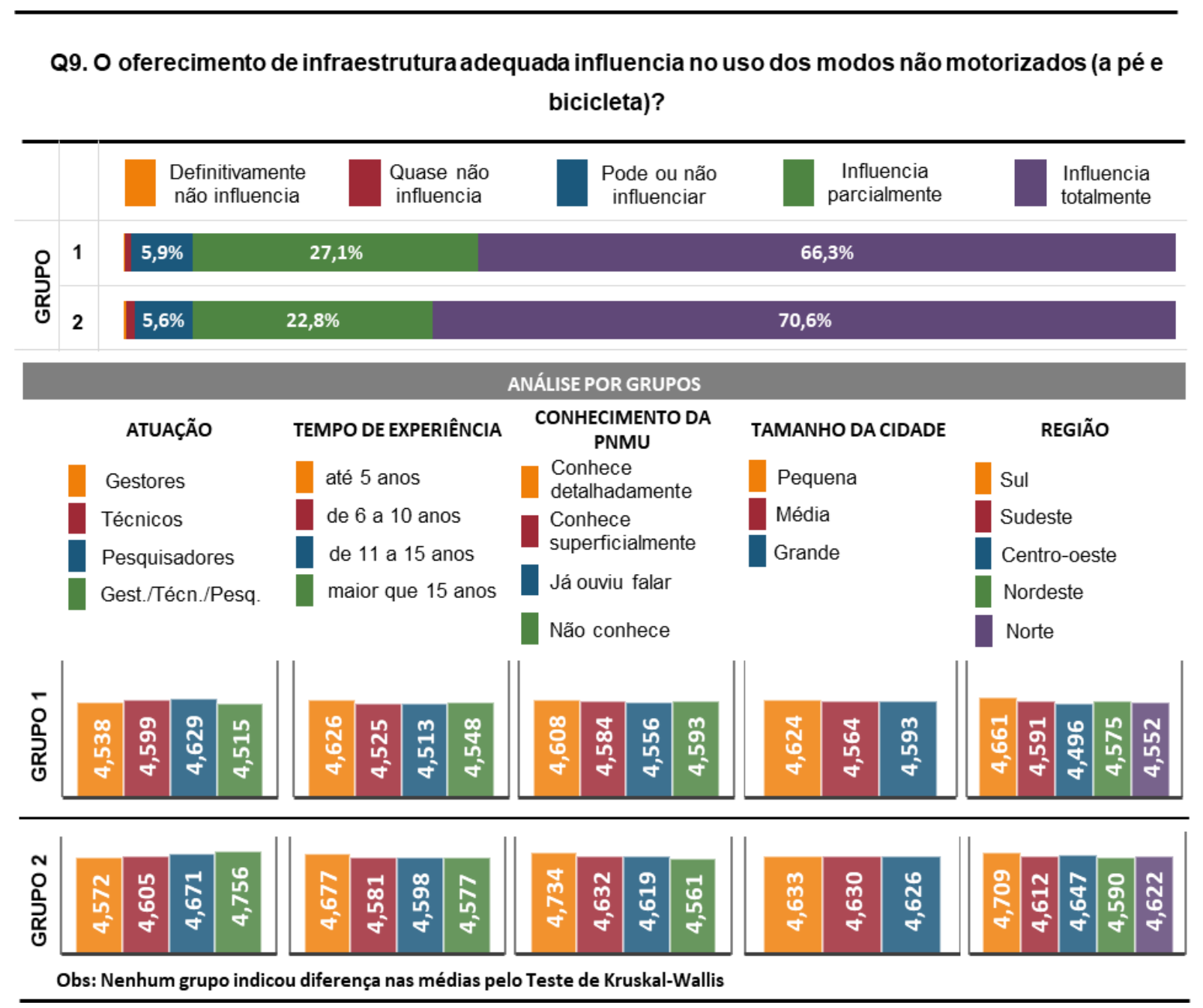

Figura 4-12 - Análise da Questão 9 e avaliação das respostas entre diferentes grupos 
A sentença Q9, que aborda o oferecimento de infraestrutura adequada como forma de incentivo ao uso dos modos não motorizados (a pé e bicicleta), obteve o maior número de respostas para a alternativa "influencia totalmente" nos dois grupos. A alternativa "influencia parcialmente" também recebeu uma parcela significativa de respostas. Assim, o grau de concordância com a questão para todos os grupos avaliados foi superior a 4,5. Não foram identificadas diferenças na opinião dos respondentes, indicando um consenso em relação à forma de atrair usuários para os modos não motorizados por meio da disponibilidade de infraestrutura.

Na próxima questão foi avaliada a percepção da influência das características do ambiente no uso dos modos não motorizados (Q10), conforme Figura 4-13.

Q10. Características do ambiente, como topografia irregular e clima quente, inviabilizam o uso dos modos não motorizados, independentemente da infraestrutura viária disponível?

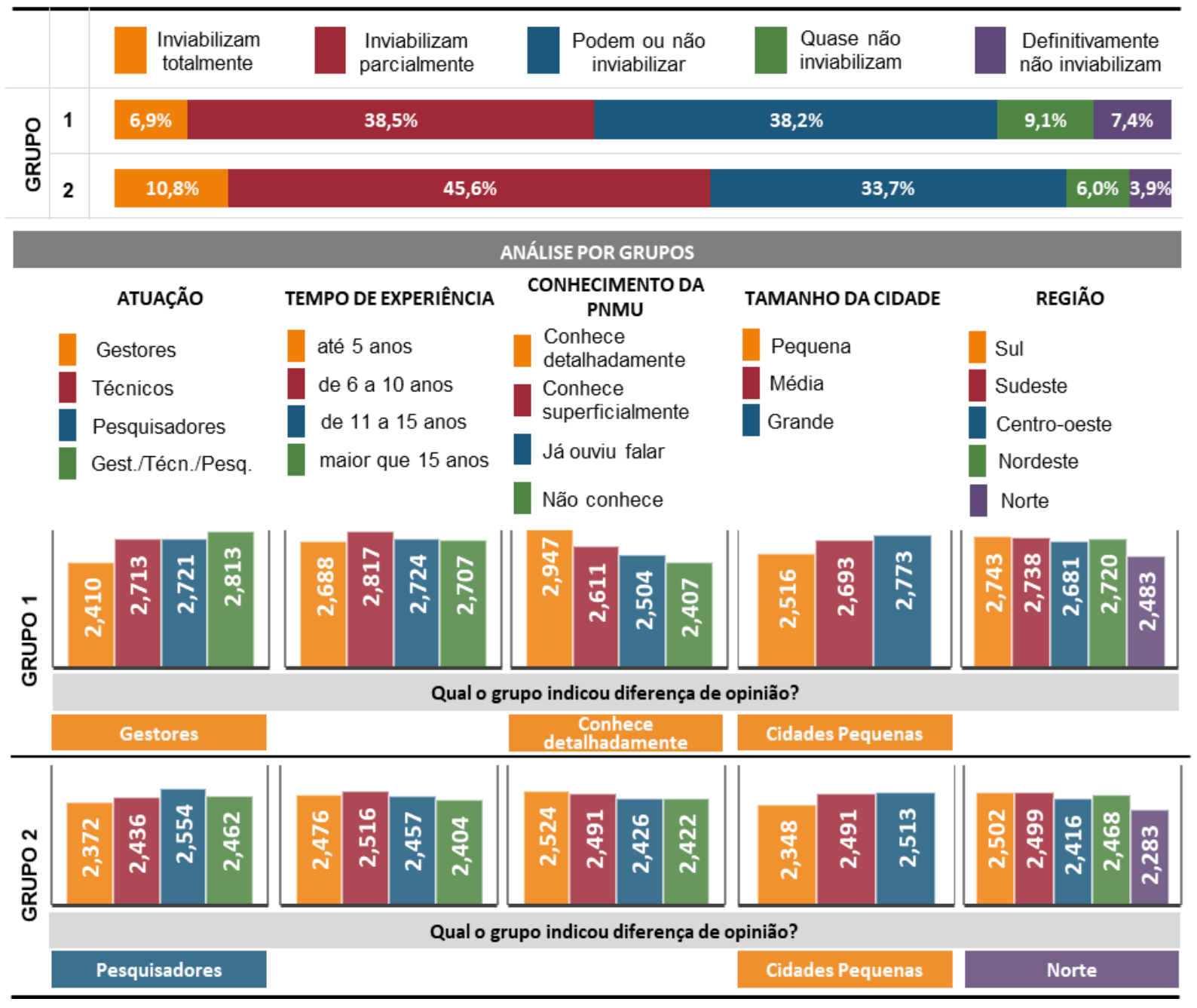

Figura 4-13 - Análise da Questão 10 e avaliação das respostas entre diferentes grupos 
Como pode ser observado na Figura 4-13, os respondentes indicam que características do ambiente "inviabilizam parcialmente" (38,5\% para o Grupo 1 e 45,6\% para o Grupo 2) o uso dos modos não motorizados. A Q10 foi uma das sentenças que obteve a maior divergência entre grupos. Segundo os resultados do Teste de Kruskal-Wallis, as diferenças entre grupos estatisticamente significativas ( $p$ valor $<0,05$ ) se concentram na divisão por atuação, conhecimento da PNMU, tamanho da cidade e região. É observada, na divisão por atuação, diferença na opinião dos "Gestores" do Grupo 1 e dos "Pesquisadores" do Grupo 2. Os profissionais da área de transportes (Grupo 1), que conhecem detalhadamente o texto da PNMU, apresentaram a maior média da avaliação, indicando uma perspectiva mais clara em relação ao tema. Também cabe destacar que, na avaliação dos profissionais de "cidades pequenas", foram verificadas médias significativamente mais baixas em relação aos outros grupos. Para o Grupo 2, foram identificadas diferenças entre as respostas da região "norte".

Na Figura 4-14 é apresentada a análise das respostas para a percepção sobre o custo da infraestrutura para modos não motorizados em comparação à infraestrutura para outros modos (Q11).

Q11. As infraestruturas adequadas para os modos não motorizados (a pé e bicicleta), quando comparadas às infraestruturas para outros modos de transporte urbano, possuem:

\begin{tabular}{|c|c|c|c|c|c|}
\hline & & $\begin{array}{l}\text { Custo muito } \\
\text { maior }\end{array}$ & Custo maior & Custo menor & $\begin{array}{l}\text { Custo muito } \\
\text { menor }\end{array}$ \\
\hline \multirow{2}{*}{ 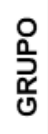 } & 1 & $2,8 \% \quad 7,3 \%$ & $56,3 \%$ & \multicolumn{2}{|c|}{$32,3 \%$} \\
\hline & 2 & $4,7 \% \quad 9,5 \%$ & $\mathbf{5 5 , 3 \%}$ & \multicolumn{2}{|c|}{$28,3 \%$} \\
\hline
\end{tabular}

Figura 4-14 - Análise das respostas da Questão 11

Analisando as respostas para a sentença Q11 percebe-se que, em comparação às infraestruturas para outros modos de transporte, para os respondentes, as infraestruturas adequadas para os modos não motorizados possuem "custo menor" ou "custo muito menor". Seguindo o mesmo processo de avaliação, os respondentes foram divididos em grupos para avaliar diferenças de opiniões, conforme apresentado na Figura 4-15. 


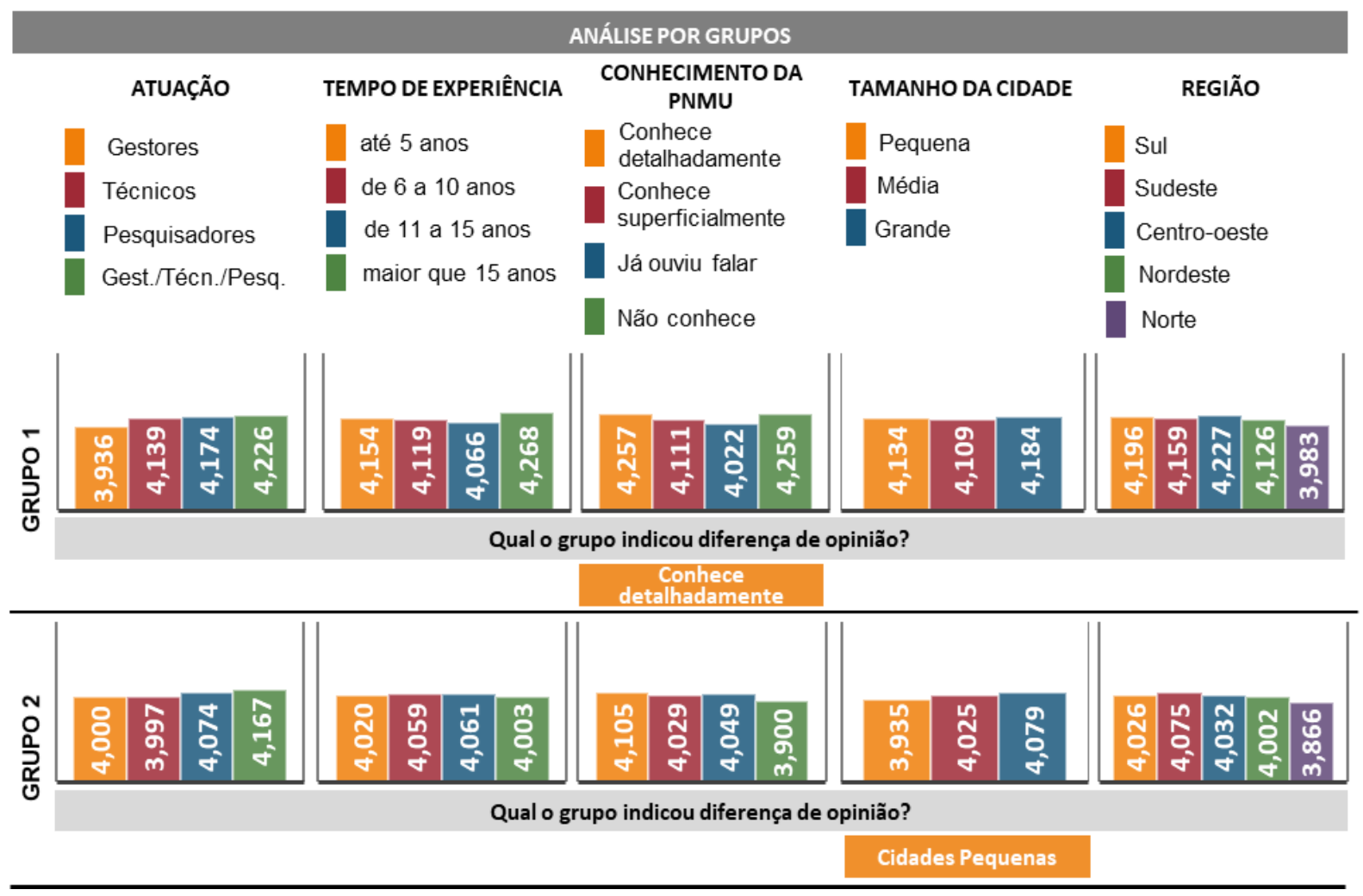

Figura 4-15 - Avaliação das respostas da sentença Q11 entre diferentes grupos

Ao avaliar as respostas por diferentes grupos, é identificado um padrão uniforme nos valores de média. As diferenças apontadas como significativas pelo teste não paramétrico foram para os profissionais que "conhecem detalhadamente a PNMU" no Grupo 1 e para profissionais de "cidades pequenas" no Grupo 2. Uma avaliação importante é que para gestores e técnicos, que são representados principalmente por profissionais tomadores de decisão em relação ao investimento público, a concordância com a questão é menor do que para os outros dois grupos. Isso pode indicar que, apesar dos profissionais reconhecerem o baixo custo necessário para as infraestruturas dos modos não motorizados, o investimento não é realizado de maneira efetiva pelo poder público.

A sentença Q12 aborda o custo para utilização dos modos a pé e bicicleta. Essa questão busca avaliar a percepção dos respondentes em relação à equidade do acesso aos modos não motorizados. A Figura 4-16 apresenta a distribuição das respostas da Questão 12 e avaliação entre diferentes grupos. 


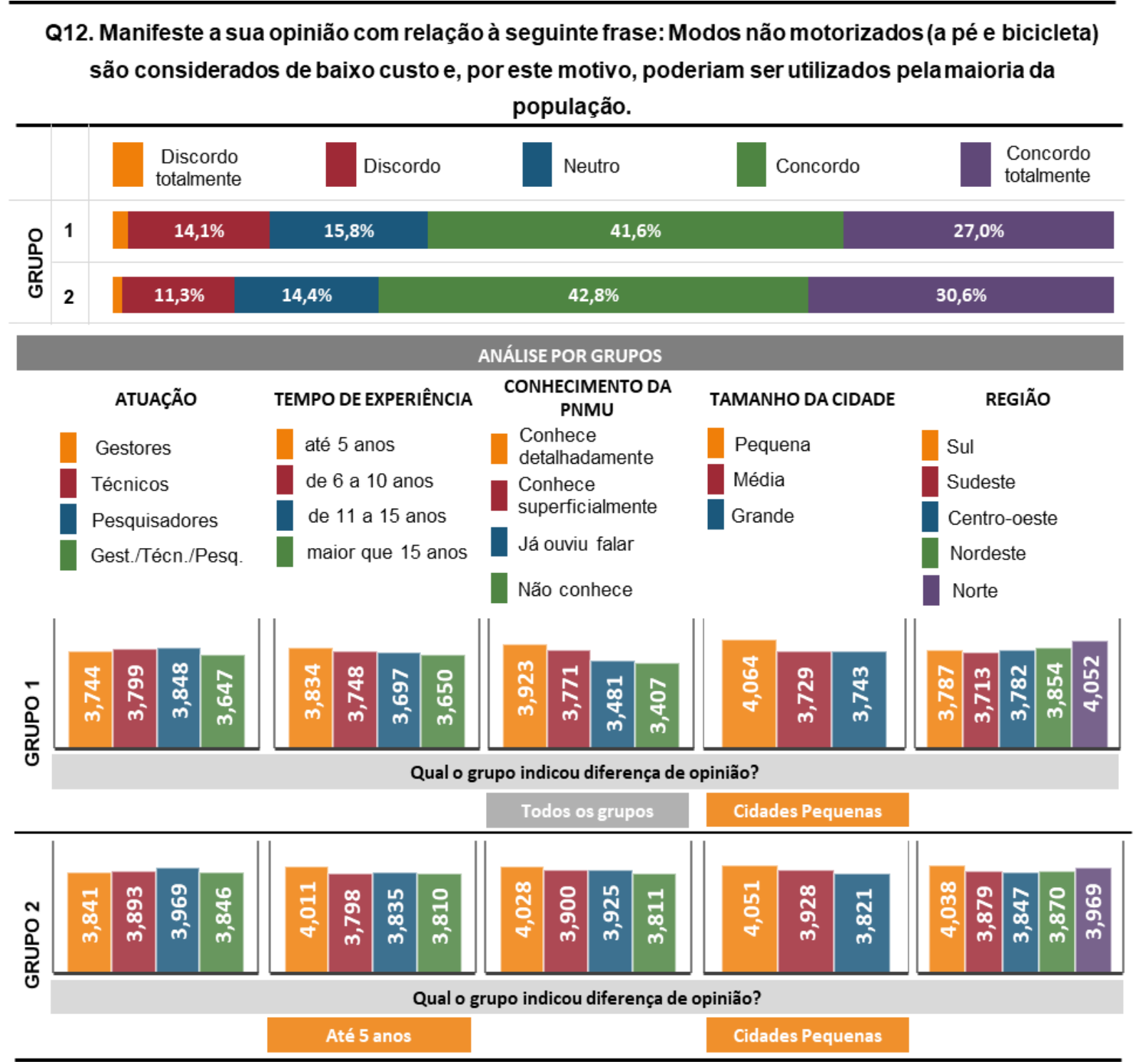

Figura 4-16 - Análise da Questão 12 e avaliação das respostas entre diferentes grupos

Em relação a Q12, observa-se uma forte tendência de concordância com a afirmativa proposta. Nesse caso, mais de $60 \%$ dos respondentes "concorda" ou "concorda totalmente" com a questão. Quando avaliada a perspectiva de diferentes grupos, respondentes de cidades pequenas possuem uma concordância maior para a sentença, o que pode estar relacionado à facilidade com que as pessoas desses locais têm para acessar e utilizar os modos não motorizados. Para o grupo formado por profissionais da área de transportes houve discordância entre todas as classes relacionadas ao conhecimento da PNMU. É possível perceber que quanto maior o conhecimento da PNMU, maior o grau de concordância com a sentença.

Na Figura 4-17 são apresentados os resultados da Q13. 


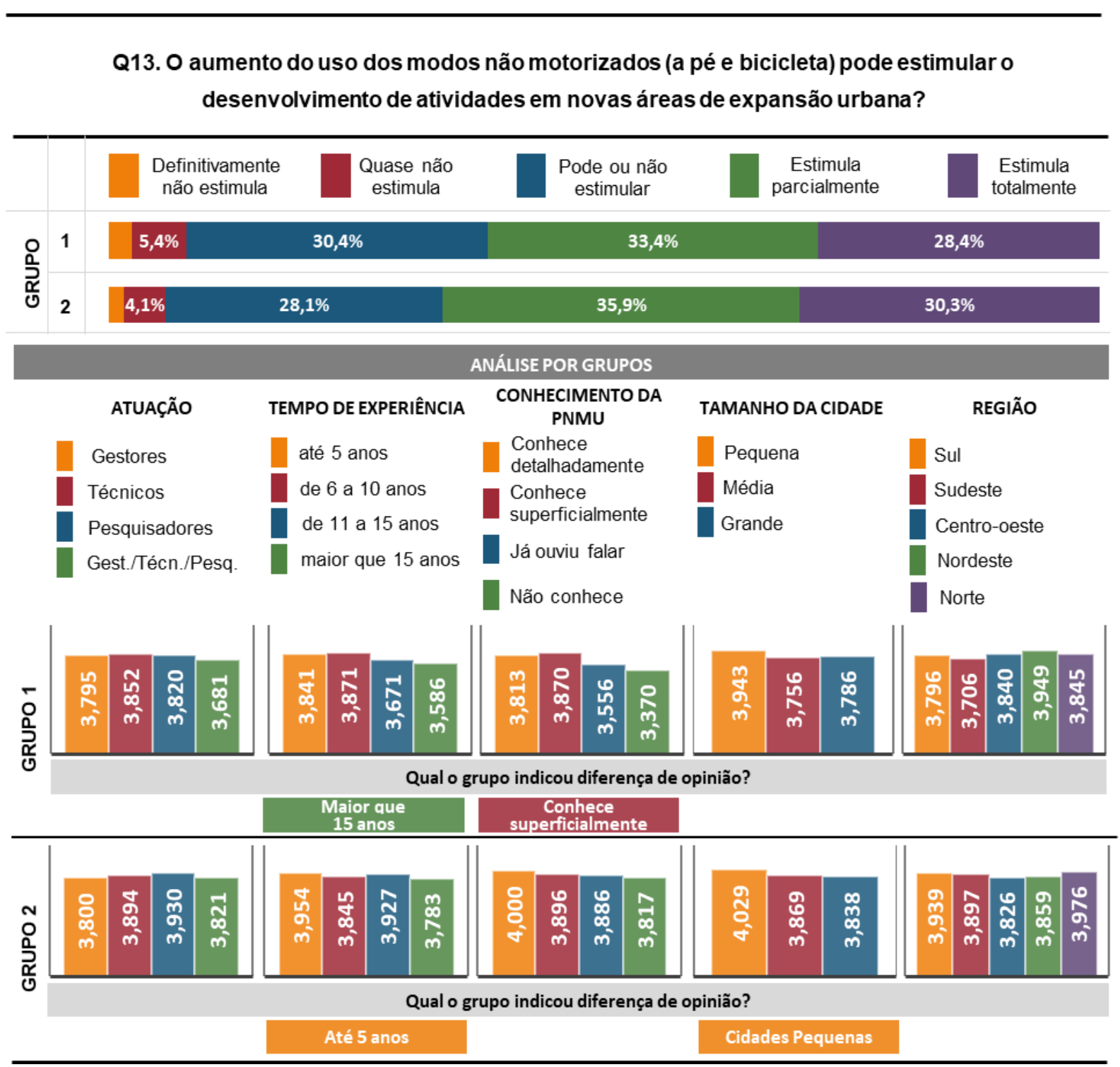

Figura 4-17 - Análise da Questão 13 e avaliação das respostas entre diferentes grupos

A questão sobre a relação entre o aumento do uso dos modos não motorizados e o desenvolvimento de atividades em novas áreas de expansão (Q13) obteve maior número de respostas para a alternativa "estimula parcialmente". O tempo de experiência indicou ser um fator significativo na avaliação desta sentença. Para o Grupo 1, os profissionais com mais de 15 anos de experiência indicaram diferença com as demais categorias. No Grupo 2, a diferença indicou ser significativa em relação a opinião dos profissionais com até 5 anos de experiência. Também apresentaram diferença os profissionais que "conhecem superficialmente" o texto da PNMU do Grupo 1 e profissionais de "cidades pequenas" do Grupo 2. 
A Questão 14 aborda a sensação de segurança em área com maior movimentação de pedestres e ciclistas. Os resultados estão apresentados na Figura 4-18.

Q14. Qual a sua sensação de segurança, em relação a roubose violência, em áreas com tráfego de pedestres e ciclistas em todos os horários do dia?

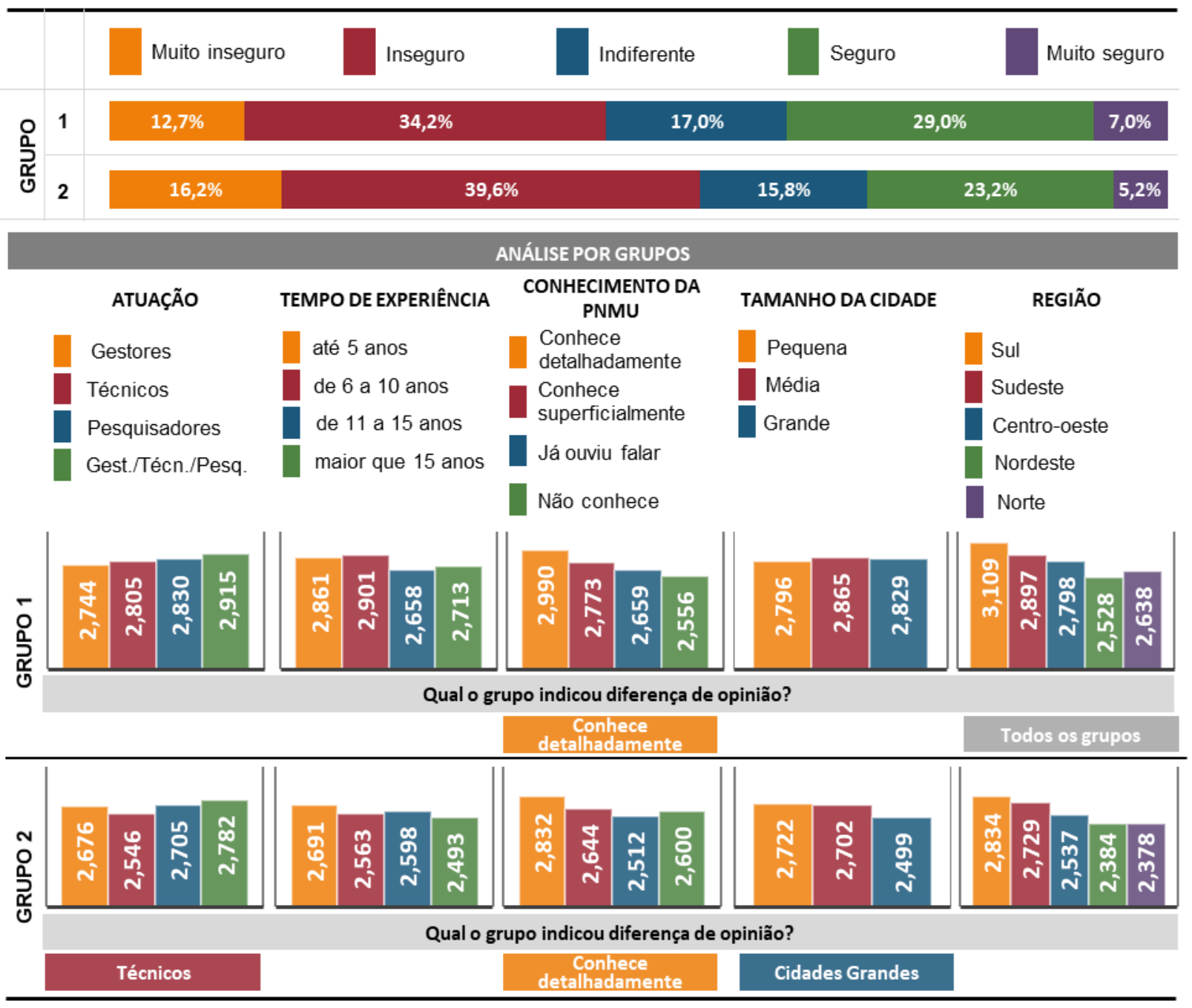

Figura 4-18 - Análise da Questão 14 e avaliação das respostas entre diferentes grupos

Sobre a sensação de segurança (Q14), em relação a roubos e violência em áreas com movimentação de pedestres e ciclistas, a opinião dos respondentes apresenta grande variação no ponto de vista para a questão. Enquanto parcela significativa dos respondentes se sentem "inseguros" nestas áreas, mais de $20 \%$ se sentem "seguros". O conhecimento da PNMU é um ponto importante na avaliação, já que os respondentes que "conhecem detalhadamente" o texto apresentaram maior valor de média para a sentença. Os profissionais de "cidades grandes" do Grupo 2 também 
apresentaram diferença significativa na avaliação, indicando menor grau de concordância com a sentença. Apesar destas divergências de opinião sobre o tema indicarem que os profissionais não percebem a importância de um ambiente mais ativo como forma de promover a segurança entre pedestres e ciclistas, a avaliação dos respondentes também pode ter sido influenciada pelos altos índices de violência das cidades brasileiras.

A última questão (Q15), apresentada na Figura 4-19, analisa um ponto importante no novo paradigma do planejamento de transportes, que é a destinação de espaços normalmente utilizados por veículos motorizados para pedestres e ciclistas.

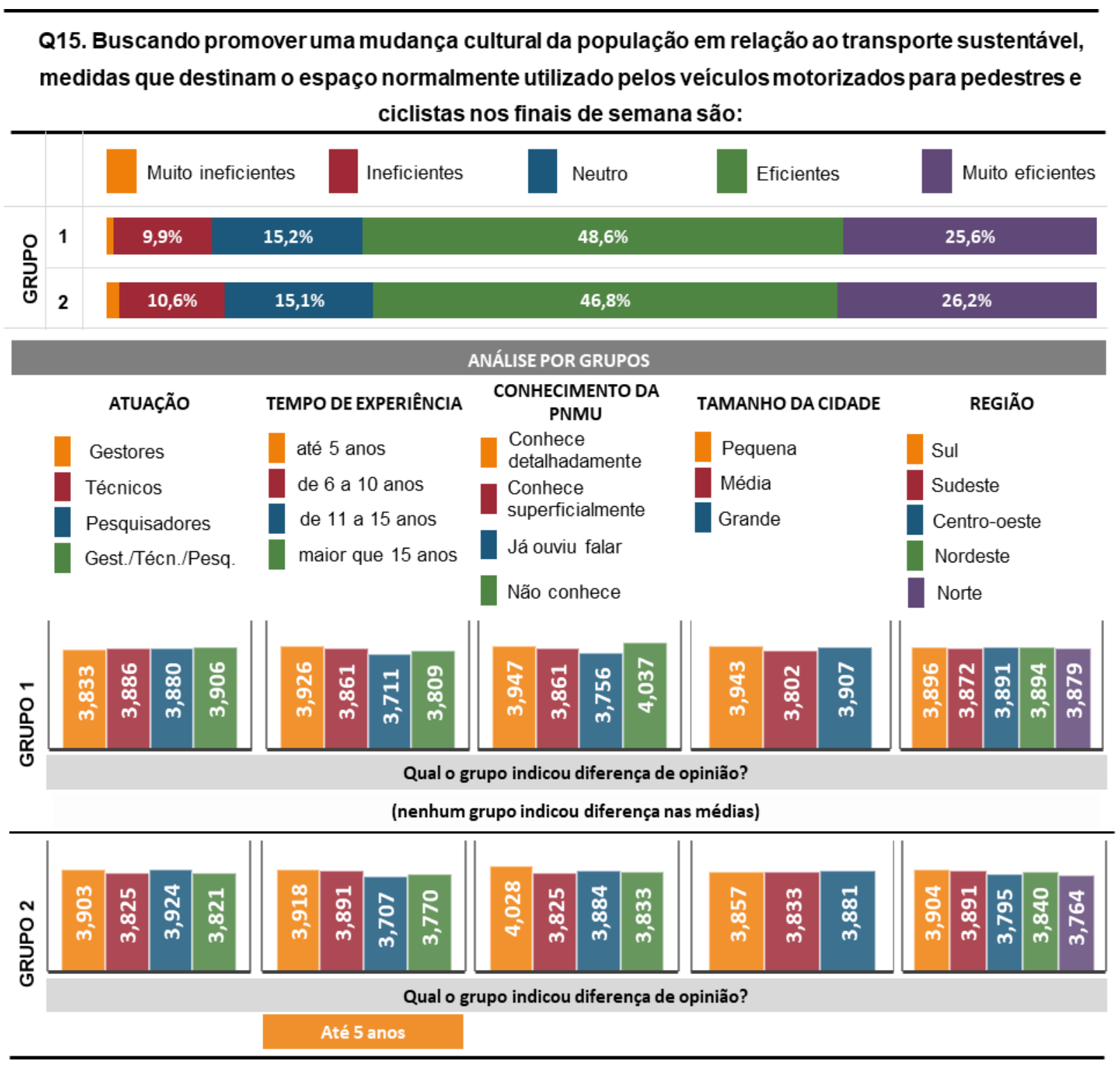

Figura 4-19 - Análise da Questão 15 e avaliação das respostas entre diferentes grupos 
Observa-se nesse último conjunto de questões uma visão voltada aos conceitos de mobilidade sustentável entre os respondentes, visto que as medidas propostas como forma de promover uma mudança cultural da população em relação ao transporte sustentável foram consideradas "eficientes" ou "muito eficientes" para ambos os grupos. Também não foram observadas diferenças significativas para as divisões formada por profissionais da área de transportes (Grupo 1). No Grupo 2, composto por respondentes de outras áreas, somente para profissionais com "até 5 anos de experiência", a diferença entre as médias foi considerada estatisticamente significativa.

Na Figura 4-20 e na Figura 4-21 é apresentada uma síntese dos resultados da diferença entre grupos por sentença.

\begin{tabular}{|c|c|c|c|c|c|c|c|c|c|c|c|c|c|c|c|c|c|}
\hline & GRUPOS & & Q1 & Q2 & Q3 & Q4 & Q5 & Q6 & Q7 & Q8 & Q9 & Q10 & Q11 & Q12 & Q13 & Q14 & Q15 \\
\hline \multirow{4}{*}{ 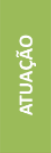 } & Gestores & A1 & A2 & & A4 & A2 & A4 & A2 & & & & & & & & & \\
\hline & Técnicos & A2 & A4 & A1 & A1 & A4 & A1 & A4 & & & & A1 & & & & & \\
\hline & Pesquisadores & A3 & A1 & A1 & A1 & A1 & A1 & A1 & & & & A1 & & & & & \\
\hline & Gest./Técn./Pesq. & A4 & A3 & A1 & A3 & A3 & A3 & A3 & & & & A1 & & & & & \\
\hline \multirow{4}{*}{ 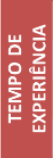 } & Até 5 anos & E1 & & & & & & & & E4 & & & & & E4 & & \\
\hline & De 6 a 10 anos & E2 & & & & & & & & & & & & & E4 & & \\
\hline & De 11 a 15 anos & E3 & & & & & & & & & & & & & & & \\
\hline & Mais de 15 anos & E4 & & & & & & & & & & & & & & & \\
\hline \multirow{4}{*}{ 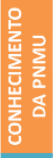 } & Detalhadamente & C1 & C4 & C4 & C3 & & C4 & & & & & & & C2 & C3 & & \\
\hline & Superficialmente & C2 & C4 & C4 & C3 & & & & C1 & & & C1 & C1 & C3 & C3 & C1 & \\
\hline & Já ouviu falar & C3 & C4 & C4 & & & C4 & C4 & C1 & & & C1 & C1 & C1 & & C1 & \\
\hline & Não conhece & C4 & & & & & & & C1 & & & C1 & & C1 & C2 & & \\
\hline \multirow{3}{*}{ 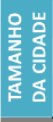 } & Pequena & T1 & & & & & & & & & & & & & & & \\
\hline & Média & $\mathrm{T} 2$ & & T1 & $\mathrm{T} 1$ & & $\mathbf{T} 1$ & & T3 & & & $\mathrm{T} 1$ & & T1 & & & \\
\hline & Grande & T3 & & T1 & T1 & & $\mathbf{T 1}$ & & & & & $\mathrm{T} 1$ & & T1 & & & \\
\hline \multirow{5}{*}{ 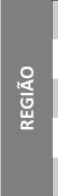 } & Sul & R1 & R2 & & R2 & & & R2 & & R3 & & & & & & R4 & \\
\hline & Sudeste & $\mathbf{R 2}$ & & & & & & & & R3 & & & & & & R4 & \\
\hline & Centro-oeste & R3 & R2 & & R2 & & & & & R5 & & & & & & R1 & \\
\hline & Nordeste & R4 & R2 & & R2 & & & & & R2 & & & & & $\mathbf{R} 2$ & R3 & \\
\hline & Norte & R5 & & R2 & & & & & & R2 & & & & & & R1 & \\
\hline
\end{tabular}

Figura 4-20 - Síntese da comparação entre grupos para as sentenças avaliadas (Q1 a Q15) pelos profissionais da área de transportes (Grupo 1), com destaque para os grupos que apresentam diferenças em cada questão 


\begin{tabular}{|c|c|c|c|c|c|c|c|c|c|c|c|c|c|c|c|c|c|}
\hline & GRUPOS & & Q1 & Q2 & Q3 & Q4 & Q5 & Q6 & Q7 & Q8 & Q9 & Q10 & Q11 & Q12 & Q13 & Q14 & Q15 \\
\hline \multirow{4}{*}{ 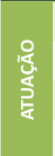 } & Gestores & A1 & & & A3 & A4 & A3 & & & & & A3 & & & & & \\
\hline & Técnicos & A2 & A4 & & A3 & A4 & & & & & & A3 & & & & A3 & \\
\hline & Pesquisadores & A3 & A4 & & & A4 & A3 & & & & & & & & & & \\
\hline & Gest./Técn./Pesq. & A4 & & & & & A3 & & & & & & & & & & \\
\hline \multirow{4}{*}{ 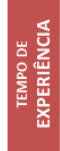 } & Até 5 anos & E1 & & & E4 & & E4 & & & & & & & & & & \\
\hline & De 6 a 10 anos & E2 & & & & & E4 & & & & & & & E1 & E1 & & E3 \\
\hline & De 11 a 15 anos & E3 & & & & & & & & & & & & E1 & & & E1 \\
\hline & Mais de 15 anos & E4 & & & & & & & & & & & & E1 & E1 & & E1 \\
\hline \multirow{4}{*}{ 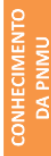 } & Detalhadamente & C1 & & & & & & & C3 & C4 & & & & & & & \\
\hline & Superficialmente & C2 & C1 & C3 & & & & & C4 & C4 & & & & & & & \\
\hline & Já ouviu falar & C3 & C1 & & & & & & C2 & C4 & & & & & & C1 & \\
\hline & Não conhece & C4 & C1 & & & & & & C1 & & & & & & & & \\
\hline \multirow{3}{*}{ 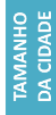 } & Pequena & T1 & & $\mathrm{T} 2 / \mathrm{T} 3$ & & & T2/T3 & & & T3 & & & & & & T3 & \\
\hline & Média & T2 & & $\mathrm{T} 1 / \mathrm{T} 3$ & T1 & & T1/T3 & & & T3 & & T1 & & & T1 & T3 & \\
\hline & Grande & T3 & & $\mathrm{T} 1 / \mathrm{T} 2$ & T1 & & $\mathrm{T} 1 / \mathrm{T} 2$ & & & & & T1 & T1 & T1 & T1 & & \\
\hline \multirow{5}{*}{ 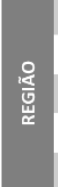 } & Sul & R1 & & & R2 & & R4 & & & & & R5 & & & & & \\
\hline & Sudeste & R2 & & & & & R5 & & R4 & & & R5 & & & & & \\
\hline & Centro-oeste & R3 & & & & & R4 & & R4 & & & & & & & & \\
\hline & Nordeste & R4 & & R2 & & & R2 & & & & & R5 & & & & & \\
\hline & Norte & R5 & & & & & R1 & & & & & & & & & & \\
\hline
\end{tabular}

Figura 4-21 - Síntese da comparação entre grupos para as sentenças avaliadas (Q1 a Q15) pelos profissionais de outras áreas (Grupo 2), com destaque para os grupos que apresentam diferenças em cada questão

\subsection{Avaliação do nível de investimento para diferentes tipos de infraestruturas de transportes}

Partindo das respostas da última questão, foi analisada a contribuição das diferentes formas de investimentos em infraestrutura de transporte para a promoção da mobilidade sustentável. Foram avaliados os investimentos nas infraestruturas para pedestres, ciclistas, transporte público coletivo, rodoviária, sobre trilhos (pesada e leve) e terminais de integração. A Figura 4-22 apresenta a média de contribuição calculada para os tipos de infraestrutura indicados, sendo que as respostas se basearam na seguinte escala: 0 (zero) para nenhuma contribuição e 100 (cem) para a máxima contribuição que o investimento público poderia fazer. 


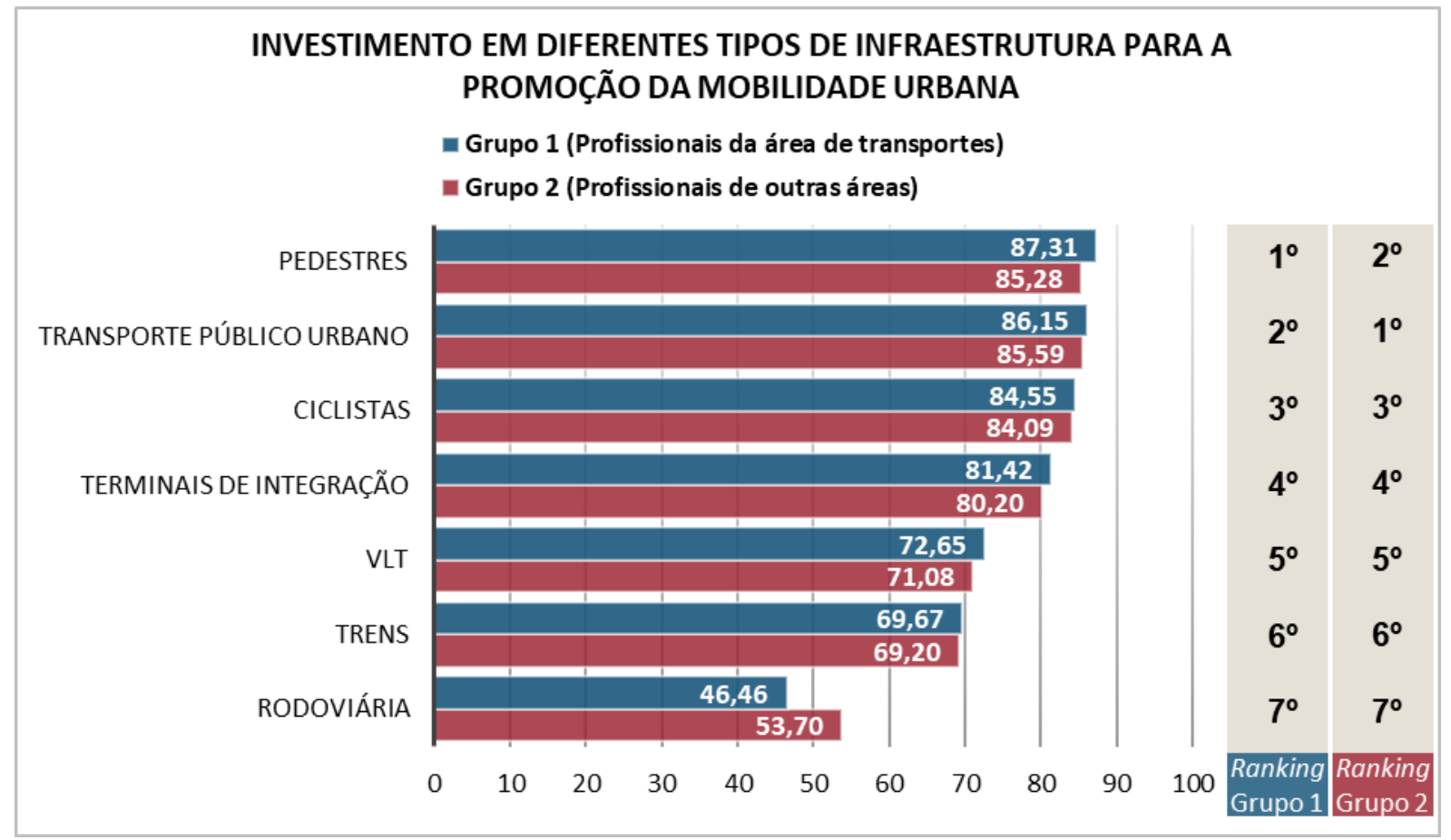

Figura 4-22 - Média das respostas para a pergunta acerca do investimentos em infraestrutura de transporte para a promoção da mobilidade sustentável

A partir das médias foi possível fazer um ranking de prioridade para os investimentos, segundo a ótica dos dois grupos avaliados. Para o Grupo 1, formado por profissionais da área de transportes, a infraestrutura para pedestres seria a que deveria receber o maior grau de investimento (média de 87,31 ) e a infraestrutura rodoviária o menor grau (média de 46,46). Para o Grupo 2, a infraestrutura para transporte público foi a que deveria receber o maior grau de investimento (média de 85,59), com uma pequena diferença para a infraestrutura para pedestres (média de 85,28). Cabe destacar que, para a maioria dos tipos de infraestrutura, as médias dos profissionais da área de transportes foram maiores do que as médias dos profissionais de outras áreas (Grupo 2). A única diferença registrada foi para os investimentos em infraestrutura rodoviária, onde o Grupo 2 apresentou média superior $(53,70)$ ao Grupo $1(46,46)$. Esta avaliação indica que os profissionais de transportes parecem estar alinhados as diretrizes da PNMU, que define prioridade dos modos não motorizados em relação aos motorizados e dos modos coletivos em relação ao individual.

O próximo passo da análise foi avaliar se existe associação entre o nível de investimento aplicado e os diferentes grupos de respondentes. $O$ teste qui-quadrado de independência foi empregado como teste de hipótese em tabelas de contingências 
construídas a partir de valores das variáveis estudadas. Seguindo a divisão de grupos realizados anteriormente, os respondentes foram avaliados segundo a atuação profissional, tempo de experiência na área, conhecimento da Política Nacional de Mobilidade Urbana (PNMU), tamanho da cidade e região do País.

Como forma de demonstrar a aplicação dos testes realizados, foi escolhida a avaliação do Grupo 1 para as variáveis investimento em infraestruturas para pedestres e conhecimento da PNMU. A Tabela 4-8 apresenta a tabela de contingência do teste qui-quadrado de independência, realizado para verificar se existe associação entre as variáveis.

Tabela 4-8 - Teste qui-quadrado de independência entre as variáveis investimento em infraestrutura para pedestres e conhecimento da PNMU do Grupo 1

\begin{tabular}{|c|c|c|c|c|c|}
\hline \multirow{2}{*}{$\begin{array}{l}\text { Conhecimento da } \\
\text { PNMU }\end{array}$} & \multirow[t]{2}{*}{ Estatísticas } & \multicolumn{3}{|c|}{$\begin{array}{c}\text { Classes de investimento em infraestrutura } \\
\text { para PEDESTRES }\end{array}$} & \multirow[t]{2}{*}{ Total } \\
\hline & & $0-33$ & $34-66$ & $67-100$ & \\
\hline $\begin{array}{l}\text { Sim, conhece } \\
\text { detalhadamente }\end{array}$ & $\begin{array}{l}\text { Observado } \\
\text { Esperado } \\
\text { Resíduos ajustados }\end{array}$ & $\begin{array}{c}15 \\
19,7 \\
-1,4\end{array}$ & $\begin{array}{c}18 \\
37,3 \\
-4,2\end{array}$ & $\begin{array}{c}383 \\
359,0 \\
4,3\end{array}$ & $\begin{array}{l}416 \\
416\end{array}$ \\
\hline $\begin{array}{l}\text { Sim, conhece } \\
\text { superficialmente }\end{array}$ & $\begin{array}{l}\text { Observado } \\
\text { Esperado } \\
\text { Resíduos ajustados }\end{array}$ & $\begin{array}{c}25 \\
26,6 \\
-0,4\end{array}$ & $\begin{array}{c}57 \\
50,2 \\
1,4\end{array}$ & $\begin{array}{c}478 \\
483,2 \\
-0,9\end{array}$ & $\begin{array}{l}560 \\
560\end{array}$ \\
\hline Já ouviu falar & $\begin{array}{l}\text { Observado } \\
\text { Esperado } \\
\text { Resíduos ajustados }\end{array}$ & $\begin{array}{l}10 \\
6,4 \\
1,5\end{array}$ & $\begin{array}{c}23 \\
12,1 \\
3,5\end{array}$ & $\begin{array}{c}102 \\
116,5 \\
-3,9\end{array}$ & $\begin{array}{l}135 \\
135\end{array}$ \\
\hline Não conhece & $\begin{array}{l}\text { Observado } \\
\text { Esperado } \\
\text { Resíduos ajustados }\end{array}$ & $\begin{array}{c}4 \\
1,3 \\
2,5\end{array}$ & $\begin{array}{c}4 \\
2,4 \\
1,1\end{array}$ & $\begin{array}{c}19 \\
23,3 \\
-2,4\end{array}$ & $\begin{array}{l}27 \\
27\end{array}$ \\
\hline Total & $\begin{array}{l}\text { Observado } \\
\text { Esperado }\end{array}$ & $\begin{array}{c}54 \\
54,0\end{array}$ & $\begin{array}{c}102 \\
102,0 \\
\end{array}$ & $\begin{array}{c}982 \\
982,0\end{array}$ & $\begin{array}{l}1138 \\
1138 \\
\end{array}$ \\
\hline Qui-quadrado & & & 35,027 & & \\
\hline p-valor & & & 0,000 & & \\
\hline V de Cramer & & & 0,124 & & \\
\hline
\end{tabular}

O cálculo do teste qui-quadrado de independência, descrito na Tabela 4-8, apresentou dois valores esperados inferiores a 5,0 (16,7\% do total de contagens esperadas). Como o teste admite até $20 \%$ das contagens esperadas inferiores a 5,0, a aplicação do teste no banco de dados foi possível. Como o valor qui-quadrado calculado $(35,027)$ equivale a um p-valor próximo de zero, a hipótese $\mathrm{H}_{0}$ é rejeitada. Sendo assim, não se pode descartar uma possível associação entre as variáveis investimentos em infraestrutura para pedestres e conhecimento da PNMU. 
Ao avaliar os residuos padronizados ajustados, observa-se que a maior magnitude corresponde ao valor entre as variáveis "classes de investimento de 67-100" e "Sim, conhece detalhadamente o texto da PNMU", indicando que a relação entre estas variáveis contribuiu significativamente para o resultado da estatística qui-quadrado. $O$ coeficiente de contingência $V$ de Cramer foi de 0,124 , o que corresponde a uma associação de $12,4 \%$ entre as variáveis analisadas.

A Figura 4-23 apresenta a distribuição dos investimentos em infraestrutura para pedestres entre as categorias de conhecimento da PNMU do Grupo 1.

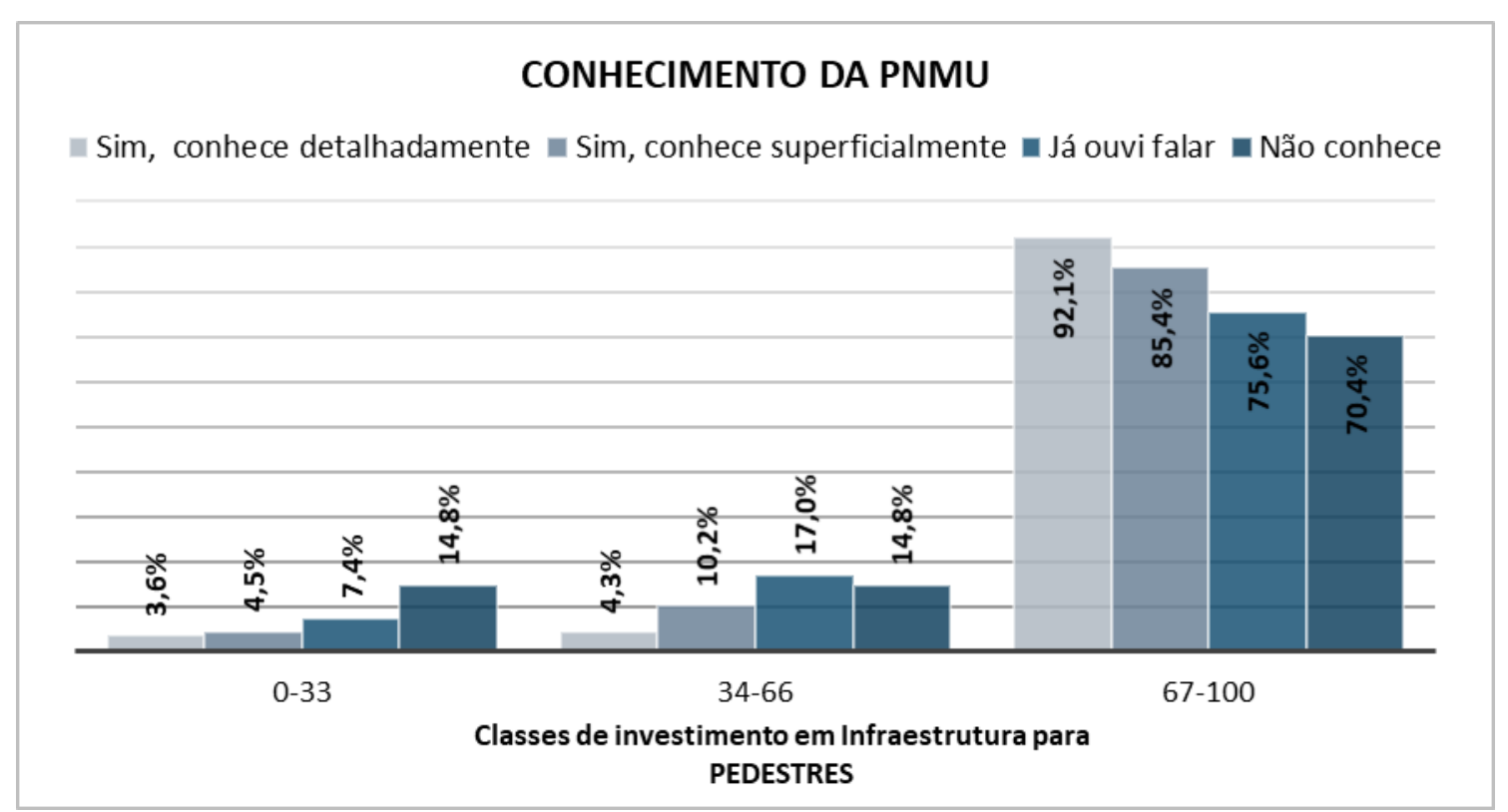

Figura 4-23 - Distribuição dos investimentos em infraestrutura para pedestres entre as categorias de conhecimento da PNMU do Grupo 1

Os resultados da Figura 4-23 mostram que a maioria dos respondentes atribuiu valores de investimento entre 67 e 100 pontos para a infraestrutura para pedestres. No entanto, cabe destacar que a categoria "conhece detalhadamente o texto da PNMU" concentrou 92,1\% dos seus respondentes nesta classe (67-100).

Seguindo o mesmo processo de análise, a Tabela 4-9 apresenta a síntese dos resultados do teste de qui-quadrado para a avaliação de independência das variáveis do Grupo 1 e a Tabela 4-10 para as variáveis do Grupo 2. 
Tabela 4-9 - Síntese do teste qui-quadrado de independência ( $p$-valor) entre as variáveis investimento em infraestrutura e os respondentes do Grupo 1

\begin{tabular}{|c|c|c|c|c|c|c|c|}
\hline & Grupos & Estatísticas & Atuação & $\begin{array}{l}\text { Tempo de } \\
\text { Experiência }\end{array}$ & $\begin{array}{l}\text { Conhecimento } \\
\text { da PNMU }\end{array}$ & $\begin{array}{l}\text { Tamanho } \\
\text { da cidade }\end{array}$ & Região \\
\hline \multirow{2}{*}{\multicolumn{2}{|c|}{ Pedestres }} & (p-valor) & 0,569 & 0,142 & $0,000^{\star}$ & 0,532 & 0,516 \\
\hline & & V de Cramer & 0,046 & 0,065 & 0,124 & 0,037 & 0,056 \\
\hline \multirow{5}{*}{ 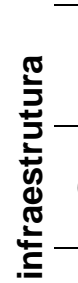 } & \multirow{2}{*}{ TPC } & (p-valor) & 0,101 & 0,614 & $0,002^{*}$ & $0,033^{\star}$ & 0,122 \\
\hline & & V de Cramer & 0,068 & 0,044 & 0,095 & 0,068 & 0,075 \\
\hline & \multirow{2}{*}{ Ciclistas } & (p-valor) & 0,156 & 0,658 & $0,000^{\star}$ & 0,811 & 0,346 \\
\hline & & V de Cramer & 0,064 & 0,043 & 0,137 & 0,026 & 0,063 \\
\hline & \multirow{2}{*}{ Rodoviária } & (p-valor) & $0,000^{*}$ & 0,245 & $0,018^{*}$ & $0,000^{*}$ & 0,390 \\
\hline 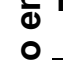 & & V de Cramer & 0,108 & 0,059 & 0,082 & 0,113 & 0,061 \\
\hline 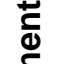 & \multirow{2}{*}{ Trens } & (p-valor) & 0,442 & 0,117 & 0,519 & 0,459 & $0,000^{*}$ \\
\hline 跑. & & V de Cramer & 0,051 & 0,067 & 0,048 & 0,040 & 0,119 \\
\hline$\stackrel{0}{\Xi}$ & \multirow{2}{*}{ VLT } & (p-valor) & 0,217 & 0,747 & 0,064 & 0,299 & $0,047^{\star}$ \\
\hline & & V de Cramer & 0,060 & 0,039 & 0,072 & 0,046 & 0,083 \\
\hline \multirow{2}{*}{\multicolumn{3}{|c|}{$\begin{array}{l}\text { Terminais ( } p \text {-valor) } \\
\text { integração } \vee \text { de Cramer }\end{array}$}} & 0,350 & 0,431 & 0,108 & 0,497 & 0,072 \\
\hline & & & 0,054 & 0,051 & 0,068 & 0,039 & 0,080 \\
\hline
\end{tabular}

* Destacados os valores onde $p$-valor $<0,05$, rejeitando-se $\mathrm{H}_{0}$ de não associação entre as variáveis.

Tabela 4-10 - Síntese do teste qui-quadrado de independência (p-valor) entre as variáveis investimento em infraestrutura e os respondentes do Grupo 2

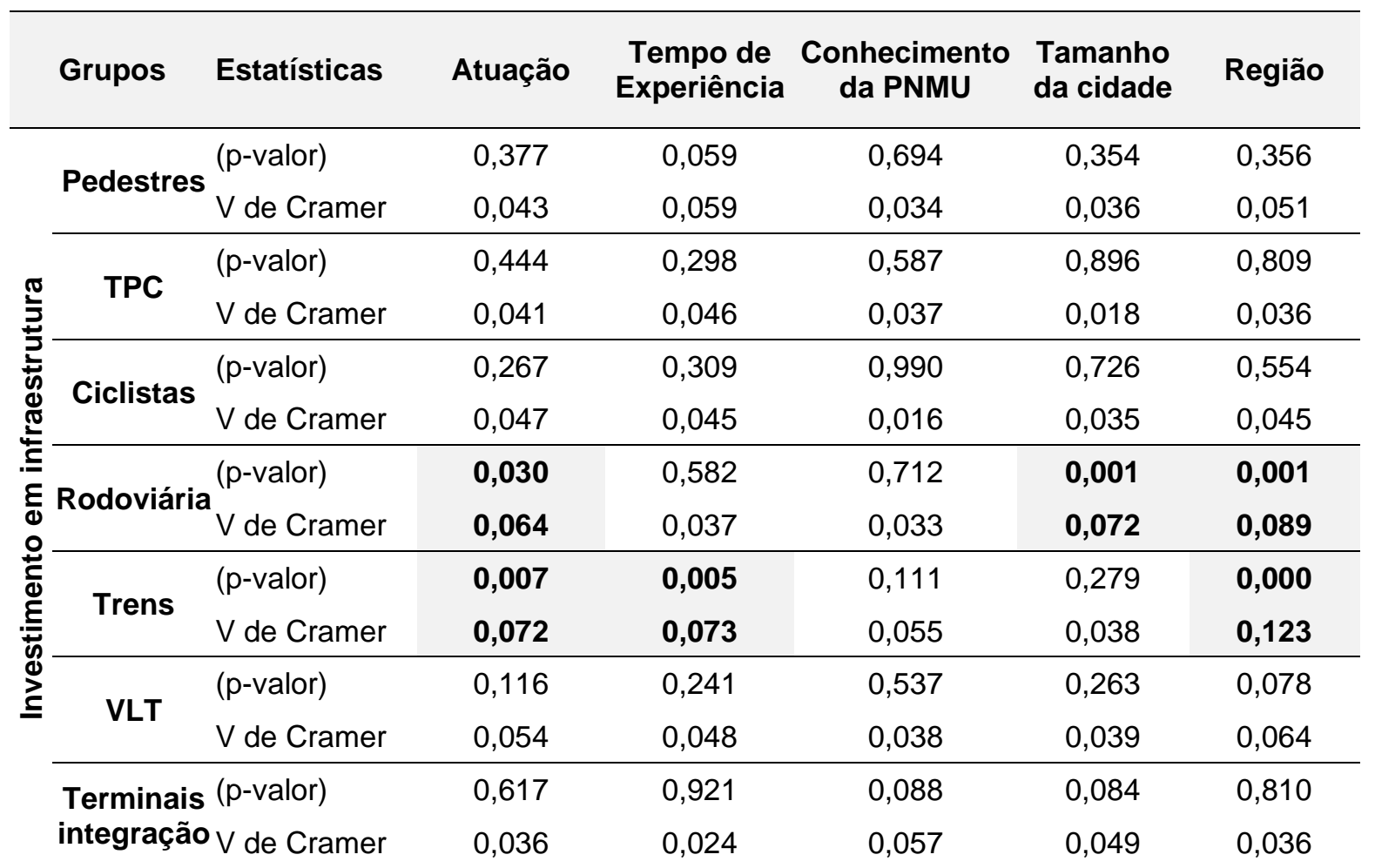

* Destacados os valores onde $p$-valor < 0,05, rejeitando-se $\mathrm{H}_{0}$ de não associação entre as variáveis. 
A avaliação dos resultados da Tabela 4-9 mostra que o conhecimento da PNMU pode ser um fator relevante para os investimentos em infraestrutura para os profissionais da área de transportes (Grupo 1), tendo em vista que o teste de independência indica associação desta variável com os investimentos em infraestrutura para pedestres, transporte público coletivo, ciclistas e rodoviária no Grupo 1. Quando avaliados os resultados do Grupo 2, entre os diferentes grupos e os investimentos em infraestrutura rodoviária e trens (pesada sobre trilhos).

Uma última avaliação foi realizada para a questão dos investimentos, buscando relacionar as respostas atribuídas para duas sentenças (Q2 e Q9) que tratam sobre oferecimento de infraestrutura e o grau de investimento atribuído para quatro tipos (pedestres, ciclistas, transporte público e rodoviária). A sentença Q2 traz a seguinte afirmativa: "Em um sistema urbano deve haver equilíbrio de investimento entre as infraestruturas necessárias para os diferentes modos de transporte (individual motorizado, transporte público, bicicleta e a pé)". Já a sentença Q9 aborda a seguinte questão: "O oferecimento de infraestrutura adequada influencia no uso dos modos não motorizados (a pé e bicicleta)".

Essa análise avalia se o discurso praticado pelos profissionais é efetivamente empregado na tomada de decisão para a promoção da mobilidade sustentável. Para isso, foi calculada a média de investimento aplicado pelos respondentes de acordo com a categoria indicada na sentença. A Figura 4-24 e a Figura 4-25 apresentam a avaliação realizada para a sentença Q2 pelos profissionais do Grupo 1 e do Grupo 2. 


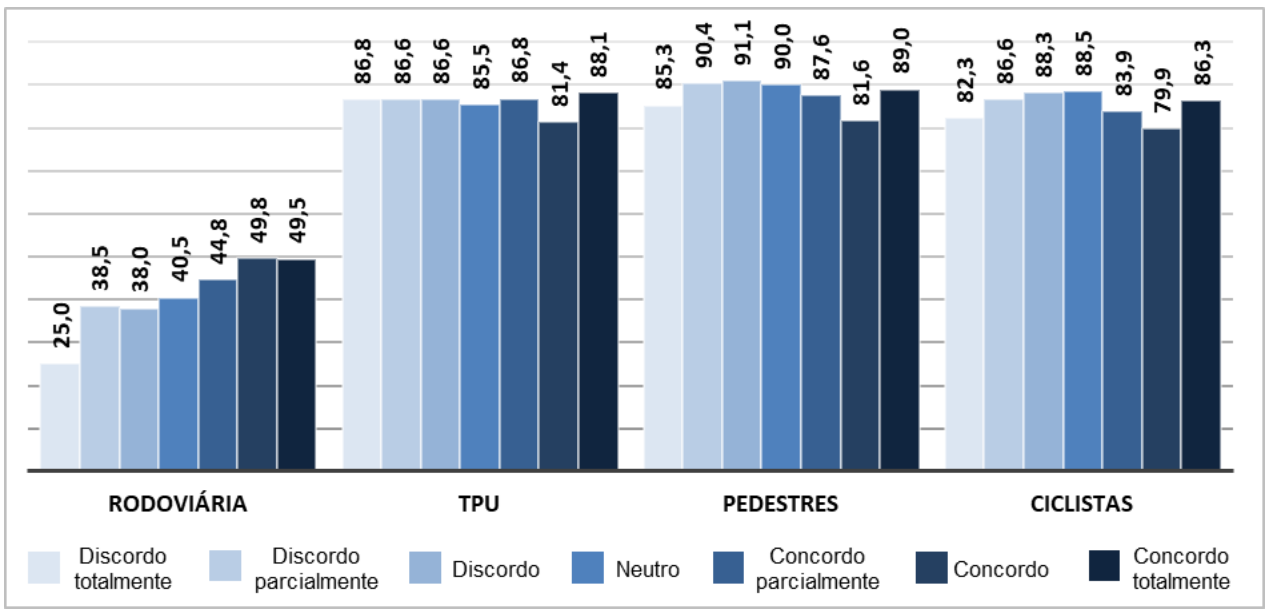

Figura 4-24 - Relação entre a média de investimento em infraestrutura para transportes e grau de concordância com a sentença "Em um sistema urbano deve haver equilíbrio de investimento entre as infraestruturas necessárias para os diferentes modos de transporte (individual motorizado, transporte público, bicicleta e a pé)" do Grupo 1 (profissionais da área de transportes)

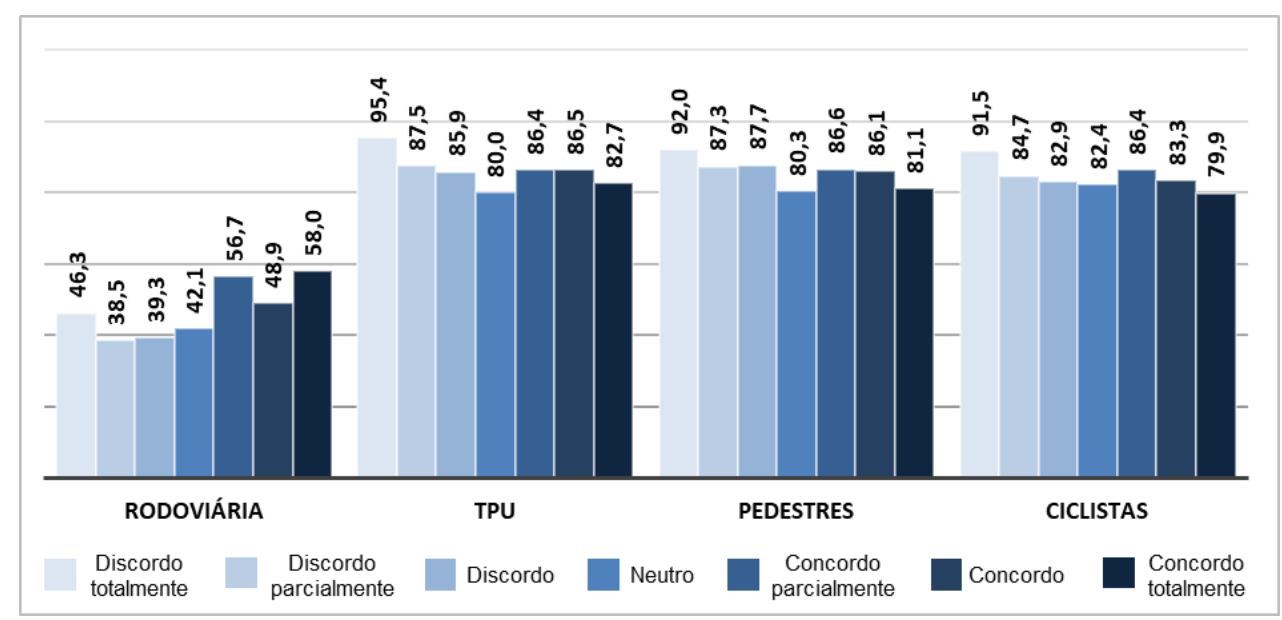

Figura 4-25 - Relação entre a média de investimento em infraestrutura para transportes e grau de concordância com a sentença "Em um sistema urbano deve haver equilíbrio de investimento entre as infraestruturas necessárias para os diferentes modos de transporte (individual motorizado, transporte público, bicicleta e a pé)" do Grupo 2 (profissionais de outras áreas)

Para a infraestrutura rodoviária, é possível perceber que quanto maior o grau de concordância com a sentença, maior o investimento aplicado. Isso ao mesmo tempo que, para as infraestruturas para transporte público, pedestres e ciclistas ocorre o inverso na aplicação dos investimentos, ou seja, os respondentes tendem a indicar um grau de investimento maior para graus de concordâncias menores. Isso mostra a percepção dos respondentes para uma melhor redistribuição dos investimentos entre os modos considerados sustentáveis (pedestres, ciclistas e transporte público), tendo em vista que quando é abordado o termo "equilíbrio de investimentos" descrito na sentença Q2, não se trata de igualdade de investimentos, e sim equilíbrio na aplicação dos recursos entre todos os tipos de infraestrutura. 
Seguindo o mesmo procedimento, foi realizado o cruzamento do grau de concordância para a Q9, que aborda a relação do oferecimento de infraestrutura como forma de incentivo ao uso dos modos não motorizados, e os investimentos em infraestrutura, conforme apresentado pela Figura 4-26 e Figura 4-27.

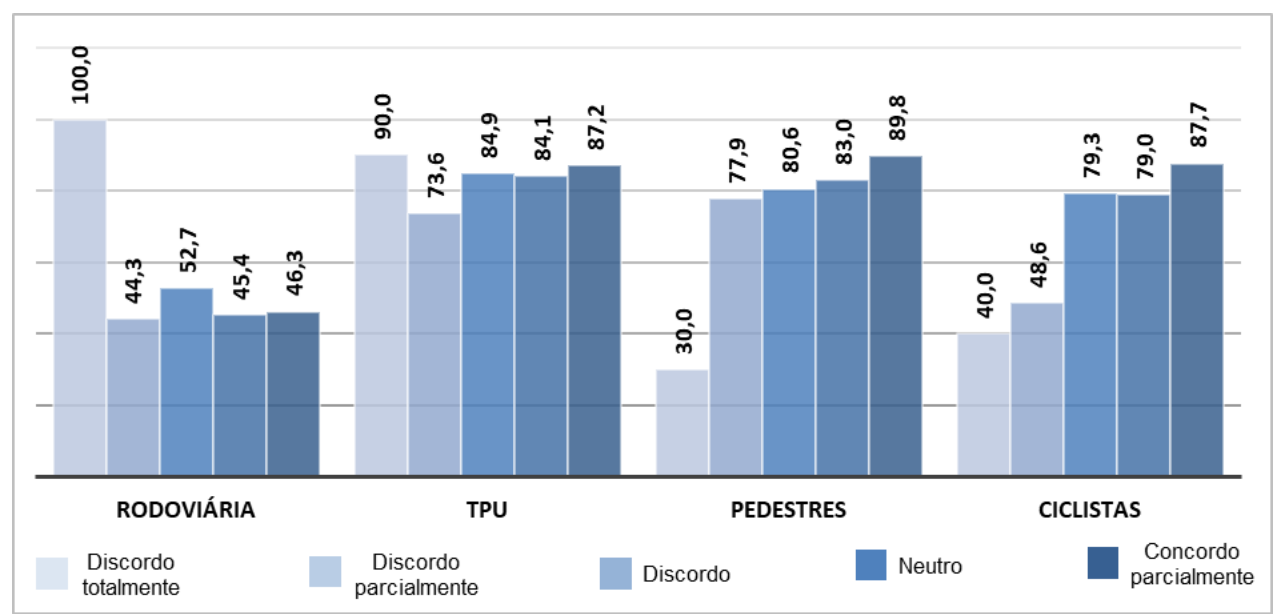

Figura 4-26 - Relação entre a média de investimento em infraestrutura para transportes e grau de concordância com a sentença "O oferecimento de infraestrutura adequada influencia no uso dos modos não motorizados (a pé e bicicleta)" do Grupo 1

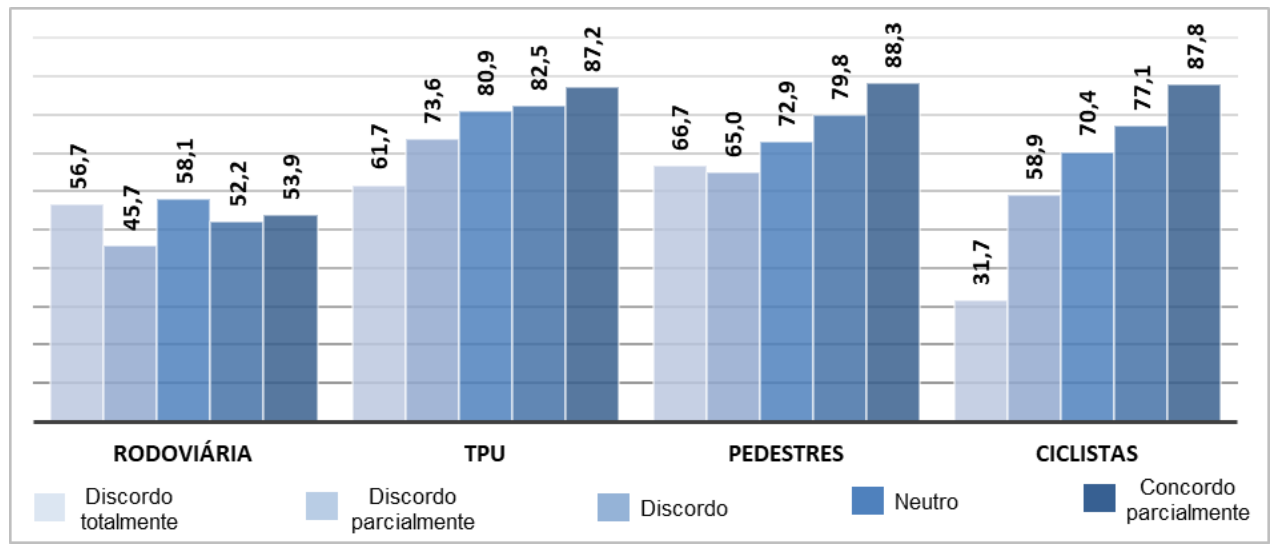

Figura 4-27 - Relação entre a média de investimento em infraestrutura para transportes e grau de concordância com a sentença "O oferecimento de infraestrutura adequada influencia no uso dos modos não motorizados (a pé e bicicleta)" do Grupo 2

Com base nesses dados é possível identificar que o grau de investimento aumenta para os modos não motorizados à medida que os respondentes têm a percepção do oferecimento de infraestrutura como forma de influenciar no uso dos modos a pé e bicicleta. 
Capítulo

\section{Discussões}

Ao analisar os resultados ficou evidente o alto nível de concordância para a maioria das declarações, o que indica que, em geral, os respondentes estão em sintonia com os conceitos analisados, principalmente os profissionais da área de transportes. Para as primeiras seis questões, isto ficou mais notório para a sentença Q1 sobre a importância da integração do uso do solo em transportes (discurso "Planejamento Urbano"), seguido das três visões de "Sustentabilidade" (Q4-A gestão da demanda reduz a demanda por automóveis; Q5-Importância do planejamento logístico para as empresas; Q6-Análise de custo-benefício deve ser considerada no custo total de viagens) e "Economia" (Q3-Investimento em infraestrutura traz aumento do número de emprego). A sentença $Q 2$ sobre o investimento equilibrado em infraestrutura de transporte entre todos os modos (discurso "Engenharia") foi o de maior divergência entre os respondentes.

Em relação à análise para as nove questões focadas no planejamento para os modos não motorizados, apesar de certa variabilidade observada, os respondentes concordaram mais com os julgamentos que favoreciam medidas que levam a melhores condições para a mobilidade urbana sustentável (Q8, Q9 e Q15). Isso ao mesmo tempo que, em geral, havia uma divergência entre as respostas que lidavam com a perda de espaço para os modos motorizados, como a redução da velocidade nas vias urbanas para encorajar o uso de modos não motorizados (Q7), indicando que deve haver maior debate sobre o tema e que as questões que incentivam a mobilidade sustentável não estão totalmente claras para os especialistas entrevistados. 
A partir da análise das questões Q7, Q8 e Q9 constatou-se que, apesar dos respondentes indicarem viabilidade para o compartilhamento de via entre diferentes modos de transportes (Q8) e que o oferecimento de infraestrutura influencia no uso dos modos a pé e bicicleta (Q9), para a maioria dos entrevistados ainda existe resistência em retirar facilidades atribuídas ao uso dos veículos automotores para incentivar a qualificação dos espaços buscando motivar a utilização dos modos não motorizados, como pode ser verificado na variabilidade das respostas da questão Q7.

Em relação ao custo dos modos não motorizados (Q11), para a maioria dos entrevistados os investimentos necessários para uma infraestrutura adequada são menores, quando comparados a infraestruturas para outros modos. A sentença sobre percepção de segurança em áreas com movimentação de pedestres e ciclistas (Q14) foi a com maior distribuição entre as respostas, indicando que este pode ser um fator importante no uso dos modos não motorizados.

Com base nesses dados é possível identificar que, mesmo não sendo necessários altos investimentos em infraestrutura para os modos não motorizados (Q11), o uso dos modos a pé e bicicleta não seria totalmente viável (Q10). No entanto, na Questão 12 a maioria dos respondentes "concorda" ou "concorda totalmente" que, por serem considerados de baixo custo para os usuários, os modos não motorizados podem ser utilizados pela maioria da população.

Nos resultados da análise das questões divididas entre grupos foram observadas algumas divergências de opinião. Para a análise quanto à atuação profissional, de maneira geral, o grupo de Técnicos e Gestores indicou maiores médias para as sentenças. A divisão dos respondentes em função do tempo de experiência indicou que não houve variação significativa entre as médias para o grupo representado pelos profissionais da área de transportes. Estas, quando ocorreram, foram predominantemente para os profissionais com experiência de até 5 anos e profissionais com mais de 15 anos de experiência.

Os resultados da análise em função do porte da cidade indicaram que $\circ$ grupo "Cidades Pequenas" apresentou maiores médias para as sentenças, em comparação aos outros grupos (Cidades Médias e Grandes). Esta informação sugere que a 
percepção dos especialistas sobre os conceitos de mobilidade sustentável varia em função do porte da cidade em que residem. A região Sudeste foi a que apresentou maior número divergências em relação à opinião das demais, quando consideradas todas as sentenças avaliadas.

A divisão em relação ao nível de conhecimento da PNMU foi a que mais apresentou diferenças nas opiniões entre os grupos, principalmente para os respondentes que indicaram conhecer detalhadamente o texto da Lei da Mobilidade, reforçando a importância dessas diretrizes para a promoção dos modos sustentáveis.

Por fim, a avaliação dos investimentos aplicados a diferentes tipos de infraestrutura indicou que a maioria dos profissionais destinou maiores investimentos a pedestres, ciclistas e transporte público. Pode ser verificada ainda a existência de uma relação entre o grau de investimento e o conhecimento da PNMU para os profissionais da área de transportes. Além disso, a comparação entre os investimentos e as sentenças Q2 e Q9 apontou uma sintonia entre o discurso praticado pelos especialistas e o grau de investimento aplicado para os modos sustentáveis. 
Capítulo

\section{Conclusões}

Este trabalho visava avaliar a opinião de pesquisadores e decisores para diferentes temas sobre a mobilidade sustentável, utilizando grupos focais e questionários online. A realização de grupos focais possibilitou identificar aspectos considerados importantes para os usuários na escolha do transporte não motorizado. A pesquisa também desenvolveu um formulário em uma plataforma online, através do qual se verificou a sintonia dos respondentes com os conceitos de mobilidade sustentável.

O trabalhou ampliou significativamente a abrangência das pesquisas anteriores para o contexto brasileiro. Ao analisar as 2863 respostas do questionário foi possível obter algumas conclusões interessantes. Para destacar as principais conclusões do estudo, serão retomadas as questões que orientaram o desenvolvimento deste trabalho, bem como alguns pontos da seção de Discussões.

1) Quais são os aspectos considerados importantes por pedestres e ciclistas para um ambiente propício ao uso dos modos não motorizados?

As informações coletadas pelos grupos focais indicaram a necessidade abordar os seguintes temas:

- redução do limite de velocidade em algumas vias como maneira de incentivar os modos não motorizados;

- importância de investimentos em sinalização, manutenção e continuidade da rede viária para o compartilhamento das vias entre diferentes modos de transporte;

- oferecimento de infraestrutura adequada como forma de incentivo ao uso dos modos não motorizados (a pé e bicicleta); 
- percepção de como as características do ambiente (topografia e clima) influenciam no uso dos modos não motorizados;

- custo da infraestrutura para modos não motorizados em comparação ao custo da infraestrutura para outros modos;

- percepção de segurança pública em áreas com movimentação de pedestres e ciclistas.

Os pontos abordados indicam que pedestres e ciclistas estão interessados tanto em ações voltadas para melhoria da infraestrutura dos modos não motorizados, quanto em medidas políticas para reduzir o espaço dos modos motorizados.

\section{2) Como pesquisadores e decisores se posicionam em relação aos temas de economia, engenharia, modos não motorizados, planejamento urbano e sustentabilidade?}

Em uma análise geral, ficou evidente a diferença de posicionamento para os temas abordados. A sentença que representou o discurso sobre planejamento urbano recebeu o maior grau de concordância entre os respondentes. Na avaliação focada para os modos não motorizados, as medidas que levam a melhores condições para a mobilidade urbana sustentável também obtiveram alto grau de concordância. Em relação ao tema que aborda o equilíbrio de investimento para diferentes tipos de infraestrutura foi observada uma maior divergência na opinião dos entrevistados. A partir destas considerações, fica evidente que os respondentes estão conscientes para uma mudança de paradigma no planejamento de transportes.

\section{3) Existe concordância entre a visão de profissionais da área de transportes e profissionais de outras áreas?}

Na maior parte das questões, é evidente a similaridade na avaliação realizada pelos dois grupos. No entanto, para a avaliação dos investimentos aplicados a diferentes tipos de infraestrutura, foi observada uma tendência maior do grupo formado por profissionais que não atuam na área de transportes em favorecer a infraestrutura rodoviária. Os especialistas da área de transportes indicaram maiores investimentos à pedestres, ciclistas e ao transporte público. 


\section{4) Quando considerada a perspectiva de diferentes grupos de avaliação, existe diferença nesse posicionamento?}

Os resultados indicaram que existem divergências de opinião para as avaliações por grupos diferentes. Esta conclusão ficou mais evidente para os grupos divididos em relação ao nível de conhecimento da PNMU. Os respondentes que indicaram conhecer a Política Nacional de Mobilidade Urbana tiveram maior sintonia com os conceitos avaliados. Isso mostra a importância dos programas de capacitação para difusão da mobilidade urbana sustentável. Outro fato a ser destacado, é que a percepção dos especialistas sobre os conceitos de mobilidade sustentável varia em função do porte da cidade e da região em que residem.

Por fim, constata-se que a metodologia descrita neste trabalho tem potencial para identificar a percepção dos respondentes em relação à mobilidade sustentável, através da comparação das diferenças e semelhanças do ponto de vista de profissionais de diferentes áreas. Nesse sentido, estudos como este podem contribuir como referência para a formulação de medidas para melhor capacitação de profissionais ligados ao planejamento de transportes, bem como na proposição de políticas públicas para o estímulo à mobilidade sustentável nos diferentes contextos brasileiros. 


\section{Referências}

ALDRED, R.; WATSON, T.; LOVELACE, R.; WOODCOCK, J. Barriers to investing in cycling: Stakeholder views from England. Transportation Research Part A: Policy and Practice, 2017. Disponível em: <http://dx.doi.org/10.1016/j.tra.2017.11.003>.

ALVES, L. M. T.; HUMBERTO, M.; SIQUEIRA, R. G. S. Efetividade da PNMU: caracterização dos municípios e identificação de variáveis relevantes para elaboração do plano de mobilidade. Revista dos Transportes Públicos. São Paulo - SP. ANTP, 2018.

AMORIM, L. C. De; OLIVEIRA, G. M. De; RODRIGUES DA SILVA, A. N. Uma visão de mobilidade urbana sustentável segundo o discurso de pesquisadores e técnicos/gestores. In: Anais do XXVIII Congresso de Pesquisa e Ensino em Transportes, ANPET. Curitiba-PR, 2014.

ANTP, Associação Nacional de Transportes Públicos. Sistema de Informações da Mobilidade Urbana da Associação Nacional de Transportes Público Simob/ANTP. p. 110, 2016. Disponível em: <http://files.antp.org.br/simob/simob2016-v6.pdf>.

ANTP, Associação Nacional de Transportes Públicos. Mobilidade humana para um Brasil urbano. 228 p., 2017.

ARBEX, R. O.; CUNHA, C. B. da. Uma avaliação do impacto do desabastecimento de combustível durante a greve dos caminhoneiros no sistema de transporte público de São Paulo: efeitos na lotação, na velocidade das viagens e na regularidade dos usuários. In: Anais do $32^{\circ}$ Congresso de Pesquisa e Ensino em Transportes, ANPET, Gramado-RS, 2018.

BANISTER, D. The sustainable mobility paradigm. Transport Policy, v. 15, n. 2, p. 73-80, 2008. Disponível em: <http://dx.doi.org/10.1016/j.tranpol.2007.10.005>.

BBC. 5 anos depois, o que aconteceu com as reivindicações dos protestos que pararam o Brasil em junho de 2013?, 2018. Disponível em: <https://www.bbc.com/portuguese/brasil-44353703>. Acesso em: 15 mar. 2019.

BRASIL. LEI No 10.257/2001. Estatuto da Cidade. Brasília - DF, 2001. 
BRASIL. LEI No 12.587/2012. Política Nacional de Mobilidade Urbana. Brasília - DF, 2012.

BRAUN, L. M.; RODRIGUEZ, D. A.; COLE-HUNTER, T.; AMBROS, A.; DONAIREGONZALEZ, D.; JERRETT, M.; MENDEZ, M. A.; NIEUWENHUIJSEN, M. J.; DE NAZELLE, A. Short-term planning and policy interventions to promote cycling in urban centers: Findings from a commute mode choice analysis in Barcelona, Spain. Transportation Research Part A: Policy and Practice, v. 89, p. 164-183, 2016. Disponível em: <http://dx.doi.org/10.1016/j.tra.2016.05.007>.

CALDEIRA, G. P.; BASTOS, J. T. Planos de mobilidade urbana e a segurança viária: uma análise das capitais brasileiras. In: Anais do $32^{\circ}$ Congresso de Pesquisa e Ensino em Transportes, ANPET, Gramado-RS, 2018.

CARVALHO, C. H. R. de. Desafios da Mobilidade Urbana no Brasil. Texto para Discussão. Brasília - DF. Instituto de Pesquisa Econômica Aplicada - IPEA, 2016.

CASSEL, D. L.; LADEIRA, M. C. M.; CYBIS, H. B. B. Caracterização dos serviços de ridesourcing e sua relação com o transporte coletivo: estudo de caso em Porto Alegre. In: Anais do $32^{\circ}$ Congresso de Pesquisa e Ensino em Transportes, ANPET, Gramado-RS, 2018.

CAULFIELD, B. Re-cycling a city - Examining the growth of cycling in Dublin. Transportation Research Part A: Policy and Practice, v. 61, p. 216-226, 2014.

CAULFIELD, B.; LEAHY, J. Learning to cycle again: Examining the benefits of providing tax-free loans to purchase new bicycles. Research in Transportation Business and Management, v. 2, p. 42-47, 2011.

COLE, R.; BURKE, M.; LESLIE, E.; DONALD, M.; OWEN, N. Perceptions of representatives of public, private, and community sector institutions of the barriers and enablers for physically active transport. Transport Policy, v. 17, n. 6, p. 496-504, 2010. Disponível em: <http://dx.doi.org/10.1016/j.tranpol.2010.05.003>.

COSTA, L. C. Desafios na elaboração dos planos de mobilidade municipais. Revista Técnica CNM, p. 137-150, 2016.

CURTIS, C.; LOW, N. Institutional barriers to sustainable transport. Ashgate, Farnham, Surrey; Burlington, VT, 2012.

DE SOUSA, A. A.; SANCHES, S. P.; FERREIRA, M. A. G. Perception of Barriers for the Use of Bicycles. Procedia - Social and Behavioral Sciences, v. 160, n. Cit, p. 304-313, 2014. Disponível em: <http://dx.doi.org/10.1016/j.sbspro.2014.12.142>.

DOUGHTY, K.; MURRAY, L. Discourses of Mobility: Institutions, Everyday Lives and Embodiment. Mobilities, v. 11, n. 2, p. 303-322, 2016. Disponível em: <http://dx.doi.org/10.1080/17450101.2014.941257>.

G1. Patinetes: entenda a polêmica entre a Prefeitura de SP e as empresas de compartilhamento, 2018. Disponível em: <https://g1.globo.com/sp/sao- 
paulo/noticia/2019/05/31/patinetes-entenda-a-polemica-entre-a-prefeitura-de-sp-eas-empresas-de-compartilhamento.ghtml>.

GABRIELLI, S.; FORBES, P.; JYLHÄ, A.; WELLS, S.; SIRÉN, M.; HEMMINKI, S.; NURMI, P.; MAIMONE, R.; MASTHOFF, J.; JACUCCI, G. Design challenges in motivating change for sustainable urban mobility. Computers in Human Behavior, v. 41, p. 416-423, 2014. Disponível em: <http://dx.doi.org/10.1016/j.chb.2014.05.026>.

GERAGHTY, A. B.; SEIFERT, W.; PRESTON, T.; HOLM, C. V.; DUARTE, T. H.; FARRAR, S. M. Partnership moves community toward complete streets. American Journal of Preventive Medicine, v. 37, n. 6 SUPPL. 2, p. S420-S427, 2009. Disponível em: <http://dx.doi.org/10.1016/j.amepre.2009.09.009>.

GÖSSLING, S.; COHEN, S.; HIGHAM, J.; PEETERS, P.; EIJGELAAR, E. Desirable transport futures. Transportation Research Part D: Transport and Environment, v. 61, n. February, p. 301-309, 2018.

GUILFORD, J. P. (1954) Psychometric Methods, 2nd ed. Mc-Graw Hill Publishing Co, London.

GUIMARÃES, T.; LUCAS, K. O papel da equidade no planejamento de transportes no Brasil. In: Anais do XXXI Congresso de Pesquisa e Ensino em Transportes, ANPET. Recife-PB, 2017.

HICKMAN, R.; HALL, P.; BANISTER, D. Planning more for sustainable mobility. Journal of Transport Geography, v. 33, p. 210-219, 2013. Disponível em: $<$ http://dx.doi.org/10.1016/j.jtrangeo.2013.07.004>.

IMRAN, M.; PEARCE, J. Discursive Barriers to Sustainable Transport in New Zealand Cities. Urban Policy and Research, v. 33, n. 4, p. 392-415, 2015. Disponível em: $<$ http://dx.doi.org/10.1080/08111146.2014.980400>.

JONES, P. The evolution of urban mobility: The interplay of academic and policy perspectives. IATSS Research, v. 38, n. 1, p. 7-13, 2014. Disponível em: <http://dx.doi.org/10.1016/j.iatssr.2014.06.001>.

JONES, T.; AZEVEDO, L. N. Economic, social and cultural transformation and the role of the bicycle in Brazil. Journal of Transport Geography, v. 30, p. 208-219, 2013. Disponível em: <http://dx.doi.org/10.1016/j.jtrangeo.2013.02.005>.

KRAWCZYK, E.; RATCLIFFE, J. Predict and provide vs explore, envision and plan: transforming the urban planning approach towards the future. Articles, p. 0-18, 2005. Disponível em: <http://arrow.dit.ie/cgi/viewcontent.cgi?article=1005\&context=futuresacart $>$.

KUKELY, G.; ABA, A.; FLEISCHER, T. New framework for monitoring urban mobility in European cities. Transportation Research Procedia, v. 24, p. 155-162, 2017. Disponível em: <http://dx.doi.org/10.1016/j.trpro.2017.05.081>.

LANZENDORF, M.; BUSCH-GEERTSEMA, A. The cycling boom in large German 
cities - Empirical evidence for successful cycling campaigns. Transport Policy, v. 36, p. 26-33, 2014. Disponível em: <http://dx.doi.org/10.1016/j.tranpol.2014.07.003>.

LEGACY, C. Transforming transport planning in the postpolitical era. Urban Studies, v. 53, n. 14, p. 3108-3124, 2016.

LIMA NETO, V. C.; GALINDO, E. P. Planos de mobilidade urbana: instrumento efetivo da política pública de mobilidade? Paranoá: Cadernos de Arquitetura e Urbanismo, n. 9, 2015.

LITMAN, T. Reinventing Transportation. Transportation Research Record, p. 8-12, 2003.

MACHADO, L.; SALOMÃO PICCININI, L. Os desafios para a efetividade da implementação dos planos de mobilidade urbana: uma revisão sistemática Challenges for the effectiveness of the implementation of urban mobility plans: a systematic review. Brazilian Journal of Urban Management, v. 10, n. 1, p. 72-94, 2018.

MAGAGNIN, R. C.; RIBEIRO, C. C. R.; PIRES, I. B. As diferentes percepções sobre os problemas de mobilidade urbana em uma cidade brasileira de médio porte: a visão dos especialistas e da população de Jundiaí (SP - Brasil). In: Anais do $7^{\circ}$ Congresso Luso Brasileiro para o Planejamento Urbano, Regional, Integrado e Sustentável, PLURIS, Maceió - AL, 2016.

MAGAGNIN, R. C.; RODRIGUES DA SILVA, A. N. A percepção do especialista sobre o tema mobilidade urbana. Transportes, v. XVI, p. 25-35, 2008.

MINISTÉRIO DAS CIDADES. PlanMob: construindo a cidade sustentável Caderno de referências para elaboração de plano de mobilidade urbana. Brasília, MCidades, 2015.

MINISTÉRIO DAS CIDADES. Levantamento sobre a situação dos Planos de Mobilidade Urbana nos municípios brasileiros, 2016. Disponível em: <http://www.cidades.gov.br/component/content/article?id=4398>.

MIRANDA, H. F.; MANCINI, M. T.; AZEVEDO FILHO, M. A. N.; ALVES, V. F. B.; RODRIGUES DA SILVA, A. N. Barreiras para Implantação de Planos de Mobilidade. Anais do XXIII Congresso de Pesquisa e Ensino em Transportes, ANPET, VitóriaES, v. 1, 2009.

PEREIRA, R. U.; FREITAS, P. H. D. S. A regulamentação dos serviços prestados pela startup Uber: o transporte privado individual de passageiros em conformidade com os preceitos de acessibilidade de um estado democrático. Revista de Direito da Cidade, v. 9, n. 4, p. 1416-1449, 2017.

PROVIDELO, J. K. E S. P. SANCHES (2011) Roadway and traffic characteristics for bicycling. Transportation, v. 38, p. 765-777. DOI 10.1007/s11116-011-9353-X

RODRIGUES DA SILVA, A. N.; AZEVEDO FILHO, M. A. N. de; MACÊDO, M. H.; SORRATINI, J. A.; DA SILVA, A. F.; LIMA, J. P.; PINHEIRO, A. M. G. S. A comparative 
evaluation of mobility conditions in selected cities of the five Brazilian regions. Transport Policy, v. 37, p. 147-156, 2015.

RODRIGUES DA SILVA, A. N.; COSTA, M. S.; MACEDO, M. H. Multiple views of sustainable urban mobility: The case of Brazil. Transport Policy, v. 15, n. 6, p. 350360, 2008.

SAELENS, B. E.; SALLIS, J. F.; FRANK, L. D. Environmental correlates of walking and cycling: Findings from the transportation, urban design, and planning literatures. Annals of Behavioral Medicine, v. 25, n. 2, p. 80-91, 2003.

SANTOS, A. L. L. dos. Uma análise exploratória de barreiras na implementação do plano de mobilidade urbana nas cidades de pequeno e médio porte no estado de São Paulo. Dissertação (Mestrado)-Universidade Estadual Paulista. Faculdade de Engenharia, Bauru, 2017. Disponível em: <https://repositorio.unesp.br/handle/11449/152539>.

SILVA, M. D. da; BALASSIANO, R. Uber - Uma análise do serviço oferecido ao usuário na cidade do Rio de Janeiro. Revista dos Transportes Públicos. São Paulo - SP, ANTP, 2018.

SILVA, F. M. V.; FIGUEIREDO, E. H. L. Direito social ao transporte: Nova diretriz e velhas premissas na mobilidade urbana. Revista Da AGU, v. 17, n. 1, 2018.

SULTANA, S.; SALON, D.; KUBY, M. Transportation sustainability in the urban context: a comprehensive review. Urban Geography, v. 00, n. 00, p. 1-30, 2017. Disponível em: <https://doi.org/10.1080/02723638.2017.1395635>.

TE BRÖMMELSTROET, M.; SKOU NICOLAISEN, M.; BÜTTNER, B.; FERREIRA, A. Experiences with transportation models: An international survey of planning practices. Transport Policy, v. 58, n. April, p. 10-18, 2017. Disponível em: <http://dx.doi.org/10.1016/j.tranpol.2017.04.007>.

TENNØY, A. Why we fail to reduce urban road traffic volumes: Does it matter how planners frame the problem? Transport Policy, v. 17, n. 4, p. 216-223, 2010. Disponível em: <http://dx.doi.org/10.1016/j.tranpol.2010.01.011>.

VASCONCELLOS, E. A. Políticas de transportes no Brasil: a construção da mobilidade excludente, Editora: Manole, Barueri, SP, 2014.

VASCONCELLOS, E. A. Urban transport policies in Brazil: The creation of a discriminatory mobility system. Journal of Transport Geography, v. 67, n. September 2017, p. 85-91, 2018.

WEGENER, M. The future of mobility in cities: Challenges for urban modelling. Transport Policy, v. 29, p. 275-282, 2013. Disponível em: <http://dx.doi.org/10.1016/j.tranpol.2012.07.004>.

XAVIER, J. C. A nova política de mobilidade urbana no Brasil: uma mudança de paradigma. ANTP, 2015. (Nota técnica). 
Apêndice

\section{Respostas do Questionário
Online}

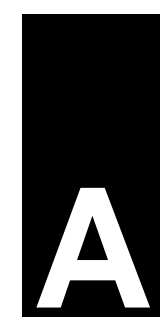

O presente Apêndice tem como objetivo divulgar e registrar os dados técnicos obtidos da aplicação de um questionário aos profissionais de diferentes áreas visando identificar obstáculos para a mobilidade sustentável. A apresentação dos dados está dividida em cinco partes: perfil do respondente, perfil profissional do respondente, frequência de utilização dos modos de transporte, questões sobre planejamento de transportes e investimento em infraestrutura de transportes. 


\section{PARTE I: PERFIL DO RESPONDENTE}

Inicialmente o questionário apresenta o Termo de Consentimento Livre e Esclarecido, onde são descritas informações gerais sobre o trabalho e os termos para participação da pesquisa. A seção seguinte do questionário contém algumas questões para caracterização geral dos respondentes. A Figura A-1 apresenta o diagrama do primeiro bloco de questões. Os resultados de cada um dos itens estão resumidos na sequência do texto.

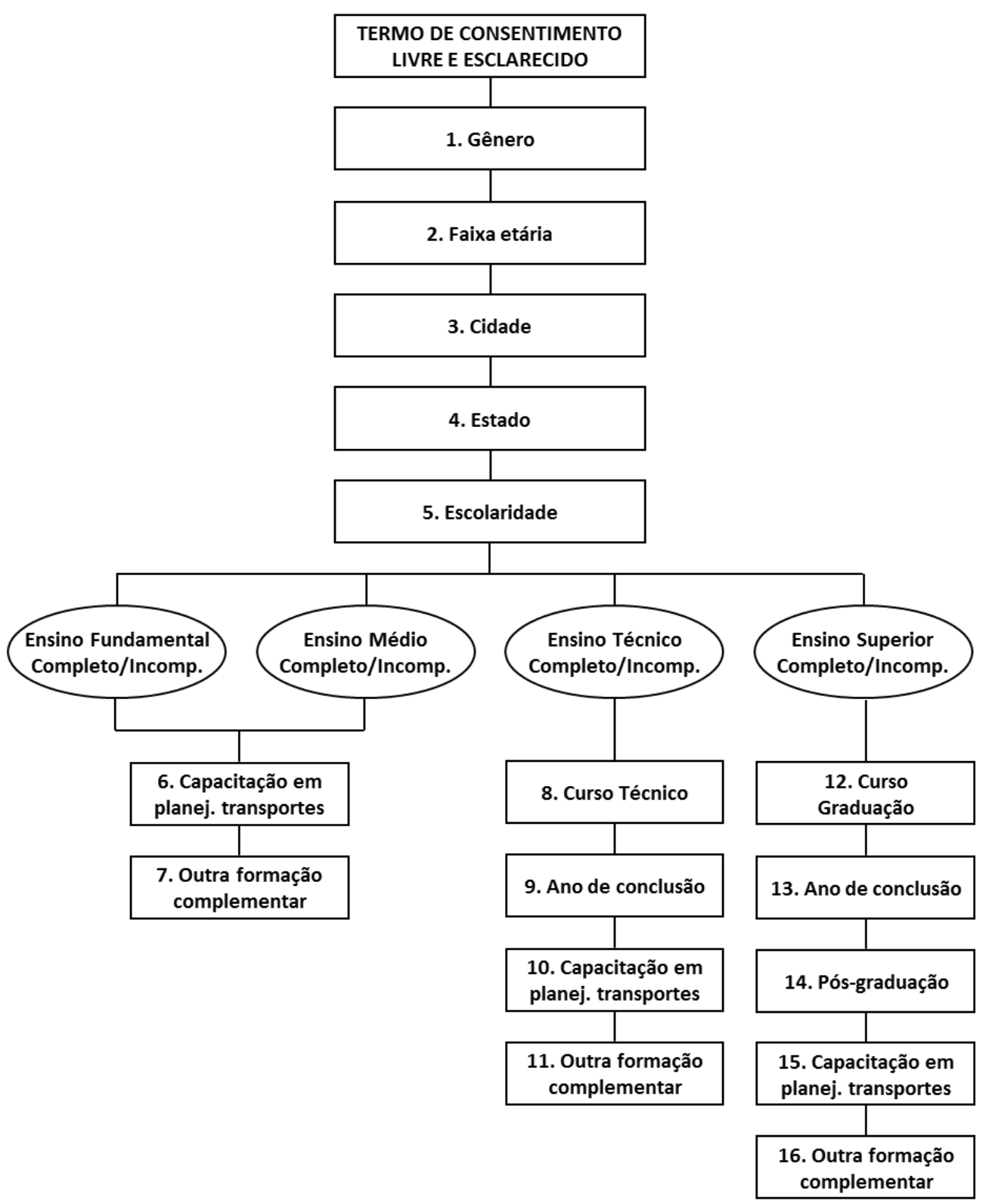

Figura A-1 - Diagrama do primeiro bloco de questões 


\section{Questão 1: Gênero}

A primeira pergunta do questionário se refere ao gênero do respondente. A Tabela A-1 e a Figura A-2 apresentam a distribuição dos dados.

Tabela A-1 - Distribuição dos respondentes por gênero

\begin{tabular}{lcc}
\hline GÊNERO & Frequência & $\%$ \\
\hline Feminino & 1440 & $50,3 \%$ \\
Masculino & 1423 & $49,7 \%$ \\
Total & 2863 & $100,0 \%$ \\
\hline
\end{tabular}

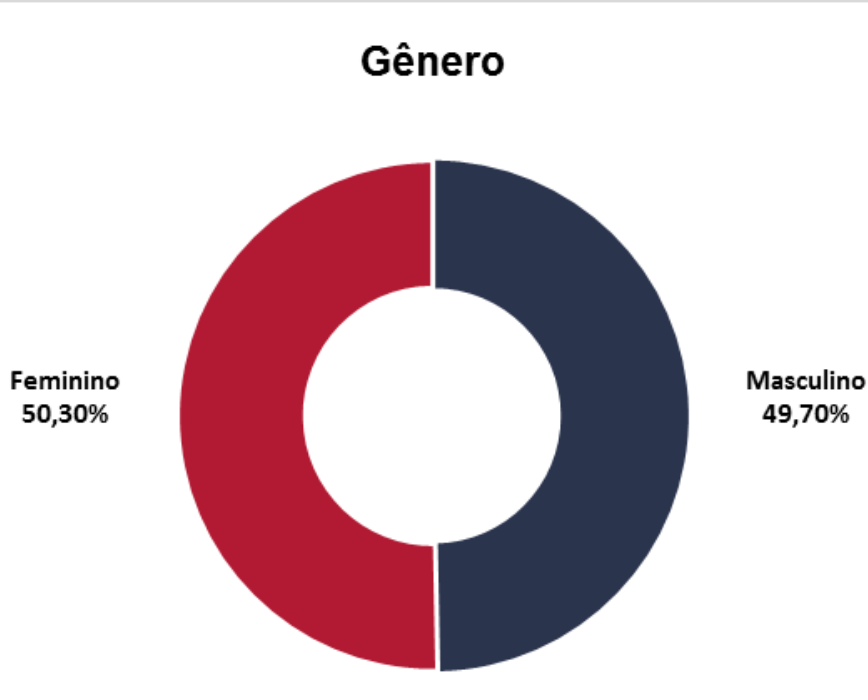

Figura A-2 - Distribuição dos respondentes por gênero 


\section{Questão 2: Faixa etária}

A segunda questão se refere a faixa etária dos respondentes. Os resultados estão apresentados na Tabela A-2 e na Figura A-3.

Tabela A-2 - Distribuição dos respondentes por faixa etária

\begin{tabular}{lcc}
\hline FAIXA ETÁRIA & Frequência & $\%$ \\
\hline até $\mathbf{2 4}$ anos & 407 & $14,2 \%$ \\
\hline de $\mathbf{2 5}$ a $\mathbf{3 0}$ anos & 685 & $23,9 \%$ \\
\hline de $\mathbf{3 1}$ a 39 anos & 734 & $25,6 \%$ \\
\hline de $\mathbf{4 0}$ a 49 anos & 523 & $18,3 \%$ \\
de 50 a 59 anos & 372 & $13,0 \%$ \\
maior que 60 anos & 142 & $5,0 \%$ \\
Total & 2863 & $100,0 \%$ \\
\hline
\end{tabular}

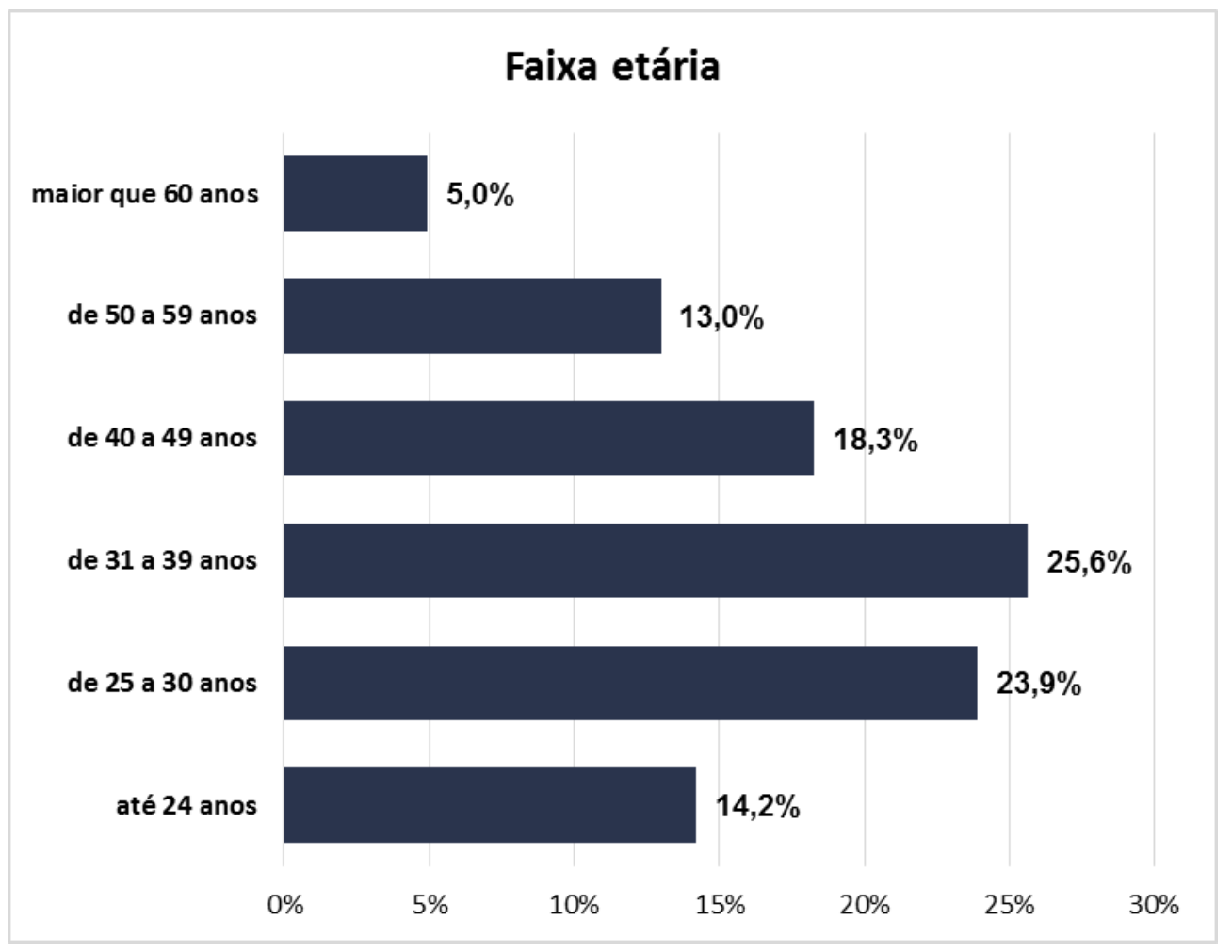

Figura A-3 - Distribuição dos respondentes por faixa etária 


\section{Questão 3: Cidade}

Na questão número 3, referente a cidade do respondente, foram identificados um total de 685 cidades diferentes. Na Tabela A-3 são apresentadas as 25 cidades com maior número de respondentes.

Tabela A-3 - Lista das 25 cidades com maior número de respondentes

\begin{tabular}{|c|c|c|c|}
\hline $\mathbf{N}$ & CIDADE & Frequência & $\%$ \\
\hline 1 & São Paulo & 159 & $5,55 \%$ \\
\hline 2 & Brasília & 120 & $4,19 \%$ \\
\hline 3 & Belo Horizonte & 115 & $4,02 \%$ \\
\hline 4 & Rio de Janeiro & 107 & $3,74 \%$ \\
\hline 5 & Porto Alegre & 82 & $2,86 \%$ \\
\hline 6 & Fortaleza & 82 & $2,86 \%$ \\
\hline 7 & Recife & 79 & $2,76 \%$ \\
\hline 8 & Salvador & 74 & $2,58 \%$ \\
\hline 9 & Curitiba & 59 & $2,06 \%$ \\
\hline 10 & Maceió & 57 & $1,99 \%$ \\
\hline 11 & Florianópolis & 48 & $1,68 \%$ \\
\hline 12 & Belém & 41 & $1,43 \%$ \\
\hline 13 & Goiânia & 39 & $1,36 \%$ \\
\hline 14 & Cuiabá & 35 & $1,22 \%$ \\
\hline 15 & Teresina & 34 & $1,19 \%$ \\
\hline 16 & São Carlos & 33 & $1,15 \%$ \\
\hline 17 & São Luís & 33 & $1,15 \%$ \\
\hline 18 & Joinville & 31 & $1,08 \%$ \\
\hline 19 & Londrina & 29 & $1,01 \%$ \\
\hline 20 & Natal & 27 & $0,94 \%$ \\
\hline 21 & Campinas & 26 & $0,91 \%$ \\
\hline 22 & Vitória & 22 & $0,77 \%$ \\
\hline 23 & João Pessoa & 22 & $0,77 \%$ \\
\hline 24 & Manaus & 22 & $0,77 \%$ \\
\hline 25 & Campo Grande & 21 & $0,73 \%$ \\
\hline 26 & Outras cidades & 1466 & $51,21 \%$ \\
\hline Total & & 2863 & $100,0 \%$ \\
\hline
\end{tabular}




\section{Questão 4: Estado}

A questão número 4 se refere ao estado do respondente. A Tabela A-4 lista o número de respondentes por estado.

Tabela A-4 - Frequência de participação por estado

\begin{tabular}{|c|c|c|c|}
\hline $\mathbf{N}$ & ESTADO & Frequência & $\%$ \\
\hline 1 & São Paulo & 541 & $18,90 \%$ \\
\hline 2 & Minas Gerais & 337 & $11,77 \%$ \\
\hline 3 & Rio de Janeiro & 205 & $7,16 \%$ \\
\hline 4 & Rio Grande do Sul & 199 & $6,95 \%$ \\
\hline 5 & Paraná & 178 & $6,22 \%$ \\
\hline 6 & Santa Catarina & 166 & $5,80 \%$ \\
\hline 7 & Bahia & 149 & $5,20 \%$ \\
\hline 8 & Distrito Federal & 126 & $4,40 \%$ \\
\hline 9 & Ceará & 119 & $4,16 \%$ \\
\hline 10 & Pernambuco & 116 & $4,05 \%$ \\
\hline 11 & Alagoas & 81 & $2,83 \%$ \\
\hline 12 & Goiás & 77 & $2,69 \%$ \\
\hline 13 & Pará & 77 & $2,69 \%$ \\
\hline 14 & Mato Grosso & 68 & $2,38 \%$ \\
\hline 15 & Espírito Santo & 60 & $2,10 \%$ \\
\hline 16 & Paraíba & 51 & $1,78 \%$ \\
\hline 17 & Maranhão & 50 & $1,75 \%$ \\
\hline 18 & Rio Grande do Norte & 49 & $1,71 \%$ \\
\hline 19 & Piauí & 40 & $1,40 \%$ \\
\hline 20 & Mato Grosso do Sul & 38 & $1,33 \%$ \\
\hline 21 & Tocantins & 31 & $1,08 \%$ \\
\hline 22 & Sergipe & 28 & $0,98 \%$ \\
\hline 23 & Amazonas & 24 & $0,84 \%$ \\
\hline 24 & Amapá & 21 & $0,73 \%$ \\
\hline 25 & Rondônia & 18 & $0,63 \%$ \\
\hline 26 & Roraima & 10 & $0,35 \%$ \\
\hline 27 & Acre & 4 & $0,14 \%$ \\
\hline Total & & 2863 & $100,0 \%$ \\
\hline
\end{tabular}




\section{Questão 5: Escolaridade}

Os resultados para a questão número 5 , referente a escolaridade, estão apresentados na Tabela A-5 e na Figura A-4.

Tabela A-5 - Distribuição dos respondentes por escolaridade

\begin{tabular}{lcc}
\hline ESCOLARIDADE & Frequência & $\%$ \\
\hline Ensino Fundamental Incompleto & 0 & $0,0 \%$ \\
Ensino Fundamental Completo & 2 & $0,1 \%$ \\
Ensino Médio Incompleto & 1 & $0,1 \%$ \\
\hline Ensino Médio Completo & 22 & $0,8 \%$ \\
\hline Ensino Técnico Incompleto & 6 & $0,2 \%$ \\
\hline Ensino Técnico Completo & 35 & $1,2 \%$ \\
Ensino Superior Incompleto & 443 & $15,4 \%$ \\
\hline Ensino Superior Completo & 2354 & $82,2 \%$ \\
\hline Total & 2863 & $100,0 \%$ \\
\hline
\end{tabular}

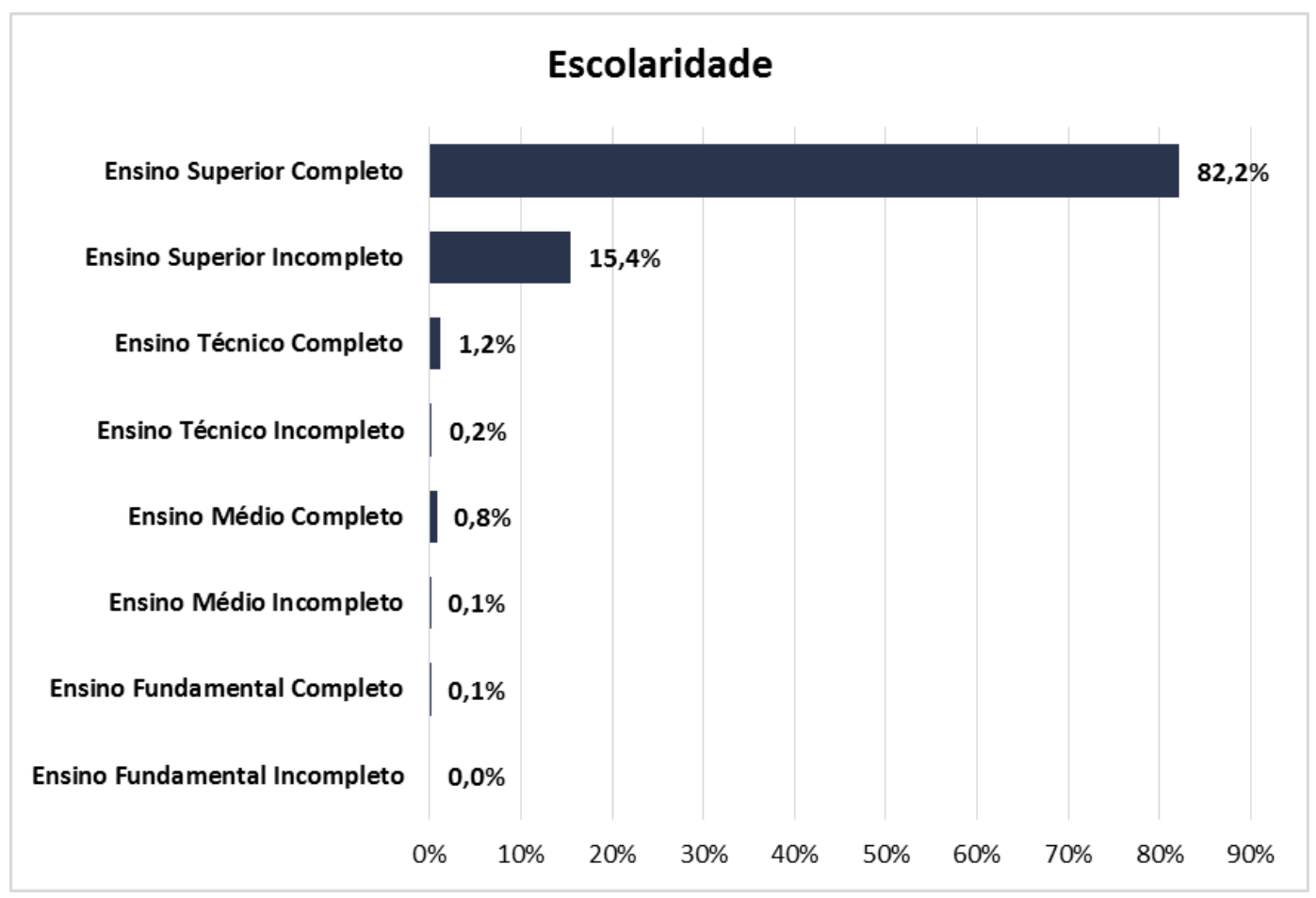

Figura A-4 - Distribuição dos respondentes por escolaridade 


\section{Escolaridade: Ensino Fundamental e Médio}

\section{Questão 6: Capacitação em Planejamento de Transportes}

Para a questão número 6 o respondente indicava a participação em cursos de capacitação em temas relacionados ao planejamento de transportes. A Tabela A-6 e Figura A-5 apresentam as respostas dos 25 participantes que possuem Ensino Fundamental ou Médio (completo e incompleto).

Tabela A-6 - Distribuição das respostas para a questão 6: "Você já participou de alguma capacitação em temas relacionados ao planejamento de transportes?"

\begin{tabular}{lcc}
\hline TIPO DE CURSO & Frequência & $\%$ \\
\hline Curso presencial & 5 & $20,0 \%$ \\
\hline Curso à distância & 8 & $32,0 \%$ \\
\hline Workshop & 1 & $4,0 \%$ \\
\hline Seminário & 6 & $24,0 \%$ \\
\hline Congresso & 4 & $16,0 \%$ \\
\hline Palestra & 13 & $52,0 \%$ \\
\hline Projeto de pesquisa & 5 & $20,0 \%$ \\
\hline Total (ensino fundamental e médio) & 25 & $100,0 \%$ \\
\hline
\end{tabular}

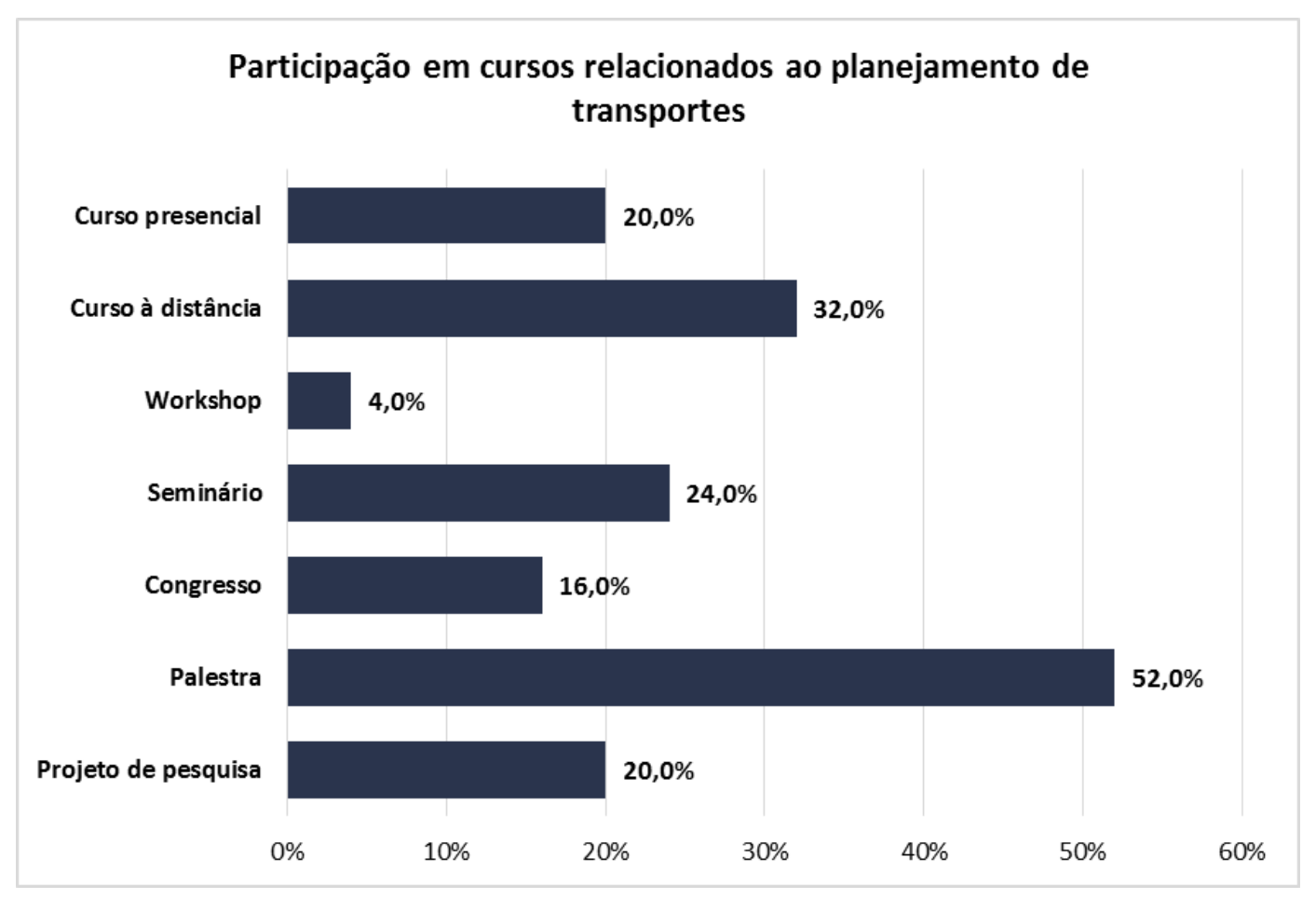

Figura A-5 - Distribuição das respostas para a questão 6 


\section{Escolaridade: Ensino Técnico}

\section{Questão 8: Curso Técnico}

A Tabela A-7 apresenta a lista dos cursos dos participantes da pesquisa com ensino técnico (completo e incompleto).

Tabela A-7 - Lista dos cursos dos respondentes com ensino técnico

\begin{tabular}{lcc}
\hline CURSO TÉCNICO & Frequência & $\%$ \\
\hline Técnico Agrícola & 1 & $2,4 \%$ \\
\hline Técnico em Administração & 2 & $4,9 \%$ \\
\hline Técnico em Agrimensura & 2 & $4,9 \%$ \\
\hline Técnico em Contabilidade & 8 & $19,5 \%$ \\
\hline Técnico em Controle Ambiental & 1 & $2,4 \%$ \\
\hline Técnico em Desenho Técnico & 1 & $2,4 \%$ \\
\hline Técnico em Edificações & 12 & $29,3 \%$ \\
\hline Técnico em Estradas & 2 & $4,9 \%$ \\
\hline Técnico em Geodésia e Cartografia & 1 & $2,4 \%$ \\
\hline Técnico em Geoprocessamento & 1 & $2,4 \%$ \\
\hline Técnico em Química Industrial & 1 & $2,4 \%$ \\
\hline Técnico em Saneamento & 2 & $4,9 \%$ \\
\hline Técnico em Segurança do Trabalho & 2 & $4,9 \%$ \\
\hline Técnico em Segurança e Higiene do Trabalho & 1 & $2,4 \%$ \\
\hline Técnico em Transporte e Trânsito & 1 & $2,4 \%$ \\
\hline Técnico em Transportes & 1 & $2,4 \%$ \\
\hline Técnico Industrial de Edificações & 1 & $2,4 \%$ \\
\hline Não informado & 1 & $2,40 \%$ \\
\hline Total & 41 & $100,0 \%$ \\
\hline
\end{tabular}


Questão 9: Ano de conclusão do curso técnico

A Tabela A-8 e a Figura A-6 apresentam os dados referentes ao ano de conclusão do curso técnico.

Tabela A-8 - Ano de conclusão do ensino técnico

\begin{tabular}{lcc}
\hline ANO DE CONCLUSÃO & Frequência & $\%$ \\
\hline anterior a $\mathbf{1 9 8 0}$ & 3 & $7,3 \%$ \\
\hline de $\mathbf{1 9 8 0}$ a 1989 & 1 & $2,4 \%$ \\
\hline de $\mathbf{1 9 9 0}$ a 1999 & 6 & $14,6 \%$ \\
\hline de $\mathbf{2 0 0 0}$ a 2009 & 4 & $9,8 \%$ \\
de $\mathbf{2 0 1 0}$ a 2017 & 24 & $58,5 \%$ \\
\hline a partir de 2017 & 3 & $7,3 \%$ \\
\hline Total & 41 & $100,0 \%$ \\
\hline
\end{tabular}

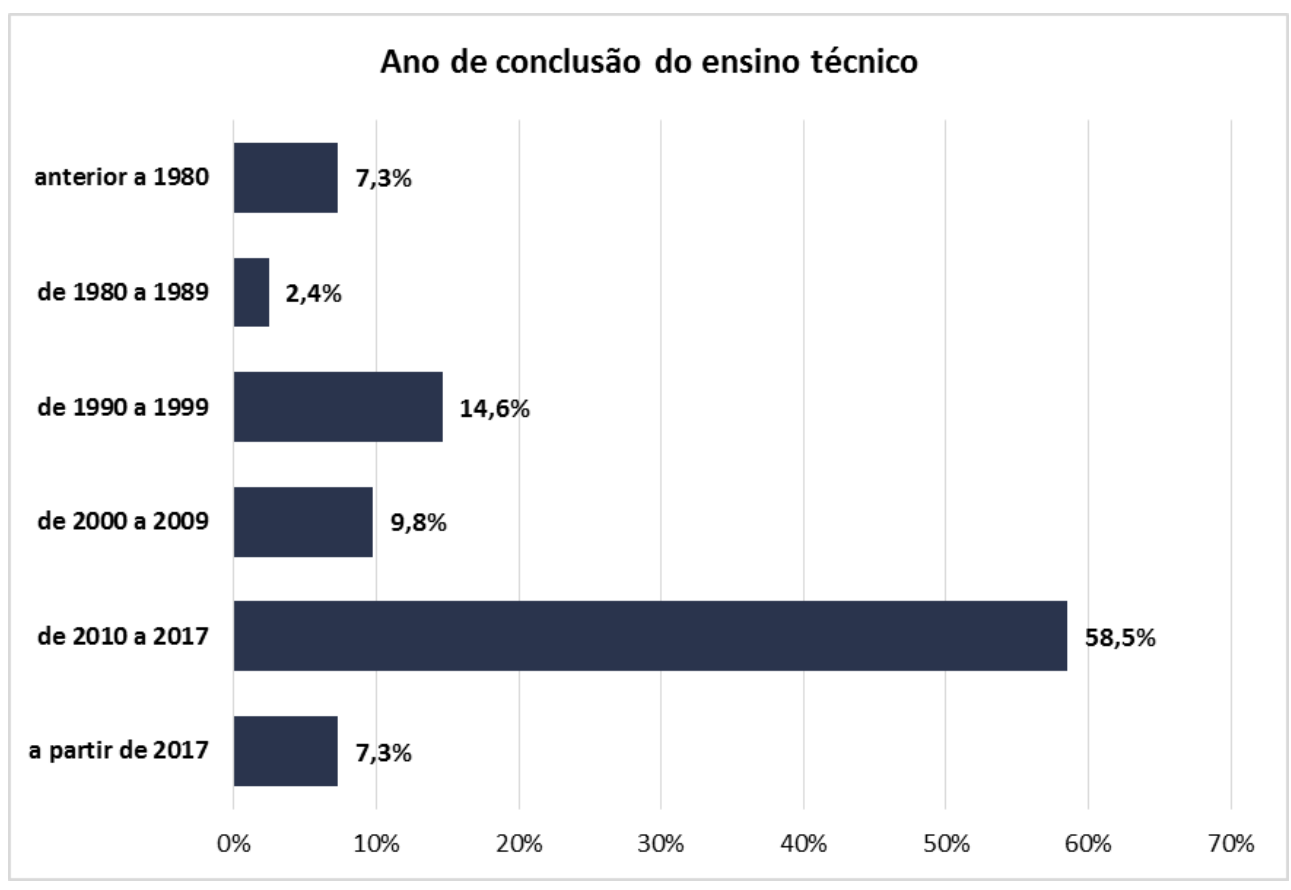

Figura A-6 - Ano de conclusão do ensino técnico 


\section{Questão 10: Capacitação em Planejamento de Transportes}

Para a questão número 10 , os respondentes com ensino técnico indicavam a participação em cursos de capacitação em temas relacionados ao planejamento de transportes. A Tabela A-9 e Figura A-10 apresentam as respostas dos 41 participantes com curso técnico (completo e incompleto).

Tabela A-9 - Distribuição das respostas para a questão 10: "Você já participou de alguma capacitação em temas relacionados ao planejamento de transportes?"

\begin{tabular}{lcc}
\hline TIPO DE CURSO & Frequência & $\%$ \\
\hline Curso presencial & 7 & $17,1 \%$ \\
Curso à distância & 16 & $39,0 \%$ \\
Workshop & 3 & $7,3 \%$ \\
\hline Seminário & 8 & $19,5 \%$ \\
Congresso & 1 & $2,4 \%$ \\
Palestra & 11 & $26,8 \%$ \\
Projeto de pesquisa & 0 & $0,0 \%$ \\
\hline Total (ensino técnico) & 41 & $100,0 \%$ \\
\hline
\end{tabular}

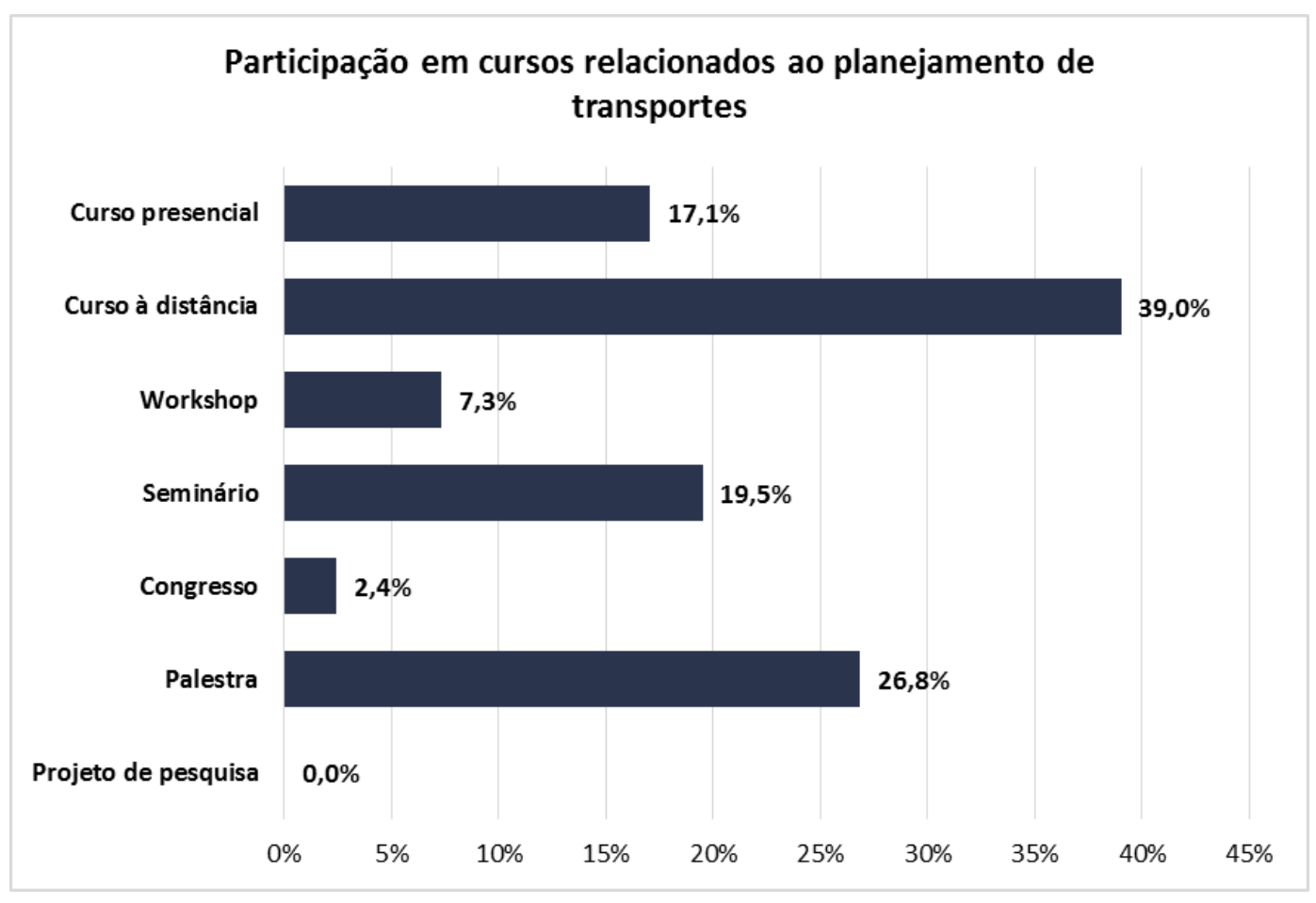

Figura A-7 - Distribuição das respostas para a questão 10 


\section{Escolaridade: Ensino Superior}

\section{Questão 12: Curso de Graduação}

No total, 2797 respondentes indicaram como escolaridade ensino superior (completo ou incompleto). A Tabela A-10 apresenta a lista dos principais cursos de graduação dos participantes. Na apresentação dos resultados, foram listados os 23 cursos com maior frequência entre os respondentes.

Tabela A-10 - Lista dos principais cursos de graduação dos respondentes

\begin{tabular}{|c|c|c|c|}
\hline $\mathbf{N}$ & CURSO DE GRADUAÇÃO & Frequência & $\%$ \\
\hline 1 & Arquitetura e Urbanismo & 932 & $33,3 \%$ \\
\hline 2 & Engenharia Civil & 569 & $20,3 \%$ \\
\hline 3 & Geografia & 175 & $6,3 \%$ \\
\hline 4 & Administração & 102 & $3,6 \%$ \\
\hline 5 & Serviço Social & 102 & $3,6 \%$ \\
\hline 6 & Direito & 94 & $3,4 \%$ \\
\hline 7 & Engenharia Ambiental & 81 & $2,9 \%$ \\
\hline 8 & Engenharias (diversas) & 66 & $2,8 \%$ \\
\hline 9 & Tecnólogos (diversos) & 46 & $1,9 \%$ \\
\hline 10 & Gestão Ambiental & 46 & $1,6 \%$ \\
\hline 11 & Economia & 37 & $1,3 \%$ \\
\hline 12 & Engenharia de Produção & 35 & $1,3 \%$ \\
\hline 13 & Engenharia Cartográfica & 31 & $1,1 \%$ \\
\hline 14 & Pedagogia & 22 & $0,8 \%$ \\
\hline 15 & Ciências Biológicas & 21 & $0,8 \%$ \\
\hline 16 & Engenharia Mecânica & 21 & $0,8 \%$ \\
\hline 17 & Engenharia Sanitária & 21 & $0,8 \%$ \\
\hline 18 & Gestão Pública & 21 & $0,8 \%$ \\
\hline 19 & Engenharia Elétrica & 20 & $0,7 \%$ \\
\hline 20 & Agronomia & 18 & $0,6 \%$ \\
\hline 21 & Contabilidade & 18 & $0,6 \%$ \\
\hline 22 & Psicologia & 18 & $0,6 \%$ \\
\hline 23 & Outros cursos & 301 & $10,8 \%$ \\
\hline Total & & 2797 & $100,0 \%$ \\
\hline
\end{tabular}




\section{Questão 13: Ano de conclusão do curso de graduação}

A Tabela A-11 e a Figura A-8 apresentam os dados referentes ao ano de conclusão dos respondentes com ensino superior.

Tabela A-11 - Ano de conclusão do curso de graduação

\begin{tabular}{lcc}
\hline ANO DE CONCLUSÃO & Frequência & $\%$ \\
\hline anterior a 1980 & 83 & $3,0 \%$ \\
\hline de $\mathbf{1 9 8 0}$ a 1989 & 221 & $7,9 \%$ \\
\hline de $\mathbf{1 9 9 0}$ a 1999 & 309 & $11,0 \%$ \\
\hline de 2000 a 2009 & 669 & $23,9 \%$ \\
de 2010 a 2017 & 1265 & $45,2 \%$ \\
\hline a partir de 2017 & 228 & $8,2 \%$ \\
\hline Não Informou/lncompleto & 22 & $0,8 \%$ \\
\hline Total & 2797 & $100,0 \%$ \\
\hline
\end{tabular}



Figura A-8 - Ano de conclusão do curso de graduação 


\section{Questão 14: Pós-graduação}

Em relação à participação em cursos de pós-graduação (concluídos ou em andamento), a Tabela A-12 e a Figura A-9 resumem os dados dos respondentes por curso.

Tabela A-12 - Participação dos respondentes em cursos de pós-graduação

\begin{tabular}{lcc}
\hline PÓS-GRADUAÇÃo & Frequência & $\%$ \\
\hline Especialização & 1146 & $41,0 \%$ \\
Mestrado & 929 & $33,2 \%$ \\
Doutorado & 355 & $12,7 \%$ \\
Total (ensino superior) & 2797 & $100,0 \%$ \\
\hline
\end{tabular}

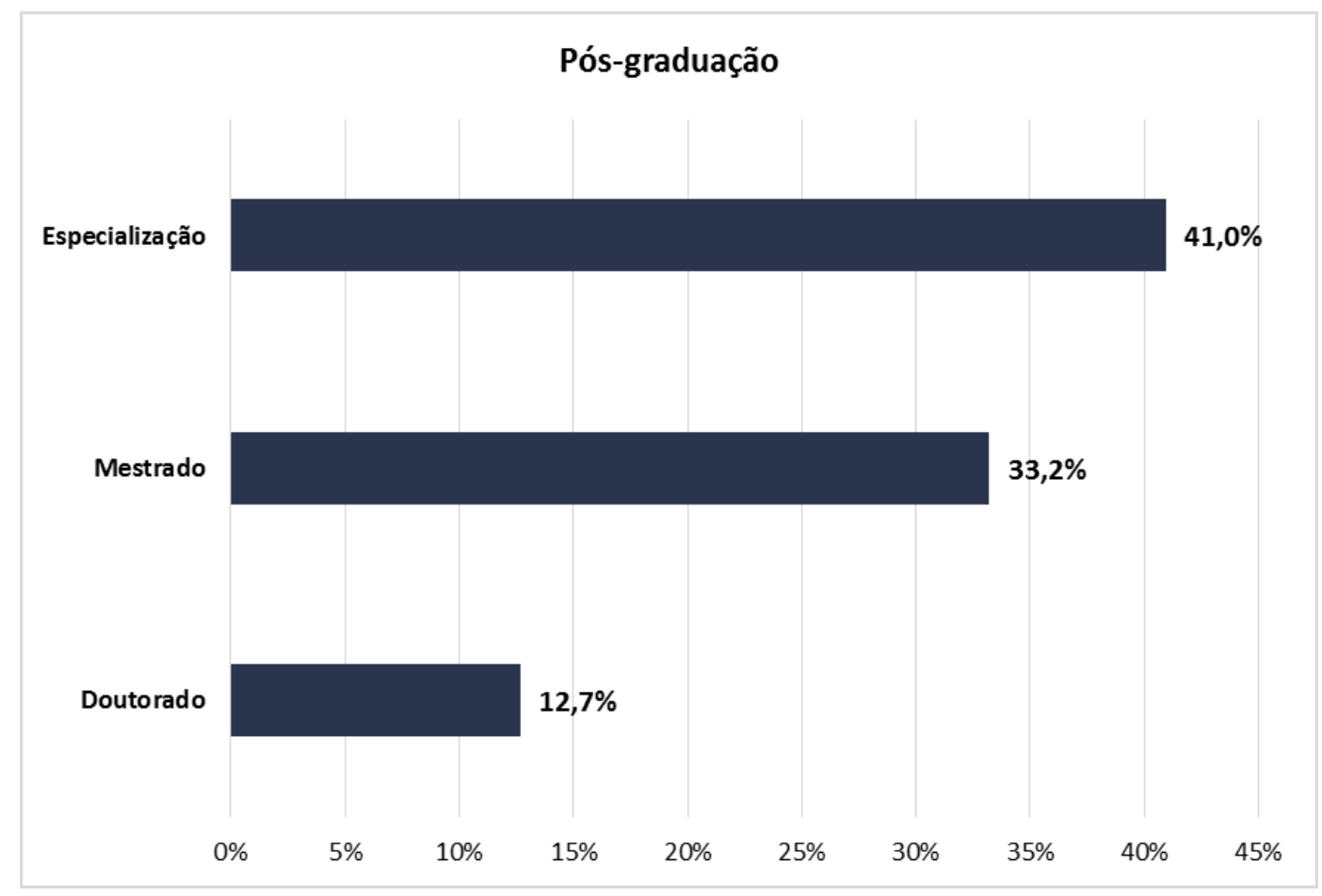

Figura A-9 - Participação dos respondentes em cursos de pós-graduação 


\section{Questão 15: Capacitação em Planejamento de Transportes}

Para a questão número 15, os respondentes com ensino superior indicavam os cursos de capacitação em temas relacionados ao planejamento de transportes que já haviam participado. A Tabela A-13 e a Figura A-10 apresentam as respostas dos 2797 participantes com ensino superior (completo e incompleto).

Tabela A-13 - Distribuição das respostas para a questão 15: "Você já participou de alguma capacitação em temas relacionados ao planejamento de transportes?"

\begin{tabular}{lcc}
\hline TIPO DE CURSO & Frequência & $\%$ \\
\hline Curso presencial & 567 & $20,3 \%$ \\
Curso à distância & 903 & $32,3 \%$ \\
Workshop & 509 & $18,2 \%$ \\
Seminário & 906 & $32,4 \%$ \\
Congresso & 615 & $22,0 \%$ \\
\hline Palestra & 1203 & $43,0 \%$ \\
\hline Projeto de pesquisa & 479 & $17,1 \%$ \\
\hline Total (ensino superior) & 567 & $20,3 \%$ \\
\hline
\end{tabular}

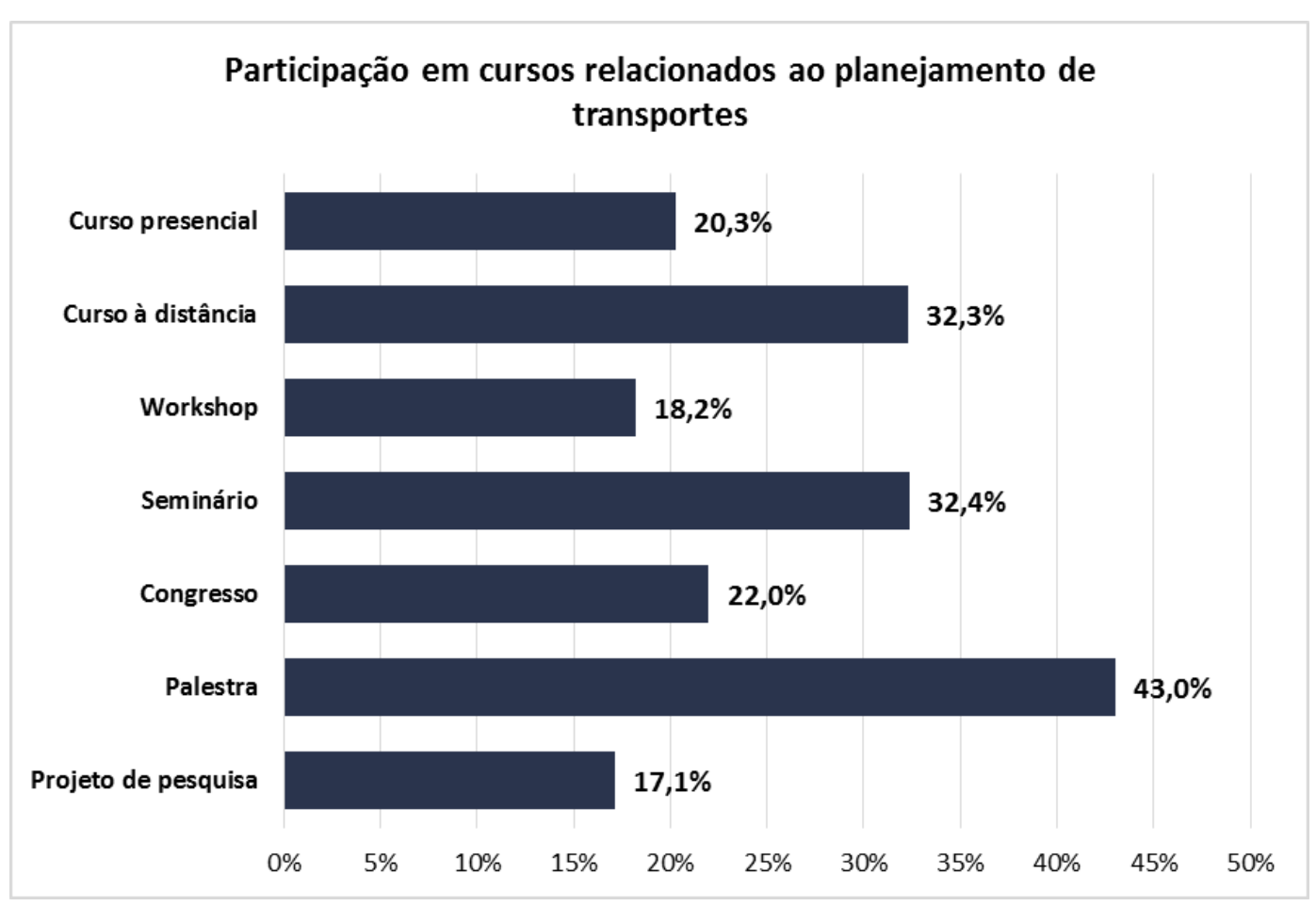

Figura A-10 - Distribuição das respostas para a questão 15: "Você já participou de alguma capacitação em temas relacionados ao planejamento de transportes?" 


\section{PARTE II: PERFIL PROFISSIONAL DO RESPONDENTE}

As questões da segunda parte do questionário são referentes ao perfil profissional do respondente. A Figura A-11 apresenta o diagrama do segundo bloco de questões. Os resultados de cada um dos itens estão resumidos na sequência do texto.

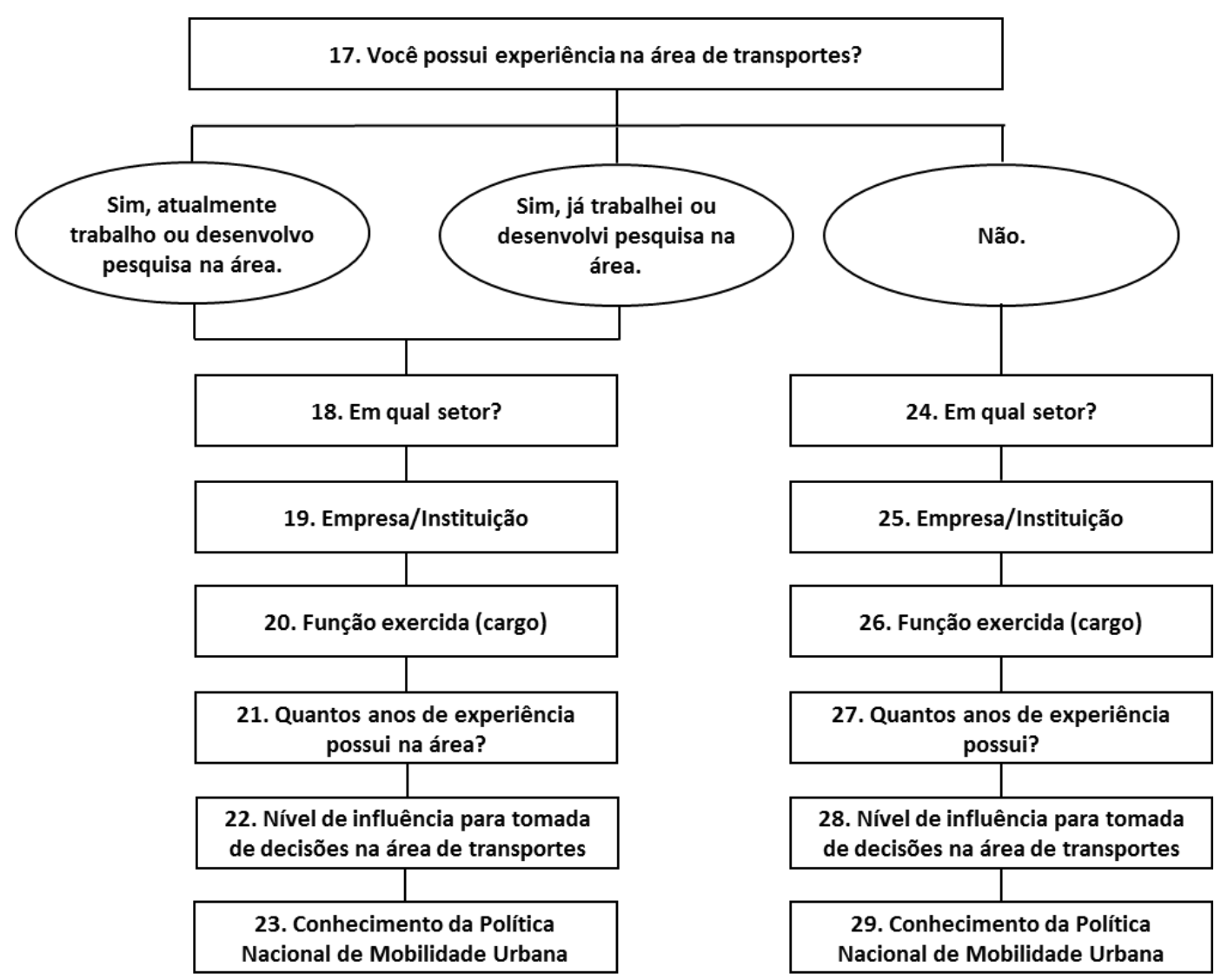

Figura A-11 - Diagrama do segundo bloco de questões 


\section{Questão 17: Experiência na Área de Transportes}

Para caracterizar o perfil profissional dos respondentes, a questão número 17 perguntava sobre a experiência profissional na área de transportes. A Tabela A-14 e a Figura A-12 apresentam a distribuição das respostas.

Tabela A-14 - Distribuição das respostas para a Questão 17: "Você possui experiência na área de transportes?"

\begin{tabular}{lcc}
\hline $\begin{array}{l}\text { EXPERIÊNCIA NA ÁREA DE } \\
\text { TRANSPORTES }\end{array}$ & Frequência & $\%$ \\
\hline $\begin{array}{l}\text { Sim, atualmente trabalho ou } \\
\text { desenvolvo pesquisa na área. }\end{array}$ & 613 & $21,4 \%$ \\
\hline $\begin{array}{l}\text { Sim, já trabalhei ou desenvolvi } \\
\text { pesquisa na área. }\end{array}$ & 525 & $18,3 \%$ \\
Não. & 1725 & $60,3 \%$ \\
\hline Total & 2863 & $100,0 \%$ \\
\hline
\end{tabular}

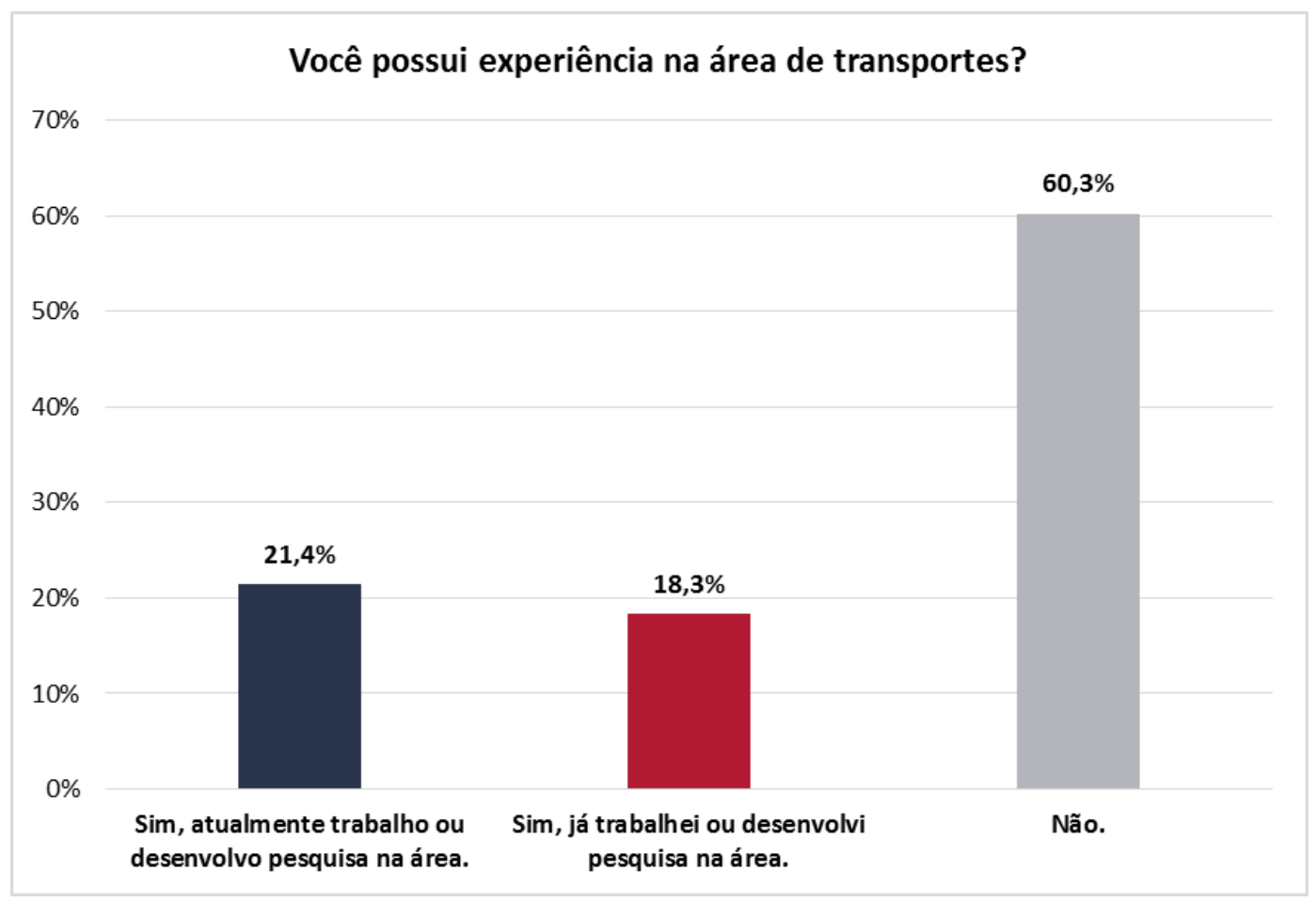

Figura A-12 - Experiência na área de transportes 


\section{Setor}

As questões 18 e 24 se referem ao setor em que o respondente trabalha ou trabalhou. A distribuição das respostas está agrupada de acordo com a experiência indicada para a área de transportes, conforme Tabela A-15 e Figura A-13.

Tabela A-15 - Setor de atuação dos respondentes

\begin{tabular}{lcccc}
\hline EM QUAL SETOR VOCÊ & $\begin{array}{c}\text { Sim, } \\
\text { atualmente } \\
\text { trabalho ou } \\
\text { desenvolvo } \\
\text { pesquisa na } \\
\text { área. }\end{array}$ & $\begin{array}{c}\text { Sim, já } \\
\text { trabalhei ou } \\
\text { desenvolvi } \\
\text { pesquisa na } \\
\text { área. }\end{array}$ & Não. & Total \\
\hline Academia (estudante, & 347 & 247 & 494 & 1088 \\
professor, pesquisador) & $(57 \%)$ & $(47 \%)$ & $(29 \%)$ & $(38 \%)$ \\
Setor público & 294 & 247 & 830 & 1371 \\
Setor privado & $(48 \%)$ & $(47 \%)$ & $(48 \%)$ & $(48 \%)$ \\
Total & 133 & 104 & 361 & 598 \\
& $(22 \%)$ & $(20 \%)$ & $(21 \%)$ & $(21 \%)$ \\
\hline & 613 & 525 & 1725 & 2863 \\
& $(100 \%)$ & $(100 \%)$ & $(100 \%)$ & $(100 \%)$ \\
\hline
\end{tabular}

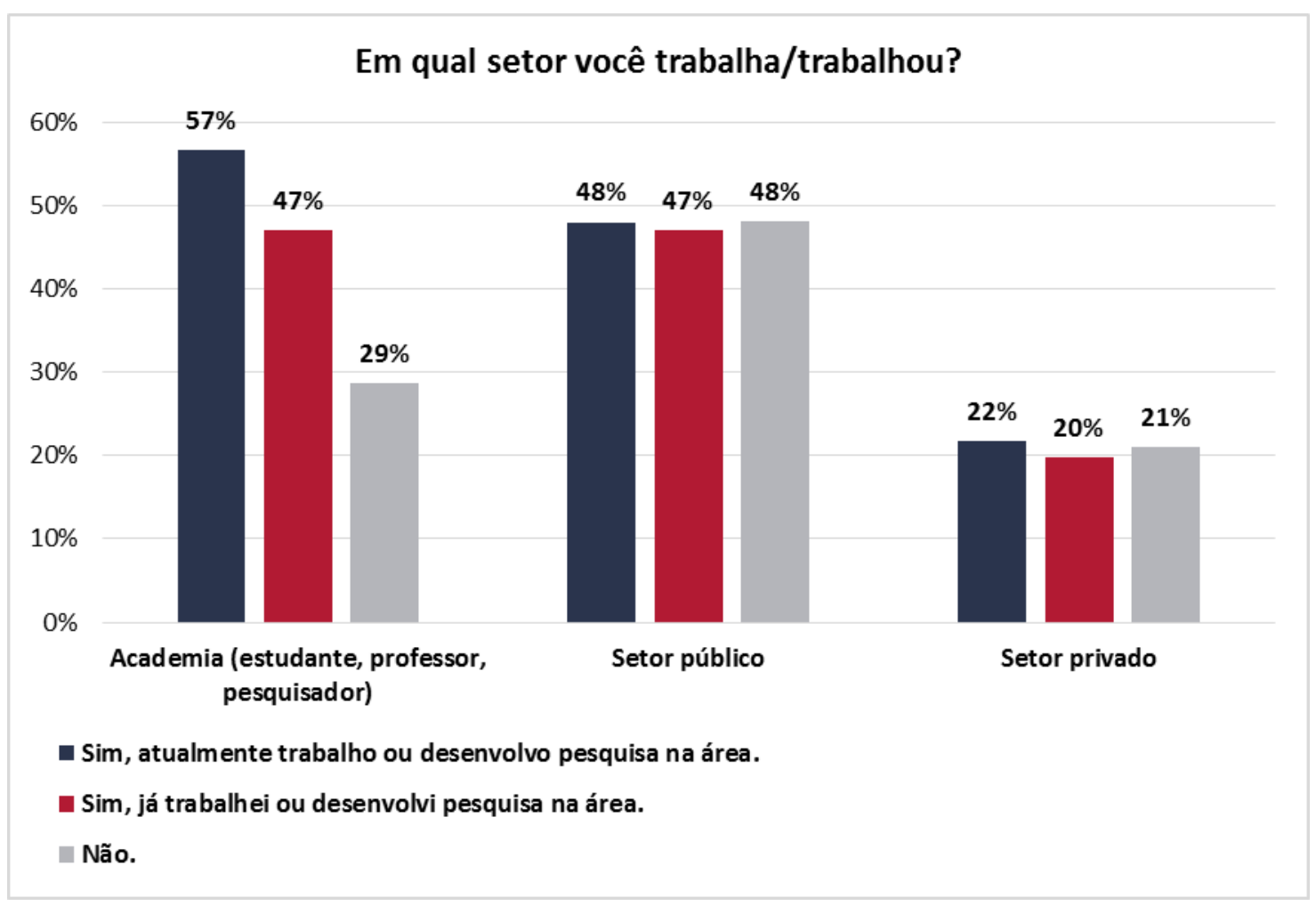

Figura A-13 - Setor de atuação dos respondentes 


\section{Função exercida (cargo)}

As questões 20 e 26 se referem as funções exercidas (cargos) em que os respondentes trabalham ou trabalharam. As respostas foram agrupadas de acordo com a experiência indicada para a área de transportes, conforme Tabela A-16 e Figura A-14.

Tabela A-16 - Funções exercidas (cargos) dos respondentes

\begin{tabular}{lcccc}
\hline QUAL A FUNÇÃo & $\begin{array}{c}\text { Sim, } \\
\text { atualmente } \\
\text { trabalho ou } \\
\text { desenvolvo } \\
\text { pesquisa na } \\
\text { área. }\end{array}$ & $\begin{array}{c}\text { Sim, já } \\
\text { trabalhei ou } \\
\text { desenvolvi } \\
\text { pesquisa na } \\
\text { área. }\end{array}$ & Não. & Total \\
\hline $\begin{array}{l}\text { Gestor (diretor, secretário, } \\
\text { prefeito, ...) }\end{array}$ & 107 & 79 & 168 & \\
\hline $\begin{array}{l}\text { Técnico (arquiteto, } \\
\text { engenheiro, }\end{array}$ & $(17 \%)$ & $(15 \%)$ & $(10 \%)$ & $(12 \%)$ \\
administrador, técnico, ...) & $(49 \%)$ & 218 & 785 & 1306 \\
Pesquisador (professor, & 358 & $(42 \%)$ & $(46 \%)$ & $(46 \%)$ \\
estudante, ...) & $(58 \%)$ & $(50 \%)$ & $(26 \%)$ & 1114 \\
Total & 613 & 525 & 1725 & 2863 \\
\hline
\end{tabular}

Nos projetos em que você atua/atuou, qual a função exercida?

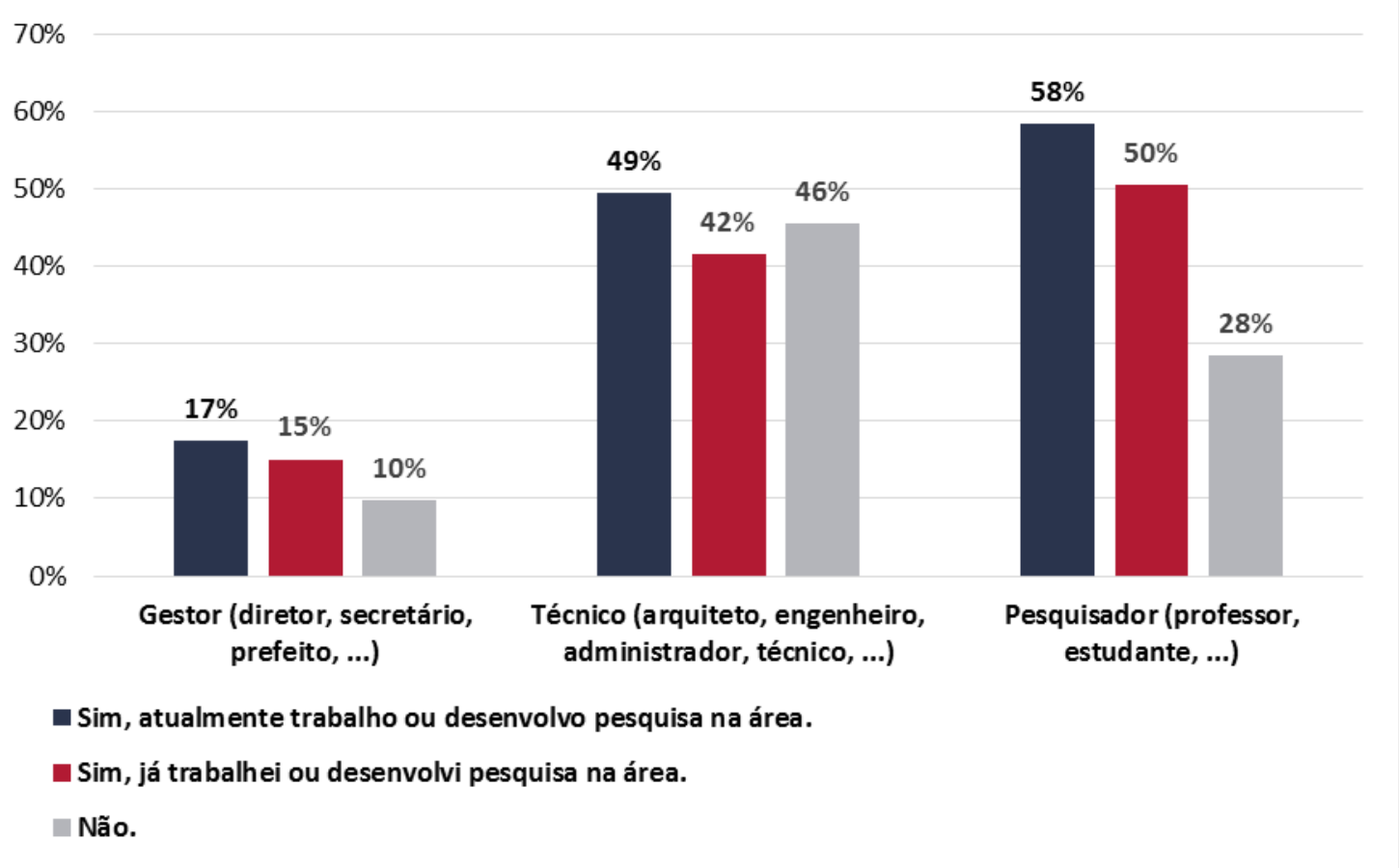

Figura A-14 - Funções exercidas (cargos) dos respondentes 


\section{Tempo de experiência}

As questões 21 e 27 se referem ao tempo de experiência dos respondentes. A distribuição das respostas está agrupada de acordo com a experiência indicada para a área de transportes, conforme Tabela A-17 e Figura A-15.

Tabela A-17 - Tempo de experiência dos respondentes

\begin{tabular}{lcccc}
\hline TEMPO DE & $\begin{array}{c}\text { Sim, } \\
\text { atualmente } \\
\text { trabalho ou } \\
\text { desenvolvo } \\
\text { pesquisa na } \\
\text { área. }\end{array}$ & $\begin{array}{c}\text { Sim, já } \\
\text { trabalhei ou } \\
\text { desenvolvi } \\
\text { pesquisa na } \\
\text { área. }\end{array}$ & Não. & Total \\
\hline até $\mathbf{5}$ anos & 307 & 396 & 851 & 1554 \\
de $\mathbf{6}$ a 10 anos & $(50 \%)$ & $(65 \%)$ & $(49 \%)$ & $(54 \%)$ \\
\hline de $\mathbf{1 1}$ a 15 anos & 126 & 76 & 341 & 543 \\
maior que 15 anos & $(21 \%)$ & $(12 \%)$ & $(20 \%)$ & $(19 \%)$ \\
\hline & $(82$ & 24 & 164 & 240 \\
Total & $(21 \%)$ & $(4 \%)$ & $(10 \%)$ & $(8 \%)$ \\
\hline
\end{tabular}

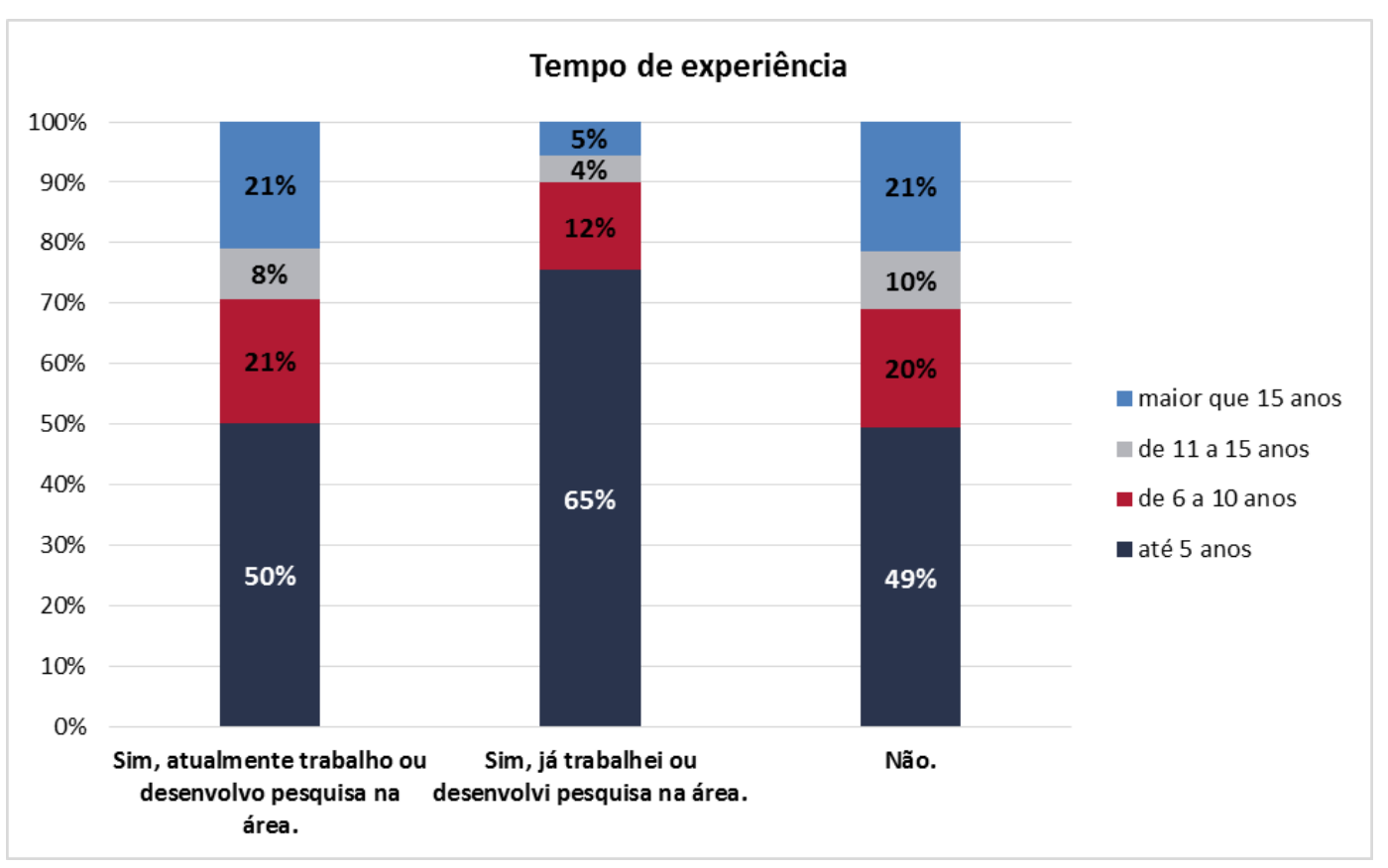

Figura A-15 - Tempo de experiência dos respondentes 


\section{Nível de influência para tomada de decisão}

As questões 22 e 28 traziam a seguinte pergunta: "Considerando o sua atual posição de trabalho, como você avalia seu nível de influência para tomada de decisão em questões relacionadas ao planejamento de transportes?". A Tabela A-18 e Figura A-16 apresentam a distribuição dos resultados, agrupando as respostas de acordo com a experiência indicada para a área de transportes.

Tabela A-18 - Nível de influência para tomada de decisão dos respondentes

\begin{tabular}{lcccc}
\hline NívEL DE & $\begin{array}{c}\text { Sim, } \\
\text { atualmente } \\
\text { trabalho ou } \\
\text { desenvolvo } \\
\text { pesquisa na } \\
\text { área. }\end{array}$ & $\begin{array}{c}\text { Sim, já } \\
\text { trabalhei ou } \\
\text { desenvolvi } \\
\text { pesquisa na } \\
\text { área. }\end{array}$ & Não. & Total \\
\hline Não possui influência & 84 & 121 & 661 & 866 \\
& $(14 \%)$ & $(23 \%)$ & $(38 \%)$ & $(30 \%)$ \\
\hline Influência baixa & 206 & 198 & 601 & 1005 \\
& $(34 \%)$ & $(38 \%)$ & $(35 \%)$ & $(35 \%)$ \\
\hline Influência moderada & 255 & 183 & 387 & 825 \\
Influência alta & $(42 \%)$ & $(35 \%)$ & $(22 \%)$ & $(29 \%)$ \\
\hline Total & 68 & 23 & 76 & 167 \\
\hline & $(11 \%)$ & $(4 \%)$ & $(4 \%)$ & $(6 \%)$ \\
\hline & 613 & 525 & 1725 & 2863 \\
& $(100 \%)$ & $(100 \%)$ & $(100 \%)$ & $(100 \%)$ \\
\hline
\end{tabular}

Considerando o sua atual posição de trabalho, como você avalia seu nível de influência para tomada de decisão em questões relacionadas ao planejamento de transportes?

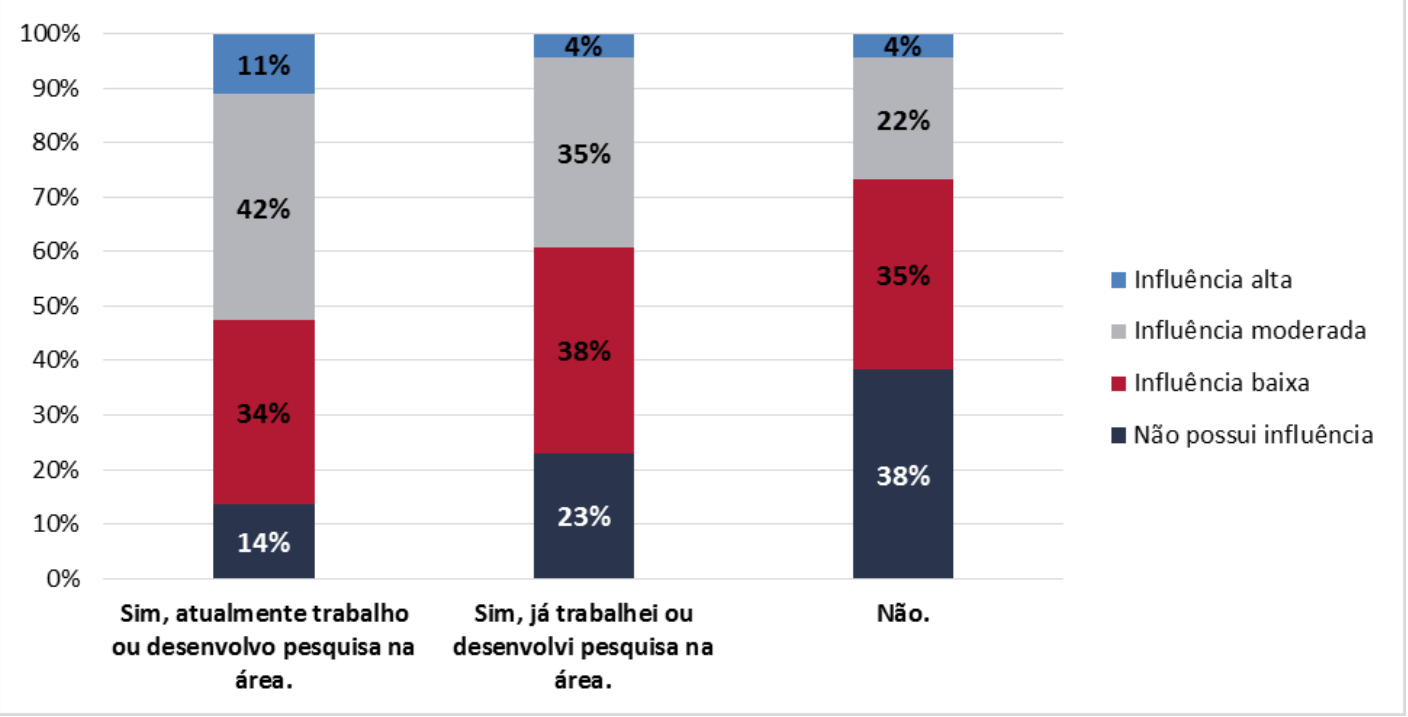

Figura A-16 - Nível de influência para tomada de decisão dos respondentes 


\section{Nível de conhecimento da Política Nacional de Mobilidade Urbana}

A última questão sobre o perfil profissional do respondente era sobre o nível de conhecimento da Política Nacional de Mobilidade Urbana (Lei oํ 12.587/2012). A Tabela A-19 e Figura A-17 apresentam a distribuição dos resultados, agrupando as respostas de acordo com a experiência indicada para a área de transportes.

Tabela A-19 - Nível de conhecimento da Política Nacional de Mobilidade Urbana (PNMU)

\begin{tabular}{lcccc}
\hline $\begin{array}{l}\text { NívEL DE } \\
\text { CONHECIMENTO DA } \\
\text { POLÍTICA NACIONAL DE } \\
\text { MOBILIDADE URBANA }\end{array}$ & $\begin{array}{c}\text { Sim, } \\
\text { atualmente } \\
\text { trabalho ou } \\
\text { desenvolvo } \\
\text { pesquisa na } \\
\text { área. }\end{array}$ & $\begin{array}{c}\text { Sim, já } \\
\text { trabalhei ou } \\
\text { desenvolvi } \\
\text { pesquisa na } \\
\text { área. }\end{array}$ & Não. & Total \\
\hline Sim, conheço & 259 & 157 & & \\
detalhadamente o texto. & $(42 \%)$ & $(30 \%)$ & 143 & 559 \\
Sim, conheço & 279 & 281 & $(8 \%)$ & $(20 \%)$ \\
superficialmente o texto. & $(46 \%)$ & $(54 \%)$ & 869 & 1429 \\
Já ouvi falar, mas ainda & 63 & 72 & $(50 \%)$ & $(50 \%)$ \\
não li o texto. & $(10 \%)$ & $(14 \%)$ & 533 & 668 \\
Não conheço. & 12 & 15 & $(31 \%)$ & $(23 \%)$ \\
\hline Total & $(2 \%)$ & $(3 \%)$ & 180 & 207 \\
\hline
\end{tabular}

Você conhece a Política Nacional de Mobilidade Urbana (Lei no 12.587/2012)?

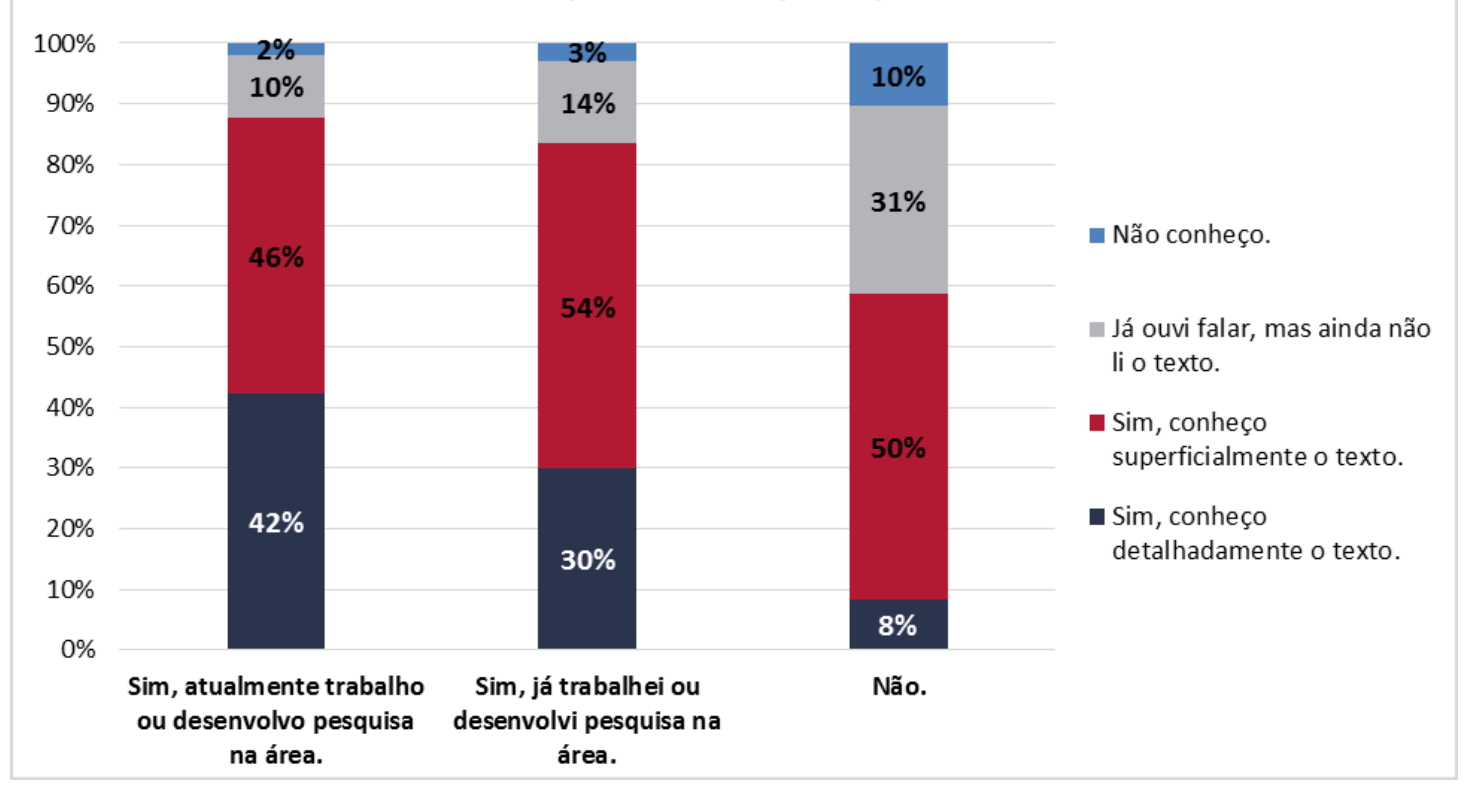

Figura A-17 - Nível de conhecimento da Política Nacional de Mobilidade Urbana 


\section{PARTE III: FREQUÊNCIA DE UTILIZAÇÃO DOS MODOS DE TRANSPORTE}

A terceira parte do questionário perguntava sobre a frequência de utilização dos modos de transporte nos deslocamentos diários. A Tabela A-20 e Figura A-18 apresentam a distribuição dos dados entre os respondentes.

Tabela A-20 - Frequência de utilização dos modos de transporte nos deslocamentos diários

\begin{tabular}{lccccc}
\hline $\begin{array}{l}\text { MODO DE } \\
\text { TRANSPORTE }\end{array}$ & Sempre & $\begin{array}{c}\text { Quase } \\
\text { sempre }\end{array}$ & Às vezes & Raramente & Nunca \\
\hline A pé & 750 & 546 & 853 & 538 & 176 \\
& $(26,2 \%)$ & $(19,1 \%)$ & $(29,8 \%)$ & $(18,8 \%)$ & $(6,1 \%)$ \\
Bicicleta & 65 & 128 & 377 & 592 & 1701 \\
& $(2,3 \%)$ & $(4,5 \%)$ & $(13,2 \%)$ & $(20,7 \%)$ & $(59,4 \%)$ \\
Carro & 989 & 748 & 635 & 384 & 107 \\
& $(34,5 \%)$ & $(26,1 \%)$ & $(22,2 \%)$ & $(13,4 \%)$ & $(3,7 \%)$ \\
Motocicleta & 109 & 143 & 168 & 297 & 2146 \\
& $(3,8 \%)$ & $(5,0 \%)$ & $(5,9 \%)$ & $(10,4 \%)$ & $(75,0 \%)$ \\
Transporte público & 519 & 386 & 606 & 795 & 557 \\
& $(18,1 \%)$ & $(13,5 \%)$ & $(21,2 \%)$ & $(27,8 \%)$ & $(19,5 \%)$ \\
\hline
\end{tabular}

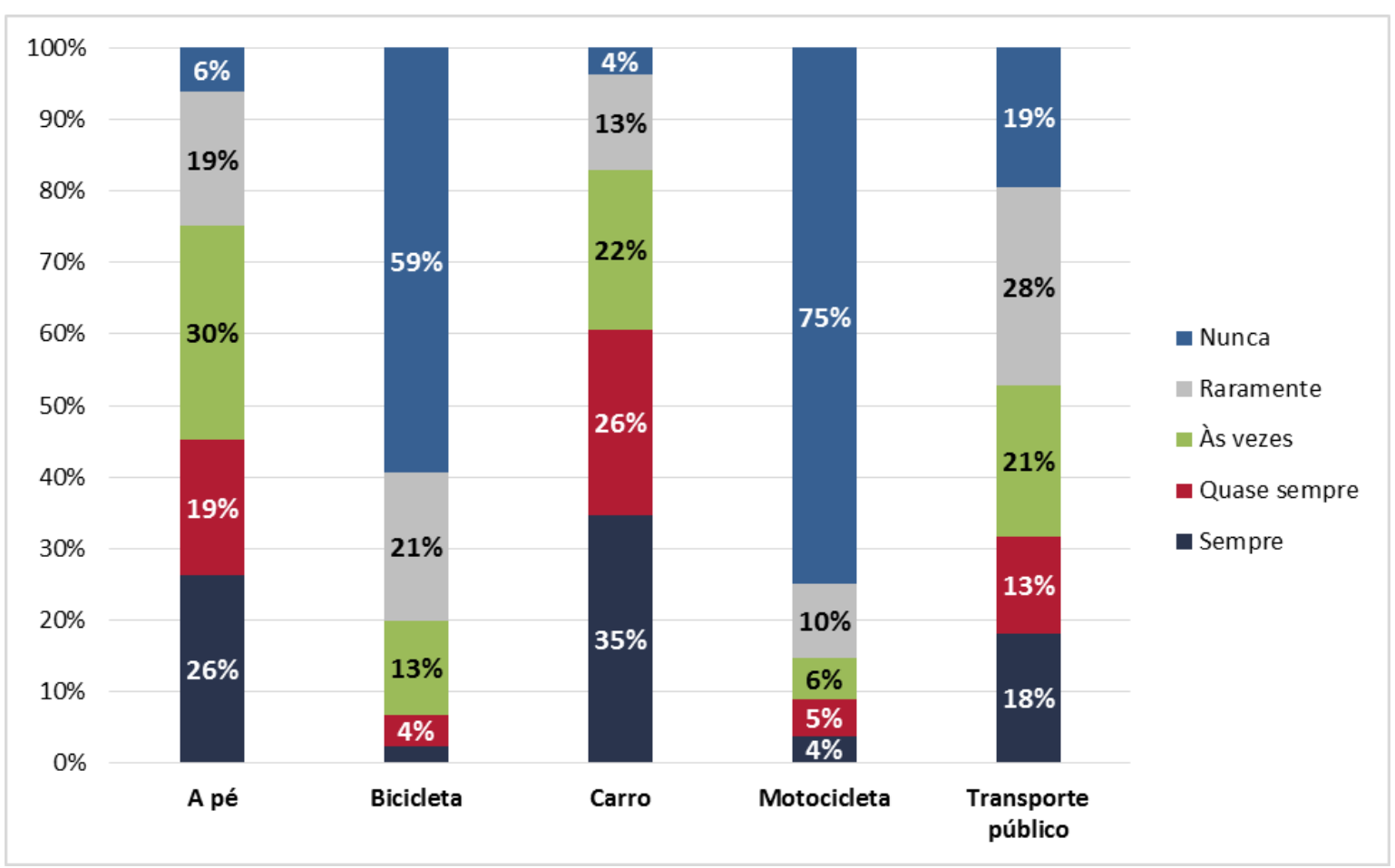

Figura A-18 - Frequência de utilização dos modos de transporte nos deslocamentos diários 


\section{PARTE IV: QUESTÕES SOBRE PLANEJAMENTO DE TRANSPORTES}

$\mathrm{Na}$ quarta parte do questionário foram apresentadas 15 sentenças sobre planejamento de transportes, no qual o respondente deveria indicar seu nível de concordância ou opinião relativa a cada uma das questões. Caso o respondente tivesse comentários sobre a questão, ele poderia fazer ao final de cada pergunta.

\section{Sentença 1: Uso integrado do solo}

A Tabela A-21 e a Figura A-19 apresentam a distribuição das respostas para cada uma das alternativas da Sentença 1 (Q1).

Tabela A-21 - Distribuição das respostas para Q1

Q1. No planejamento de uma cidade, a infraestrutura de transporte deveria proporcionar um sistema integrado de uso do solo e transportes.

\begin{tabular}{cccccccc}
\hline $\begin{array}{c}\text { Concordo } \\
\text { totalmente }\end{array}$ & Concordo & $\begin{array}{c}\text { Concordo } \\
\text { parcialmente }\end{array}$ & Neutro & $\begin{array}{c}\text { Discordo } \\
\text { parcialmente }\end{array}$ & Discordo & $\begin{array}{c}\text { Discordo } \\
\text { totalmente }\end{array}$ & TOTAL \\
\hline 2082 & 676 & 83 & 16 & 4 & 0 & 2 & 2863 \\
$(72,7 \%)$ & $(23,6 \%)$ & $(2,9 \%)$ & $(0,6 \%)$ & $(0,1 \%)$ & $(0,0 \%)$ & $(0,1 \%)$ & $(100,0 \%)$ \\
\hline
\end{tabular}

Q1. No planejamento de uma cidade, a infraestrutura de transporte deveria proporcionar um sistema integrado de uso do solo e transportes.

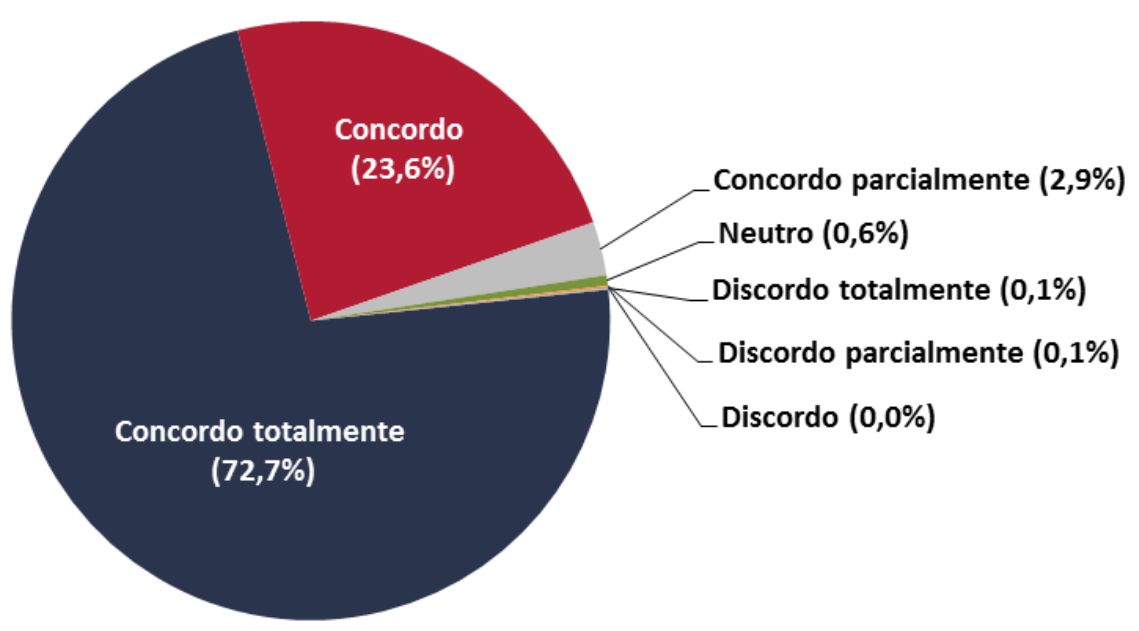

Figura A-19 - Distribuição das respostas para Q1 


\section{Sentença 2: Distribuição dos investimentos em infraestrutura de transportes}

A Tabela A-22 e a Figura A-20 apresentam a distribuição das respostas para cada uma das alternativas da Sentença 2 (Q2).

Tabela A-22 - Distribuição das respostas para Q2

Q2. Em um sistema urbano deve haver equilíbrio de investimento entre as infraestruturas necessárias para os diferentes modos de transporte (individual motorizado, transporte público, bicicleta e a pé).

\begin{tabular}{cccccccc}
\hline $\begin{array}{c}\text { Concordo } \\
\text { totalmente }\end{array}$ & Concordo & $\begin{array}{c}\text { Concordo } \\
\text { parcialmente }\end{array}$ & Neutro & $\begin{array}{c}\text { Discordo } \\
\text { parcialmente }\end{array}$ & Discordo & $\begin{array}{c}\text { Discordo } \\
\text { totalmente }\end{array}$ & TOTAL \\
\hline 1283 & 655 & 525 & 27 & 190 & 140 & 43 & 2863 \\
$(44,8 \%)$ & $(22,9 \%)$ & $(18,3 \%)$ & $(0,9 \%)$ & $(6,6 \%)$ & $(4,9 \%)$ & $(1,5 \%)$ & $(100,0 \%)$ \\
\hline
\end{tabular}

Q2. Em um sistema urbano deve haver equilíbrio de investimento entre as infraestruturas necessárias para os diferentes modos de transporte (individual motorizado, transporte público, bicicleta e a pé).

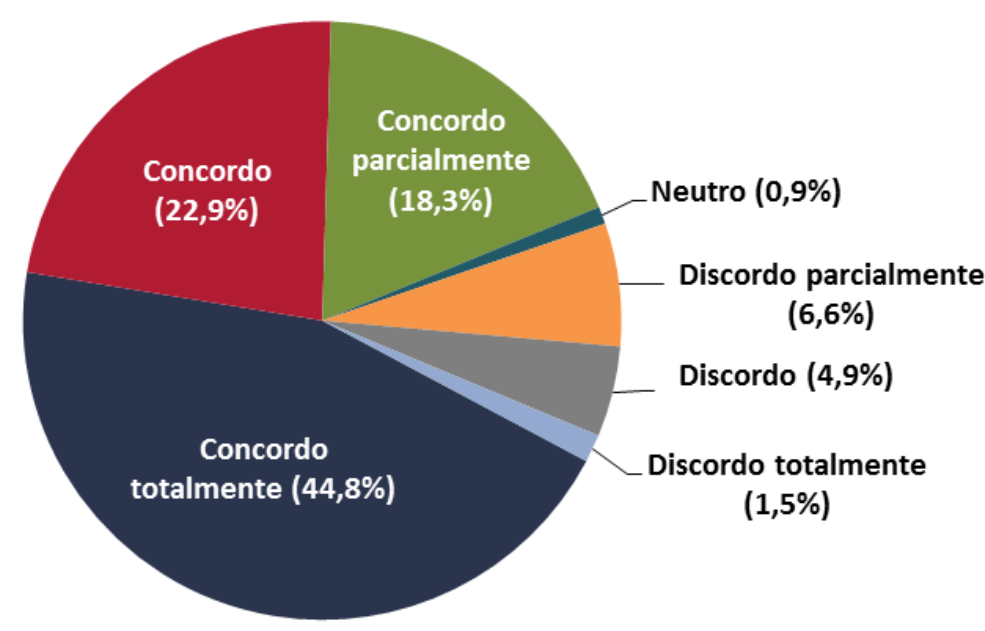

Figura A-20 - Distribuição das respostas para Q2 


\section{Sentença 3: Investimento em infraestrutura de transportes}

A Tabela A-23 e a Figura A-21 apresentam a distribuição das respostas para cada uma das alternativas da Sentença $3(\mathrm{Q} 3)$.

Tabela A-23 - Distribuição das respostas para Q3

Q3. Investimentos em todos os principais tipos de infraestrutura de transportes (estradas, ferrovias, aeroportos, ciclovias e passeios) contribuem para o crescimento das oportunidades de emprego.

\begin{tabular}{cccccccc}
\hline $\begin{array}{c}\text { Concordo } \\
\text { totalmente }\end{array}$ & Concordo & $\begin{array}{c}\text { Concordo } \\
\text { parcialmente }\end{array}$ & Neutro & $\begin{array}{c}\text { Discordo } \\
\text { parcialmente }\end{array}$ & Discordo & $\begin{array}{c}\text { Discordo } \\
\text { totalmente }\end{array}$ & TOTAL \\
\hline 1512 & 922 & 321 & 58 & 34 & 14 & 2 & 2863 \\
$(52,8 \%)$ & $(32,2 \%)$ & $(11,2 \%)$ & $(2,0 \%)$ & $(1,2 \%)$ & $(0,5 \%)$ & $(0,1 \%)$ & $(100,0 \%)$ \\
\hline
\end{tabular}

Q3. Investimentos em todos os principais tipos de infraestrutura de transportes (estradas, ferrovias, aeroportos, ciclovias e passeios) contribuem para o crescimento das oportunidades de emprego.

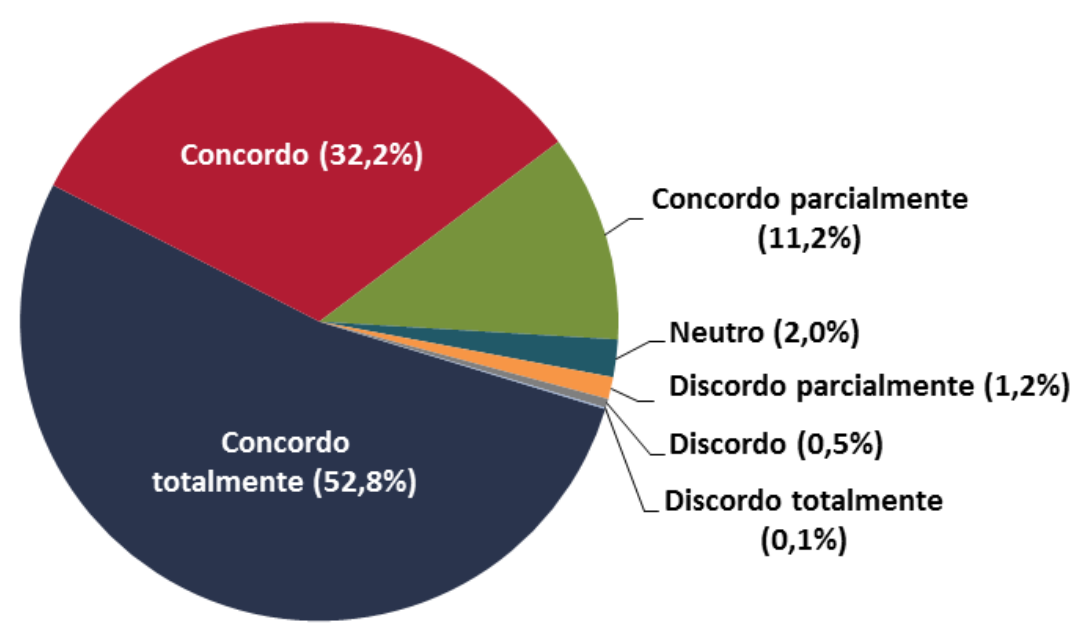

Figura A-21 - Distribuição das respostas para Q3 


\section{Sentença 4: Gestão da demanda de viagens por carro}

A Tabela A-23 e a Figura A-22 apresentam a distribuição das respostas para cada uma das alternativas da Sentença 4 (Q4).

Tabela A-24 - Distribuição das respostas para Q4

Q4. A gestão da demanda de viagens por carro - buscando a redução dessa demanda - deve constar em qualquer estratégia de transporte urbano.

\begin{tabular}{cccccccc}
\hline $\begin{array}{c}\text { Concordo } \\
\text { totalmente }\end{array}$ & Concordo & $\begin{array}{c}\text { Concordo } \\
\text { parcialmente }\end{array}$ & Neutro & $\begin{array}{c}\text { Discordo } \\
\text { parcialmente }\end{array}$ & Discordo & $\begin{array}{c}\text { Discordo } \\
\text { totalmente }\end{array}$ & TOTAL \\
\hline 1386 & 961 & 331 & 94 & 48 & 32 & 11 & 2863 \\
$48,4 \%$ & $33,6 \%$ & $11,6 \%$ & $3,3 \%$ & $1,7 \%$ & $1,1 \%$ & $0,4 \%$ & $100,0 \%$ \\
\hline
\end{tabular}

Q4. A gestão da demanda de viagens por carro - buscando a redução dessa demanda - deve constar em qualquer estratégia de transporte urbano.

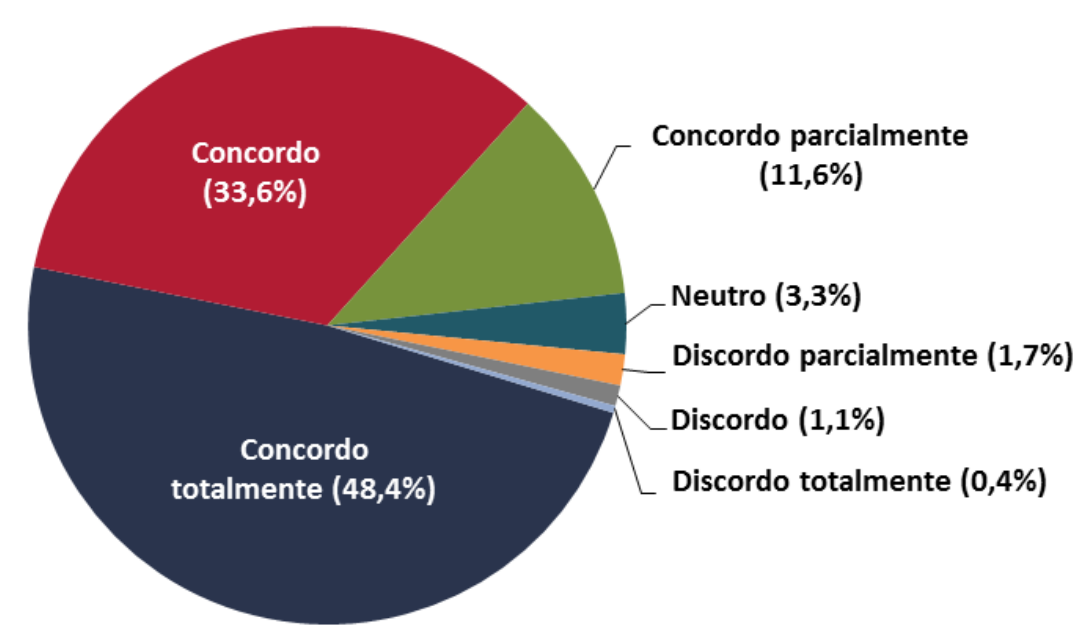

Figura A-22 - Distribuição das respostas para Q4 


\section{Sentença 5: Planejamento logístico}

A Tabela A-25 e a Figura A-23 apresentam a distribuição das respostas para cada uma das alternativas da Sentença $5(\mathrm{Q} 5)$.

Tabela A-25 - Distribuição das respostas para Q5

Q5. A redução do transporte desnecessário de cargas, obtida através de um adequado planejamento logístico, pode se converter em benefícios econômicos para as empresas.

\begin{tabular}{cccccccc}
\hline $\begin{array}{c}\text { Concordo } \\
\text { totalmente }\end{array}$ & Concordo & $\begin{array}{c}\text { Concordo } \\
\text { parcialmente }\end{array}$ & Neutro & $\begin{array}{c}\text { Discordo } \\
\text { parcialmente }\end{array}$ & Discordo & $\begin{array}{c}\text { Discordo } \\
\text { totalmente }\end{array}$ & TOTAL \\
\hline 1503 & 1036 & 160 & 139 & 14 & 9 & 2 & 2863 \\
$52,5 \%$ & $36,2 \%$ & $5,6 \%$ & $4,9 \%$ & $0,5 \%$ & $0,3 \%$ & $0,1 \%$ & $100,0 \%$ \\
\hline
\end{tabular}

Q5. A redução do transporte desnecessário de cargas, obtida através de um adequado planejamento logístico, pode se converter em benefícios econômicos para as empresas.

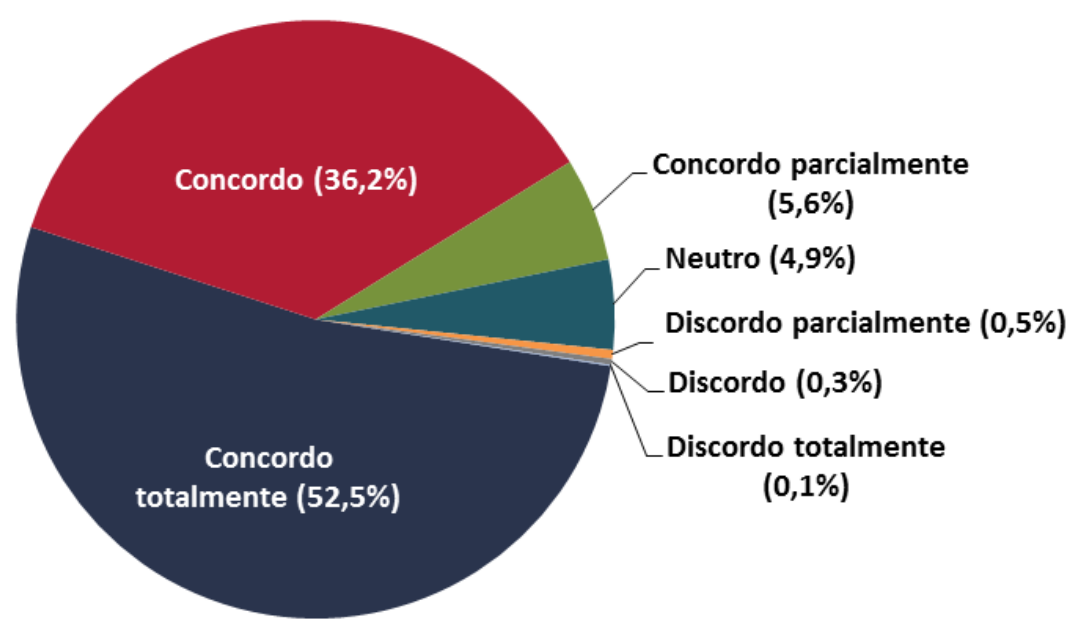

Figura A-23 - Distribuição das respostas para Q5 


\section{Sentença 6: Custos totais de viagens}

A Tabela A-26 e a Figura A-24 apresentam a distribuição das respostas para cada uma das alternativas da Sentença 6 (Q6).

Tabela A-26 - Distribuição das respostas para Q6

Q6. Os custos totais de viagens (incluindo mortes e lesões derivadas de acidentes de trânsito e doenças decorrentes de poluição, bem como o isolamento daqueles que não tem acesso ao automóvel em uma cidade dependente do carro) devem sempre ser considerados em qualquer análise de custo-benefício.

\begin{tabular}{cccccccc}
\hline $\begin{array}{c}\text { Concordo } \\
\text { totalmente }\end{array}$ & Concordo & $\begin{array}{c}\text { Concordo } \\
\text { parcialmente }\end{array}$ & Neutro & $\begin{array}{c}\text { Discordo } \\
\text { parcialmente }\end{array}$ & Discordo & $\begin{array}{c}\text { Discordo } \\
\text { totalmente }\end{array}$ & TOTAL \\
\hline 1346 & 1053 & 278 & 134 & 33 & 16 & 3 & 2863 \\
$(47,0 \%)$ & $(36,8 \%)$ & $(9,7 \%)$ & $(4,7 \%)$ & $(1,2 \%)$ & $(0,6 \%)$ & $(0,1 \%)$ & $(100,0 \%)$ \\
\hline
\end{tabular}

Q6. Os custos totais de viagens (incluindo mortes e lesões derivadas de acidentes de trânsito e doenças decorrentes de poluição, bem como o isolamento daqueles que não tem acesso ao automóvel em uma cidade dependente do carro) devem sempre ser considerados em qualquer análise de custo-benefício.

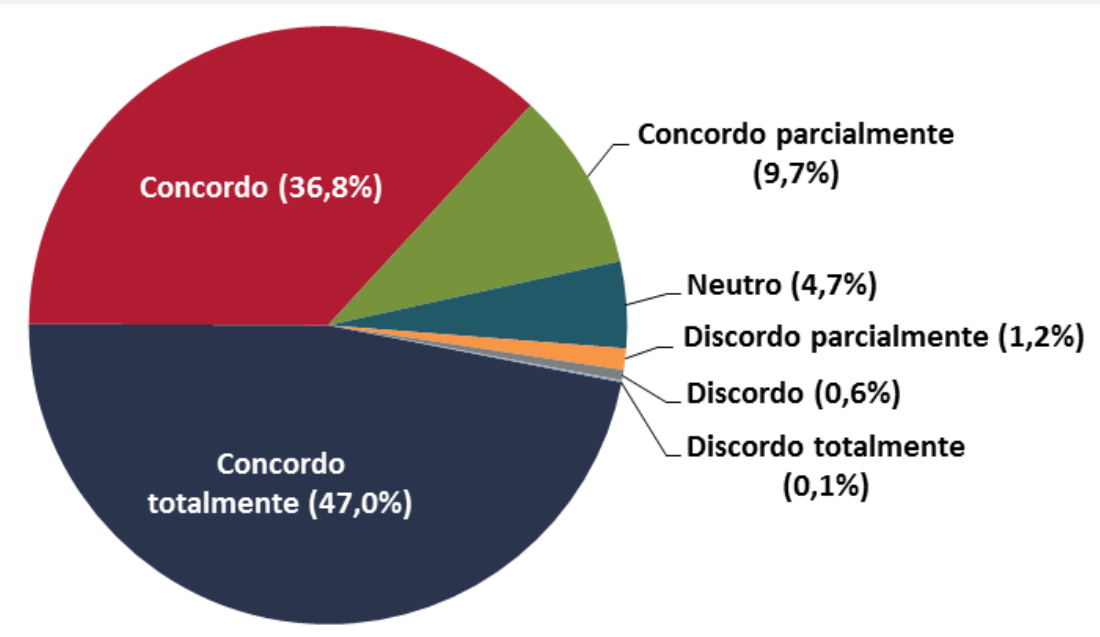

Figura A-24 - Distribuição das respostas para Q6 


\section{Sentença 7: Redução do limite de velocidade em algumas vias}

A Tabela A-27 e a Figura A-25 apresentam a distribuição das respostas para cada uma das alternativas da Sentença 7 (Q7).

Tabela A-27 - Distribuição das respostas para Q7

Q7. Você acredita que a redução do limite de velocidade para os veículos motorizados (automóveis, motocicletas, caminhões e ônibus) em algumas vias possa estimular a locomoção de pedestres e ciclistas?

\begin{tabular}{cccccc}
\hline $\begin{array}{c}\text { Estimula } \\
\text { totalmente }\end{array}$ & $\begin{array}{c}\text { Estimula } \\
\text { parcialmente }\end{array}$ & $\begin{array}{c}\text { Pode ou não } \\
\text { estimular }\end{array}$ & $\begin{array}{c}\text { Quase não } \\
\text { estimula }\end{array}$ & $\begin{array}{c}\text { Definitivamente } \\
\text { não estimula }\end{array}$ & TOTAL \\
\hline 617 & 968 & 760 & 315 & 203 & 2863 \\
$(21,6 \%)$ & $(33,8 \%)$ & $(26,5 \%)$ & $(11,0 \%)$ & $(7,1 \%)$ & $(100,0 \%)$ \\
\hline
\end{tabular}

Q7. Você acredita que a redução do limite de velocidade para os veículos motorizados (automóveis, motocicletas, caminhões e ônibus) em algumas vias possa estimular a locomoção de pedestres e ciclistas?

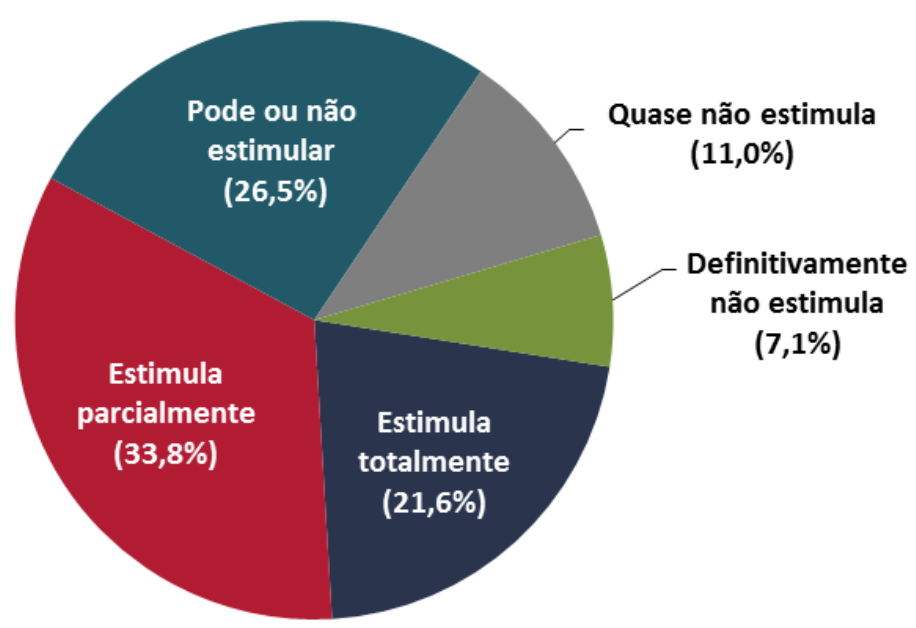

Figura A-25 - Distribuição das respostas para Q7 
Sentença 8: Importância de investimentos para compartilhamento da rede viária

A Tabela A-28 e a Figura A-26 apresentam a distribuição das respostas para cada uma das alternativas da Sentença 8 (Q8).

Tabela A-28 - Distribuição das respostas para Q8

Q8. Na sua opinião, qual a importância de investimentos em sinalização, manutenção e continuidade da rede viária para o compartilhamento das vias entre os diferentes modos de transporte (individual motorizado, transporte público, a pé e bicicleta)?

\begin{tabular}{cccccc}
\hline $\begin{array}{c}\text { Muito } \\
\text { importantes }\end{array}$ & Importantes & $\begin{array}{c}\text { Moderadamente } \\
\text { importantes }\end{array}$ & $\begin{array}{c}\text { Pouco } \\
\text { importantes }\end{array}$ & $\begin{array}{c}\text { Não são } \\
\text { importantes }\end{array}$ & TOTAL \\
\hline 2205 & 561 & 90 & 6 & 1 & 2863 \\
$(77,0 \%)$ & $(19,6 \%)$ & $(3,1 \%)$ & $(0,2 \%)$ & $(0,0 \%)$ & $(100,0 \%)$ \\
\hline
\end{tabular}

Q8. Na sua opinião, qual a importância de investimentos em sinalização, manutenção e continuidade da rede viária para o compartilhamento das vias entre os diferentes modos de transporte (individual motorizado, transporte público, a pé e bicicleta)?

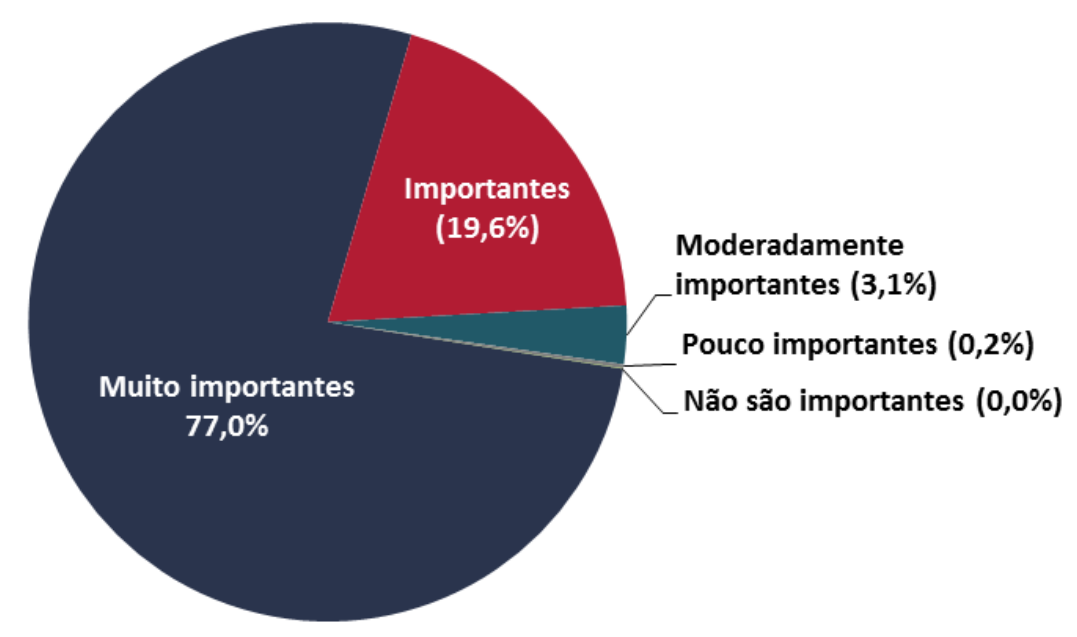

Figura A-26 - Distribuição das respostas para Q8 


\section{Sentença 9: Oferecimento de infraestrutura para modos não motorizados}

A Tabela A-29 e a Figura A-27 apresentam a distribuição das respostas para cada uma das alternativas da Sentença 9 (Q9).

Tabela A-29 - Distribuição das respostas para Q9

Q9. O oferecimento de infraestrutura adequada influencia no uso dos modos não motorizados (a pé e bicicleta)?

\begin{tabular}{cccccc}
\hline $\begin{array}{c}\text { Influencia } \\
\text { totalmente }\end{array}$ & $\begin{array}{c}\text { Influencia } \\
\text { parcialmente }\end{array}$ & $\begin{array}{c}\text { Pode ou não } \\
\text { influenciar }\end{array}$ & $\begin{array}{c}\text { Quase não } \\
\text { influencia }\end{array}$ & $\begin{array}{c}\text { Definitivamente } \\
\text { não influencia }\end{array}$ & TOTAL \\
\hline 1973 & 702 & 163 & 21 & 4 & 2863 \\
$(68,9 \%)$ & $(24,5 \%)$ & $(5,7 \%)$ & $(0,7 \%)$ & $(0,1 \%)$ & $(100,0 \%)$ \\
\hline
\end{tabular}

Q9. O oferecimento de infraestrutura adequada influencia no uso dos modos não motorizados (a pé e bicicleta)?

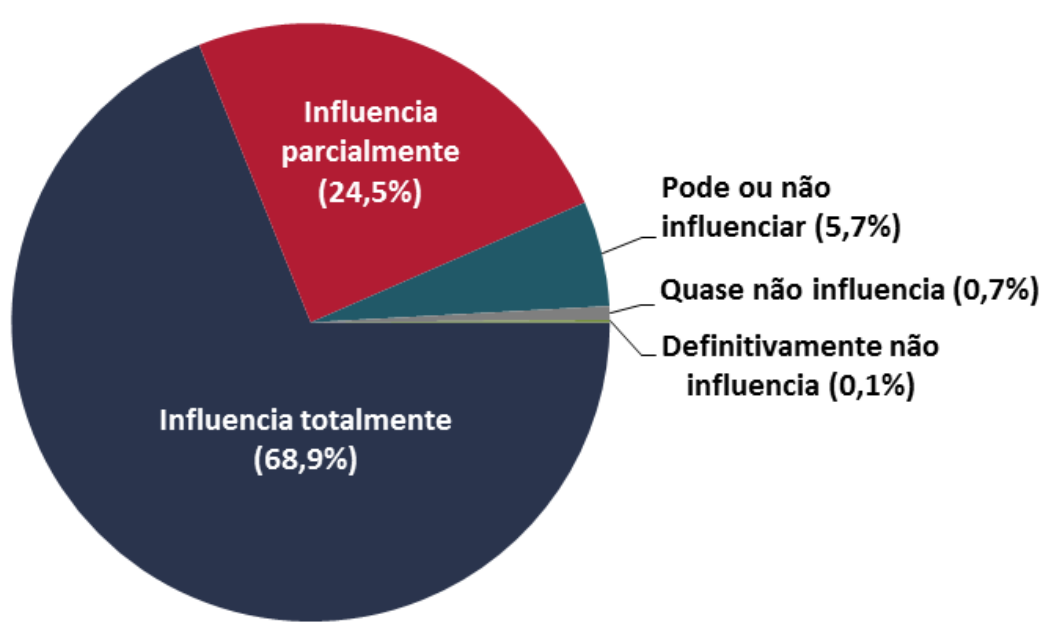

Figura A-27 - Distribuição das respostas para Q9 
Sentença 10: Influência das características do ambiente no uso dos modos não motorizados

A Tabela A-30 e a Figura A-28 apresentam a distribuição das respostas para cada uma das alternativas da Sentença 10 (Q10).

Tabela A-30 - Distribuição das respostas para Q10

Q10. Características do ambiente, como topografia irregular e clima quente, inviabilizam o uso dos modos não motorizados, independentemente da infraestrutura viária disponível?

\begin{tabular}{cccccc}
\hline $\begin{array}{c}\text { Inviabilizam } \\
\text { totalmente }\end{array}$ & $\begin{array}{c}\text { Inviabilizam } \\
\text { parcialmente }\end{array}$ & $\begin{array}{c}\text { Podem ou não } \\
\text { inviabilizar }\end{array}$ & $\begin{array}{c}\text { Quase não } \\
\text { inviabilizam }\end{array}$ & $\begin{array}{c}\text { Definitivamente } \\
\text { não inviabilizam }\end{array}$ & TOTAL \\
\hline 264 & 1224 & 1017 & 207 & 151 & 2863 \\
$(9,2 \%)$ & $(42,8 \%)$ & $(35,5 \%)$ & $(7,2 \%)$ & $(5,3 \%)$ & $(100,0 \%)$ \\
\hline
\end{tabular}

Q10. Características do ambiente, como topografia irregular e clima quente, inviabilizam o uso dos modos não motorizados, independentemente da infraestrutura viária disponível?

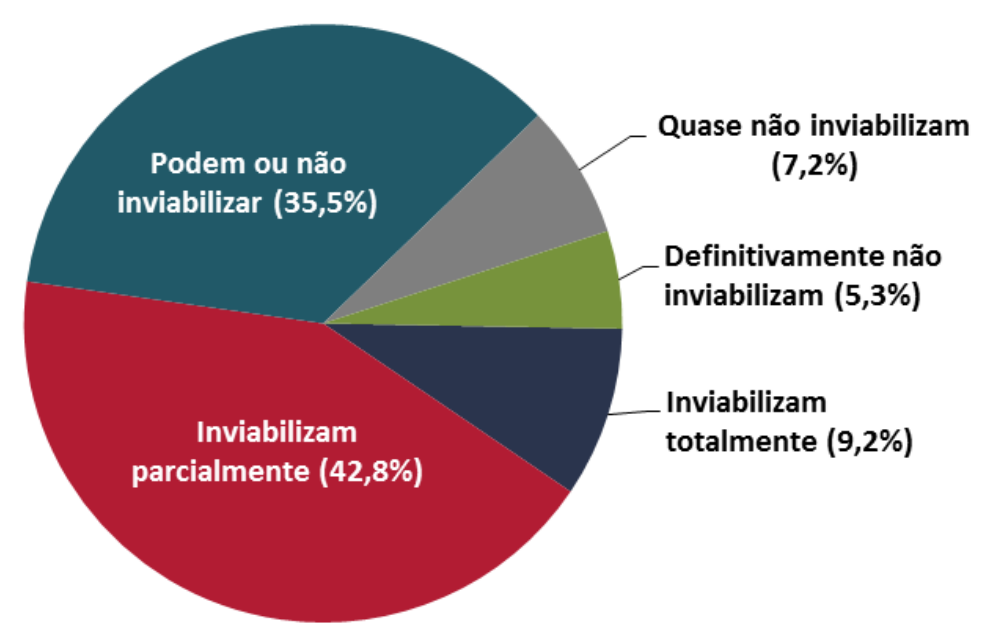

Figura A-28 - Distribuição das respostas para Q10 


\section{Sentença 11: Custo da infraestrutura para os modos não motorizados}

A Tabela A-31 e a Figura A-29 apresentam a distribuição das respostas para cada uma das alternativas da Sentença 11 (Q11).

Tabela A-31 - Distribuição das respostas para Q11

Q11. As infraestruturas adequadas para os modos não motorizados (a pé e bicicleta), quando comparadas às infraestruturas para outros modos de transporte urbano, possuem:

\begin{tabular}{cccccc}
\hline $\begin{array}{c}\text { Custo muito } \\
\text { maior }\end{array}$ & Custo maior & Custo igual & Custo menor & $\begin{array}{c}\text { Custo muito } \\
\text { menor }\end{array}$ & TOTAL \\
\hline 52 & 113 & 247 & 1595 & 856 & 2863 \\
$(1,8 \%)$ & $(3,9 \%)$ & $(8,6 \%)$ & $(55,7 \%)$ & $(29,9 \%)$ & $(100,0 \%)$ \\
\hline
\end{tabular}

Q11. As infraestruturas adequadas para os modos não motorizados (a pé e bicicleta), quando comparadas às infraestruturas para outros modos de transporte urbano, possuem:

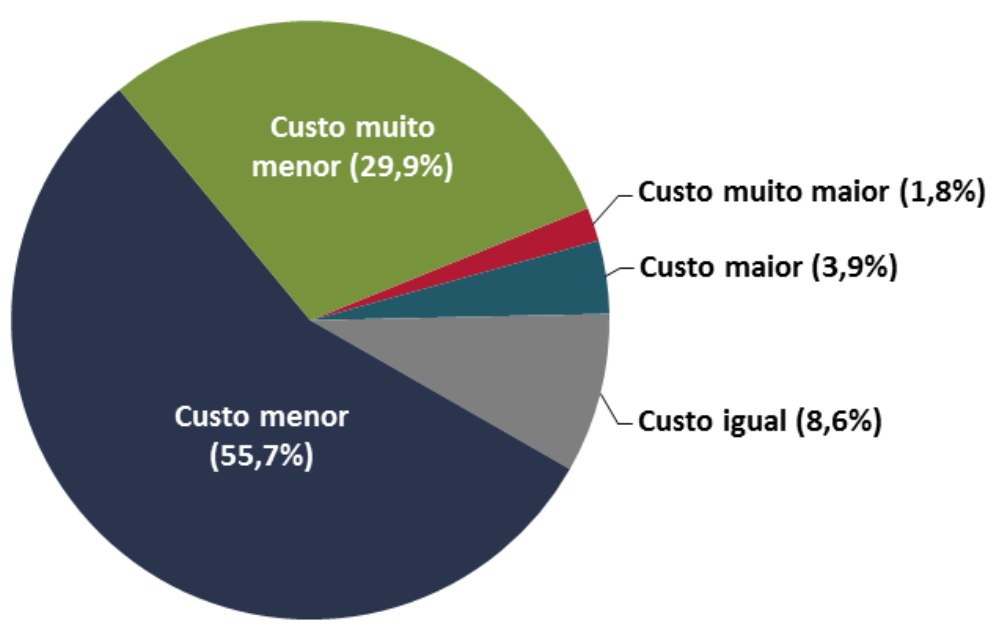

Figura A-29 - Distribuição das respostas para Q11 


\section{Sentença 12: Incentivo para modos não motorizados}

A Tabela A-32 e a Figura A-30 apresentam a distribuição das respostas para cada uma das alternativas da Sentença 12 (Q12).

Tabela A-32 - Distribuição das respostas para Q12

Q12. Manifeste a sua opinião com relação à seguinte frase: Modos não motorizados (a pé e bicicleta) são considerados de baixo custo e, por este motivo, poderiam ser utilizados pela maioria da população.

\begin{tabular}{cccccc}
\hline $\begin{array}{c}\text { Concordo } \\
\text { totalmente }\end{array}$ & Concordo & Neutro & Discordo & $\begin{array}{c}\text { Discordo } \\
\text { totalmente }\end{array}$ & TOTAL \\
\hline 834 & 1212 & 429 & 356 & 32 & 2863 \\
$(29,1 \%)$ & $(42,3 \%)$ & $(15,0 \%)$ & $(12,4 \%)$ & $(1,1 \%)$ & $(100,0 \%)$ \\
\hline
\end{tabular}

Q12. Manifeste a sua opinião com relação à seguinte frase: Modos não motorizados (a pé e bicicleta) são considerados de baixo custo e, por este motivo, poderiam ser utilizados pela maioria da população.

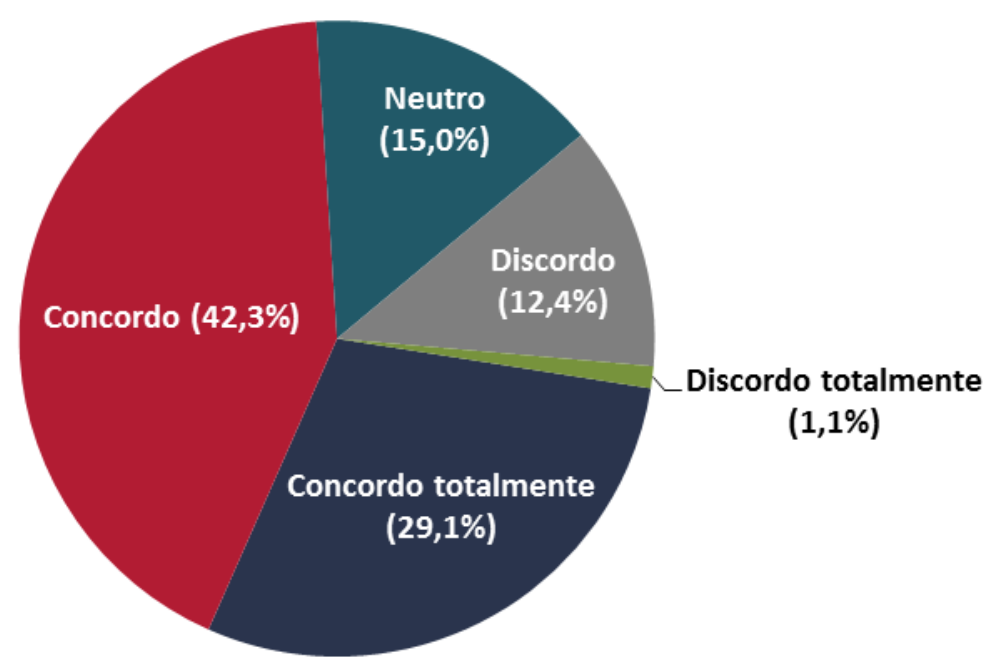

Figura A-30 - Distribuição das respostas para Q12 


\section{Sentença 13: Uso dos modos não motorizados e expansão urbana}

A Tabela A-33 e a Figura A-31 apresentam a distribuição das respostas para cada uma das alternativas da Sentença 13 (Q13).

Tabela A-33 - Distribuição das respostas para Q13

Q13. O aumento do uso dos modos não motorizados (a pé e bicicleta) pode estimular o desenvolvimento de atividades em novas áreas de expansão urbana?

\begin{tabular}{cccccc}
\hline $\begin{array}{c}\text { Estimula } \\
\text { totalmente }\end{array}$ & $\begin{array}{c}\text { Estimula } \\
\text { parcialmente }\end{array}$ & $\begin{array}{c}\text { Pode ou não } \\
\text { estimular }\end{array}$ & $\begin{array}{c}\text { Quase não } \\
\text { estimula }\end{array}$ & $\begin{array}{c}\text { Definitivamente } \\
\text { não estimula }\end{array}$ & TOTAL \\
\hline 846 & 1000 & 830 & 133 & 54 & 2863 \\
$(29,5 \%)$ & $(34,9 \%)$ & $(29,0 \%)$ & $(4,6 \%)$ & $(1,9 \%)$ & $(100,0 \%)$ \\
\hline
\end{tabular}

Q13. O aumento do uso dos modos não motorizados (a pé e bicicleta) pode estimular o desenvolvimento de atividades em novas áreas de expansão urbana?

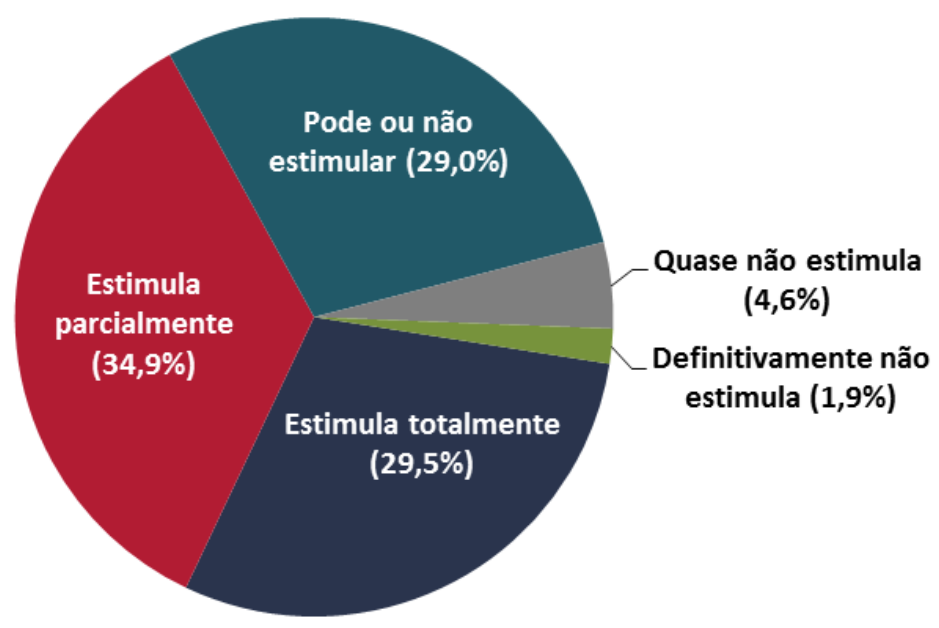

Figura A-31 - Distribuição das respostas para Q13 
Sentença 14: Área com tráfego de modos não motorizados e segurança pública

A Tabela A-34 e a Figura A-32 apresentam a distribuição das respostas para cada uma das alternativas da Sentença 14 (Q14).

Tabela A-34 - Distribuição das respostas para Q14

Q14. Qual a sua sensação de segurança, em relação a roubos e violência, em áreas com tráfego de pedestres e ciclistas em todos os horários do dia?

\begin{tabular}{cccccc}
\hline Muito seguro & Seguro & Indiferente & Inseguro & Muito inseguro & TOTAL \\
\hline 169 & 730 & 467 & 1072 & 425 & 2863 \\
$(5,9 \%)$ & $(25,5 \%)$ & $(16,3 \%)$ & $(37,4 \%)$ & $(14,8 \%)$ & $(100,0 \%)$ \\
\hline
\end{tabular}

Q14. Qual a sua sensação de segurança, em relação a roubos e violência, em áreas com tráfego de pedestres e ciclistas em todos os horários do dia?

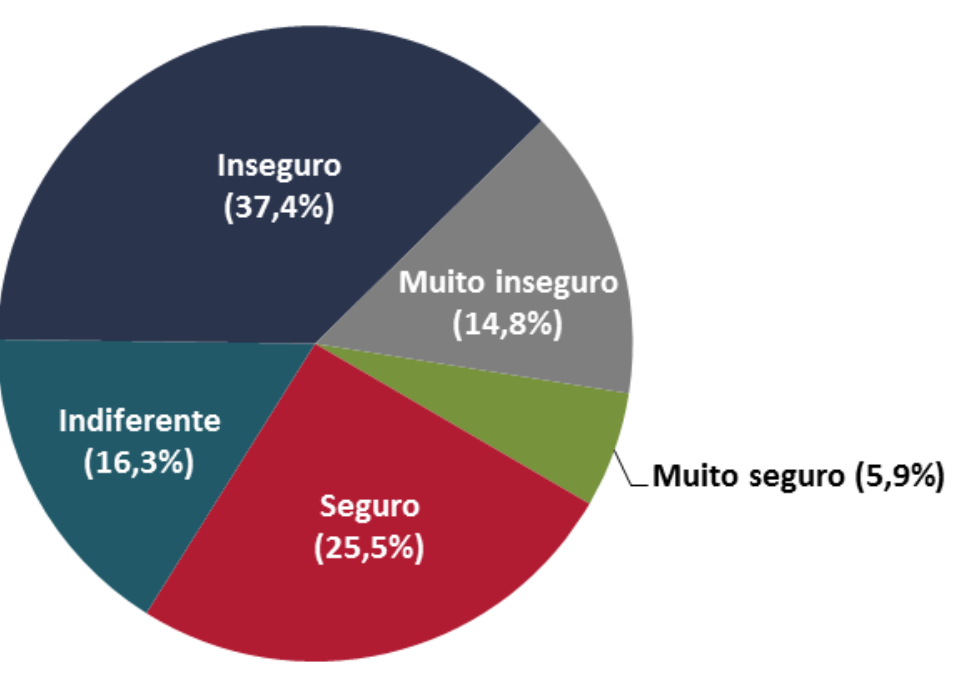

Figura A-32 - Distribuição das respostas para Q14 


\section{Sentença 15: Medidas para promover o uso dos modos não motorizados}

A Tabela A-35 e a Figura A-33 apresentam a distribuição das respostas para cada uma das alternativas da Sentença 15 (Q15).

Tabela A-35 - Distribuição das respostas para Q15

\begin{tabular}{cccccc}
\hline $\begin{array}{c}\text { Q15. Buscando promover uma mudança cultural da população em relação ao transporte } \\
\text { sustentável, medidas que destinam o espaço normalmente utilizado pelos veículos } \\
\text { motorizados para pedestres e ciclistas nos finais de semana são: }\end{array}$ \\
$\begin{array}{c}\text { Muito } \\
\text { eficientes }\end{array}$ & Eficientes & Neutro & Ineficientes & $\begin{array}{c}\text { Muito } \\
\text { ineficientes }\end{array}$ & TOTAL \\
\hline 743 & 1361 & 433 & 296 & 30 & 2863 \\
$(26,0 \%)$ & $(47,5 \%)$ & $(15,1 \%)$ & $(10,3 \%)$ & $(1,0 \%)$ & $(100,0 \%)$ \\
\hline
\end{tabular}

Q15. Buscando promover uma mudança cultural da população em relação ao transporte sustentável, medidas que destinam o espaço normalmente utilizado pelos veículos motorizados para pedestres e ciclistas nos finais de semana são:

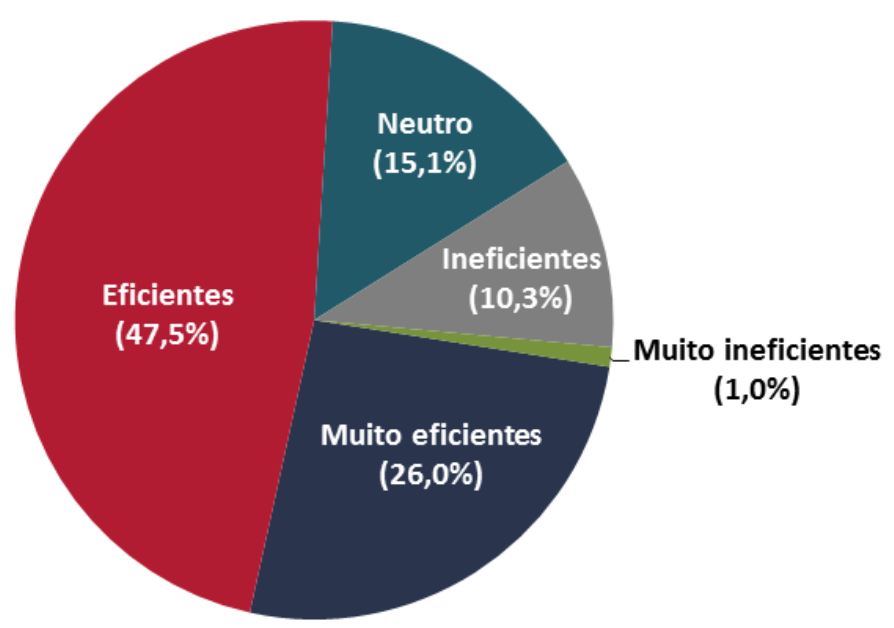

Figura A-33 - Distribuição das respostas para Q15 


\section{PARTE V: INVESTIMENTO EM INFRAESTRUTURA DE TRANSPORTES}

$\mathrm{Na}$ última parte do questionário foi solicitada a opinião do respondente acerca da contribuição das diferentes formas de investimentos em infraestrutura de transporte para promover a mobilidade sustentável. Em uma escala de 0 a 100, o respondente deveria classificar diferentes tipos de infraestruturas de transportes com relação à sua contribuição para promover a mobilidade sustentável, sendo 0 (zero) para nenhuma contribuição e 100 (cem) para a máxima contribuição que o investimento público poderia fazer. A média das respostas para cada tipo infraestrutura são apresentados na Tabela A-36 e na Figura A-34.

Tabela A-36 - Média de investimento em infraestrutura para a promoção da mobilidade sustentável

\begin{tabular}{lc}
\hline TIPO DE INFRAESTRUTURA & Média \\
\hline Pesada sobre trilhos (trens) & 69 \\
\hline Leve sobre trilhos (bondes, VLT's) & 72 \\
\hline Rodoviária & 51 \\
\hline Transporte público coletivo & 86 \\
Pedestres & 86 \\
Ciclistas & 84 \\
\hline Transferência de transportes (Terminais de integração) & 81 \\
\hline
\end{tabular}

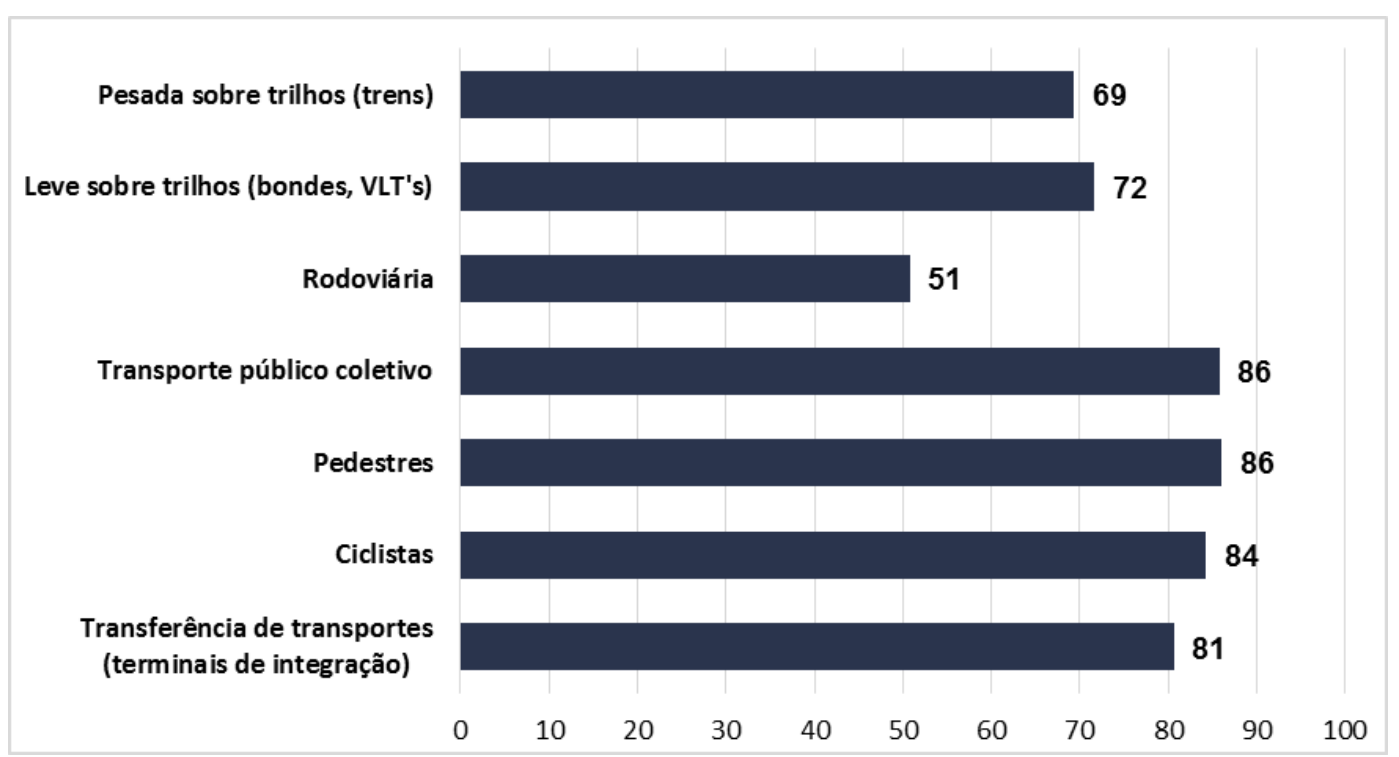

Figura A-34 - Média de investimento em infraestrutura para a promoção da mobilidade sustentável 
Apêndice

\section{Aplicação do Método dos Intervalos Sucessivos}

O presente Apêndice tem como objetivo apresentar os resultados da aplicação do Método dos Intervalos Sucessivos. Como forma de demonstrar o Método, serão detalhados os cálculos do Grupo 1 (profissionais da área de transportes) para cada uma das sentenças. 


\section{AVALIAÇÃO PARA O GRUPO 1: PROFISSIONAIS DA ÁREA DE TRANSPORTES}

\section{Sentença 1: Uso integrado do solo}

A Tabela B-1 apresenta o cálculo da escala intervalar para a sentença Q1 e a Figura

B-1 apresenta a distribuição das categorias na curva normal.

Tabela B-1 - Método dos Intervalos Sucessivos para a sentença Q1

Q1. No planejamento de uma cidade, a infraestrutura de transporte deveria proporcionar um sistema integrado de uso do solo e transportes.

\begin{tabular}{|c|c|c|c|c|c|c|c|}
\hline \multirow{2}{*}{$\begin{array}{l}\text { Parâmetros } \\
\text { estatísticos }\end{array}$} & \multicolumn{7}{|c|}{ Categorias } \\
\hline & $\begin{array}{l}\text { Discordo } \\
\text { totalmente }\end{array}$ & Discordo & $\begin{array}{c}\text { Discordo } \\
\text { parcialmente }\end{array}$ & Neutro & $\begin{array}{c}\text { Concordo } \\
\text { parcialmente }\end{array}$ & Concordo & $\begin{array}{l}\text { Concordo } \\
\text { totalmente }\end{array}$ \\
\hline Frequência & 1 & 0 & 1 & 2 & 36 & 209 & 889 \\
\hline Frequência relativa (pj) & 0,0009 & 0,0000 & 0,0009 & 0,0018 & 0,0316 & 0,1837 & 0,7812 \\
\hline Frequência acumulada (Pj) & 0,0009 & 0,0009 & 0,0018 & 0,0035 & 0,0351 & 0,2188 & 1,0000 \\
\hline $\begin{array}{l}\text { Limite inferior da categoria } \\
(\mathrm{z} 1 \mathrm{j})\end{array}$ & - & $-3,1284$ & $-3,1284$ & $-2,9187$ & $-2,6954$ & $-1,8100$ & $-0,7762$ \\
\hline $\begin{array}{l}\text { Limite superior da } \\
\text { categoria }(\mathrm{z} 2 \mathrm{j})\end{array}$ & $-3,1284$ & $-3,1284$ & $-2,9187$ & $-2,6954$ & $-1,8100$ & $-0,7762$ & - \\
\hline $\begin{array}{l}\text { Ordenada do limite inferior } \\
\text { da categoria }(y 1 j)\end{array}$ & 0,0000 & 0,0030 & 0,0030 & 0,0056 & 0,0106 & 0,0775 & 0,2952 \\
\hline $\begin{array}{l}\text { Ordenada do limite } \\
\text { superior da categoria (y2j) }\end{array}$ & 0,0030 & 0,0030 & 0,0056 & 0,0106 & 0,0775 & 0,2952 & 0,0000 \\
\hline $\begin{array}{l}\text { Valor estimado da } \\
\text { categoria }(x \mathrm{j})\end{array}$ & $-3,4027$ & - & $-3,0126$ & $-2,7955$ & $-2,1176$ & $-1,1850$ & 0,3778 \\
\hline
\end{tabular}

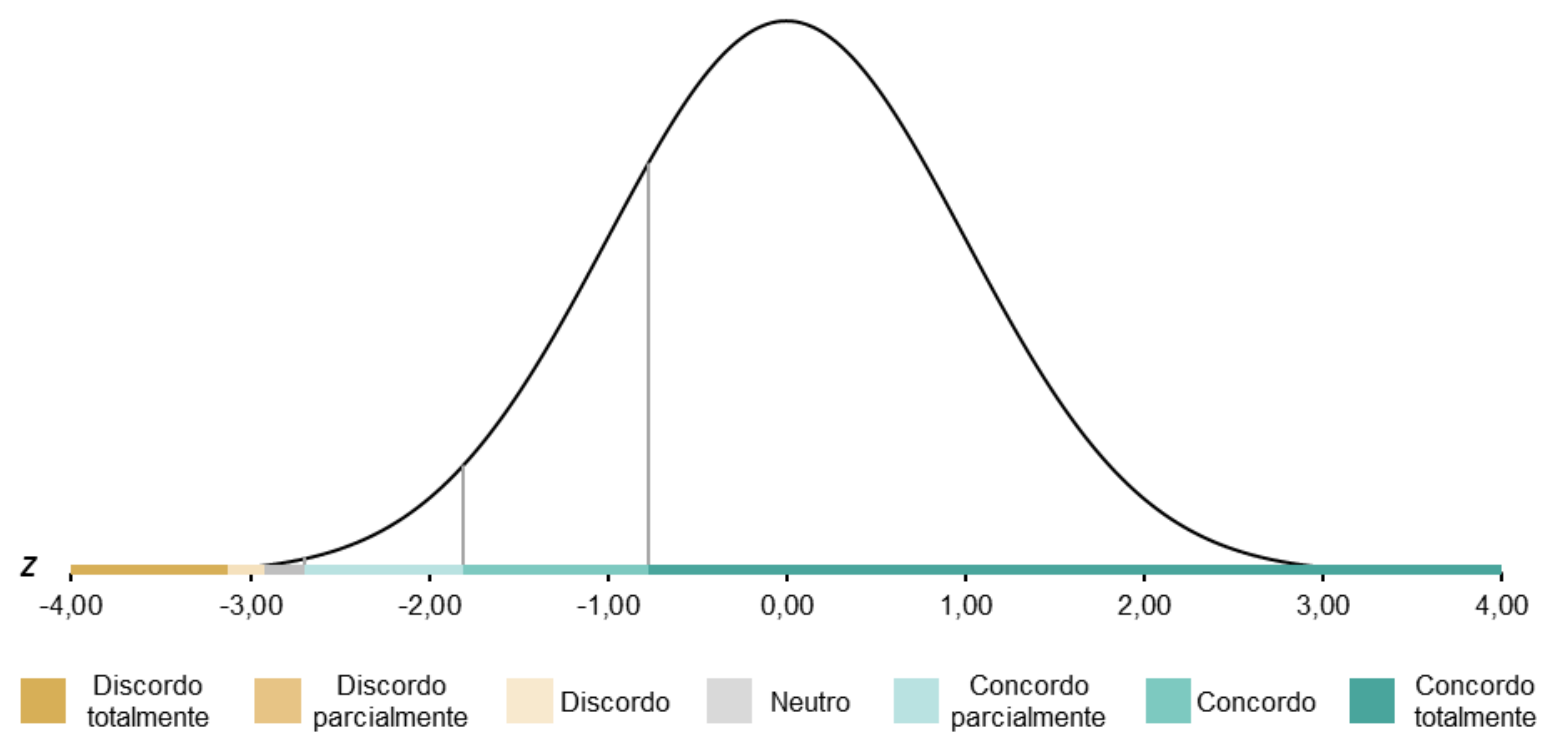

Figura B-1 - Distribuição das categorias da sentença Q1 na curva normal 


\section{Sentença 2: Distribuição dos investimentos em infraestrutura de transportes}

A Tabela B-2 apresenta o cálculo da escala intervalar para a sentença Q2 e a Figura B-2 apresenta a distribuição das categorias na curva normal.

Tabela B-2 - Método dos Intervalos Sucessivos para a sentença Q2

Q2. Em um sistema urbano deve haver equilíbrio de investimento entre as infraestruturas necessárias para os diferentes modos de transporte (individual motorizado, transporte público, bicicleta e a pé).

\begin{tabular}{|c|c|c|c|c|c|c|c|}
\hline \multirow{2}{*}{$\begin{array}{l}\text { Parâmetros } \\
\text { estatísticos }\end{array}$} & \multicolumn{7}{|c|}{ Categorias } \\
\hline & $\begin{array}{l}\text { Discordo } \\
\text { totalmente }\end{array}$ & Discordo & $\begin{array}{l}\text { Discordo } \\
\text { parcialmente }\end{array}$ & Neutro & $\begin{array}{l}\text { Concordo } \\
\text { parcialmente }\end{array}$ & Concordo & $\begin{array}{l}\text { Concordo } \\
\text { totalmente }\end{array}$ \\
\hline Frequência & 20 & 61 & 96 & 10 & 250 & 242 & 459 \\
\hline Frequência relativa (pj) & 0,0176 & 0,0536 & 0,0844 & 0,0088 & 0,2197 & 0,2127 & 0,4033 \\
\hline Frequência acumulada (Pj) & 0,0176 & 0,0712 & 0,1555 & 0,1643 & 0,3840 & 0,5967 & 1,0000 \\
\hline $\begin{array}{l}\text { Limite inferior da categoria } \\
\text { (z1j) }\end{array}$ & - & $-2,1066$ & $-1,4671$ & $-1,0130$ & $-0,9768$ & $-0,2950$ & 0,2447 \\
\hline $\begin{array}{l}\text { Limite superior da } \\
\text { categoria (z2j) }\end{array}$ & $-2,1066$ & $-1,4671$ & $-1,0130$ & $-0,9768$ & $-0,2950$ & 0,2447 & - \\
\hline $\begin{array}{l}\text { Ordenada do limite inferior } \\
\text { da categoria }(y 1 j)\end{array}$ & 0,0000 & 0,0434 & 0,1360 & 0,2388 & 0,2476 & 0,3820 & 0,3872 \\
\hline $\begin{array}{l}\text { Ordenada do limite } \\
\text { superior da categoria (y2j) }\end{array}$ & 0,0434 & 0,1360 & 0,2388 & 0,2476 & 0,3820 & 0,3872 & 0,0000 \\
\hline $\begin{array}{l}\text { Valor estimado da } \\
\text { categoria }(x \mathbf{j})\end{array}$ & $-2,4680$ & $-1,7280$ & $-1,2190$ & $-0,9948$ & $-0,6117$ & $-0,0245$ & 0,9599 \\
\hline
\end{tabular}

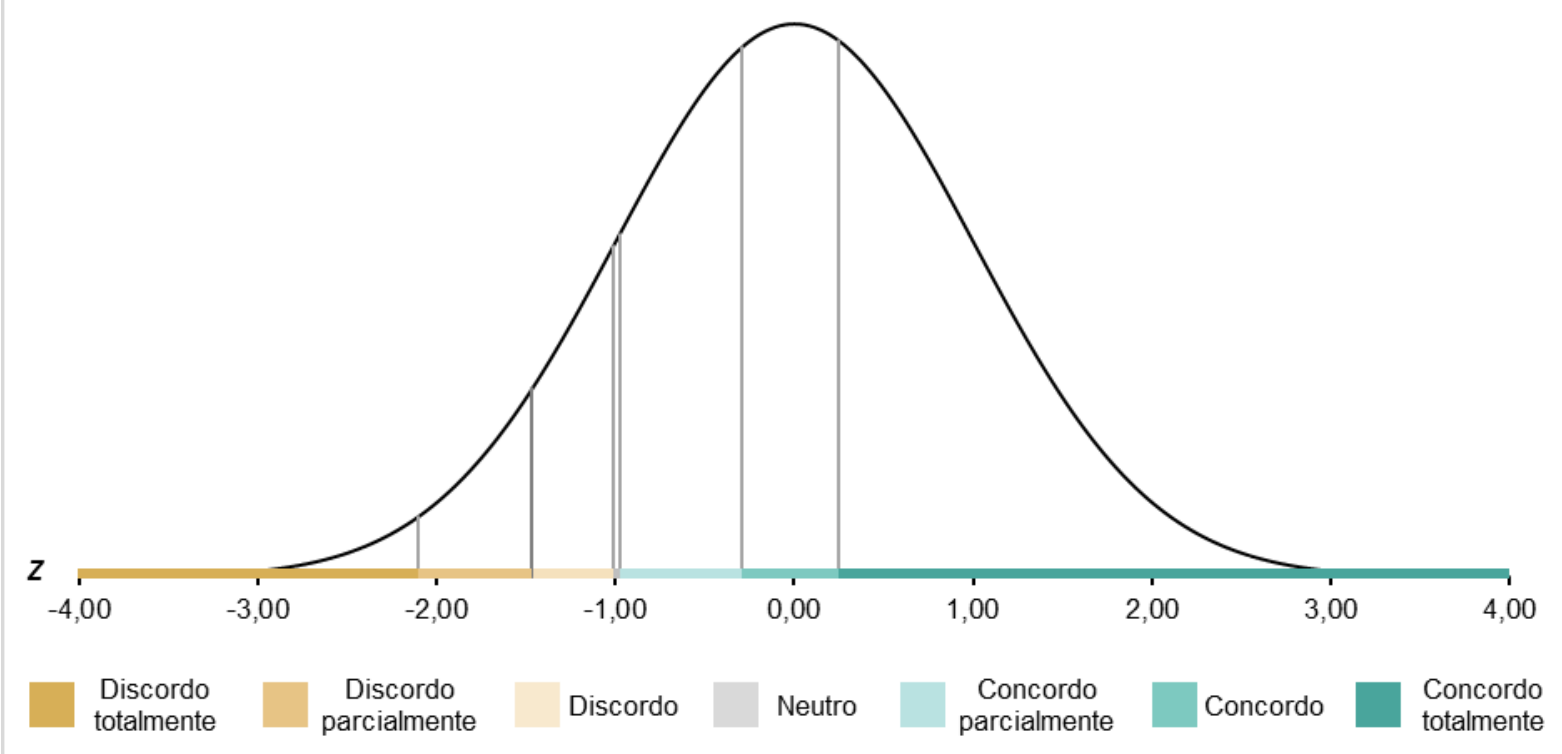

Figura B-2 - Distribuição das categorias da sentença Q2 na curva normal 


\section{Sentença 3: Investimento em infraestrutura de transportes}

A Tabela B-3 apresenta o cálculo da escala intervalar para a sentença Q3 e Figura B-3 apresenta a distribuição das categorias na curva normal.

Tabela B-3 - Método dos Intervalos Sucessivos para a sentença Q3

\begin{tabular}{|c|c|c|c|c|c|c|c|}
\hline \multirow{2}{*}{$\begin{array}{l}\text { Parâmetros } \\
\text { estatísticos }\end{array}$} & \multicolumn{7}{|c|}{ Categorias } \\
\hline & $\begin{array}{l}\text { Discordo } \\
\text { totalmente }\end{array}$ & Discordo & $\begin{array}{c}\text { Discordo } \\
\text { parcialmente }\end{array}$ & Neutro & $\begin{array}{l}\text { Concordo } \\
\text { parcialmente }\end{array}$ & Concordo & $\begin{array}{l}\text { Concordo } \\
\text { totalmente }\end{array}$ \\
\hline Frequência & 2 & 6 & 18 & 17 & 156 & 350 & 589 \\
\hline Frequência relativa (pj) & 0,0018 & 0,0053 & 0,0158 & 0,0149 & 0,1371 & 0,3076 & 0,5176 \\
\hline Frequência acumulada (Pj) & 0,0018 & 0,0070 & 0,0228 & 0,0378 & 0,1749 & 0,4824 & 1,0000 \\
\hline $\begin{array}{l}\text { Limite inferior da categoria } \\
\text { (z1j) }\end{array}$ & 0,0000 & $-2,9187$ & $-2,4557$ & $-1,9982$ & $-1,7770$ & $-0,9351$ & $-0,0441$ \\
\hline $\begin{array}{l}\text { Limite superior da } \\
\text { categoria (z2j) }\end{array}$ & $-2,9187$ & $-2,4557$ & $-1,9982$ & $-1,7770$ & $-0,9351$ & $-0,0441$ & 0,0000 \\
\hline $\begin{array}{l}\text { Ordenada do limite inferior } \\
\text { da categoria ( } y 1 j)\end{array}$ & 0,0000 & 0,0056 & 0,0196 & 0,0542 & 0,0823 & 0,2577 & 0,3986 \\
\hline $\begin{array}{l}\text { Ordenada do limite } \\
\text { superior da categoria (y2j) }\end{array}$ & 0,0056 & 0,0196 & 0,0542 & 0,0823 & 0,2577 & 0,3986 & 0,0000 \\
\hline $\begin{array}{l}\text { Valor estimado da } \\
\text { categoria }(x \mathbf{j})\end{array}$ & $-3,2076$ & $-2,6407$ & $-2,1890$ & $-1,8799$ & $-1,2794$ & $-0,4581$ & 0,7700 \\
\hline
\end{tabular}

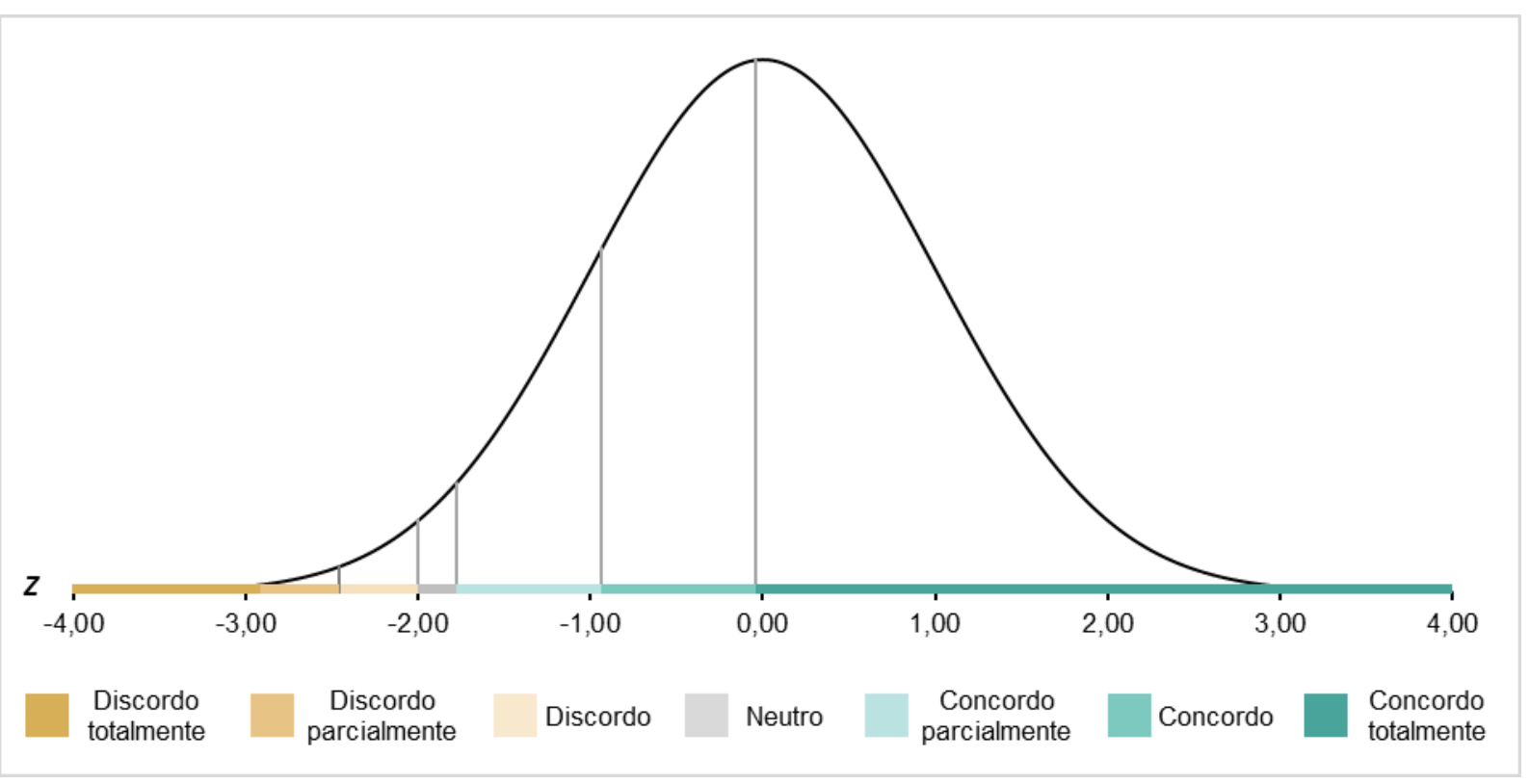

Figura B-3 - Distribuição das categorias da sentença Q3 na curva normal 


\section{Sentença 4: Gestão da demanda de viagens por carro}

A Tabela B-4 apresenta o cálculo da escala intervalar para a sentença Q4 e a Figura B-4 apresenta a distribuição das categorias na curva normal.

Tabela B-4 - Método dos Intervalos Sucessivos para a sentença Q4

Q4. A gestão da demanda de viagens por carro - buscando a redução dessa demanda - deve constar em qualquer estratégia de transporte urbano.

\begin{tabular}{|c|c|c|c|c|c|c|c|}
\hline \multirow{2}{*}{$\begin{array}{l}\text { Parâmetros } \\
\text { estatísticos }\end{array}$} & \multicolumn{7}{|c|}{ Categorias } \\
\hline & $\begin{array}{l}\text { Discordo } \\
\text { totalmente }\end{array}$ & Discordo & $\begin{array}{c}\text { Discordo } \\
\text { parcialmente }\end{array}$ & Neutro & $\begin{array}{l}\text { Concordo } \\
\text { parcialmente }\end{array}$ & Concordo & $\begin{array}{l}\text { Concordo } \\
\text { totalmente }\end{array}$ \\
\hline Frequência & 4 & 10 & 19 & 32 & 128 & 348 & 597 \\
\hline Frequência relativa (pj) & 0,0035 & 0,0088 & 0,0167 & 0,0281 & 0,1125 & 0,3058 & 0,5246 \\
\hline Frequência acumulada (Pj) & 0,0035 & 0,0123 & 0,0290 & 0,0571 & 0,1696 & 0,4754 & 1,0000 \\
\hline $\begin{array}{l}\text { Limite inferior da categoria } \\
(z 1 j)\end{array}$ & 0,0000 & $-2,6954$ & $-2,2476$ & $-1,8957$ & $-1,5794$ & $-0,9558$ & $-0,0617$ \\
\hline $\begin{array}{l}\text { Limite superior da } \\
\text { categoria }(\mathrm{z} 2 \mathrm{j})\end{array}$ & $-2,6954$ & $-2,2476$ & $-1,8957$ & $-1,5794$ & $-0,9558$ & $-0,0617$ & 0,0000 \\
\hline $\begin{array}{l}\text { Ordenada do limite inferior } \\
\text { da categoria }(y 1 \mathrm{j})\end{array}$ & 0,0000 & 0,0106 & 0,0319 & 0,0662 & 0,1146 & 0,2527 & 0,3982 \\
\hline $\begin{array}{l}\text { Ordenada do limite } \\
\text { superior da categoria (y2j) }\end{array}$ & 0,0106 & 0,0319 & 0,0662 & 0,1146 & 0,2527 & 0,3982 & 0,0000 \\
\hline $\begin{array}{l}\text { Valor estimado da } \\
\text { categoria (xj) }\end{array}$ & $-3,0016$ & $-2,4313$ & $-2,0505$ & $-1,7232$ & $-1,2274$ & $-0,4759$ & 0,7590 \\
\hline
\end{tabular}

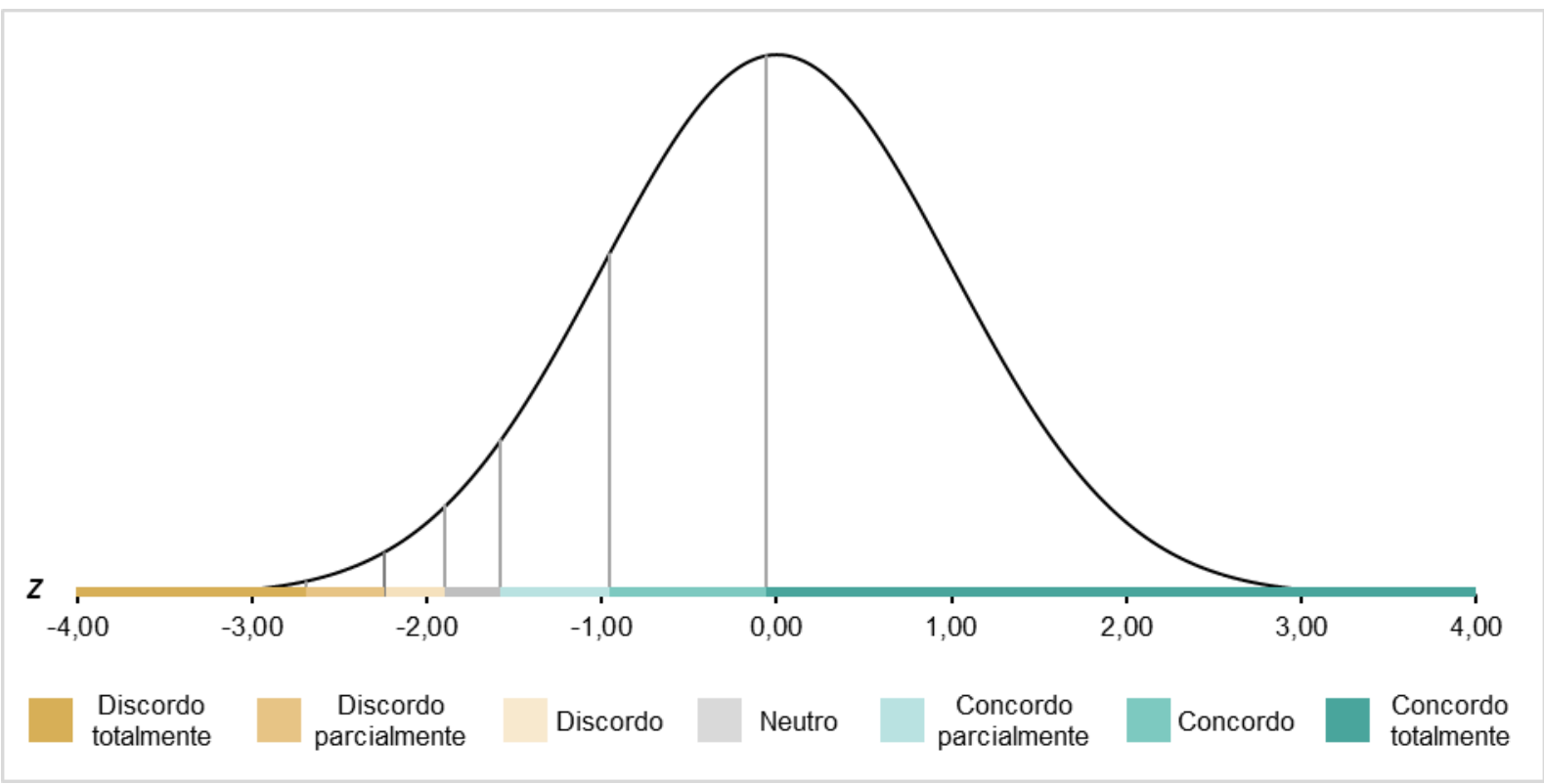

Figura B-4 - Distribuição das categorias da sentença Q4 na curva normal 


\section{Sentença 5: Planejamento logístico}

A Tabela B-5 apresenta o cálculo da escala intervalar para a sentença Q5 e a Figura B-5 apresenta a distribuição das categorias na curva normal.

Tabela B-5 - Método dos Intervalos Sucessivos para a sentença Q5

Q5. A redução do transporte desnecessário de cargas, obtida através de um adequado planejamento logístico, pode se converter em benefícios econômicos para as empresas.

\begin{tabular}{|c|c|c|c|c|c|c|c|}
\hline \multirow{2}{*}{$\begin{array}{l}\text { Parâmetros } \\
\text { estatísticos }\end{array}$} & \multicolumn{7}{|c|}{ Categorias } \\
\hline & $\begin{array}{l}\text { Discordo } \\
\text { totalmente }\end{array}$ & Discordo & $\begin{array}{l}\text { Discordo } \\
\text { parcialmente }\end{array}$ & Neutro & $\begin{array}{l}\text { Concordo } \\
\text { parcialmente }\end{array}$ & Concordo & $\begin{array}{l}\text { Concordo } \\
\text { totalmente }\end{array}$ \\
\hline Frequência & 1 & 4 & 5 & 43 & 66 & 396 & 623 \\
\hline Frequência relativa (pj) & 0,0009 & 0,0035 & 0,0044 & 0,0378 & 0,0580 & 0,3480 & 0,5475 \\
\hline Frequência acumulada (Pj) & 0,0009 & 0,0044 & 0,0088 & 0,0466 & 0,1046 & 0,4525 & 1,0000 \\
\hline $\begin{array}{l}\text { Limite inferior da categoria } \\
\text { (z1j) }\end{array}$ & 0,0000 & $-3,1284$ & $-2,6202$ & $-2,3745$ & $-1,6790$ & $-1,2559$ & $-0,1192$ \\
\hline $\begin{array}{l}\text { Limite superior da } \\
\text { categoria (z2j) }\end{array}$ & $-3,1284$ & $-2,6202$ & $-2,3745$ & $-1,6790$ & $-1,2559$ & $-0,1192$ & 0,0000 \\
\hline $\begin{array}{l}\text { Ordenada do limite inferior } \\
\text { da categoria ( } y 1 j)\end{array}$ & 0,0000 & 0,0030 & 0,0129 & 0,0238 & 0,0974 & 0,1813 & 0,3961 \\
\hline $\begin{array}{l}\text { Ordenada do limite } \\
\text { superior da categoria (y2j) }\end{array}$ & 0,0030 & 0,0129 & 0,0238 & 0,0974 & 0,1813 & 0,3961 & 0,0000 \\
\hline $\begin{array}{l}\text { Valor estimado da } \\
\text { categoria }(x \mathbf{j})\end{array}$ & $-3,4027$ & $-2,8150$ & $-2,4849$ & $-1,9488$ & $-1,4459$ & $-0,6173$ & 0,7236 \\
\hline
\end{tabular}

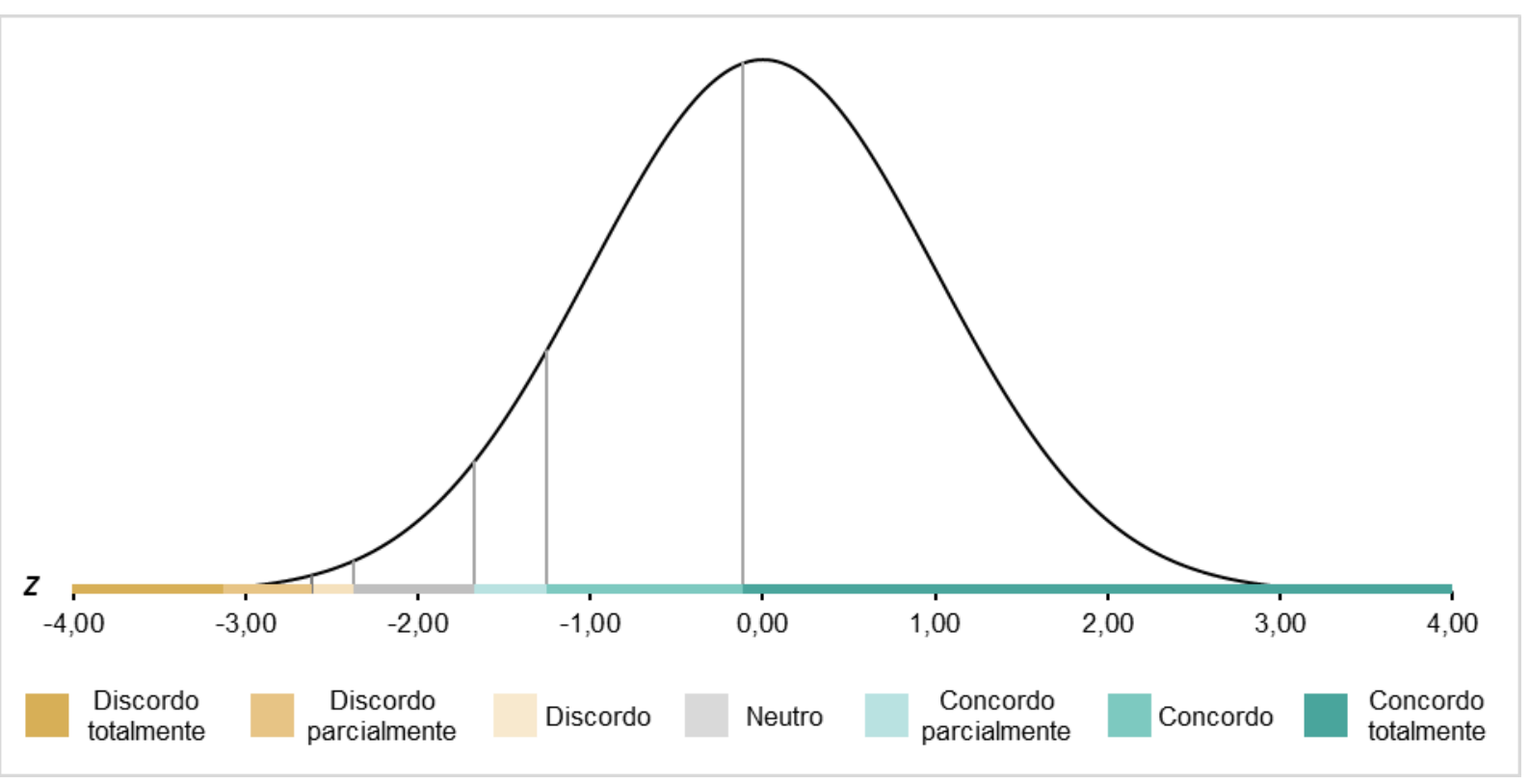

Figura B-5 - Distribuição das categorias da sentença Q5 na curva normal 


\section{Sentença 6: Custos totais de viagens}

A Tabela B-6 apresenta o cálculo da escala intervalar para a sentença Q6 e a Figura B-6 apresenta a distribuição das categorias na curva normal.

Tabela B-6 - Método dos Intervalos Sucessivos para a sentença Q6

\begin{tabular}{|c|c|c|c|c|c|c|c|}
\hline \multicolumn{8}{|c|}{$\begin{array}{l}\text { Q6. Os custos totais de viagens (incluindo mortes e lesões derivadas de acidentes de trânsito e doenças } \\
\text { decorrentes de poluição, bem como o isolamento daqueles que não tem acesso ao automóvel em uma } \\
\text { cidade dependente do carro) devem sempre ser considerados em qualquer análise de custo-benefício. }\end{array}$} \\
\hline \multirow{2}{*}{$\begin{array}{l}\text { Parâmetros } \\
\text { estatísticos }\end{array}$} & \multicolumn{7}{|c|}{ Categorias } \\
\hline & $\begin{array}{l}\text { Discordo } \\
\text { totalmente }\end{array}$ & Discordo & $\begin{array}{c}\text { Discordo } \\
\text { parcialmente }\end{array}$ & Neutro & $\begin{array}{c}\text { Concordo } \\
\text { parcialmente }\end{array}$ & Concordo & $\begin{array}{l}\text { Concordo } \\
\text { totalmente }\end{array}$ \\
\hline Frequência & 1 & 5 & 15 & 44 & 111 & 380 & 582 \\
\hline Frequência relativa (pj) & 0,0009 & 0,0044 & 0,0132 & 0,0387 & 0,0975 & 0,3339 & 0,5114 \\
\hline Frequência acumulada (Pj) & 0,0009 & 0,0053 & 0,0185 & 0,0571 & 0,1547 & 0,4886 & 1,0000 \\
\hline $\begin{array}{l}\text { Limite inferior da categoria } \\
(\mathrm{z} 1 \mathrm{j})\end{array}$ & 0,0000 & $-3,1284$ & $-2,5574$ & $-2,0868$ & $-1,5794$ & $-1,0167$ & $-0,0286$ \\
\hline $\begin{array}{l}\text { Limite superior da } \\
\text { categoria (z2j) }\end{array}$ & $-3,1284$ & $-2,5574$ & $-2,0868$ & $-1,5794$ & $-1,0167$ & $-0,0286$ & 0,0000 \\
\hline $\begin{array}{l}\text { Ordenada do limite inferior } \\
\text { da categoria }(y 1 j)\end{array}$ & 0,0000 & 0,0030 & 0,0152 & 0,0452 & 0,1146 & 0,2379 & 0,3988 \\
\hline $\begin{array}{l}\text { Ordenada do limite } \\
\text { superior da categoria (y2j) }\end{array}$ & 0,0030 & 0,0152 & 0,0452 & 0,1146 & 0,2379 & 0,3988 & 0,0000 \\
\hline $\begin{array}{l}\text { Valor estimado da } \\
\text { categoria (xj) }\end{array}$ & $-3,4027$ & $-2,7696$ & $-2,2804$ & $-1,7947$ & $-1,2644$ & $-0,4817$ & 0,7797 \\
\hline
\end{tabular}

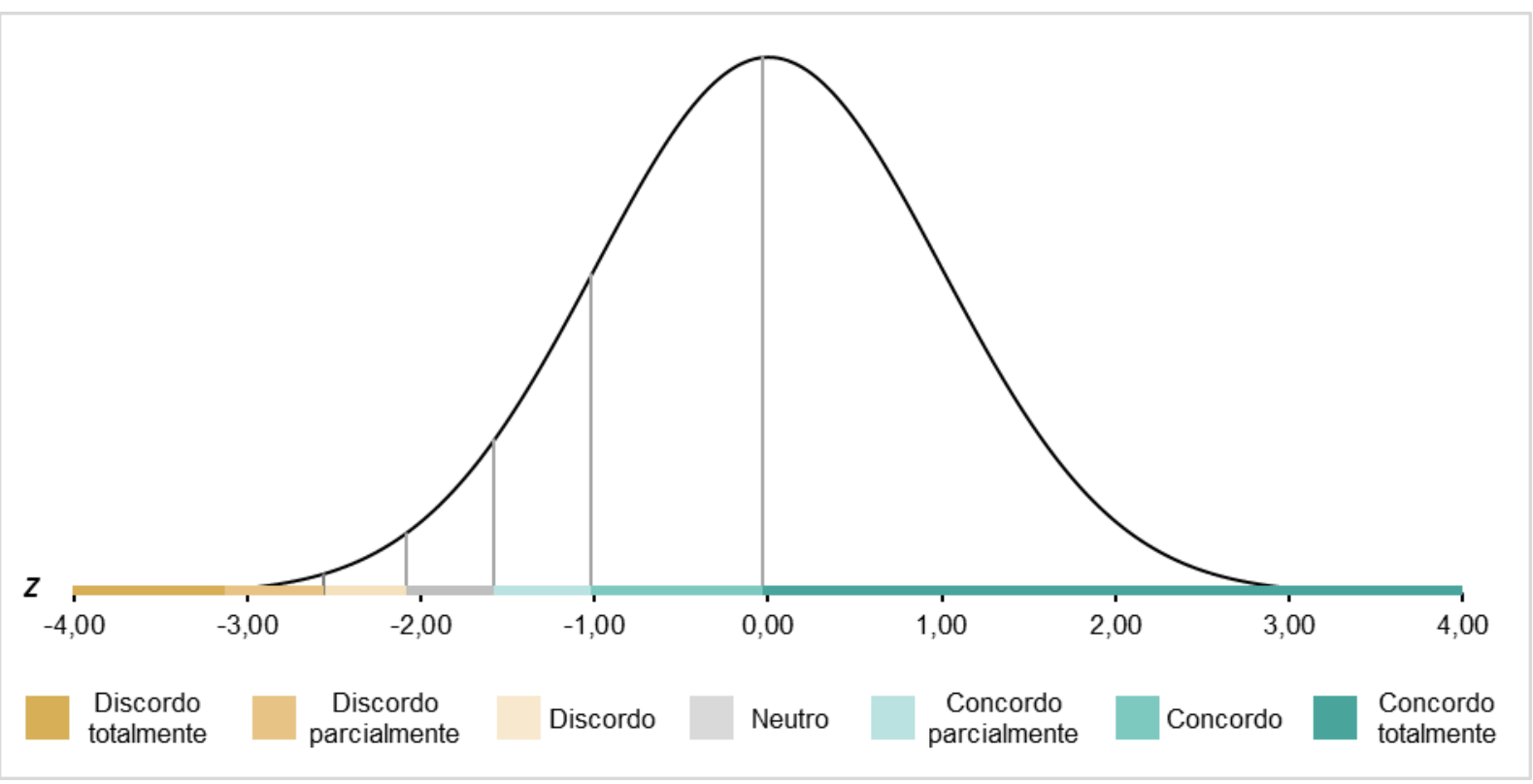

Figura B-6 - Distribuição das categorias da sentença Q6 na curva normal 


\section{Cálculo da escala intervalar de referência para o Grupo 1}

A partir dos valores das escalas estimadas para sentença, foi calculado a diferença média entre categorias adjacentes (DM) e a diferença média acumulada (DMA). Por fim, é estimado a escala intervalar de referência para o grupo, conforme apresenta a Tabela B-7.

Tabela B-7 - Cálculo da escala intervalar de referência para o Grupo 1

\begin{tabular}{|c|c|c|c|c|c|c|c|}
\hline \multicolumn{8}{|c|}{ Grupo 1 - Especialistas da área de transportes } \\
\hline \multirow[b]{3}{*}{ DISCURSO } & \multicolumn{7}{|c|}{ CATEGORIAS } \\
\hline & & 2 & 3 & 4 & 5 & 6 & 7 \\
\hline & $\begin{array}{c}\text { Discordo } \\
\text { totalmen- } \\
\text { te }\end{array}$ & Discordo & $\begin{array}{l}\text { Discordo } \\
\text { parcial- } \\
\text { mente }\end{array}$ & Neutro & $\begin{array}{c}\text { Concordo } \\
\text { parcial- } \\
\text { mente }\end{array}$ & Concordo & $\begin{array}{c}\text { Concordo } \\
\text { totalmen- } \\
\text { te }\end{array}$ \\
\hline $\begin{array}{l}\text { Q1 Planejamento } \\
\text { Urbano }\end{array}$ & $-3,4027$ & - & $-3,0126$ & $-2,7955$ & $-2,1176$ & $-1,1850$ & 0,3778 \\
\hline Q2 Engenharia & $-2,4680$ & $-1,7280$ & $-1,2190$ & $-0,9948$ & $-0,6117$ & $-0,0245$ & 0,9599 \\
\hline Q3 Economia & $-3,2076$ & $-2,6407$ & $-2,1890$ & $-1,8799$ & $-1,2794$ & $-0,4581$ & 0,7700 \\
\hline Q4 Sustentabilidade & $-3,0016$ & $-2,4313$ & $-2,0505$ & $-1,7232$ & $-1,2274$ & $-0,4759$ & 0,7590 \\
\hline Q5 Sustentabilidade & $-3,4027$ & $-2,8150$ & $-2,4849$ & $-1,9488$ & $-1,4459$ & $-0,6173$ & 0,7236 \\
\hline Q6 Sustentabilidade & $-3,4027$ & $-2,7696$ & $-2,2804$ & $-1,7947$ & $-1,2644$ & $-0,4817$ & 0,7797 \\
\hline$\sum$ Diferenças & - & 3,0980 & 2,1609 & 2,0994 & 3,1904 & 4,7040 & 7,6126 \\
\hline Diferença Média (DM) & 0,0000 & 0,6196 & 0,4322 & 0,3499 & 0,5317 & 0,7840 & 1,2688 \\
\hline DM Acumulada (DMA) & 0,0000 & 0,6196 & 1,0518 & 1,4017 & 1,9334 & 2,7174 & 3,9862 \\
\hline $\begin{array}{c}\text { Escala Intervalar de } \\
\text { Referência }\end{array}$ & $-1,4017$ & $-0,7821$ & $-0,3499$ & 0,0000 & 0,5317 & 1,3157 & 2,5845 \\
\hline
\end{tabular}

